\begin{tabular}{|c|c|c|}
\hline $\begin{array}{c}\text { UnB } \\
\text { Universidade } \\
\text { de Brasília }\end{array}$ & $\begin{array}{c}\text { UNIVRSIDADE FEDERAL } \\
\text { DA PARAIBA }\end{array}$ & $\begin{array}{l}\text { UFRN } \\
\text { UNIVERSIDADE FEDERAL DO } \\
\text { RIO GRANDE DO NORTE }\end{array}$ \\
\hline \multicolumn{3}{|c|}{ Programa Multiinstitucional e Inter-Regional de Pós-Graduação em Ciências Contábeis } \\
\hline
\end{tabular}

RICARDO AUGUSTO CAPOVILLA

ANÁLISE DAS ESTRUTURAS DE CONTROLE INTERNO DE ORGANIZAÇÕES GOVERNAMENTAIS POR MEIO DE MODELO DE MATURIDADE

BRASÍLIA 
UNIVERSIDADE DE BRASÍLIA - UnB

Reitor:

Prof. Dr. Ivan Marques de Toledo Camargo

Vice-Reitor:

Professora Dra. Sonia Nair Báo

Decano de Pesquisa e Pós-graduação:

Prof. Dr. Jaime Martins de Santana

Diretor da Faculdade de Economia, Administração e Contabilidade:

Prof. Dr. Roberto de Goes Ellery Júnior

Chefe do Departamento de Ciências Contábeis e Atuariais:

Prof. Dr. José Antônio de França

Coordenador Geral do Programa Multi-institucional e Inter-regional de Pós-graduação em Ciências Contábeis da UNB, UFPB e UFRN:

Prof. Dr. Rodrigo de Souza Gonçalves 


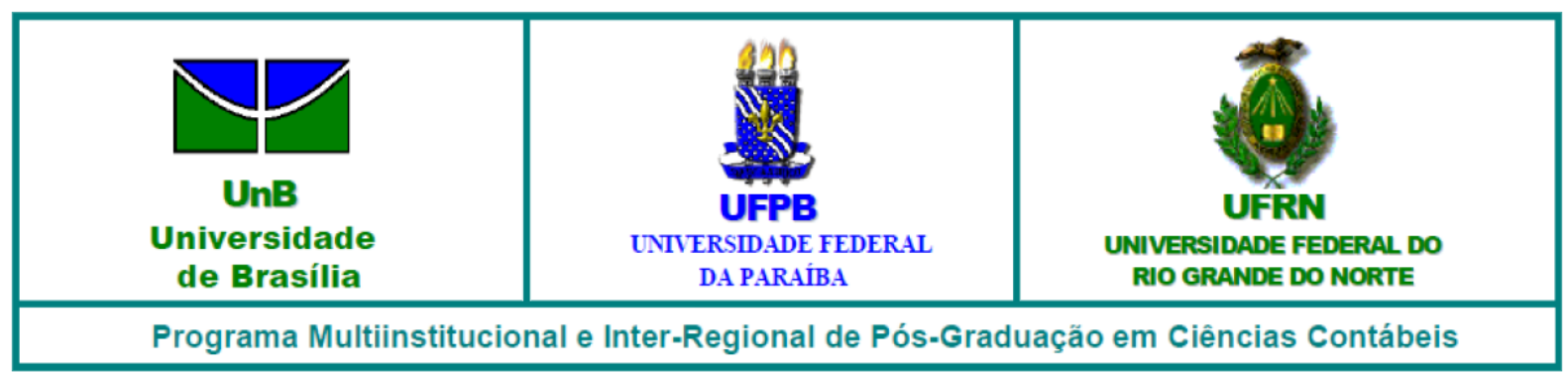

RICARDO AUGUSTO CAPOVILLA

\section{ANÁLISE DAS ESTRUTURAS DE CONTROLE INTERNO DE ORGANIZAÇÕES GOVERNAMENTAIS POR MEIO DE MODELO DE MATURIDADE}

Dissertação apresentada em cumprimento aos requisitos do Programa Multi-institucional e Inter-Regional de Pós-Graduação em Ciências Contábeis da Universidade de Brasília, da Universidade Federal da Paraíba e da Universidade Federal do Rio Grande do Norte para a obtenção do grau de Mestre em Ciências Contábeis.

Linha de pesquisa: Impactos da Contabilidade na Sociedade

Orientador: Prof. Dr. Rodrigo de Souza Gonçalves

BRASÍLIA 
Capovilla, Ricardo Augusto

Análise das Estruturas de Controle Interno de Organizações Governamentais por meio de Modelo de Maturidade / Ricardo Augusto Capovilla - Brasília, DF, 2016. 249 p.

Orientador: Prof. Dr. Rodrigo de Souza Gonçalves

Dissertação (mestrado) - Universidade de Brasília. Faculdade de Economia, Administração e Ciências Contábeis e Atuariais - FACE. Programa Multi-Institucional e Inter-Regional de Pós-Graduação em Ciências Contábeis (UnB/UFPB/UFRN).

1. Maturidade. 2. Controle Interno. 3. Administração Pública. 4. Brasil. I. Gonçalves, Rodrigo de Souza. II. Universidade de Brasília. III. Universidade Federal da Paraíba. IV. Universidade Federal do Rio Grande do Norte. 


\section{ANÁLISE DAS ESTRUTURAS DE CONTROLE INTERNO DE ORGANIZAÇÕES GOVERNAMENTAIS POR MEIO DE MODELO DE MATURIDADE}

Dissertação apresentada em cumprimento aos requisitos do Programa Multi-institucional e Inter-Regional de Pós-Graduação em Ciências Contábeis da Universidade de Brasília, da Universidade Federal da Paraíba e da Universidade Federal do Rio Grande do Norte para a obtenção do grau de Mestre em Ciências Contábeis.

Comissão Avaliadora:

Prof. Dr. Rodrigo de Souza Gonçalves

Programa Multi-Institucional e Inter-Regional de Pós-Graduação em Ciências Contábeis da $\mathrm{UNB} / \mathrm{UPPB} / \mathrm{UFRN}$

Presidente da Banca

Prof. Dr. Antônio Benedito Silva Oliveira Pontifícia Universidade Católica de São Paulo - PUC-SP

Membro Externo

Prof. Dr. José Alves Dantas

Programa de Pós-Graduação em Ciências Contábeis da Universidade de Brasília - UnB Membro Interno não Vinculado

Brasília, 2016. 


\section{AGRADECIMENTO}

A Deus.

Ao Prof. Dr. Rodrigo de Souza Gonçalves, orientador deste trabalho, testado nas fibras mais íntimas de sua paciência. Muito obrigado, professor!

Aos professores do Programa Multi-institucional e Inter-Regional de PósGraduação em Ciências Contábeis da UnB, da UFPB e da UFRN, que generosamente colocaram à nossa disposição seus dilatados conhecimentos. Em especial o Prof. Dr. César Augusto Tibúrcio Silva, o Prof. Dr. Bruno Vinícius Ramos Fernandes, a Profa. Dra. Fátima de Souza Freire, a Profa. Dra. Fernanda Fernandes Rodrigues, o Prof. Ph. D. Otávio Ribeiro de Medeiros, o Prof. Dr. Paulo Roberto Barbosa Lustosa, a Profa. Dra. Clésia Camilo Pereira, o Prof. Dr. Eduardo Tadeu Vieira, a Profa. Dra. Diana Vaz de Lima, o Prof. Dr. Marcelo Driemeyer Wilbert, o Prof. Dr. Jomar Miranda Rodrigues, o Prof. Dr. José Alves Dantas, e a Profa. Dra. Mariana Guerra.

Aos mestres Carlos Alberto Martins Silva, Eduardo Ganassin e Keylla Dennyse Celestino da Silva, pelo carinho e companheirismo durante a jornada. Aos mestres Afonso Arinos de Farias Gonçalves e Bianca Gabriel Fellet, cuja providência foi essencial para que eu chegasse até aqui.

Aos meus filhos Heitor e Heloísa, pelo carinho, e à minha querida esposa Ellen e Dona Vera minha sogra, que suportaram os encargos da minha ausência com paciência e compreensão.

Finalmente, ao Tribunal de Contas da União, patrocinador da empreitada. Em especial os senhores Junnius Marques Arifa e Marcelo Barros Gomes, além de todos os colegas que participaram da pesquisa, fornecendo inestimável contribuição para a realização de seus objetivos.

Que Deus os abençoe. Muito obrigado. 


\section{RESUMO}

O estudo teve o objetivo de analisar a maturidade das estruturas de controle interno de organizações governamentais brasileiras que implementam políticas públicas para a agricultura, propondo um modelo de maturidade baseado no framework do COSO e padrões do GAO. O modelo foi estruturado em quatro níveis de maturidade: (0) Incipiente, (1) Inicial, (2) Em Formação e (3) Estabelecido, representando os estágios da implantação de uma estrutura de controle interno nas organizações. As cinco dimensões do modelo correspondem aos componentes de controle interno do framework COSO I: Ambiente de Controle; Avaliação de Riscos; Atividades de Controle; Informação e Comunicação; e Monitoramento (COSO, 2013). Para cada dimensão, foram definidas subdimensões e variáveis, que formaram a base para a avaliação do nível de maturidade das organizações estudadas. O modelo de maturidade foi empiricamente testado por meio de um estudo de casos múltiplos (YIN, 2010), avaliando as estruturas de controle interno de três organizações governamentais ligadas à função agricultura. Os estudos de caso reuniram elementos para a análise comparativa (CONILL et al., 1991; HORTALE et al., 1999), que identificou as similaridades e diferenças das estruturas avaliadas. O teste empírico do modelo de maturidade permitiu o diagnóstico das capacidades das estruturas de controle interno das entidades, constatando-se limitações significativas em todas as dimensões. A partir das limitações, foram identificados os riscos decorrentes e recomendadas ações para o aprimoramento das estruturas de controle interno das entidades, demonstrando-se a utilidade do modelo de maturidade na orientação ao gestor público para o aprimoramento das estruturas de controle interno sob sua responsabilidade. As análises comparativas colocaram as capacidades em perspectiva, possibilitando a utilização do modelo de maturidade para o estímulo à melhoria contínua das estruturas de controle interno das entidades. A evolução das estruturas de controle interno das organizações governamentais pode diminuir as oportunidades de que os recursos e o patrimônio público sejam utilizados em proveito de interesses que divergem dos interesses dos cidadãos.

Palavras-chave: 1. Maturidade. 2. Controle Interno. 3. Administração Pública. 


\begin{abstract}
This study aimed to analyze the maturity of internal control frameworks of brazilian governmental organizations that implement public policies for agriculture, developing a maturity model based on the COSO Internal Control Framework and GAO standards. The model is structured in four maturity levels: (0) Incipient, (1) Initial, (2) Developing, and (3) Established, representing the deployment stages of an internal control framework in organizations. The five dimensions of the model correspond to the internal control components, according to the COSO I Framework: Control Environment; Risk Assessment; Control Activities; Information and Communication; and Monitoring (COSO, 2013). For each dimension, sub dimensions and variables were defined, establishing the basis for the assessing of the maturity level of the organizations studied. The maturity model was empirically tested through a multiple case study (YIN, 2010), which evaluated the internal control structures of three government organizations related to agriculture function. The case studies gathered elements for comparative analysis (CONILL et al., 1991; HORTALE et al., 1999), which identified the similarities and differences of the evaluated structures. The empirical test of the maturity model enabled the identification of the capabilities of the entities' internal control frameworks, showing significant limitations in all dimensions. From the limitations, risks were identified and actions for the improvement of the entities' internal control frameworks were recommended, demonstrating the usefulness of the maturity model in guiding public managers in the improvement of internal control frameworks under their responsibility. Comparative analysis put into perspective the capabilities, allowing the use of the maturity model for stimulating continuous improvement of the entities' internal control frameworks. The evolution of government organizations' internal control frameworks can reduce the opportunities of public resources and public assets being used for the benefit of interests different from the citizens' interests.
\end{abstract}

Keywords: 1. Maturity. 2. Internal Control. 3. Public Administration. 


\section{LISTA DE ABREVIATURAS}

AIA

AICPA

BSC

CEP

CEPEA

CLT

CMM

Cobit

Conab

COSO

EFS

ERM

ERP

GAO

IAASB

IBGC

IFAC

IIA

Incra

Intosai

ISA

ISACA

ISSAI

MAPA

MCASP

MDA

MME

PAINT

PCAOB

PIB

RAINT

RMB

RUP

SAS

SDLC

SEC

SEI

SIAFI

SIASG

SLA

SOX

SPIU

TCU

TI

XBRL
American Institute of Accountants American Institute of Certified Public Accountants

Balanced Scorecard

Comissão de Ética Pública

Centro de Estudos Avançados em Economia Aplicada

Consolidação das Leis do Trabalho

Capability Maturity Model

Control Objectives for Information and related Technology

Companhia Nacional de Abastecimento

Committee of Sponsoring Organizations of the Treadway Commission Entidades de Fiscalização Superiores (Supreme Audit Institutions)

Enterprise Risk Management

Enterprise Resource Planning

U.S. Government Accountability Office International Auditing and Assurance Board Instituto Brasileiro de Governança Corporativa International Federation of Accountants Institute of Internal Auditors (Instituto de Auditores Internos) Instituto Nacional de Colonização e Reforma Agrária International Organisation of Supreme Audit Institutions International Standard of Auditing

Information Systems Audit and Control Association International Standards of Supreme Audit Institutions Ministério da Agricultura, Pecuária e Abastecimento Manual de Contabilidade Aplicada ao Setor Público

Ministério do Desenvolvimento Agrário Ministério de Minas e Energia Plano Anual de Auditoria Interna Public Company Accounting Oversight Board Produto Interno Bruto Relatório Anual de Atividades de Auditoria Interna Relatório Mensal de Bens Rational Unified Process Statement on Auditing Standards Systems Development Life Cycle (Ciclo de Vida de Desenvolvimento de Sistemas) Securities and Exchange Comission (Comissão de Valores Mobiliários dos EUA)

Software Engineering Institute

Sistema Integrado de Administração Financeira Sistema Integrado de Administração de Serviços Gerais Service-Level Agreement (Acordo de Nível de Serviços)

Sarbanes-Oxley

Sistema de Gerenciamento dos Imóveis de Uso Especial da União

Tribunal de Contas da União

Tecnologia da Informação

Extensible Business Reporting Language 


\section{ÍNDICE DE QUADROS}

Quadro 1 - Exemplos de modelos de maturidade desenvolvidos para organizações governamentais ..21

Quadro 2 - Princípios do Controle Interno Contábil segundo Gil et al. (2013).

Quadro 3 - Dimensões, Subdimensões e Variáveis da Proposta de Modelo de Maturidade (préavaliação)

Quadro 4 - Fatores de Riscos Internos e Externos . .76

Quadro 5 - Divisão dos Questionários de Avaliação ..........................................................................90

Quadro 6 - Resultados da avaliação de juízes especialistas ................................................................91

Quadro 7 - Dimensões, subdimensões e variáveis da proposta de modelo de maturidade (pós-avaliação)

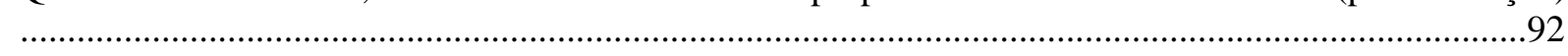

Quadro 8 - Características do Nível de Maturidade (1) Inicial............................................................94

Quadro 9 - Características do Nível de Maturidade (2) Em Formação ................................................94

Quadro 10 - Características do Nível de Maturidade Elaborado (3) ....................................................95

Quadro 11 - Tipologia do atendimento aos critérios de enquadramento das variáveis do modelo de maturidade.

Quadro 12 - Lógica de avaliação do nível de maturidade das estruturas de controle interno das entidades estudadas .98

Quadro 13 - Resultados da Variável 1.1.1 - Destinatários dos Padrões de Conduta 100

Quadro 14 - Resultados da Variável 1.1.2 - Disseminação dos Padrões de Conduta, Ética e Valores

Quadro 15 - Resultados da Variável 1.1.3 - Estrutura Organizacional para Avaliação da Aderência aos Padrões de Conduta 103

Quadro 16 - Análise Comparativa da Subdimensão 1.1 - Padrões de Conduta ...................................105

Quadro 17 - Riscos e Recomendações da Subdimensão 1.1 - Padrões de Conduta .............................105

Quadro 18 - Resultados da Variável 1.2.1 - Políticas de Due Diligence para o Corpo Diretivo ........106

Quadro 19 - Resultados da Variável 1.2.2 - Requisitos de Competências do Corpo Diretivo ..... 107

Quadro 20 - Analise Comparativa da Subdimensão 1.2 - Independência e Competência do Corpo Diretivo .108

Quadro 21 - Riscos e Recomendações da Subdimensão 1.2 - Independência e Competência do Corpo Diretivo 109

Quadro 22 - Resultados da Variável 1.3.1 - Responsabilidades de Controle Interno na Organização 109

Quadro 23 - Resultados da Variável 1.3.2 - Requisitos de Competências na Organização. .111

Quadro 24 - Análise Comparativa da Subdimensão 1.3 - Responsabilidades de Controle Interno e Requisitos de Competências.

Quadro 25 - Riscos e Recomendações da Subdimensão 1.3 - Responsabilidades de Controle Interno e Requisitos de Competências. 113

Quadro 26 - Resultados da Variável 1.4.1 - Programa de Desenvolvimento de Competências .........113

Quadro 27 - Resultados da Variável 1.5.1 - Fatores da Avaliação de Desempenho.

Quadro 28 - Resultados da Variável 1.5.2 - Níveis Organizacionais da Avaliação de Desempenho.116 Quadro 29 - Resultados da Variável 1.5.3 - Níveis Organizacionais das Metas de Desempenho .118 
Quadro 30 - Resultados da Variável 1.5.4 - Recompensas e Sanções da Avaliação de Desempenho119

Quadro 31 - Resultados da Variável 1.5.5 - Frequência da Avaliação de Desempenho.

Quadro 32 - Análise Comparativa da Subdimensão 1.5 - Avaliação de Desempenho .121

Quadro 33 - Riscos e Recomendações da Subdimensão 1.5 - Avaliação de Desempenho. .122

Quadro 34 - Avaliação do Nível de Maturidade das Entidades na Dimensão 1 - Ambiente de Controle

Quadro 35 - Resultados da Variável 2.1.1 - Processo de Formulação de Objetivos. 123

Quadro 36 - Resultados da Variável 2.1.2 - Participantes do Processo de Formulação de Objetivos 125

Quadro 37 - Resultados da Variável 2.1.3 - Tipos de Objetivos. .126

Quadro 38 - Resultados da Variável 2.1.4 - Níveis Organizacionais dos Objetivos. 127

Quadro 39 - Resultados da Variável 2.1.5 - Mensuração dos Objetivos 128

Quadro 40 - Análise Comparativa da Subdimensão 2.1 - Definição de Objetivos 129

Quadro 41 - Riscos e Recomendações da Subdimensão 2.1 - Definição de Objetivos 130

Quadro 42 - Resultados da Variável 2.2.1 - Processo de Avaliação de Riscos .131

Quadro 43 - Resultados da Variável 2.2.2 - Participantes da Avaliação de Riscos. 132

Quadro 44 - Resultados da Variável 2.2.3 - Fatores Considerados na Avaliação de Riscos 133

Quadro 45 - Resultados da Variável 2.2.4 - Níveis Organizacionais da Avaliação de Riscos .134

Quadro 46 - Análise Comparativa da Subdimensão 2.2 - Identificação, Análise e Resposta aos Riscos .135

Quadro 47 - Riscos e Recomendações da Subdimensão 2.2 - Identificação, Análise e Resposta aos Riscos..... 135

Quadro 48 - Avaliação do Nível de Maturidade das Entidades na Dimensão 2 - Avaliação de Riscos

Quadro 49 - Resultados da Variável 3.1.1 - Documentação das Atividades de Controle. 137

Quadro 50 - Resultados da Variável 3.1.2 - Níveis Organizacionais das Atividades de Controle .....138

Quadro 51 - Resultados da Variável 3.1.3 - Representação Fidedigna da Informação ContábilFinanceira 139

Quadro 52 - Resultados da Variável 3.1.4 - Segregação de Funções 141

Quadro 53 - Análise Comparativa da Subdimensão 3.1 - Projeto de Controles para Mitigação de Riscos .142

Quadro 54 - Riscos e Recomendações da Subdimensão 3.1 - Projeto de Controles para Mitigação de Riscos..... 142

Quadro 55 - Resultados da Variável 3.2.1 - Políticas e Procedimentos de Controle. 143

Quadro 56 - Análise Comparativa da Subdimensão 3.2 - Implantação de Controles 145

Quadro 57 - Riscos e Recomendações da Subdimensão 3.2 - Implantação de Controles .145

Quadro 58 - Resultados da Variável 3.3.1 - Uso da Computação de Usuário Final. 146

Quadro 59 - Resultados da Variável 3.3.2 - Políticas de Segurança de TI 147

Quadro 60 - Resultados da Variável 3.3.3 - Processos de Aquisição, Desenvolvimento e Manutenção da TI 148

Quadro 61 - Análise Comparativa da Subdimensão 3.3 - Projeto de Controles sobre a Tecnologia..149 
Quadro 62 - Riscos e Recomendações da Subdimensão 3.3 - Projeto de Controles sobre a Tecnologia .150

Quadro 63 - Avaliação do Nível de Maturidade das Entidades na Dimensão 3 - Atividades de Controle

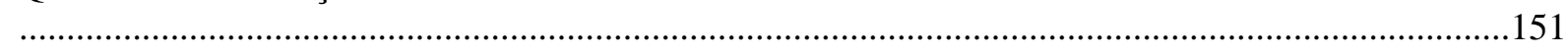

Quadro 64 - Resultados da Variável 4.1.1 - Relevância e Qualidade da Informação..........................151

Quadro 65 - Resultados da Variável 4.1.2 - Comunicação Interna e Externa......................................152

Quadro 66 - Análise Comparativa da Subdimensão 4.1 - Sistema de Informação da Entidade ..........153

Quadro 67 - Riscos e Recomendações da Subdimensão 4.1 - Sistema de Informação da Entidade...154

Quadro 68 - Avaliação do Nível de Maturidade das Entidades na Dimensão 4 - Informação e

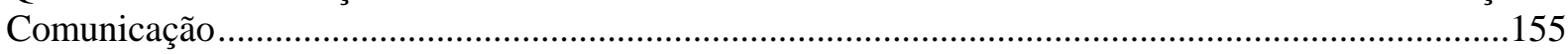

Quadro 69 - Resultados da Variável 5.1.1 - Monitoramento Contínuo .............................................155

Quadro 70 - Resultados da Variável 5.1.2 - Avaliações Avulsas ......................................................156

Quadro 71 - Resultados da Variável 5.1.3 - Comunicação das Deficiências de Controle Interno e

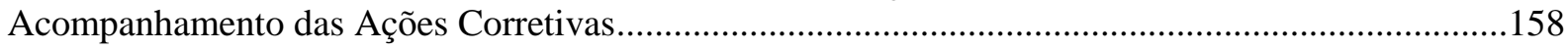

Quadro 72 - Análise Comparativa da Subdimensão 5.1 - Monitoramento da Estrutura de Controle Interno

Quadro 73 - Riscos e Recomendações da Subdimensão 5.1 - Monitoramento da Estrutura de Controle

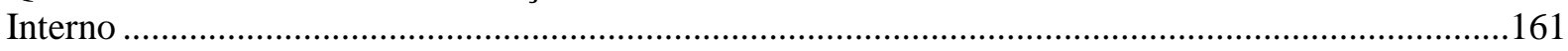

Quadro 74 - Avaliação do Nível de Maturidade das Entidades na Dimensão 5 - Monitoramento.....162

Quadro 75 - Avaliação do Nível de Maturidade das Estruturas de Controle Interno das Entidades Estudadas. 


\section{SUMÁRIO}

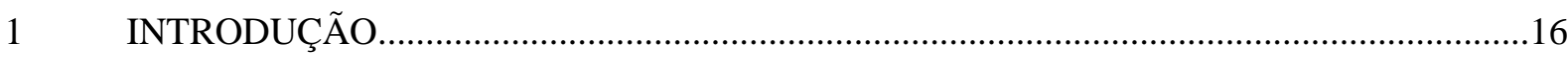

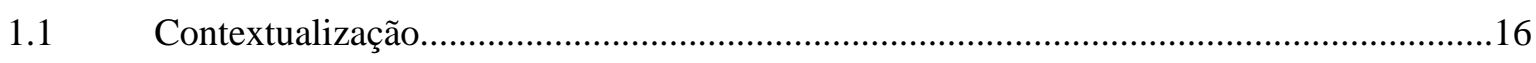

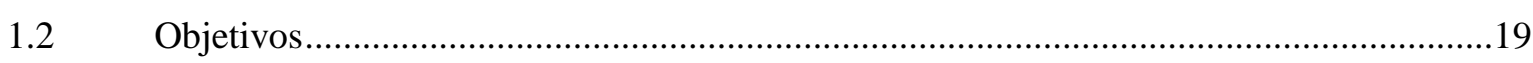

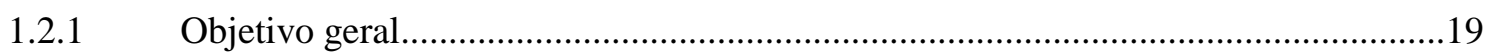

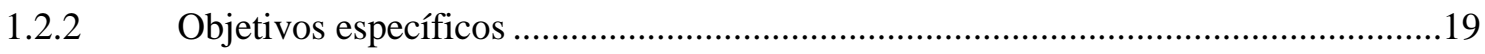

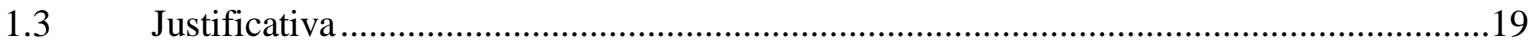

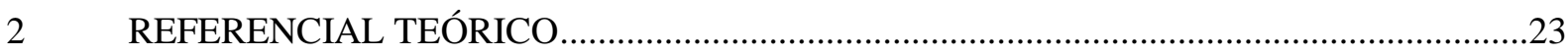

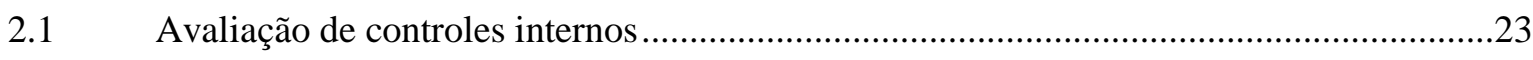

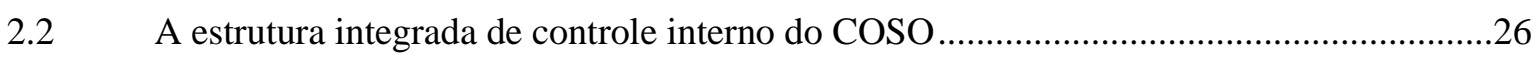

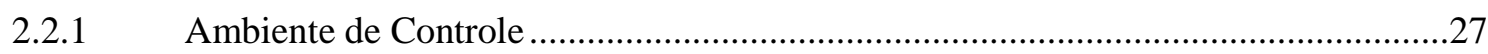

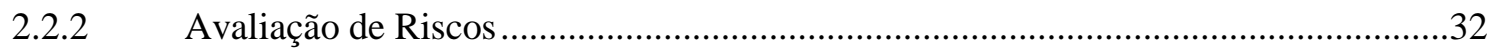

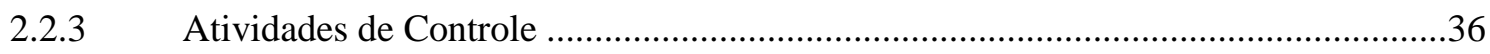

2.2.4 Informação e Comunicação ................................................................................

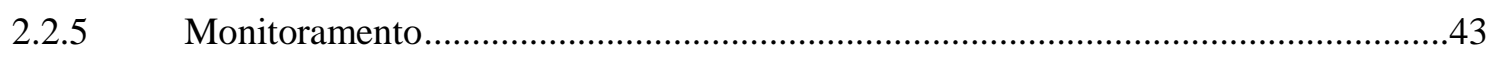

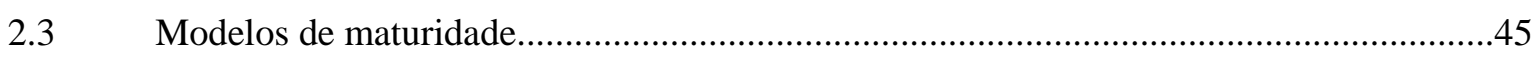

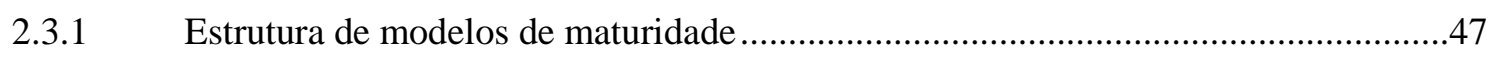

2.3.2 Críticas aos modelos de maturidade .......................................................................... 49

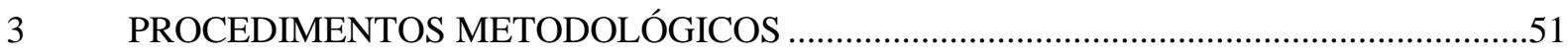

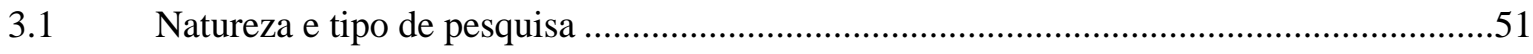

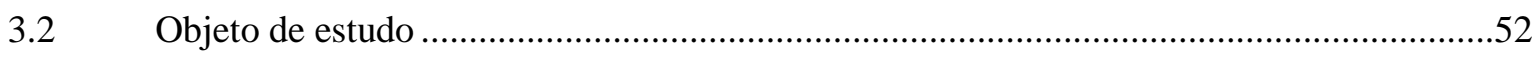

3.2.1 Ministério da Agricultura, Pecuária e Abastecimento - MAPA...................................53

3.2.2 Instituto Nacional de Colonização e Reforma Agrária - Incra ....................................55

3.2.3 Companhia Nacional de Abastecimento - Conab.......................................................56

3.3 Proposta de Modelo de Maturidade para Avaliação dos Controles Internos em Entidades

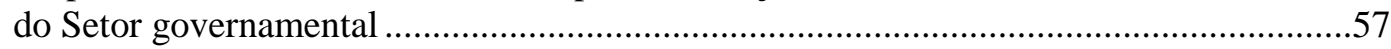

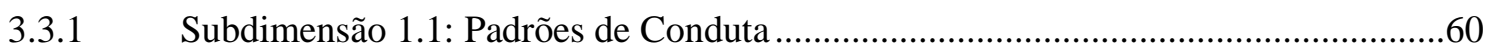

3.3.2 Subdimensão 1.2: Independência e Competência do Corpo Diretivo..........................63

3.3.3 Subdimensão 1.3: Responsabilidades de Controle Interno e Requisitos de

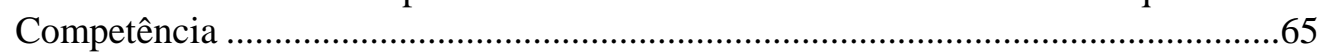

3.3.4 Subdimensão 1.4: Atração, Desenvolvimento e Retenção de Indivíduos ....................67

3.3.5 Subdimensão 1.5: Avaliação de Desempenho ..............................................................68

3.3.6 Subdimensão 2.1: Definição de Objetivos ................................................................

3.3.7 Subdimensão 2.2: Identificação, Análise e Resposta aos Riscos.................................74

3.3.8 Subdimensão 3.1: Projeto de Controles para Mitigação de Riscos...............................78

3.3.9 Subdimensão 3.2: Implantação de Controles ...............................................................

3.3.10 Subdimensão 3.3: Projeto de Controles sobre a Tecnologia.......................................82

3.3.11 Subdimensão 4.1: Sistema de Informação da Entidade ..............................................85 
3.3.12 Subdimensão 5.1: Monitoramento da Estrutura de Controle Interno..........................87

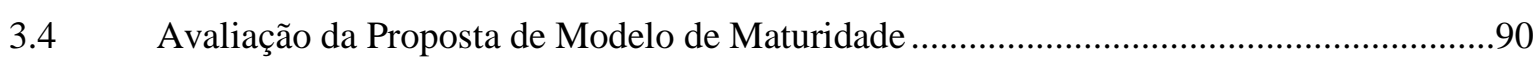

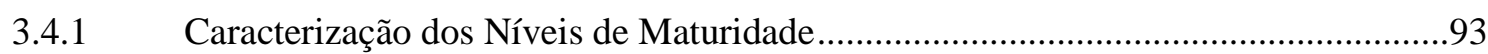

3.5 Procedimentos para a Avaliação da Maturidade das Estruturas de Controle Interno das

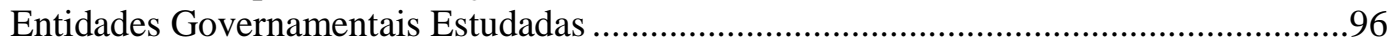

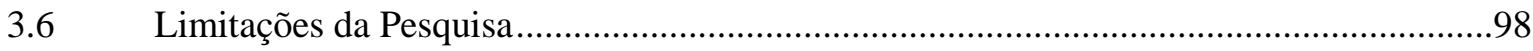

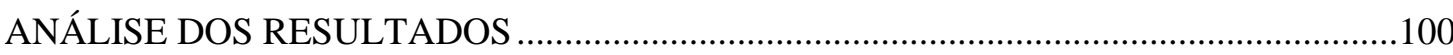

4.1 Resultados da Dimensão 1 - Ambiente de Controle .........................................................100

4.1.1 Resultados da Subdimensão 1.1 - Padrões de Conduta .............................................100

4.1.2 Resultados da Subdimensão 1.2 - Independência e Competência do Corpo Diretivo .106

4.1.3 Resultados da Subdimensão 1.3 - Responsabilidades de Controle Interno e Requisitos de Competências

4.1.4 Resultados da Subdimensão 1.4 - Atração, Desenvolvimento e Retenção de

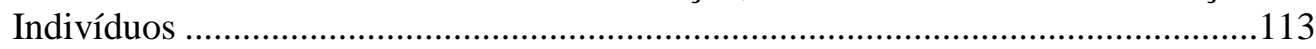

4.1.5 Resultados da Subdimensão 1.5 - Avaliação de Desempenho .................................115

4.1.6 Avaliação do Nível de Maturidade das Entidades na Dimensão 1 - Ambiente de

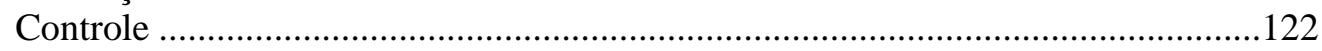

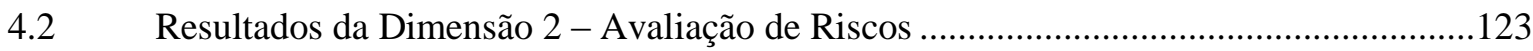

4.2.1 Resultados da Subdimensão 2.1 - Definição de Objetivos ........................................123

4.2.2 Resultados da Subdimensão 2.2 - Identificação, Análise e Resposta aos Riscos....131

4.2.3 Avaliação do Nível de Maturidade das Entidades na Dimensão 2 - Avaliação de

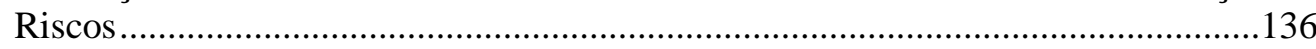

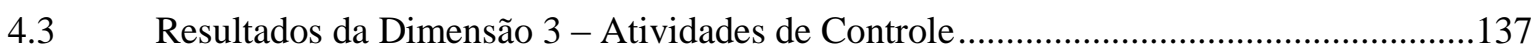

4.3.1 Resultados da Subdimensão 3.1 - Projeto de Controles para Mitigação de Riscos.137

4.3.2 Resultados da Subdimensão 3.2 - Implantação de Controles....................................143

4.3.3 Resultados da Subdimensão 3.3 - Projeto de Controles sobre a Tecnologia............146

4.3.4 Avaliação do Nível de Maturidade das Entidades na Dimensão 3 - Atividades de

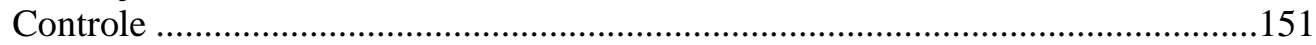

4.4 Resultados da Dimensão 4 - Informação e Comunicação ................................................151

4.4.1 Resultados da Subdimensão 4.1 - Sistema de Informação da Entidade ...................151

4.4.2 Avaliação do Nível de Maturidade das Entidades na Dimensão 4 - Informação e

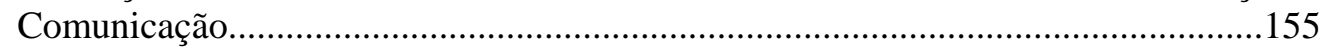

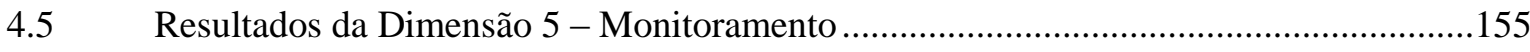

4.5.1 Resultados da Subdimensão 5.1 - Monitoramento da Estrutura de Controle Interno .155

4.5.2 Avaliação do Nível de Maturidade das Entidades na Dimensão 5 - Monitoramento

4.6 Avaliação do Nível de Maturidade das Estruturas de Controle Interno ..............................162

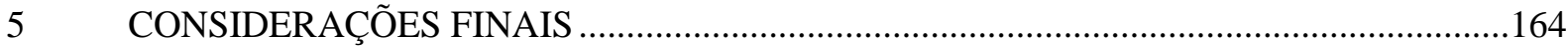

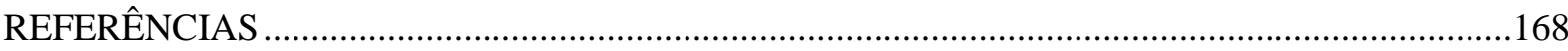


APÊNDICE A - Inventário de boas práticas de controles internos 173

APÊNDICE B - Variáveis identificadas e boas práticas de controles internos relacionadas 184

APÊNDICE C - Elementos textuais de estruturação do framework COSO e Green Book GAO 191

APÊNDICE D - Relação entre Princípios COSO, Subdimensões e Variáveis da Proposta de modelo de Maturidade 197

APÊNDICE E - Modelo de Formulário para Avaliação por Especialistas. 199

APÊNDICE F - Modelo de Comunicações com os Especialistas ......................................................202

APÊNDICE G - Avaliação das Variáveis da Proposta de Modelo de Maturidade ..............................204

APÊNDICE H - Modelo de Solicitação de documentos às Entidades estudadas..................................230

APÊNDICE I - Proposta de Modelo de Maturidade de Sistemas de Controle Interno em Entidades Governamentais.

APÊNDICE J - Avaliação do Nível de Maturidade das Entidades Estudadas nas Dimensões .243

ANEXO A - Tipos de Atividades de Controle segundo o GAO .247

ANEXO B - Descrição dos Níveis do Modelo de Maturidade do Cobit (versão 4.1). 249 


\section{1}

\section{CONTEXTUALIZAÇÃO}

A discussão a respeito de controle interno tem suas raízes no problema de agência. Jensen e Meckling (1976, p. 308) definem o relacionamento de agência como "um contrato sob o qual uma ou mais pessoas (os principais) empregam outra pessoa (o agente) para realizar algum serviço em seu nome, o que envolve a delegação de alguma autoridade de tomada de decisão ao agente"1. . problema de agência surge quando os interesses do principal e do agente são conflitantes, ou seja, as decisões do agente não observam os interesses do principal. O principal pode limitar as divergências aos seus interesses estabelecendo incentivos ao agente e incorrendo em custos de monitoramento e outras atividades de controle, como auditoria, sistemas formais de controle, limites orçamentários e sistemas de compensação que alinham os interesses do agente aos interesses do principal (JENSEN; MECKLING, 1976).

A relação de agência existe nas companhias, cooperativas, sindicatos e outras organizações do setor privado, e também no âmbito do Estado. Sanchez (2003) analisa o problema de agência no âmbito do sistema político, onde o cidadão é principal e os políticos são agentes, e no âmbito da burocracia estatal, onde o governo é principal e os empregados são agentes, destacando a importância de controles que diminuam a assimetria de informação que existe em ambos os casos. Essa assimetria de informação estimula o agente a se comportar de maneira diversa da expectativa do principal. Não obstante, o sistema político e a burocracia estatal existem em razão de uma necessidade final, a organização dos bens e recursos públicos para a implantação de políticas e a prestação bens e serviços de interesse da sociedade.

A evolução histórica dos paradigmas a respeito do papel do Estado e dos princípios que orientam a administração pública reforça, nos dias atuais, a necessidade de mecanismos que estimulem a gestão das organizações governamentais em conformidade com os interesses do cidadão. Gomes (2006) afirma que até a segunda guerra mundial predominava uma concepção liberal do Estado, preocupada em assegurar o direito à propriedade por meio de uma institucionalidade jurídica. Após a segunda guerra, consolida-se a proposta de "um Estado que pudesse implementar e financiar programas e planos de ação destinados a promover os interesses sociais coletivos dos membros de uma determinada sociedade" (GOMES, 2006, p.

\footnotetext{
${ }^{1}$ We define an agency relationship as a contract under which one or more persons (the principal(s)) engage another person (the agent) to perform some service on their behalf which involves delegating some decision making authority to the agent.
} 
204), que convencionou-se denominar welfare state ou Estado do bem-estar social. Essa proposta preconizava a intervenção direta do Estado na atividade econômica e a prestação de serviços de seguridade social (previdência, saúde, assistência) e educação.

De acordo com Matias-Pereira (2005), essa expansão do fornecimento de produtos e serviços por parte do Estado no pós-guerra, aliada à ineficiência da estrutura estatal, conduziram a resultados deficitários. A crise do petróleo de 1973 encerra o período de crescimento econômico que propiciava o financiamento dos déficits governamentais, levando o Estado a uma crise fiscal. À crise fiscal somaram-se uma crise de governabilidade, em razão da incapacidade dos governos de resolver os problemas econômicos e sociais, e a globalização, que enfraqueceu controles do Estado e diminuiu o poder de definição das políticas macroeconômicas.

A década de 1980 marca o início de um período de reformas do Estado, que "deixa de ser o responsável direto pelo desenvolvimento econômico e social via a produção de bens e serviços, para se adequar a uma nova função de 'Estado gerencial'” (MATIAS-PEREIRA, 2005, p. 2). O paradigma gerencial inclui a gestão pública profissional, pautada por princípios aplicados ao setor privado, com o objetivo de reduzir os gastos e aumentar a eficiência na prestação de serviços ao cidadão, destacando ainda o papel da transparência para o exercício do controle social e controle da corrupção (MATIAS-PEREIRA, 2005). O modelo gerencialista busca superar externalidades negativas do modelo burocrático Weberiano, focado na especialização funcional, no procedimento e no excessivo formalismo dos controles, resultando numa estrutura inchada, ineficiente, onerosa e ensimesmada, incapaz de atender às necessidades da sociedade num ambiente de incerteza e rápidas mudanças (AMORIM, 2000; LUSTOSA DA COSTA, 2010).

No Brasil, o Plano Diretor da Reforma do Aparelho do Estado de 1995 estabeleceu as bases teóricas para a reforma e, apesar da complexidade das mudanças ainda necessárias, o paradigma gerencial tem avançado na cultura e nas instituições. Não obstante, discute-se atualmente uma evolução à administração pública gerencial, que tem sido chamada de "governança pública"”2. Essa concepção preconiza a participação de diferentes atores na formulação e gestão das políticas públicas, e a construção das políticas públicas em estruturas horizontais, pelo estabelecimento de relações de cooperação entre organizações

\footnotetext{
2 Necessário destacar que a governança pública não corresponde ao conceito de governança da linguagem empresarial e contábil, embora empreste dele algumas características (SECCHI, 2009).
} 
governamentais e da sociedade. O papel primordial do Estado deixa de ser a implantação, passando a ser a articulação e controle das políticas públicas. O cidadão, mais que cliente, passa a ser parceiro (PECI et al., 2008; SECCHI, 2009).

A necessidade de uma gestão pública cada vez mais eficiente, eficaz e transparente despertou o interesse pela governança das organizações governamentais. Em 2001, o estudo 13 da International Federation of Accountants - IFAC recomendou o estabelecimento de estruturas de controle interno nessas organizações e a avaliação periódica de sua eficácia. $\mathrm{O}$ controle interno é definido como um processo integrado, realizado pela gerência e funcionários de uma organização, desenhado para responder aos riscos e prover segurança razoável de que a organização executará eficazmente suas operacionais, cumprirá suas obrigações de accountability, cumprirá as leis e regulamentos a que está sujeita, e manterá seus ativos protegidos de perda e mau uso, de modo a cumprir a sua missão (INTOSAI, 2004).

Nesse contexto, os gestores públicos têm sido estimulados a implantar estruturas de controle interno eficazes, que contribuam para diminuir o risco de que as organizações governamentais sejam administradas em desacordo com os interesses dos cidadãos. A implantação e o aprimoramento de estruturas de controle interno podem ser feitos com o auxílio de padrões, e modelos de referência e melhores práticas, como o framework de Controle Interno do COSO. Este trabalho pretende contribuir para essas tarefas, desenvolvendo um instrumento de avaliação que incorpora a noção de evolução das capacidades do processo de controle interno em estágios, conhecido como modelo de maturidade.

Um modelo de maturidade pode ser definido como "um conjunto estruturado de elementos que descrevem as características de processos eficazes em diferentes estágios de desenvolvimento" (PULLEN, 2007, p. 9), que estabelece um caminho evolutivo antecipado, desejado ou típico (BECKER et al., 2009) e serve aos propósitos de diagnóstico, evolução e comparação das capacidades desses processos (PÖPPELBUß; RÖGLINGER, 2011). O modelo de maturidade para estruturas de controle interno em organizações governamentais pretende proporcionar ao gestor público orientação para iniciativas de implantação, condução e avaliação da estrutura de controle interno sob sua responsabilidade, bem como na identificação e priorização das melhorias necessárias, além de propiciar a comparação das capacidades das estruturas de controle interno, podendo ser utilizado pelas instâncias de supervisão e controle da administração pública para estimular a melhoria contínua das organizações governamentais.

A instalação e aprimoramento de estruturas de controle interno nas organizações governamentais responsáveis pela formulação e realização de políticas públicas, especialmente 
para o setor da agricultura, é importante em razão da relevância estratégica do setor para o desenvolvimento econômico e social do Brasil. $\mathrm{O}$ agronegócio tem contribuído significativamente para o Produto Interno Bruto - PIB e a balança comercial do País (USP, 2016; BRASIL, 2016); a agricultura familiar tem gerado renda e segurança alimentar para famílias pobres (GUILHOTO et al., 2006); a agricultura tem contribuído também para a matriz energética do País (BRASIL, 2015).

Desse modo, a seguinte pergunta orienta a pesquisa: qual o nível de maturidade das estruturas de controle interno das organizações governamentais responsáveis pela formulação e realização de políticas públicas para a agricultura brasileira?

\subsection{OBJETIVOS}

\subsubsection{Objetivo geral}

Analisar a maturidade das estruturas de controle interno de organizações governamentais brasileiras que implementam políticas públicas para a agricultura.

\subsubsection{Objetivos específicos}

a) Propor e validar instrumento de avaliação da maturidade das estruturas de controle interno de organizações governamentais, com base em modelos de maturidade existentes e nas boas práticas de controle interno recomendadas pelos frameworks do COSO e padrões do U.S. Government Accountability Office - GAO;

b) Avaliar o nível de maturidade das estruturas de controle interno de um conjunto selecionado de organizações governamentais brasileiras que implementam políticas públicas para a agricultura.

\subsection{JUSTIFICATIVA}

Nos últimos anos, a manutenção de uma política econômica que buscou o crescimento da economia por um modelo de estímulo ao consumo das famílias, de aumento real do salário mínimo e redução da taxa básica de juros, e de estimulo ao investimento do setor privado, por meio de desonerações, redução de custos e facilitação de financiamentos, associada à expansão dos gastos governamentais, levaram o Brasil a um cenário de crise econômica e fiscal (MARTINS, 2015).

Além disso, a revelação de esquemas de corrupção e fraude para desvio de recursos públicos em diversas organizações governamentais brasileiras (Conab, Ministério dos Esportes, 
Ministério dos Transportes, Agência Nacional do Petróleo, Petrobrás) fomentou um cenário de insatisfação social, alimentando uma crise política.

Esse contexto aumenta a pressão para que o Estado brasileiro reduza seus gastos, tornando-se mais eficiente e eficaz, e mostra a necessidade de desenvolver mecanismos para que a gestão das entidades do Estado seja mais transparente e condizente com os interesses dos cidadãos. Nesse ambiente, o aprimoramento das estruturas de controle interno das organizações governamentais vai ao encontro das demandas da sociedade.

Os frameworks de controle interno e boas práticas associadas auxiliam a implantação e a avaliação da eficácia dos controles internos de uma organização, definindo os componentes e princípios que devem estar presentes e funcionando para que a estrutura de controle interno propicie razoável segurança de que os objetivos da organização serão realizados e seus relatórios financeiros estarão livres de distorções relevantes. Um modelo de maturidade acrescenta à avaliação dos controles internos a noção de evolução das capacidades do processo de controle interno em estágios.

Pöppelbuß e Röglinger (2011, p. 3) afirmam que "modelos de maturidade basicamente representam teorias sobre como capacidades organizacionais evoluem, estágio por estágio, ao longo de um caminho de maturação antecipado, desejado ou lógico"3. Os autores destacam ainda que um modelo de maturidade pode ser descritivo (quando usado como ferramenta de diagnóstico, para avaliação das capacidades de uma entidade com base em critérios determinados), prescritivo (quando identifica níveis de maturidade desejados e fornece orientações quanto a indicadores de melhoria) e comparativo (quando permite o benchmarking interno e externo).

Os propósitos também diferenciam os modelos de maturidade dos padrões de auditoria. Os padrões de auditoria orientam o trabalho do auditor, que deve obter entendimento adequado da eficácia dos controles internos da entidade para avaliar o risco de auditoria, que pode ser genericamente definido como o risco de que o auditor expresse uma opinião de auditoria inadequada. Uma estrutura de controle ineficaz aumenta a incerteza quanto à eficiência e eficácia das operações, à conformidade com as leis e regulamentos aplicáveis e à ausência de distorções materialmente relevantes nas informações financeiras da entidade. Nessa

\footnotetext{
${ }^{3}$ Based on the assumption of predictable patterns, maturity models basically represent theories about how organizational capabilities evolve in a stage-by-stage manner along an anticipated, desired, or logical maturation path.
} 
situação, o risco de auditoria é maior e o auditor deve realizar procedimentos adicionais para obter evidências que deem embasamento mais seguro à sua opinião.

Já o modelo de maturidade auxilia auditores e gestores a classificar estruturas de controle interno conforme suas capacidades, possibilitando a comparação entre as estruturas de diferentes organizações e apresentando um caminho evolutivo que orienta a organização quanto às providências necessárias para a obtenção de um nível de maturidade ideal. A comparação proporcionada pelos modelos de maturidade pode estimular a melhoria das organizações do setor governamental, que tendem a se tornar mais eficientes e eficazes, bem como a melhoria da gestão pública, que tende a se tornar mais transparente e conformada ao interesse dos cidadãos.

O desenvolvimento de modelos de maturidade a partir de frameworks e boas práticas não é algo inédito. A Information Systems Audit and Control Association - Isaca, associação internacional que desenvolve metodologias e certificações para as atividades de auditoria e controle de sistemas de informação, desenvolveu um framework que integra boas práticas para a governança da tecnologia da informação (TI) nas organizações, denominado Control Objectives for Information and related Technology - Cobit. O Cobit inclui um modelo de maturidade em seis níveis, cuja descrição pode ser encontrada no item 3.1.1 deste trabalho, e que serviu como referência para a construção do modelo de maturidade proposto neste trabalho.

No Brasil, Bramont (2012) propôs diretrizes básicas para um modelo preliminar de maturidade em governança corporativa para empresas brasileiras, com base no Código de Melhores Práticas do Instituto Brasileiro de Governança Corporativa, distribuindo cinquenta práticas de governança extraídas do código nos níveis de maturidade "iniciado", "expandido", "institucionalizado", "aprimorado" e "completo".

Há ainda outros modelos de maturidade propostos para aplicação em organizações governamentais. O quadro a seguir apresenta uma síntese com alguns exemplos:

Quadro 1 - Exemplos de modelos de maturidade desenvolvidos para organizações governamentais

\begin{tabular}{|l|l|l|}
\hline \multirow{2}{*}{ Tema (Autor) } & \multicolumn{2}{|c|}{ Estrutura } \\
\cline { 2 - 3 } & \multicolumn{1}{|c|}{ Níveis } & \multicolumn{1}{c|}{ Dimensões } \\
\hline Governo eletrônico & 1. Catálogo; & 1. Funcionalidades; \\
Layne e Lee (2001) & 2. Transação; & 2. Desafios. \\
Andersen e Henriksen (2006) & 3. Integração vertical; & \\
\hline
\end{tabular}

Continua na página seguinte. 
Continuação do Quadro 1 - Exemplos de modelos de maturidade desenvolvidos para organizações governamentais

\begin{tabular}{|c|c|c|}
\hline \multirow{2}{*}{ Tema (Autor) } & \multicolumn{2}{|c|}{ Estrutura } \\
\hline & Níveis & Dimensões \\
\hline $\begin{array}{l}\text { Interoperabilidade de sistemas } \\
\text { e organizações } \\
\text { Gottschalk (2009) }\end{array}$ & $\begin{array}{l}\text { 1. Interoperabilidade de } \\
\text { computadores; } \\
\text { 2. Interoperabilidade de processos; } \\
\text { 3. Interoperabilidade de } \\
\text { conhecimento; } \\
\text { 4. Interoperabilidade de valor; } \\
\text { 5. Interoperabilidade de objetivos. }\end{array}$ & 1. Habilidades ou capacidades. \\
\hline $\begin{array}{l}\text { Governo aberto } \\
\text { Lee e Kwak (2012) }\end{array}$ & $\begin{array}{l}\text { 1. Condições iniciais; } \\
\text { 2. Transparência de dados; } \\
\text { 3. Participação aberta; } \\
\text { 4. Colaboração aberta; } \\
\text { 5. Envolvimento onipresente. }\end{array}$ & $\begin{array}{l}\text { 1. Dados; } \\
\text { 2. Processos de participação e } \\
\text { colaboração; } \\
\text { 3. Resultados; } \\
\text { 4. Métricas. }\end{array}$ \\
\hline $\begin{array}{l}\text { Transparência para } \\
\text { accountability } \\
\text { Lourenço e Serra (2014) }\end{array}$ & $\begin{array}{l}\text { 0. Sem infraestrutura técnica; } \\
\text { 1. Condições iniciais; } \\
\text { 2. Portais de dados; } \\
\text { 3. Redes de accountability; } \\
\text { 4. Estrutura e organização geral. }\end{array}$ & $\begin{array}{l}\text { 1. Características ou } \\
\text { funcionalidades. }\end{array}$ \\
\hline $\begin{array}{l}\text { Gestão de riscos } \\
\text { Federal Records Council e } \\
\text { National Archives and Records } \\
\text { Administration (2014) }\end{array}$ & $\begin{array}{l}\text { 0. Ausente; } \\
\text { 1. Em desenvolvimento; } \\
\text { 2. Funcionando; } \\
\text { 3. Habilitada; } \\
\text { 4. Incorporada. }\end{array}$ & $\begin{array}{l}\text { 1. Apoio da gerência e estrutura } \\
\text { organizacional; } \\
\text { 2. Políticas, padrões e } \\
\text { governança; } \\
\text { 3. Operações do programa de } \\
\text { gestão de riscos. }\end{array}$ \\
\hline $\begin{array}{l}\text { Auditoria interna de entidades } \\
\text { do setor público } \\
\text { IIA (2009) }\end{array}$ & $\begin{array}{l}\text { 1. Inicial; } \\
\text { 2. Infraestrutura; } \\
\text { 3. Integrado; } \\
\text { 4. Gerenciado; } \\
\text { 5. Otimizado. }\end{array}$ & $\begin{array}{l}\text { 1. Serviços e papel da auditoria } \\
\text { interna; } \\
\text { 2. Gestão de pessoas; } \\
\text { 3. Práticas profissionais; } \\
\text { 4. Gestão de desempenho e } \\
\text { accountability; } \\
\text { 5. Relacionamentos e cultura } \\
\text { organizacional; } \\
\text { 6. Estruturas de governança. }\end{array}$ \\
\hline
\end{tabular}

Fonte: Elaborado pelo autor.

Considerando a proposta de realizar uma avaliação das estruturas de controle interno de entidades do setor governamental por meio de um modelo de maturidade, verificase a utilidade e oportunidade deste trabalho. O instrumento poderá auxiliar gestores públicos, orientando suas iniciativas de melhoria dos controles, e auxiliar as instâncias de controle da administração pública, que poderão estimular a melhoria contínua das estruturas de controle interno das entidades governamentais por meio da comparação, contribuindo assim para a realização do interesse social. 
Hay (1993) afirma que o conceito de controle interno foi incluído nos padrões profissionais de auditoria dos países de língua inglesa ${ }^{4}$ nas décadas de 1920 e 1930, evoluindo a partir dos anos 1950, principalmente em razão de críticas públicas a procedimentos de auditoria que antecederam falências de companhias, da resistência dos auditores à expansão de suas responsabilidades e da crescente padronização dos termos aplicados para a definição.

Outro fator relevante foi a mudança na ênfase da auditoria, afastando-se da detecção de fraude. Nesse sentido, os padrões do American Institute of Accountants - AIA ${ }^{5}$ afirmavam em 1936 que o objetivo do controle interno era a salvaguarda dos ativos; desde então, as mudanças no conceito de controle interno vêm refletido a ênfase na confiabilidade dos dados utilizados para a elaboração das demonstrações financeiras. A tendência identificada foi de ampliação da visão de controle interno (HAY, 1993).

A exigência de avaliação do controle interno foi introduzida nos padrões de auditoria do AIA em 1948, quando o controle interno era definido nos seguintes termos:

Controle interno abrange o plano da organização e todos os métodos e medidas coordenados adotados por uma empresa para salvaguardar seus ativos, verificar a acurácia e confiabilidade de seus dados contábeis, promover a eficiência operacional e encorajar a aderência às políticas gerenciais prescritas. ${ }^{6}$ (AIA, 1949, p. 6, apud HAY, 1993)

Em 1958, um padrão de auditoria do AICPA dividiu o controle interno em controles contábeis (confiabilidade dos dados contábeis) e controles administrativos (eficiência operacional e aderência às políticas gerenciais), afastando do auditor a responsabilidade pelos controles administrativos; em 1979, o AICPA resgatou um conceito mais abrangente do controle interno, destacando a importância de fatores como a estrutura organizacional e a liderança da alta gerência para um “ambiente de controle interno contábil” (HAY, 1993).

O contexto das fraudes contábeis e falências de grandes corporações a partir da década de 1980 ensejou novos desenvolvimentos. Em 1985, foi criada a Treadway

\footnotetext{
${ }^{4}$ Estados Unidos, Reino Unido, Austrália e Nova Zelândia.

${ }^{5}$ O AIA antecedeu o American Institute of Certified Public Accountants - AICPA.

${ }^{6}$ Internal control comprises the plan of organization and all of the co-ordinate methods and measures adopted within a business to safeguard its assets, check the accuracy and reliability of its accounting data, promote operational efficiency, and encourage adherence to prescribed managerial policies.
} 
Commission $^{7}$, com a missão de estudar as causas da ocorrência de fraudes em relatórios financeiros e fazer recomendações para a redução de sua incidência; o relatório da Comissão, entregue em 1987, enfatiza o ambiente de controle, os códigos de conduta e comitês de auditoria competentes e compromissados, invocando as associações patrocinadoras a desenvolver um referencial comum integrando os diversos conceitos de controle interno.

O conceito de "estrutura de controle interno" é introduzido pelo AICPA em 1988, como "as políticas e procedimentos estabelecidos para prover segurança razoável de que os objetivos específicos da entidade serão realizados" "AICPA, 1988, p. 4, apud HAY, 1993).

Em 1992, o $\mathrm{COSO}^{9}$ publicou a primeira versão do Internal Control - Integrated Framework, uma estrutura para orientar o desenho, implantação, condução e avaliação da eficácia do controle interno nas organizações, que ficou conhecida como COSO I. Nos anos seguintes foram desenvolvidos outros frameworks de controle interno, destacando-se como referências a Orientação Turnbull (Reino Unido) e a Orientação sobre Controles do CoCo (Canadá). Em 1995, o AICPA emitiu o padrão de auditoria SAS nº 78, adotando a definição de controle interno do COSO e seus cinco componentes.

As fraudes contábeis e falências de grandes corporações ocorridas no início dos anos 2000 (Enron, Worldcom e outras) motivaram a edição da Lei Sarbanes-Oxley - SOX, que estabelece normas de governança corporativa a todas as empresas que possuem valores mobiliários registrados na Securities and Exchange Commission - SEC, inclusive estrangeiras. A seção 302 da SOX define que os principais diretores executivos e financeiros das organizações são responsáveis pela fidedignidade das afirmações contidas nos relatórios financeiros; a seção 404 determina que os relatórios anuais incluam um relatório de controle interno, afirmando a responsabilidade da gerência pelo estabelecimento e manutenção de uma estrutura adequada de controle interno, e contendo uma avaliação da eficácia da estrutura e dos procedimentos para a elaboração dos relatórios financeiros, atestada pelo auditor independente da organização.

As exigências da Lei SOX e a necessidade de restaurar a confiança na atividade de contabilidade e auditoria influenciaram também o desenvolvimento de padrões internacionais

\footnotetext{
${ }^{7}$ Comissão Nacional sobre Fraudes em Relatórios Financeiros.

${ }^{8}[\ldots]$ the policies and procedures established to provide reasonable assurance that specific entity objectives will be achieved.

${ }^{9}$ Comitê das Organizações Patrocinadoras da Treadway Commission.
} 
de auditoria, entre eles os International Standards of Auditing - ISA $^{10}$, as Normas Internacionais para a Prática Profissional de Auditoria Interna ${ }^{11}$ e os International Standards of Supreme Audit Institutions - ISSAI ${ }^{12}$. Esses padrões passaram a incluir normas para controle de qualidade, avaliação de controles internos, gerenciamento de riscos, fraude, e governança corporativa. Quanto às organizações governamentais, a Lei SOX inspira a seguinte recomendação do estudo 13 do IFAC (2001):

Ao relatar sobre a eficácia da estrutura de controle interno da entidade, corpos governantes devem incluir no relatório anual uma declaração assegurando que a estrutura de controle interno que eles estabeleceram é adequada para a natureza da organização e eficaz na prática. A declaração descreve os arranjos que eles estabeleceram para habilita-los a fazer a declaração requerida. Estes podem ter a forma de uma revisão dos vários sistemas, riscos e oportunidades, bem como o monitoramento dos principais processos e procedimentos de controle. Os critérios contra os quais o sistema é medido são assim identificados, bem como a data na qual a conclusão é feita. ${ }^{13}$ (IFAC, 2001, p. 45)

Em 2004, o COSO publicou o Enterprise Risk Management - Integrated

Framework, uma estrutura para o gerenciamento de riscos corporativos, que ficou conhecida como COSO II ou COSO ERM. O COSO II não substitui o COSO I, mas incorpora os elementos necessários ao gerenciamento de riscos corporativos. O controle interno é parte integrante da gestão de riscos.

Em 2013, o COSO apresentou a atualização do framework COSO I. As principais novidades da atualização foram: a introdução dos princípios, que formalizaram conceitos fundamentais da versão original, tornando mais claros os requisitos de um controle interno eficaz; a inclusão de considerações refletindo as mudanças ocorridas nos ambientes de negócios e operações, que se tornaram mais complexas e dependentes da tecnologia; e a expansão dos objetivos operacionais e de relatórios, aumentando o seu escopo de aplicação (COSO, 2013c).

\footnotetext{
${ }^{10}$ Padrões internacionais de auditoria emitidos pelo International Auditing and Assurance Board - IAASB, órgão do IFAC.

${ }^{11}$ Normas Internacionais para a Prática Profissional de Auditoria Interna, emitidas pelo Institute of Internal Auditors - IIA.

12 Padrões internacionais de auditoria de Entidades de Fiscalização Superiores, emitidos pela International Organisation of Supreme Audit Institutions - Intosai, que incluem a auditoria financeira (ISSAI 1000-2999), a auditoria de desempenho (ISSAI 3000-3999) e a auditoria de conformidade (ISSAI 4000-4999).

${ }^{13}$ In reporting on the effectiveness of the entity's framework of internal control, governing bodies need to include in the annual report a statement to the effect that the framework of internal control they have established is both appropriate to the nature of the organization and effective in practice. The statement outlines the arrangements that they have established to enable them to make the required statement. These may take the form of a review of the various systems, risks and opportunities, as well as monitoring of the key control processes and procedures. The criteria against which the system is measured are thus identified, as well as the date on which the conclusion is made.
} 
O controle interno é definido pelo COSO (2013) como "um processo conduzido pelo corpo diretivo, gerência e outros profissionais da entidade, e desenvolvido para proporcionar segurança razoável com respeito à realização dos objetivos relacionados às operações, divulgação e conformidade" ${ }^{14}$.

Os objetivos de controle interno são operacionais (eficácia e à eficiência das operações), de divulgação (confiabilidade, tempestividade e transparência das divulgações financeiras e não financeiras, internas e externas) e de conformidade (cumprimento de leis e regulamentações) (COSO, 2013). A Intosai (2004) inclui os objetivos operacionais (execução de operações ordenadas, éticas, econômicas, eficientes e eficazes), de accountability (disponibilização tempestiva de informações financeiras e não-financeiras, relevantes e confiáveis, para as partes interessadas internas e externas), de conformidade (cumprimento de leis e regulamentações) e de salvaguarda (proteção dos recursos contra perda, mau uso e danos, devido a desperdício, abuso, má gestão, erros, fraudes e irregularidades).

Os cinco componentes da estrutura de controle interno do COSO I são: ambiente de controle; avaliação de riscos; atividades de controle; informação e comunicação; e monitoramento. Cada componente possui um conjunto de princípios que auxilia a compreensão de seu conteúdo e orienta os esforços de desenvolvimento do componente. O COSO estabelece um relacionamento entre os objetivos, os componentes do controle interno e a estrutura organizacional da entidade, conforme a figura a seguir:

\footnotetext{
${ }^{14}$ Internal control is a process, effected by an entity's board of directors, management, and other personnel, designed to provide reasonable assurance regarding the achievement of objectives relating to operations, reporting, and compliance.
} 
Figura 1 - Cubo COSO - Relação entre Componentes, Objetivos e Estrutura Organizacional

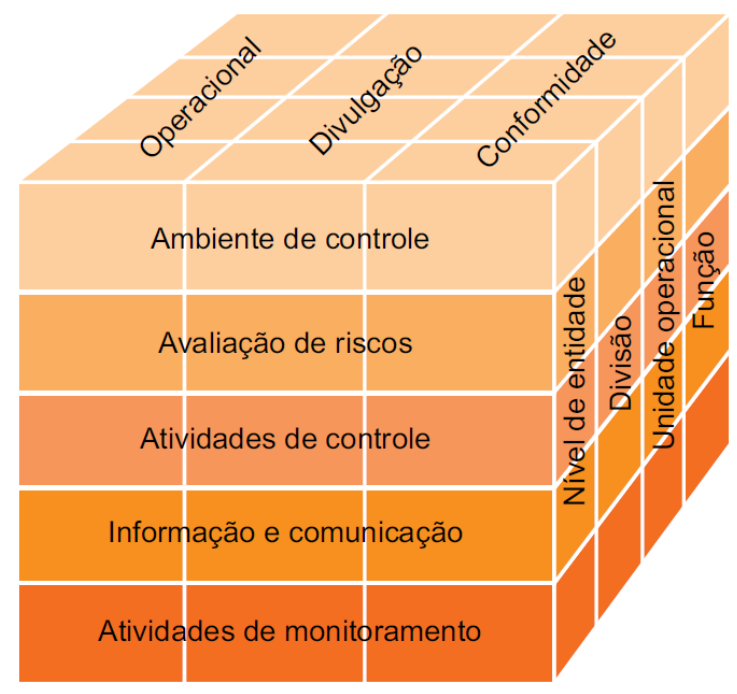

Fonte: COSO (2013).

As limitações inerentes ao controle interno não permitem a obtenção de certeza absoluta quanto à realização dos objetivos da entidade. Tais limitações são decorrentes de fatores como a inadequação dos objetivos estabelecidos, fatores humanos na tomada de decisões (erro, viés), a capacidade da gerência de burlar o controle interno, o conluio entre gerência, funcionários e/ou terceiros para burlar o controle interno, além de eventos externos, fora do controle da organização. Apesar de as limitações impedirem a obtenção de segurança absoluta quanto à realização dos objetivos da entidade, o desenho adequado dos controles pode auxiliar a diminuir tais limitações (COSO, 2013).

Os componentes da estrutura de controle interno do COSO e princípios relacionados são apresentados a seguir.

\subsubsection{Ambiente de Controle}

O primeiro componente é o ambiente de controle, definido pelo COSO (2013) nos seguintes termos:

O ambiente de controle é o conjunto de padrões, processos e estruturas que proveem a base para a realização do controle interno ao longo da organização. $\mathrm{O}$ corpo diretivo e a alta gerência estabelecem o tom no topo a respeito da importância do controle interno incluindo os padrões de conduta esperados. A gerência reforça as expectativas nos vários níveis da organização. O ambiente de controle abrange a integridade e os valores éticos da organização; os parâmetros que habilitam o corpo diretivo a cumprir suas responsabilidades de supervisão; a estrutura organizacional e a atribuição de autoridade e responsabilidade; o processo de atração, desenvolvimento e retenção de indivíduos competentes; e o rigor quanto às medidas de desempenho, incentivos e recompensas para direcionar a responsabilização pelo 
desempenho. $\mathrm{O}$ ambiente de controle resultante tem impacto penetrante em todo o sistema geral de controle interno ${ }^{15}$. (COSO, 2013)

$\mathrm{O}$ ambiente de controle estabelece as bases para a eficácia de uma estrutura de controle interno. Whittington e Pany (2012) afirmam que o ambiente de controle é a base para os demais componentes; Johnstone et al. (2012) afirmam que deficiências no ambiente de controle estão associadas com fraudes financeiras conhecidas, como o caso das instituições financeiras Lehman Brothers e Bear Sterns, cujos conselhos de administração foram dominados pela alta gerência e não exerciam adequadamente a supervisão. Exemplos de deficiências no ambiente de controle incluem: baixo nível de consciência de controle na organização; comitê de auditoria que não tem membros independentes; falta de cobrança de um comportamento ético na organização; administração que burla os controles sobre as transações contábeis; e pessoal sem competência para cumprir suas atribuições (JOHNSTONE et al., 2012).

O Ambiente de Controle abrange os princípios de 1 a 5 do COSO, descritos nos itens a seguir.

\subsubsection{Princípio 1: A organização demonstra comprometimento com a integridade e os valores éticos}

De acordo com o COSO (2013), o comprometimento com a integridade e os valores éticos começa com o exemplo dado pelos líderes da organização. As diretrizes, o estilo gerencial e a conduta pessoal dos indivíduos do corpo diretivo e da gerência influenciam o comportamento de empregados, terceirizados ${ }^{16}$ e parceiros de negócios, devendo estimulá-los a fazer o que é certo, e não apenas cumprir as leis. Assim, é importante que a organização estabeleça padrões de conduta, que além de refletir as leis e regulamentos a que a entidade está sujeita, devem refletir as expectativas de ética e os valores das partes interessadas, inclusive empregados, clientes, fornecedores e a sociedade em geral. Os padrões de conduta devem ser comunicados de maneira regular e consistente, para que os indivíduos tenham conhecimento

\footnotetext{
${ }^{15}$ The control environment is the set of standards, processes, and structures that provide the basis for carrying out internal control across the organization. The board of directors and senior management establish the tone at the top regarding the importance of internal control including expected standards of conduct. Management reinforces expectations at the various levels of the organization. The control environment comprises the integrity and ethical values of the organization; the parameters enabling the board of directors to carry out its oversight responsibilities; the organizational structure and assignment of authority and responsibility; the process for attracting, developing, and retaining competent individuals; and the rigor around performance measures, incentives, and rewards to drive accountability for performance. The resulting control environment has a pervasive impact on the overall system of internal control.

${ }^{16} \mathrm{O}$ termo se refere a indivíduos ou entidades contratados para prestar serviços relevantes para a realização dos objetivos da entidade ou atuar em nome da entidade.
} 
dos comportamentos inaceitáveis e suas consequências. A organização deve ter processos para avaliar o desempenho dos indivíduos no cumprimento dos padrões de conduta, sendo tempestiva e coerente na identificação e tratamento de desvios. Essas medidas favorecem o estabelecimento de uma cultura organizacional forte, que apoia o funcionamento da estrutura de controle interno da entidade.

Abordando a questão da filosofia e estilo gerencial, o GAO (2001) indica que o comprometimento com a integridade e os valores éticos pode se manifestar no apoio dado pela gerência às funções de contabilidade, tecnologia da informação, recursos humanos, monitoramento, e auditoria interna e externa; na salvaguarda de ativos e informações valiosos; na interação entre a alta gerência e os gerentes operacionais; na preocupação com a relevância e a qualidade das evidenciações; e no apoio a uma gestão baseada no desempenho.

D’Aquila (1998) identifica em seu estudo uma relação positiva entre um "tom no topo" adequado e decisões de evidenciação que apresentam as informações financeiras de forma justa, afirmando que a edição de um código de conduta e a ausência de pressões por resultados em curto prazo, por si só, não são suficientes para influenciar as decisões de evidenciação dos contadores. Esse achado reafirma a influência do "tom no topo" sobre as decisões dos empregados nas organizações.

O IFAC (2001) destaca a sensibilidade das relações com fornecedores, afirmando que membros do corpo diretivo e servidores envolvidos com aquisições e contratos devem ser cuidadosos com a aceitação de presentes, favores, entretenimento e outros, para não se comprometerem nem parecerem comprometidos com um fornecedor.

\subsubsection{Princípio 2: $\mathrm{O}$ corpo diretivo demonstra independência em relação à gerência e exerce a supervisão do desenvolvimento e o desempenho do controle interno}

Segundo o COSO (2013), os integrantes do corpo diretivo devem conhecer e honrar suas responsabilidades de supervisão, o que inclui atribuições específicas para a supervisão de cada componente da estrutura de controle interno da entidade. Para tanto, é necessário ter conhecimento do negócio, das expectativas das partes interessadas e dos requisitos das leis e regulamentos aplicáveis, bem como manter um conjunto de competências que os habilitem a inquirir a alta gerência e adotar medidas corretivas adequadas. Além disso, é necessário que a maioria dos indivíduos do corpo diretivo seja independente da gerência, preservando o ceticismo e a objetividade nas suas avaliações e a imparcialidade nas decisões. 
O GAO (2001) destaca a importância das estruturas organizacionais internas que possuem funções de revisão das atividades da entidade, como o conselho diretor e a auditoria interna, além do relacionamento da entidade com o parlamento e com as organizações de supervisão pertencentes ao Executivo ${ }^{17}$.

Jensen (1993) reforça a importância de ter indivíduos com competências especializadas no corpo diretivo de uma entidade, afirmando que, em razão da ausência de membros especializados em finanças, o corpo diretivo e a gerência frequentemente não compreendem a importância da maximização do valor de mercado no longo prazo, e não conseguem traduzir esse objetivo num alicerce viável para a estratégia corporativa e a política operacional das corporações. O mesmo princípio pode ser aplicado ao corpo diretivo de organizações governamentais, que deve incluir membros que compreendam o papel da organização no contexto das políticas públicas que opera e as necessidades dos cidadãos que são o público-alvo dessas políticas.

O IFAC (2001) destaca a importância de os membros do corpo diretivo receberem treinamento de indução, obtendo entendimento quanto ao contexto do setor público no qual a entidade opera e quanto às suas operações, além de treinamento de sensibilização contínua, para manutenção e desenvolvimento de suas competências.

\subsubsection{Princípio 3: A gerência estabelece, com a supervisão do corpo diretivo,} estruturas, linhas hierárquicas, e autoridades e responsabilidades adequadas na busca dos objetivos

Segundo o COSO (2013), a alta gerência e o corpo diretivo devem estabelecer uma estrutura organizacional e linhas hierárquicas que auxiliem o cumprimento de suas responsabilidades de supervisão, facilitando assim a realização dos objetivos da entidade. Para cada tipo de estrutura (geografia do mercado, segmento de negócios, entidades legais), devem ser estabelecidas linhas hierárquicas diretas, que orientam a delegação de autoridades e responsabilidades, e linhas hierárquicas secundárias, que aprimoram o fluxo de informações. A delegação de autoridades e responsabilidades deve ser restrita ao necessário para a realização dos objetivos da entidade, segregando funções para reduzir o risco de condutas indevidas; deve ainda levar em consideração a competência do delegado e sua aderência aos padrões de conduta, políticas e procedimentos da entidade. A estrutura organizacional deve ser periodicamente

\footnotetext{
${ }^{17}$ No Brasil, pode-se mencionar como exemplos a Controladoria-Geral da União - CGU e os órgãos centrais dos Sistemas Federais de Planejamento e Orçamento, Administração Financeira, Contabilidade, Pessoal Civil e outros.
} 
avaliada e adaptada conforme o surgimento de novas prioridades ou a necessidade de racionalização, sempre em suporte à realização dos objetivos da entidade.

O GAO (2001) indica que a delegação de autoridade e responsabilidade deve ser comunicada com clareza, para que cada empregado tenha ciência de suas tarefas e responsabilidades referentes ao controle interno. É necessário estabelecer uma relação adequada entre a responsabilidade e autoridade, dando poder os empregados nos níveis adequados a resolver problemas e implantar melhorias, e possibilitando que os níveis organizacionais inferiores realizem o trabalho sem a intervenção da alta gerência; a delegação deve ser acompanhada de procedimentos eficazes para que a gerência monitore os resultados.

\subsubsection{Princípio 4: A organização demonstra comprometimento com a atração,} desenvolvimento e retenção de indivíduos competentes, em alinhamento com seus objetivos

De acordo com o COSO (2013), as políticas e práticas da entidade devem deixar claros, para os todos os cargos em todos os níveis da organização, os requisitos de competências (habilidades, conhecimento e experiência), a responsabilidade pela realização das principais funções de negócios, além das bases para a avaliação de insuficiências e excessos e ações remediais. A gerência deve estabelecer estruturas e processos para atrair, treinar, aconselhar, avaliar e reter indivíduos (inclusive terceirizados) competentes e em quantidade suficiente para apoiar a realização dos objetivos; a quantidade de recursos e as competências necessárias em cada posição devem ser periodicamente ajustadas, conforme a relevância dos riscos a serem mitigados. Planos de contingência e planos de sucessão devem ser desenvolvidos para os cargos e funções essenciais para a realização dos objetivos da entidade, incluindo os principais executivos, fornecedores e parceiros estratégicos.

O GAO (2001) indica que a demonstração de comprometimento com a competência inclui ações como a definição de critérios para a contratação de pessoal qualificado, inclusive em seu comportamento ético; o estabelecimento de um programa de treinamento contínuo, provendo supervisão e treinamento em trabalho para os empregados; a realização da promoção, compensação e rotação de funcionários com base em avaliações periódicas de desempenho, ligadas aos objetivos e metas definidos no plano estratégico da entidade; a inclusão de integridade e valores éticos entre os fatores de avaliação de desempenho; o feedback e o aconselhamento dos funcionários quanto ao seu desempenho; a tomada de ações remediais em resposta a violações aos padrões de conduta; e a definição de políticas para a demissão de 
funcionários com desempenho constantemente insuficiente ou quando há violações graves das políticas da entidade.

O IFAC (2001) destaca a importância dos programas de treinamento para que todos os indivíduos da entidade possam desenvolver as competências necessárias para a realização de seu trabalho. Para atrair e reter pessoas competentes, as organizações governamentais devem ainda desenvolver políticas de recrutamento e cuidar das condições de trabalho e nível salarial.

\subsubsection{Princípio 5: A organização responsabiliza os indivíduos por suas incumbências de controle interno na busca pelos objetivos}

Segundo o COSO (2013), o diretor executivo e a alta gerência são responsáveis pelo desenho, implantação, comando e avaliação de uma estrutura de controle interno para apoiar a realização dos objetivos da entidade; essa responsabilidade é delegada para as unidades e subunidades organizacionais, e para terceirizados. A estrutura organizacional deve incluir mecanismos para que os indivíduos sejam comunicados dessas responsabilidades e demonstrem a adequação e eficácia do ambiente de controle, avaliação de riscos, atividades de controle, informação e comunicação, e monitoramento estabelecidos para a realização dos objetivos operacionais, de conformidade e comunicação da entidade, para que a gerência promova a responsabilização, adotando medidas corretivas conforme necessário.

Nesse sentido, o corpo diretivo e a gerência devem definir um sistema de medidas de desempenho, incentivos e recompensas, e avaliar continuamente a relevância desse sistema para o cumprimento das atribuições de controle interno; devem ainda avaliar o desempenho na realização das responsabilidades de controle interno em todos os níveis da entidade, recompensando ou disciplinando conforme adequado. É destacada ainda a necessidade de avaliar e ajustar pressões excessivas, que podem estimular indivíduos a burlar processos e envolverem-se em atividade fraudulenta ou corrupção (COSO, 2013).

\subsubsection{Avaliação de Riscos}

O segundo componente é a avaliação de riscos, definida pelo COSO (2013) nos seguintes termos:

A avaliação de riscos envolve um processo dinâmico e interativo para identificar e avaliar os riscos à realização dos objetivos. Os riscos para a realização desses objetivos ao longo da entidade são considerados em relação às tolerâncias de risco estabelecidas. Assim, a avaliação de riscos forma a base para determinar como os riscos serão gerenciados. Uma condição prévia à avaliação de riscos é o estabelecimento de objetivos, ligados aos diferentes níveis da entidade. A gerência especifica os objetivos dentro de categorias 
relacionadas às operações, relatórios e conformidade, com clareza suficiente para identificar e analisar os riscos a esses objetivos. A gerência também considera a adequação dos objetivos à entidade. A avaliação de riscos também exige que a gerência considere o impacto de possíveis mudanças no ambiente externo e dentro de seu próprio modelo de negócio que podem tornar o controle interno ineficaz ${ }^{18}$. (COSO, 2013)

Segundo a Intosai (2004), este componente deve incluir procedimentos para: a identificação dos riscos, levando em consideração os objetivos da entidade e fatores internos e externos que podem afetá-los; a avaliação dos riscos, estimando a probabilidade da ocorrência e severidade dos impactos esperados; a avaliação do apetite da organização aos riscos; e o desenvolvimento de respostas aos riscos - aceitação, transferência, mitigação ou eliminação.

O COSO (2013) define risco como "a possibilidade de que um evento ocorra e afete adversamente a realização dos objetivos". Segundo Johnstone et al. (2012), toda organização enfrenta o risco de distorção material em suas divulgações financeiras. A avaliação de riscos deve ser um processo robusto, considerando os riscos internos (como mudanças nas responsabilidades da administração ou na TI, modelo de negócios ruim) e externos (recessão econômica, mudanças na competição, na regulação dos negócios ou na confiabilidade da cadeia de fornecedores) para evitar que a organização e seus auditores se sujeitem a bancarrota e litigância.

A Avaliação de Riscos abrange os princípios de 6 a 9 do COSO, descritos nos itens a seguir.

\subsubsection{Princípio 6: A organização especifica os objetivos com clareza suficiente para permitir a identificação e a avaliação dos riscos relacionados aos objetivos}

Segundo o GAO (2014), os objetivos devem ser definidos em termos específicos, para que todos os níveis da entidade compreendam o que deve ser realizado, quem realizará, como realizará e em que prazo deve ser realizado. Os termos também devem ser mensuráveis, de modo que o desempenho na realização dos objetivos possa ser avaliado sem viés ou subjetividade. Os objetivos devem ser alinhados com as diretrizes e o plano estratégico da

\footnotetext{
${ }^{18}$ Risk assessment involves a dynamic and iterative process for identifying and assessing risks to the achievement of objectives. Risks to the achievement of these objectives from across the entity are considered relative to established risk tolerances. Thus, risk assessment forms the basis for determining how risks will be managed. A precondition to risk assessment is the establishment of objectives, linked at different levels of the entity. Management specifies objectives within categories relating to operations, reporting, and compliance with sufficient clarity to be able to identify and analyze risks to those objectives. Management also considers the suitability of the objectives for the entity. Risk assessment also requires management to consider the impact of possible changes in the external environment and within its own business model that may render internal control ineffective.
} 
entidade, e refletir as expectativas internas e requisitos externos, inclusive as leis e regulamentos aplicáveis; é necessário revisar periodicamente os objetivos, para manter sua coerência com essas expectativas e requisitos. A entidade deve estabelecer processos para definir os objetivos e refiná-los conforme são utilizados para estabelecer a estrutura de controle interno. Esses processos devem incluir a definição de metas de desempenho e, quando for adequado, a definição de tolerâncias a risco, que são os níveis de variação considerados aceitáveis na avaliação da realização dos objetivos.

O GAO (2001) indica que devem ser estabelecidos objetivos em nível de entidade e em nível de atividade. Os objetivos em nível de entidade, apesar de abrangentes, devem ser identificáveis especificamente com a entidade; devem também ser coerentes com as estratégias operacionais, e devem ser comunicados com clareza para todos os empregados da entidade. Os objetivos em nível de atividade devem ser desenvolvidos a partir dos objetivos da entidade e planos estratégicos. É importante que todos os níveis da gerência participem da formulação dos objetivos das atividades e estejam comprometidos com a sua concretização, e que a entidade identifique os objetivos de atividade que são críticos para a realização dos objetivos em nível de entidade, alocando quantidade adequada de recursos e monitorando a sua realização.

O estudo de Chun e Rainey (2005) sobre ambiguidade de objetivos em organizações governamentais dos EUA identifica a existência de uma relação negativa entre medidas de ambiguidade dos objetivos dessas organizações e a eficácia gerencial. Jung (2014) encontrou em seu estudo evidências de que a ambiguidade de objetivos prejudica o desempenho das agências e programas governamentais.

\subsubsection{Princípio 7: A organização identifica os riscos à realização de seus objetivos} por toda a entidade e analisa os riscos como uma base para determinar a forma como os riscos devem ser gerenciados

De acordo com o COSO (2013), os riscos devem ser identificados e avaliados em todos os níveis organizacionais relevantes para a realização de seus objetivos, desde o nível de entidade até o nível de processos e transações. A avaliação de riscos deve levar em consideração os impactos de fatores externos (economia, natureza, regulação, operações no estrangeiro, sociais, tecnologia) e internos (infraestrutura, estrutura gerencial, pessoal, acesso a ativos, tecnologia) na realização dos objetivos, tendo a participação dos níveis adequados da gerência da entidade, com conhecimento e experiência adequados para a tarefa. A análise dos riscos deve incluir a avaliação da significância, utilizando critérios como a probabilidade de ocorrência e o 
impacto do risco, além da velocidade e persistência do impacto. A resposta aos riscos deve considerar os riscos inerentes e residuais, escolhendo respostas adequadas para reduzi-los ao nível de tolerância a risco aceito pela entidade.

O GAO (2001) indica que a identificação de riscos deve fazer parte de um processo de planejamento estratégico de curto e longo prazos. A identificação de riscos deve levar em consideração os achados de auditorias e outras avaliações, bem como experiências anteriores de fracasso na realização dos objetivos da entidade; os riscos identificados nos níveis hierárquicos mais baixos da entidade devem ser levados ao conhecimento da alta gerência.

O paradigma gerencial impõe à administração pública o encargo de gerenciar os riscos decorrentes das exigências de desempenho e accountability. Nesse sentido, não será mais suficiente a avaliação de riscos segundo a abordagem intuitiva e reativa que caracterizou a administração pública no passado. Para atender às demandas da administração pública gerencial, a avaliação de riscos deve ser realizada por uma abordagem formal e sistemática (BARRETT, 2000).

\subsubsection{Princípio 8: A organização considera o potencial para fraude na avaliação dos riscos à realização dos objetivos}

Segundo o COSO (2013), a avaliação dos riscos deve levar em consideração diferentes tipos de fraude - nos relatórios financeiros e não financeiros, apropriação indevida de ativos, atos ilegais ou corruptos, e o management override ${ }^{19}$. O risco de fraude inclui os incentivos e pressões, que normalmente estão relacionados com fatores do ambiente de controle, como metas de desempenho inexequíveis, objetivos conflitantes de diferentes partes interessadas e desequilíbrio entre as recompensas para o desempenho financeiro de curto prazo e as recompensas para interessados no longo prazo. O risco de fraude inclui também as oportunidades, que normalmente estão relacionadas a atividades de controle e monitoramento mal elaboradas ou mal executadas, e supervisão ruim da gerência, além de fatores como estrutura organizacional complexa ou instável, alta taxa de rotatividade nas equipes de contabilidade, operações, gerenciamento de riscos, auditoria interna e tecnologia, e sistemas de tecnologia ineficazes. Fazem parte do risco de fraude as atitudes e racionalizações, que tentam justificar ações indevidas, como uma pessoa que toma um "empréstimo" da entidade (se

${ }^{19} \mathrm{O}$ termo se refere à capacidade da gerencia de burlar os controles internos. 
apropria indevidamente do dinheiro, mas com a intenção de pagar), ou a pessoa que acredita que a entidade deve algo a ela em razão da insatisfação com o emprego.

Tratando de management override, o GAO (2001) indica que é necessário que a entidade discipline as circunstâncias, frequência e os níveis de gerência autorizados a eximirse dos controles, a documentação completa das razões e ações específicas adotadas, além da notificação imediata dos níveis mais altos da gerência e corpo diretivo da entidade.

\subsubsection{Princípio 9: A organização identifica e avalia as mudanças que poderiam afetar significativamente a estrutura de controle interno}

De acordo com o COSO (2013), o processo de identificação de riscos deve levar em consideração mudanças no ambiente externo (regulatório ou econômico) e no ambiente físico (desastres naturais que impactem a entidade ou sua cadeia de parceiros de negócios). Devem ser consideradas também as mudanças no modelo de negócios, como a entrada em novas linhas de negócios ou alterações significativas nas linhas de negócios existentes por novos relacionamentos com terceiros, aquisições e despojamentos significativos, operações no estrangeiro, crescimento rápido e introdução de novas tecnologias; e as mudanças de pessoal, como a mudança nos principais cargos da alta gerência ou uma alta taxa de rotatividade de pessoal.

O GAO (2014) entende que a gerência deve desenvolver um processo preditivo para identificar antecipadamente e planejar respostas para manter a eficácia da estrutura de controle interno. O GAO (2001) indica a necessidade de observar os efeitos decorrentes de: mudanças do pessoal em cargos estratégicos ou alta rotatividade de pessoal em qualquer área; mudanças significativas ou introdução de novos sistemas de informação; rápida expansão ou diminuição das operações; introdução de novas tecnologias nos processos operacionais; novos produtos ou serviços; e estabelecimento de operações em novas localidades geográficas.

\subsubsection{Atividades de Controle}

As atividades de controle são o terceiro componente, definido pelo COSO (2013) nos seguintes termos:

Atividades de controle são as ações estabelecidas por meio de políticas e procedimentos que ajudam a garantir que as diretrizes da gerência para mitigar os riscos à realização dos objetivos sejam realizadas. Atividades de controle são realizadas em todos os níveis da entidade, em vários estágios dentro dos processos de negócio e no ambiente de tecnologia. Elas podem ser preventivas ou detectivas em sua natureza e podem conter uma série de atividades manuais

e automatizadas tais como autorizações e aprovações, verificações, 
reconciliações e revisões de desempenho de negócio. A segregação de funções é tipicamente inserida na seleção e desenvolvimento de atividades de controle. Onde a segregação de funções não é prática, a gerência seleciona e desenvolve atividades de controle alternativas ${ }^{20}$. (COSO, 2013)

As atividades de controle são estabelecidas para responder aos riscos de que os objetivos (de um processo ou de uma organização) não sejam alcançados; se não houver riscos, não há sentido em estabelecer controles, até porque todo controle envolve algum custo para a organização. Nesse sentido, o estabelecimento de atividades de controle depende da identificação prévia dos objetivos e dos riscos relacionados.

Gil et al. (2013) classificam os controles em administrativos e contábeis e discorrem sobre os princípios aplicáveis ao controle interno. O controle interno administrativo deve atender aos princípios da disponibilidade, eficácia, eficiência e obediência às diretrizes administrativas; já o controle interno contábil está sujeito aos princípios da própria ciência contábil, nos termos do quadro a seguir:

Quadro 2 - Princípios do Controle Interno Contábil segundo Gil et al. (2013)

\begin{tabular}{|c|l|}
\hline Princípio & \multicolumn{1}{c|}{ Descrição } \\
\hline Integridade & Proteção contra modificações indevidas, intencionais ou acidentais. \\
\hline Confidencialidade & Limitação do acesso e uso somente às partes autorizadas. \\
\hline $\begin{array}{c}\text { Fidelidade da informação } \\
\text { em relação aos dados }\end{array}$ & $\begin{array}{l}\text { Possibilidade de confronto e rastreamento da informação até as suas } \\
\text { fontes: documentos, relatórios, dados etc. }\end{array}$ \\
\hline Segurança ambiental & $\begin{array}{l}\text { Diminuição dos prejuízos ambientais causados pelo descumprimento } \\
\text { das normas aplicáveis. }\end{array}$ \\
\hline Segurança física & $\begin{array}{l}\text { Procedimentos e ferramentas para a manutenção da segurança física de } \\
\text { bens tangíveis e intangíveis. }\end{array}$ \\
\hline Segurança lógica & $\begin{array}{l}\text { Procedimentos e ferramentas para a manutenção da execução adequada } \\
\text { dos procedimentos operacionais da entidade, pressupondo a existência } \\
\text { de trilha de auditoria para rastreamento das operações. }\end{array}$ \\
\hline Conformidade & Cumprimento das normas e regulamentos legais aplicáveis. \\
\hline Irrevogabilidade & $\begin{array}{l}\text { Garantia de que as transações e informações não possam ser negadas ou } \\
\text { repudiadas pelas partes. }\end{array}$ \\
\hline
\end{tabular}

Fonte: Gil et al. (2013).

Idealmente, as atividades de controle são predominantemente de caráter preventivo, automáticas (o menos dependente possível da ação humana) e embutidas nos próprios processos de negócios da entidade. Davis e Blaschek (2006) destacam que os sistemas de controle interno na Administração Pública brasileira são focados em aspectos formais e legais, controle posterior

\footnotetext{
${ }^{20} \mathrm{Control}$ activities are the actions established through policies and procedures that help ensure that management's directives to mitigate risks to the achievement of objectives are carried out. Control activities are performed at all levels of the entity, at various stages within business processes, and over the technology environment. They may be preventive or detective in nature and may encompass a range of manual and automated activities such as authorizations and approvals, verifications, reconciliations, and business performance reviews. Segregation of duties is typically built into the selection and development of control activities. Where segregation of duties is not practical, management selects and develops alternative control activities.
} 
e correição, sendo assim ineficazes no atual contexto econômico de maior risco e incerteza e incapazes de inibir a fraude e a malversação de dinheiro público.

As Atividades de Controle abrangem os princípios de 10 a 12 do COSO, que são descritos nos itens a seguir.

\subsubsection{Princípio 10: A organização seleciona e desenvolve atividades de controle que contribuem para a mitigação dos riscos à realização dos objetivos a níveis aceitáveis}

Segundo o COSO (2013), as atividades de controle são a forma de concretizar as respostas aos riscos da entidade. Para tanto, é necessário que a seleção e o desenvolvimento de atividades de controle sejam integrados à avaliação de riscos. Normalmente, controles são elaborados quando a entidade escolhe mitigar ou compartilhar um risco, sendo possível também o desenvolvimento de controles para evitar riscos. As particularidades de uma entidade, como o seu ambiente, a complexidade, natureza e escopo de suas operações, o nível da regulação aplicável, operações regionais e multinacionais, e a utilização de um sistema sofisticado de Enterprise Resource Planning - ERP podem influenciar seus controles.

Atividades de controle devem ser implantadas nos processos de negócios relevantes para a realização dos objetivos da entidade, de modo que as transações sejam registradas de forma completa (todas as transações devem ser registradas), precisa (o valor certo na rubrica certa, ao longo do processamento da transação) e válida (transações autorizadas e aprovadas). Os controles em nível de transação podem incluir: autorizações e aprovações; verificações; controles físicos; controles sobre dados constantes; reconciliações; e controles da supervisão (COSO, 2013).

Além dos controles em nível de transação, é necessário desenvolver atividades de controle que operam num nível mais abrangente, em níveis organizacionais mais altos. Esses controles geralmente serão revisões de desempenho de negócios ou revisões analíticas. É necessário desenvolver um mix de atividades de controle, entre atividades manuais e automáticas, preventivas e detectivas, eficaz para a mitigação dos riscos (COSO, 2013). O anexo A deste trabalho descreve uma lista de tipos de atividades de controle apresentados pelo GAO, que acrescenta: controles sobre a administração do capital humano; estabelecimento e revisão de medidas e indicadores de desempenho; restrições de acesso e accountability por recursos e registros; e a adequada documentação das transações e do controle interno. 


\subsubsection{Princípio 11: A organização seleciona e desenvolve atividades gerais de controle sobre a tecnologia para apoiar a realização dos objetivos}

De acordo com o GAO (2014), controles gerais de tecnologia são as políticas e procedimentos de grande abrangência (níveis de entidade, sistema e aplicação) estabelecidos para criar um ambiente que propicie o adequado funcionamento dos sistemas de informações e controles automatizados de uma entidade, abrangendo o "gerenciamento da segurança, acesso lógico e físico, gerenciamento da configuração, segregação de funções, e planejamento de contingência"21 (GAO, 2014, p. 53).

O COSO (2013) entende que a gerência deve compreender a dependência e ligação entre os processos de negócios e controles automatizados e a tecnologia; o GAO (2014) também entende que a TI não é uma preocupação de controle apartada, afirmando que é necessário dispor a tecnologia de modo a apoiar o funcionamento de um sistema de informação da entidade, que deve atender aos requisitos de informações dos processos operacionais da entidade de forma tempestiva.

A infraestrutura de TI necessária para atender aos objetivos da entidade e responder aos riscos relacionados pode ser complexa. Assim, é necessário estabelecer atividades de controle que evitem que as operações da entidade sejam afetadas por falhas nas redes de comunicação, recursos computacionais ou de eletricidade, incluindo procedimentos de cópia de segurança e planos de continuidade das operações (GAO, 2014).

O gerenciamento da segurança tem como objetivo a preservação da confidencialidade, integridade e disponibilidade dos dados e informações da entidade. Nesse sentido, é necessário prover uma identificação única para os usuários e limitar os direitos de acesso aos recursos de TI ao necessário para o cumprimento de suas responsabilidades, apoiando a segregação de funções da entidade. É necessário ainda levar em consideração as ameaças de origem externa, normalmente em razão da conexão com redes de comunicação, em especial a internet, e as ameaças de origem interna, que normalmente decorrem da insatisfação dos empregados da entidade (GAO, 2014).

A entidade deve também adotar processos de gerenciamento da mudança da TI. O exemplo mais comum é a adoção de um ciclo de vida de desenvolvimento de sistemas, ou

\footnotetext{
${ }^{21}$ General controls include security management, logical and physical access, configuration management, segregation of duties, and contingency planning.
} 
SDLC, uma metodologia que "define fases específicas e a documentação de requisitos, aprovações e pontos de controle dentre as atividades de controle sobre a aquisição, desenvolvimento e manutenção da tecnologia"22 (GAO, 2014, p. 55). O COSO (2013) afirma que essa metodologia deve levar em consideração a complexidade e os riscos decorrentes das mudanças, e deve incluir os sistemas de informações desenvolvidos pela entidade, mesmo quando desenvolvido por terceiros, além dos pacotes de aplicativos adquiridos de fornecedores externos.

Sanchez (2003) destaca que o uso intensivo da TI pode fortalecer os controles e diminuir a assimetria de informação na relação entre burocracia e governo e na relação entre Estado e sociedade, contribuindo para uma gestão mais eficiente dos recursos públicos e para maior transparência e controle da corrupção.

\subsubsection{Princípio 12: A organização implanta atividades de controle por meio de políticas que estabelecem o que é esperado e dos procedimentos que colocam em prática essas políticas}

Segundo o COSO (2013), as políticas são a declaração documentada da gerência da entidade a respeito do que deve ser feito para concretizar o controle, e os procedimentos são as ações que implantam as políticas. É razoável a expectativa de que as políticas e procedimentos sejam formalmente documentados; em entidades de pequeno porte, eles podem estar enraizados no costume organizacional e ser comunicados oralmente, mas isso facilita sua burla e reduz o accountability. Independentemente de sua forma, as políticas devem estabelecer responsabilidade e accountability pelas atividades de controle, que normalmente pertencem ao dono dos riscos relevantes associados, e os procedimentos devem ser realizados tempestivamente, por indivíduos competentes. Além disso, os problemas identificados pelos controles devem ser investigados e corrigidos; e as políticas e procedimentos de controle devem ser revisados periodicamente as atividades de controle, para manutenção de sua relevância e eficácia, levando em consideração as mudanças nos objetivos e riscos da entidade.

O GAO (2014) entende que a gerência deve documentar nas políticas a responsabilidade de cada unidade pelos objetivos e riscos de um processo operacional, e pelo desenho, implantação e eficácia operacional dos controles internos; cada unidade deve

\footnotetext{
${ }^{22}$ An SDLC provides a structure for a new information technology design by outlining specific phases and documenting requirements, approvals, and checkpoints within control activities over the acquisition, development, and maintenance of technology.
} 
aprofundar o detalhamento das políticas em nível adequado para que a gerência realize o monitoramento dos controles, ou elaborar procedimentos, os quais devem incluir a tempestividade dos controles e as ações corretivas caso alguma deficiência seja encontrada. As políticas e procedimentos devem ser comunicados aos empregados, para que eles realizem as atividades de controle sob sua responsabilidade.

\subsubsection{Informação e Comunicação}

O quarto componente é informação e comunicação, definido pelo COSO (2013) nos seguintes termos:

Informação é necessária para a entidade efetue responsabilidades de controle interno para apoiar a realização de seus objetivos. A gerência obtém ou produz e utiliza informações relevantes e de qualidade, de fontes internas e externas, para apoiar o funcionamento do controle interno. Comunicação é o processo contínuo e interativo de prover, compartilhar e obter a informação necessária. Comunicação interna é o meio pelo qual a informação é disseminada por toda a organização, fluindo acima, abaixo e ao longo da entidade. Ela habilita o pessoal a receber uma mensagem clara da alta gerência de que as responsabilidades de controle devem consideradas seriamente. Comunicação externa é dupla: ela habilita a comunicação para dentro de informação externa relevante e provê informação para partes externas em resposta a requisitos e expectativas $^{23}$. (COSO, 2013)

Johnstone et al. (2012) afirmam que o componente de informação e comunicação inclui o sistema contábil da organização e os métodos para registrar e reportar as transações; Whittington e Pany (2012) destacam que o sistema de informações contábeis deve ser capaz de registrar todas as transações válidas, com detalhamento suficiente para a correta classificação, identificação do valor monetário e período contábil, e apresentação adequada das transações e divulgações relacionadas nas demonstrações contábeis.

Jensen (1993) ressalta a importância desse componente para o funcionamento da estrutura de controle interno, afirmando que, em grandes corporações, o diretor executivo quase sempre tem o poder de controlar a agenda e a informação dada ao corpo diretivo. Assim, mesmo que o corpo diretivo possua membros altamente capazes, fica limitada a sua capacidade de contribuir para o monitoramento e avaliação do diretor executivo e da estratégia da companhia.

\footnotetext{
${ }^{23}$ Information is necessary for the entity to carry out internal control responsibilities to support the achievement of its objectives. Management obtains or generates and uses relevant and quality information from both internal and external sources to support the functioning of internal control. Communication is the continual, iterative process of providing, sharing, and obtaining necessary information. Internal communication is the means by which information is disseminated throughout the organization, flowing up, down, and across the entity. It enables personnel to receive a clear message from senior management that control responsibilities must be taken seriously. External communication is twofold: it enables inbound communication of relevant external information and provides information to external parties in response to requirements and expectations.
} 
A Informação e Comunicação abrange os princípios de 13 a 15 do COSO, descritos nos itens a seguir.

\subsubsection{Princípio 13: A organização obtém ou produz e utiliza informações relevantes} e de qualidade para apoiar o funcionamento do controle interno

Segundo o COSO (2013), a organização deve estabelecer um sistema de informações que auxilie a entidade na realização de seus objetivos. Esse sistema deve incluir processos que identifiquem a informação necessária para o funcionamento de cada componente da estrutura de controle interno da entidade, coletem dados relevantes de fontes internas e externas confiáveis, e os processem em informação de qualidade - tempestiva, atual, precisa, completa, acessível, protegida, verificável e preservada. As informações devem ser periodicamente revisadas para a manutenção de sua relevância no suporte ao funcionamento da estrutura de controle interno. Todo esse processo deve levar em consideração a relação entre o custo de obtenção da informação e sua contribuição para a realização dos objetivos da entidade.

Smythe (1996) afirma que, no atual contexto das organizações, um grande desafio é disciplinar a torrente de informação que flui da gerência, reduzindo a "poluição" de modo a aumentar o nível de compreensão por parte dos indivíduos que a recebem.

\subsubsection{Princípio 14: A organização comunica internamente informações necessárias para apoiar o funcionamento do controle interno, incluindo objetivos e responsabilidades pelo controle interno}

Segundo o COSO (2013), é necessário implantar um processo para comunicar internamente as informações necessárias para que todos os indivíduos compreendam e realizem suas responsabilidades de controle interno; esse processo deve incluir a comunicação entre a gerência e o corpo diretivo, para que ambos possam cumprir suas funções em relação aos objetivos da entidade.

É necessário disponibilizar canais de comunicação alternativos para comunicações anônimas ou confidenciais, que também servem como redundância quando os canais normais forem inoperantes ou ineficazes. A gerência deve informar aos empregados a respeito das linhas de comunicação alternativas e confidenciais, como funcionam, como devem ser usadas e como é garantida a confidencialidade da informação. A seleção do método de comunicação deve levar em consideração a tempestividade, a audiência e a natureza da informação, bem como o custo e os requisitos legais e regulamentares aplicáveis (COSO, 2013; GAO, 2014). 
Chmielecki (2015) analisa os fatores que prejudicam a eficácia da comunicação interna nas organizações, destacando: o uso de processos de comunicação de mão única; a ausência de planejamento e investimento; o excesso de informação; o uso do modelo tradicional de hierarquia e a incongruência entre o tipo de informação e a forma escolhida para a transmissão. Pandey e Garnett (2006) destacam o efeito negativo do red tape ${ }^{24}$ sobre a comunicação; Marson et al. (2013) destacam a necessidade de levar em consideração as características culturais da organização na elaboração e gestão do plano de comunicação interna, sob risco de ver frustradas as iniciativas de implantação de novos meios de comunicação.

\subsubsection{Princípio 15: A organização comunica-se com partes externas sobre assuntos que afetam o funcionamento do controle interno}

De acordo com o COSO (2013) e o GAO (2014), os processos de comunicação externa devem levar em consideração as necessidades de informações de interessados externos. No âmbito das corporações privadas, estão incluídos acionistas, parceiros, donos, reguladores, clientes, analistas financeiros e outros; no âmbito das organizações governamentais, as entidades se reportam também ao chefe do governo, legisladores, reguladores e cidadãos. Tal fato possui reflexos também quanto à seleção da forma e métodos de comunicação, que devem ser adequados a audiências com diferentes características. Os canais de comunicação externa devem também permitir a entrada de informações relevantes para a gerência e o corpo diretivo; as informações relevantes que resultarem de avaliações realizadas por partes externas devem ser levadas ao conhecimento do corpo diretivo.

O IFAC (2001) afirma que entre os interessados de organizações governamentais podem incluir: a entidade ou indivíduos que indicam ou elegem o corpo diretivo e têm a responsabilidade de avaliar o desempenho; acionistas e credores; contratados; parceiros; outras entidades governamentais; usuários dos serviços; grupos de interesse; analistas e outros colecionadores de estatísticas; a mídia; e a comunidade em geral.

\subsubsection{Monitoramento}

O monitoramento é o quinto componente, definido pelo COSO (2013) nos seguintes termos:

\footnotetext{
24 De acordo com Bozeman (1993, apud PANDEY; GARNETT, 2006), trata-se de regras, regulamentos e procedimentos que permanecem válidos e impõem um fardo de conformidade, mas não atendem às legitimas propostas que tais regras intencionavam servir.
} 
Avaliações contínuas, avaliações avulsas ou alguma combinação de ambas são utilizadas para verificar se cada um dos cinco componentes de controle interno, inclusive os controles para efetuar os princípios dentro de cada componente, está presente e funcionando. Avaliações contínuas, incorporadas aos processos de negócio em diferentes níveis da entidade, proveem informação tempestiva. Avaliações avulsas, conduzidas periodicamente, irão variar em escopo e frequência dependendo da avaliação dos riscos, da eficácia das avaliações contínuas e de outras considerações da gerência. Os achados são avaliados conforme critérios estabelecidos por reguladores, corpos definidores de padrões, ou pela gerência e corpo diretivo, e as deficiências são comunicadas para a gerência e o corpo diretivo conforme adequado ${ }^{25}$. (COSO, 2013)

Segundo Whittington e Pany (2012), a função de auditoria interna é importante para o sistema de monitoramento de uma organização, ajudando a evitar que a administração transgrida o controle interno. Crepaldi (2013) destaca que a auditoria interna verifica se a estrutura de controle interno está sendo respeitada pelos funcionários e se há circunstâncias que demandam a adaptação do sistema.

O Monitoramento abrange os princípios de 16 e 17 do COSO, descritos nos itens a seguir.

\subsubsection{Princípio 16: A organização seleciona, desenvolve e realiza avaliações} contínuas e/ou avulsas para se certificar de que os componentes do controle interno estão presentes e funcionando

Segundo o COSO (2013), a gerência deve estabelecer uma combinação equilibrada de avaliações contínuas e avaliações avulsas para monitorar a estrutura de controle interno da entidade.

As avaliações contínuas são integradas aos processos da entidade, fornecendo feedback rápido para gerentes operacionais ou funcionais que têm competência para identificar mudanças nas condições do processo. As atividades incluem comparações, reconciliações e outras atividades regulares de gerência e supervisão. A objetividade e a eficiência dessas atividades podem ser aprimoradas pelo uso de ferramentas computadorizadas (COSO, 2013; GAO, 2014).

\footnotetext{
${ }^{25}$ Ongoing evaluations, separate evaluations, or some combination of the two are used to ascertain whether each of the five components of internal control, including controls to effect the principles within each component, is present and functioning. Ongoing evaluations, built into business processes at different levels of the entity, provide timely information. Separate evaluations, conducted periodically, will vary in scope and frequency depending on assessment of risks, effectiveness of ongoing evaluations, and other management considerations. Findings are evaluated against criteria established by regulators, standard-setting bodies, or management and the board of directors, and deficiencies are communicated to management and the board of directors as appropriate.
} 
As avaliações avulsas são realizadas por pessoas que não estão diretamente envolvidas nas atividades, propiciando feedback mais objetivo. As atividades incluem avaliações da auditoria interna ou de especialistas, avaliações cruzadas entre unidades operacionais ou funcionais, benchmarking ou avaliação por pares, e autoavaliações. A periodicidade e o escopo das avaliações avulsas devem ser definidos conforme a avaliação de riscos da entidade, a eficácia do monitoramento contínuo e as mudanças no ambiente de negócios. Entidades que atuam em setores que estão em período de rápidas mudanças podem ter a necessidade de avaliações avulsas em maior frequência; a constatação de uma necessidade de realizar frequentemente avaliações avulsas pode ser indicativa da necessidade de aprimorar as avaliações contínuas (COSO, 2013; GAO, 2014).

\subsubsection{Princípio 17: A organização avalia e comunica deficiências no controle interno} de maneira tempestiva às partes responsáveis por tomar ações corretivas, inclusive a alta gerência e o corpo diretivo, conforme adequado.

Segundo o COSO (2013), a gerência e o corpo diretivo devem avaliar os resultados das avaliações contínuas e avulsas. As deficiências identificadas pelas atividades de monitoramento devem ser comunicadas aos responsáveis pela tomada de ações corretivas; deficiências graves devem ser comunicadas à alta gerência e corpo diretivo. É necessário ainda verificar se as deficiências identificadas são remediadas tempestivamente.

O GAO (2014) acrescenta que as deficiências de controle interno devem ser avaliadas e documentadas, e as ações corretivas devem ser definidas conforme o tipo de deficiência identificada, que pode ser no projeto, na implantação ou na eficácia operacional do controle e seu processo relacionado. Os achados e recomendações de auditorias e outras avaliações independentes também devem ser avaliados e corrigidos, ou justificados se a gerência discordar da avaliação.

\subsection{MODELOS DE MATURIDADE}

Wendler (2012) afirma que o interesse em modelos de maturidade cresceu nas duas últimas décadas, o que pode ser observado pelo aumento de publicações científicas sobre o tema. Segundo o autor (p. 1317), “modelos de maturidade oferecem às organizações uma possibilidade simples, mas eficaz, de medir a qualidade de seus processos" 26 .

\footnotetext{
${ }^{26}$ Maturity models offer organizations a simple but effective possibility to measure the quality of their processes.
} 
Becker et al. (2009, p. 1) afirmam que "Um modelo de maturidade consiste em uma sequência de níveis de maturidade para uma classe de objetos. Ele representa o caminho de evolução antecipado, desejado ou típico desses objetos formatado em fases distintas. Normalmente, esses objetos são organizações ou processos”"27. Pöppelbuß e Röglinger (2011) acrescentam que modelos de maturidade são conhecidos também como modelos de estágios de crescimento, modelos de estágios ou teorias de estágios.

Estudos diversos são citados como precursores das teorias e modelos de estágios. Exemplos incluem: Maslow (1954), que teorizou a hierarquia das necessidades humanas; Greiner (1972), que analisou as fases sequenciais de empresas em processo de crescimento, estabelecendo um modelo para auxiliar a empresa a descobrir em qual estágio se encontra e adotar as práticas gerenciais que a conduzirão para a fase seguinte; Nolan (1973; 1979), que analisou a maturidade do processamento de dados nas organizações, a partir de uma perspectiva de ciclo de vida; Crosby (1979), que descreveu a maturidade do gerenciamento de qualidade nas organizações em cinco estágios; e Paulk et al. (1993), que desenvolveram o Capability Maturity Model - CMM, modelo que se tornou referência para avaliação da maturidade do processo de desenvolvimento de software.

Wendler (2012) identificou em seu estudo a aplicação de modelos de maturidade a mais de vinte domínios, entre eles: governo / setor público; gestão de negócios; gerenciamento de informações; gerenciamento de processos; funções de negócios; inteligência de negócios; processos de colaboração; finanças e controle; governança de TI e sustentabilidade. Além disso, segundo Pöppelbuß e Röglinger (2011), modelos de maturidade podem se referir a diferentes classes de entidades, como pessoas, processos, sistemas sociais ou objetos específicos do domínio de aplicação.

De acordo com Pöppelbuß e Röglinger (2011), um modelo de maturidade pode ser usado como ferramenta de diagnóstico, para análise do estado atual das capacidades da entidade avaliada, com base em critérios determinados (propósito descritivo); identificar o nível de maturidade desejado e fornecer orientações quanto a providências de melhoria (propósito prescritivo); e permitir o benchmarking interno e externo (propósito comparativo). Nesse sentido, um modelo de maturidade para controles internos pode auxiliar a organização a compreender as capacidades atuais da estrutura de controle interno da entidade, permitindo a

\footnotetext{
${ }^{27}$ A maturity model consists of a sequence of maturity levels for a class of objects. It represents an anticipated, desired, or typical evolution path of these objects shaped as discrete stages. Typically, these objects are organizations or processes.
} 
identificação das providências de melhoria para a obtenção de um nível de maturidade desejado e a comparação com outras entidades. Wendler (2012) sintetiza:

Em primeiro lugar, modelos de maturidade geram uma consciência dos aspectos analisados: seu estado, importância, potenciais, requisitos, complexidade e assim por diante. Além disso, eles podem servir como quadro de referência para implementar uma abordagem sistemática e bem dirigida para melhorias, garantir uma certa qualidade, evitar erros, e avaliar as próprias capacidades numa base comparável. ${ }^{28}$ (WENDLER, 2012, p. 2)

De Bruin et al. (2005) entendem que os diferentes propósitos funcionam como fases evolucionárias dos modelos de maturidade. Nesse sentido, inicialmente o modelo é descritivo, para a obtenção de um entendimento mais profundo a respeito da realidade do seu domínio de aplicação; esse modelo evolui para ser prescritivo somente quando a realidade é conhecida e melhorias substanciais e repetíveis podem ser feitas. O modelo de maturidade poderá ser usado comparativamente quando aplicado num espectro abrangente de organizações, obtendo dados suficientes para a comparação válida.

\subsubsection{Estrutura de modelos de maturidade}

Wendler (2012) afirma que, apesar das diferenças na estrutura, todo modelo de maturidade deve ter dois componentes para atender ao seu propósito: um conjunto de níveis ou estágios, sequenciais e hierárquicos, que descrevem a evolução de um objeto de maneira simplificada; e as dimensões ou capacidades, que são os objetos mensurados. Fraser et al. (2002) identificam os seguintes componentes na estrutura de um modelo de maturidade: níveis; descritores; descrições para cada nível; dimensões; áreas de processo; atividades para cada área de processo; e uma descrição para cada atividade conforme realizada em cada nível de maturidade.

Maier et al. (2012) afirmam que a seleção de uma escala de níveis de maturidade depende de uma declaração explícita da lógica subjacente à evolução, o que significa escolher um ponto de alavancagem para a mudança organizacional (a estrutura organizacional, os processos, as pessoas, os produtos). Os autores identificaram diversas possibilidades para essa lógica subjacente, destacando: a existência e aderência a um processo estruturado (ex. infraestrutura, transparência e formalidade); a alteração da estrutura organizacional (políticas e funções de trabalho); ênfase nas pessoas (habilidades, treinamento e construção de

\footnotetext{
${ }^{28}$ First of all, maturity models generate an awareness of the analyzed aspects: their state, importance, potentials, requirements, complexity, and so on. Furthermore, they may serve as reference frame to implement a systematic and welldirected approach for improvements, ensure a certain quality, avoid errors, and assess one's own capabilities on a comparable basis.
} 
relacionamentos); e ênfase no aprendizado (consciência, mentalidade e atitude). Em alguns casos, foi encontrada uma combinação desses critérios; os autores afirmam que "os níveis precisam ser distintos, bem definidos, e precisam mostrar uma progressão lógica porque a definição clara facilita a interpretação dos resultados" (Maier et al, p. 150). De Bruin et al. (2005) afirmam que a prática de representar os níveis de maturidade como um número de estágios cumulativos, em que os requisitos de estágios superiores se acumulam aos requisitos estágios inferiores e com os números 5 representando alto grau de maturidade e 1 representando baixa maturidade, difundiu-se com o CMM, modelo para avaliação das capacidades do processo de desenvolvimento de software elaborado por Paulk et al. (1993).

Quanto à descrição dos níveis de maturidade, De Bruin et al. (2005) entendem que os estágios devem receber rótulos curtos que indiquem o significado do estágio, e que os rótulos devem ter uma descrição, sintetizando os principais requisitos e medidas do estágio, especialmente naqueles aspectos que estabelecem a diferença em relação aos estágios inferiores.

Wendler (2012) define dimensões como as condições, processos, aplicações, unidades organizacionais, domínios de problema e outros, que são os objetos mensurados pelos modelos de maturidade; nesse sentido, os modelos podem ser unidimensionais ou multidimensionais, embora atualmente a maior parte dos modelos seja multidimensional. Maier et al. (2012) utilizam o termo process areas (áreas de processo) para designar as dimensões. Os autores acrescentam que a seleção das áreas de processo é um dos aspectos mais difíceis da elaboração de um modelo de maturidade; que o ideal é estabelecer áreas de processo que sejam mutuamente excludentes e coletivamente exaustivas ${ }^{29}$; e que uma avaliação eficaz deve ser baseada num framework conceitual subjacente, elaborado a partir de princípios de melhores práticas.

De Bruin et al. (2005) afirmam que a abordagem unidimensional, apesar de sua ampla aceitação, não representa adequadamente a maturidade em domínios complexos, porque tal forma de avaliação resulta numa "avaliação média" da maturidade que provê pouca orientação para organizações que desejam melhorar sua posição. Nesse caso, os autores sugerem a utilização de uma abordagem stage-gate, pela divisão dos domínios em componentes (aspectos principais e independentes de um domínio, refletidos nas definições gerais dos níveis

\footnotetext{
${ }^{29}$ Segundo Maier et al. (2012), as áreas de processo, tomadas em seu conjunto, devem ter ampla abrangência, exaurindo o escopo do domínio de estudo.
} 
de maturidade e que permitem o agrupamento dos resultados para a audiência do modelo) e subcomponentes (áreas de capacidade específicas dentro dos componentes, que proveem maior detalhamento permitindo o direcionamento de melhorias no nível de maturidade). A divisão dos domínios em camadas adicionais permite a avaliação de um conjunto de áreas distintas, auxilia as organizações a obter entendimento mais profundo de suas forças e fraquezas no domínio, para direcionar estratégias específicas de melhoria, permitindo melhor alocação de recursos.

\subsubsection{Críticas aos modelos de maturidade}

De acordo com Pöppelbuß e Röglinger (2011), as críticas a modelos de maturidade encontradas nos estudos analisados podem se referir ao processo de design do modelo, ou aos modelos em si, como produtos desse processo de design.

Wendler (2012) afirma que os pesquisadores devem, por um lado, verificar a existência de modelos de maturidade antes de desenvolver um novo, e por outro verificar a adequação dos modelos existentes à proposta pretendida. Além disso, observou a existência de muitos modelos de maturidade desenvolvidos apenas conceitualmente, sem qualquer validação.

Pöppelbuß e Röglinger (2011) sintetizam em seu estudo as críticas de autores diversos. De Bruin et. al (2005) afirmam que os modelos de maturidade já foram caracterizados como "receitas passo a passo" que simplificam excessivamente a realidade e carecem de fundamentação empírica; Teo e King (1997) entendem que modelos de maturidade tendem a negligenciar a existência potencial de múltiplos caminhos igualmente vantajosos; Mettler e Rohner (2009) afirmam que os modelos de maturidade devem ser configuráveis porque fatores externos e internos podem restringir a sua aplicabilidade em sua versão padronizada; King e Kraemer (1984) entendem que modelos de maturidade não devem focar numa sequência de níveis em direção a um estado final, mas em fatores que conduzem a evolução e mudança; finalmente, Becker et al. (2009) e Iversen et al. (1999) criticam a documentação insatisfatória do processo de desenvolvimento e a adoção do diagrama de níveis de maturidade do modelo CMM sem a avaliação de sua adequação.

Não obstante as críticas, Wendler (2012) destaca em seu estudo o crescimento do interesse acadêmico por modelos de maturidade, materializado na quantidade de estudos publicados sobre o tema nos últimos anos. Scott (2007) afirma que a profusão de modelos proprietários, elaborados por empresas de consultoria e de desenvolvimento de software, revela uma tendência de crescimento da adoção de modelos de maturidade. 
Este trabalho propõe um modelo para a avaliação da maturidade de estruturas de controle interno, objeto para o qual não foi identificada proposição de modelo nos estudos anteriores. O modelo proposto neste trabalho tem seus fundamentos teóricos nos padrões de avaliação de controle interno do COSO, tendo sido validado por avaliação de juízes (COY; DIXON, 2004) e testado empiricamente por meio de estudo de casos múltiplos (YIN, 2010), envolvendo organizações governamentais com diferentes estruturas de governança e controle interno. Os procedimentos adotados para o desenvolvimento do modelo são descritos no capítulo 3 e documentados nos apêndices deste trabalho. 
Este capítulo tem por objetivo descrever as etapas necessárias para a execução da pesquisa, além de sua caracterização e limitações, dividindo-se em seis seções. A primeira seção - natureza e tipo de pesquisa - descreve as características do estudo e os procedimentos realizados para dar consecução aos seus objetivos; a segunda seção - objeto de pesquisa apresenta a justificativa para a escolha das organizações nas quais foram realizados os estudos de caso; na terceira seção - proposta da matriz de maturidade - são evidenciados os itens que compõem a matriz e sua sustentação teórica; na quarta seção são apresentados os procedimentos de avaliação da matriz de maturidade proposta; a quinta seção descreve os procedimentos adotados para avaliar a maturidade das estruturas de controle interno das entidades estudadas; na última seção são apresentadas as limitações do estudo.

\subsection{NATUREA E TIPO DE PESQUISA}

Este estudo tem natureza qualitativa. Raupp e Beuren (2006) afirmam que a abordagem qualitativa se caracteriza pela descrição da complexidade do problema e análise de variáveis de influência, e por não utilizar instrumentos estatísticos para analisar o problema.

Quanto à tipologia, trata-se de estudo de casos múltiplos. Yin (2010, p. 39) define a técnica de estudo de caso em duas partes: quanto ao escopo, o autor afirma que se trata de "uma investigação empírica que investiga um fenômeno contemporâneo em profundidade e em seu contexto de vida real, especialmente quando os limites entre o fenômeno e o contexto não são claramente evidentes"; quanto à coleta e às estratégias de análise dos dados, Yin (2010) afirma que o estudo de caso

enfrenta a situação tecnicamente diferenciada em que existirão muito mais variáveis de interesse do que pontos de dados, e, como resultado, conta com múltiplas fontes de evidência, com os dados precisando convergir de maneira triangular, e como outro resultado, beneficia-se do desenvolvimento anterior das proposições teóricas para orientar a coleta e a análise de dados. (YIN, 2010, p. 40)

Os estudos de caso reuniram elementos para uma análise comparativa. Conill et al. (1991, apud Hortale et al., 1999, p. 84) afirmam que a comparação pode ser entendida como “a busca de semelhanças, diferenças ou relações entre fenômenos que podem ser contemporâneos ou não, que ocorram em espaços distintos ou não, tendo em vista conhecer determinações, causalidades e inter-relações". Os autores afirmam ainda que a comparação pode ser feita sob diferentes correntes filosóficas de descrição e análise, citando o funcionalismo, o materialismohistórico e as "novas correntes"; embora não se pretenda a descrição detalhada das 
características de cada corrente, cabe destacar que este trabalho pode ser entendido como uma comparação funcionalista, realizada com o objetivo de descrever, classificar e estabelecer indicadores para explicar a estrutura e o funcionamento das estruturas de controle interno ${ }^{30}$.

\subsection{OBJETO DE ESTUDO}

Os estudos de caso foram realizados no MAPA, Incra e Conab. Trata-se de entidades da função agricultura, que é estratégica para o Brasil por diversas razões.

A agricultura é a base da economia brasileira desde a sua colonização. De acordo com o Centro de Estudos Avançados em Economia Aplicada - CEPEA $^{31}$, a participação do agronegócio no PIB brasileiro manteve a média de 24\% no período de 1994 a 2013 (USP, 2016). De acordo com o MAPA, o agronegócio correspondeu a 40\% das exportações brasileiras no período de 1989 a 2015, em média, tendo contribuído positivamente para o saldo da balança comercial do país durante todo esse período (BRASIL, 2016).

Nas últimas décadas, a agricultura também tem alavancado o desenvolvimento social do país, destacando-se o papel da agricultura familiar na geração de emprego e na produção de alimentos para consumo interno, gerando renda para famílias pobres, reduzindo o êxodo rural e aumentado a segurança alimentar no Brasil. Além disso, o agronegócio familiar também provê contribuição expressiva para a riqueza do país, com participação média próxima a 10\% do PIB no período de 1995 a 2003 (GUILHOTO et al., 2006).

A agricultura também é relevante para a matriz energética brasileira. Segundo o Ministério de Minas e Energia - MME, a bioenergia (etanol e bagaço da cana, lenha, lixívia, resíduos de madeira, resíduos da agroindústria e biodiesel) correspondeu a 27,6\% da matriz energética no ano de 2014 (BRASIL, 2015).

Considerando a importância das políticas públicas para o desenvolvimento da agricultura brasileira, as entidades governamentais responsáveis por tais políticas devem estabelecer e aprimorar seus sistemas de controle interno, aumentando a segurança de que irão atingir seus objetivos.

Adicionalmente, a partir da seleção das organizações, procurou-se testar a aplicação da matriz de maturidade proposta em entidades com diferentes funções na Administração

${ }^{30}$ Conill et al. (1991, p. 331) afirmam que "Predominam neste grupo os trabalhos descritivos que visam classificações e o estabelecimento de indicadores que expliquem a estrutura e o funcionamento de diversos sistemas oficiais de atenção à saúde, de forma a compará-los.”

${ }^{31}$ Da Escola Superior de Agricultura "Luiz de Queiroz", da Universidade de São Paulo - ESALQ/USP. 
Pública, diferentes estruturas organizacionais e de governança. O MAPA é órgão público, integrante da administração direta; o Incra é autarquia, integrante da administração indireta; e a Conab é empresa pública, também integrante da administração indireta. Além disso, a realização de estudo de casos múltiplos permite testar a funcionalidade comparativa da matriz de maturidade proposta, que é a base para um mecanismo de estímulo à melhoria das estruturas de controle interno das organizações governamentais.

\subsubsection{Ministério da Agricultura, Pecuária e Abastecimento - MAPA}

O MAPA é o órgão da Administração Pública Federal responsável pela formulação e gestão das políticas públicas do setor agropecuário, de fomento ao agronegócio e de regulação e normatização de serviços vinculados ao setor. As políticas públicas de responsabilidade do MAPA incluem: produção, comercialização, abastecimento, armazenagem e garantia de preços mínimos; produção e fomento agropecuário; mercado, comercialização e abastecimento agropecuário, inclusive estoques reguladores e estratégicos; informação agrícola; defesa sanitária animal e vegetal; fiscalização dos insumos utilizados nas atividades agropecuárias e da prestação de serviços no setor; classificação e inspeção de produtos e derivados animais e vegetais; proteção, conservação e manejo do solo; pesquisa tecnológica em agricultura e pecuária; meteorologia e climatologia; cooperativismo e associativismo rural; energização rural, agroenergia, inclusive eletrificação rural; assistência técnica e extensão rural; políticas relativas ao café, açúcar e álcool.

O MAPA tem natureza jurídica de órgão público do Poder Executivo Federal, integrante da administração direta, vinculado à Presidência da República. Do ponto de vista jurídico, o MAPA não consubstancia pessoa jurídica específica, integrando a estrutura da União.

O organograma geral do MAPA inclui seis órgãos de assistência direta e imediata ao Ministro $^{32}$; sete órgãos específicos singulares ${ }^{33}$; trinta e três unidades descentralizadas ${ }^{34}$;

\footnotetext{
${ }^{32}$ Gabinete do Ministro - GM, Secretaria-Executiva - SE, Assessoria de Apoio às Câmaras Setoriais e Temáticas - ACST, Assessoria de Comunicação e Eventos - ACE, Consultoria Jurídica - CONJUR e Ouvidoria.

33 Secretaria de Política Agrícola - SPA, Secretaria de Defesa Agropecuária - SDA, Secretaria de Desenvolvimento do Agronegócio e Cooperativismo - SDC, Secretaria de Produção e Agroenergia - SPAE, Secretaria de Relações Internacionais do Agronegócio - SRI, Instituto Nacional de Meteorologia - INMET e Comissão Executiva do Plano da Lavoura Cacaueira - CEPLAC.

3427 Superintendências Federal de Agricultura, Pecuária e Abastecimento - SFA e 6 Laboratórios Nacionais de Agricultura - Lanagro.
} 
cinco órgãos colegiados ${ }^{35}$ e cinco entidades vinculadas ${ }^{36}$. Cabe destacar que não estão incluídos no escopo do estudo de caso do MAPA as entidades vinculadas e os órgãos colegiados, além de INMET e Ceplac ${ }^{37}$.

O MAPA não possui em sua estrutura órgãos de governança com as funções de conselho de administração, conselho fiscal e auditoria interna ${ }^{38}$. Estão presentes a corregedoria, a ouvidoria e a comissão de ética.

O quadro de pessoal do MAPA possui 10.085 servidores de carreira (dos quais 9.749 de carreira vinculada ao órgão) e 202 servidores sem vínculo com a administração pública; dentre esses servidores, 854 ocupam cargo em comissão e 689 ocupam função gratificada.

As principais despesas do MAPA em 2015 totalizaram $\mathrm{R} \$$ 4.634.273.000,00, distribuídos nas seguintes rubricas: pagamento de pessoal e encargos sociais (R\$ 3.360.747.000,00); outras despesas correntes ( $\mathrm{R} \$$ 940.715.000,00); e investimentos ( $\mathrm{R} \$$ $332.812 .000,00)$.

Apesar de sua importância para as políticas públicas de agricultura no Brasil, as auditorias anuais da gestão ${ }^{39}$ do MAPA nos exercícios de 2013 e 2014, bem como auditorias recentes do $\mathrm{TCU}^{40}$ revelaram fragilidades na gestão do Plano Estratégico, no acompanhamento de acordos de gestão, na gestão das aquisições e contratos e na gestão de transferências voluntárias, além de fragilidades na gestão de programas, como o Programa de Subvenção ao Prêmio do Seguro Rural e o Programa de Desenvolvimento da Economia Cafeeira.

35 Comitê Gestor Interministerial do Seguro Rural - CGSR, Comissão Coordenadora da Criação do Cavalo Nacional - CCCCN, Comissão Especial de Recursos - CER, Conselho Deliberativo da Política do Café - CDPC e Conselho Nacional de Política Agrícola - CNPA.

${ }^{36}$ Companhia Nacional de Abastecimento - Conab, Empresa Brasileira de Pesquisa Agropecuária - EMBRAPA, Central de Abastecimento de Minas Gerais S.A - CEASA/MG, Companhia de Armazéns e Silos do Estado de Minas Gerais - CASEMG e Companhia de Entrepostos e Armazéns Gerais de São Paulo - CEAGESP.

${ }^{37}$ INMET e CEPLAC foram criados originalmente como entidades vinculadas. Apesar de posteriormente terem sido integradas à estrutura do Ministério, preservaram sua autonomia administrativa.

${ }^{38}$ O MAPA possui Assessor Especial de Controle Interno, responsável pela interlocução entre os órgãos de controle interno e externo e os dirigentes do Ministério, além do acompanhamento das recomendações e determinações exaradas pelos órgãos de controle e do assessoramento ao Ministro de Estado na prestação de contas e outros assuntos relacionados ao controle.

39 A auditoria anual de gestão é realizada pela CGU e faz parte dos processos de prestação de contas dos administradores e demais responsáveis dos órgãos e entidades da administração pública federal direta e indireta, nos termos do art. 71, inciso II da Constituição da República Federativa do Brasil de 1988.

${ }^{40}$ Acórdão no 453/2014-TCU-Plenário e Acórdão no 493/2015-TCU-Plenário. 


\subsubsection{Instituto Nacional de Colonização e Reforma Agrária - Incra}

O Incra é a autarquia do Poder Executivo Federal, supervisionada pelo Ministério do Desenvolvimento Agrário - MDA (integrante da administração indireta), criada em 1970, que tem a missão de executar a reforma agrária e realizar o ordenamento fundiário nacional.

O organograma geral do Incra inclui dois órgãos colegiados ${ }^{41}$, dois órgãos de assistência direta e imediata ao Presidente ${ }^{42}$, três órgãos seccionais ${ }^{43}$, cinco órgãos específicos singulares ${ }^{44}$ e órgãos descentralizados ${ }^{45}$. Cabe destacar que não estão incluídos no escopo do estudo de caso do Incra os órgãos descentralizados.

O Incra não possui em sua estrutura órgãos de governança com as funções de conselho de administração e conselho fiscal. Há um conselho diretor e comitês de decisão regional, órgãos colegiados com competências deliberativas específicas. O Incra possui auditoria interna, mas não conta com unidade de corregedoria. O Incra conta com um comitê de tecnologia da informação e um comitê de segurança da informação.

O quadro de pessoal do Incra possui 5.461 servidores, dos quais 2.118 ocupam cargo de nível superior, 2.689 de nível intermediário, 404 de outras carreiras, 166 não possuem vínculo com o serviço público e 250 cedidos ou afastados.

As principais despesas do Incra em 2015 totalizaram R\$ 2.321.337.250,00, distribuídos nas seguintes rubricas: desapropriação de imóveis rurais para reforma agrária (R\$ 373.109.500,00); pagamento de pessoal aposentado ( $\mathrm{R} \$ 503.580 .420,00$ ); pagamento de pessoal ativo da União ( $\mathrm{R}$ \$ 450.742.320,00); assistência técnica e extensão rural para reforma agrária (R \$ 210.195.800,00); desenvolvimento de assentamentos rurais (R \$ 171.182.930,00); administração da unidade ( $\mathrm{R}$ \$ 175.272.530,00); concessão de crédito instalação às famílias assentadas ( $\mathrm{R} \$ 266.000 .000,00)$; e outras despesas $(\mathrm{R} \$ 171.253 .750,00)$.

Apesar de sua importância para as políticas de desenvolvimento agrário no Brasil, as auditorias anuais da gestão do Incra nos exercícios de 2013 e 2014, bem como auditorias

\footnotetext{
${ }^{41}$ Conselho Diretor - CD e Comitês de Decisão Regional - CDR.

${ }^{42}$ Gabinete - GAB e Assessoria de Comunicação Social - GABC.

${ }^{43}$ Diretoria de Gestão Administrativa - DA, Procuradoria Federal Especializada - PFE e Auditoria Interna - AUD.

${ }^{44}$ Diretoria de Gestão Estratégica - DE, Diretoria de Ordenamento da Estrutura Fundiária - DF, Diretoria de Obtenção de Terras e Implantação de Projetos de Assentamento - DT, Diretoria de Desenvolvimento de Projetos de Assentamento - DD e Superintendência Nacional de Regularização Fundiária na Amazônia Legal - SRFA.

${ }^{45}$ Superintendências Regionais - SR, Unidades Avançadas - SRUA e Divisões de Regularização Fundiária na Amazônia Legal - SRFA.
} 
recentes do $\mathrm{TCU}^{46}$ revelaram que a ausência de controles e a fragilidade de processos, procedimentos e sistemas informatizados do Incra ensejaram irregularidades na implementação do Programa Nacional de Reforma Agrária, o que levou o TCU a suspender os processos de seleção e assentamento de novos beneficiários enquanto os problemas identificados no Programa não forem sanados.

\subsubsection{Companhia Nacional de Abastecimento - Conab}

A Conab é uma empresa pública, vinculada ao MAPA (integrante da administração indireta), criada em 1990 a partir da fusão da Companhia de Financiamento da Produção, da Companhia Brasileira de Alimentos, e da Companhia Brasileira de Armazenamento.

A Conab é responsável pelas políticas de estoques estratégicos, abastecimento e sustentação de preços agropecuários. As políticas públicas de responsabilidade da Conab incluem: garantia de preços mínimos de produtos agropecuários; formação, armazenagem, remoção e escoamento dos estoques reguladores e estratégicos de produtos agropecuários; e abastecimento e regulação da oferta de produtos agropecuários, no mercado interno.

A estrutura organizacional da Conab inclui: três órgãos superiores de deliberação colegiada $^{47}$; cinco órgãos diretores ${ }^{48}$; órgãos consultivos e de assessoramento $^{49}$; órgãos executivos $^{50}$ e órgãos executivos descentralizados ${ }^{51}$. As estruturas de governança da Conab incluem: conselho de administração, conselho fiscal, comitê executivo de tecnologia da informação, auditoria interna, corregedoria geral, comissão de ética e comissão de assédio moral.

Os empregados da Conab têm sua relação de trabalho regida pela Consolidação das Leis do Trabalho. O quadro de pessoal da empresa reúne 4.794 empregados, dos quais 2.287 são contratos ininterruptos e 2.507 são reintegrados e anistiados via judicial ou administrativa;

\footnotetext{
${ }^{46}$ Acórdão no 775/2016 - TCU - Plenário.

47 Conselho de Administração, Conselho Fiscal e Diretoria Colegiada.

${ }^{48}$ Presidência, Diretoria de Operações a Abastecimento, Diretoria de Política Agrícola e Informações, Diretoria de Gestão de Pessoas e Diretoria Administrativa, Financeira e de Fiscalização.

${ }^{49}$ Gabinete da Presidência; Comissão de Ética; Comissão de Prevenção e Combate ao Assédio Moral; Conselho Disciplinar; Assessoria da Presidência; Corregedoria-Geral; Consultoria Jurídica; Superintendência de Marketing e Comunicação; Ouvidoria; Superintendência de Controladoria e Riscos; Superintendência de Estratégia e Organização; Superintendência de Acompanhamento das Regionais; Auditoria Interna; Gerência Jurídica Regional; e Núcleos Regionais da Auditoria Interna.

50 Superintendências de Áreas e Gerências de Áreas.

${ }^{51}$ Superintendências Regionais, Gerências Regionais, Setores e Unidades Armazenadoras.
} 
há ainda 427 estagiários e 762 terceirizados, contratados para serviços de limpeza e vigilância. A média de idade dos empregados da Conab é de 55 anos.

O orçamento total da Conab para o ano de 2014 foi de $\mathrm{R} \$ 2.988 .340 .462,00$, tendo sido executado o montante de $\mathrm{R} \$ 1.424 .963 .815,00$ (47,7\%) até o encerramento do exercício. Cabe destacar que a Conab é uma empresa estatal dependente (os recursos necessários para o custeio interno e a execução das políticas públicas de sua responsabilidade são oriundos do Tesouro Nacional), não dispondo de autonomia orçamentária e financeira.

Apesar de sua importância para as políticas de abastecimento de alimentos no Brasil, as auditorias anuais da gestão da Conab nos exercícios de 2013 e 2014, bem como auditorias recentes do $\mathrm{TCU}^{52}$ revelaram a ausência de implantação do Planejamento Estratégico, fragilidades nos processos de fiscalização das operações de subvenção, nas aquisições de TI, no atendimento às recomendações da auditoria interna, e fragilidades nos programas, como o Programa Vendas em Balcão e o Programa de Aquisição de Alimentos.

\subsection{PROPOSTA DE MODELO DE MATURIDADE PARA AVALIAÇÃO DOS CONTROLES INTERNOS EM ENTIDADES DO SETOR GOVERNAMENTAL}

A identificação de categorias para a definição das dimensões, subdimensões, variáveis, critérios de enquadramento e níveis de maturidade foi realizada com base no arcabouço teórico do estudo: os frameworks do COSO e respectivos manuais de boas práticas de controles internos ${ }^{53}$; padrões de controle interno do GAO e ferramenta de avaliação ${ }^{54}$; e orientações da Intosai para padrões de controles internos ${ }^{55}$.

O primeiro passo foi o reconhecimento e enumeração das boas práticas de controle interno, cujos resultados são apresentados no apêndice A deste trabalho. A partir desse conjunto de boas práticas, foi realizada a identificação das variáveis para a proposta do modelo de maturidade, cujos resultados são apresentados no apêndice B.

\footnotetext{
52 Auditoria Operacional TC 024.338/2015-0.

${ }^{53}$ COSO Internal Control - Integrated Framework: Framework and Appendices (2013); COSO Internal Control Integrated Framework: Internal Control over External Financial Reporting: A Compendium of Approaches and Examples (2013).

${ }^{54}$ GAO Standards for Internal Control in the Federal Government (The Green Book) (2014); GAO Internal Control Management and Evaluation Tool (2001).

${ }^{55}$ Intosai GOV 9100 - Guidelines for Internal Controls Standards for the Public Sector (2004); e Intosai GOV 9130 - Guidelines for Internal Controls Standards for the Public Sector - Further Information on Entity Risk Management (2007).
} 
O passo seguinte foi a identificação das dimensões e subdimensões do modelo, o que foi feito com embasamento nos elementos textuais de estruturação do framework COSO e do Green Book do GAO, apresentados no apêndice C deste trabalho.

Adotando as orientações de Wendler (2012) e Maier et al. (2012), as dimensões da proposta de modelo de maturidade são os diferentes domínios de conhecimento ou áreas do processo de controle interno, consubstanciadas nos componentes do framework COSO I: 1. Ambiente de Controle; 2. Avaliação de Riscos; 3. Atividades de Controle; 4. Informação e Comunicação; e 5. Monitoramento.

A divisão das dimensões da proposta de modelo de maturidade em subdimensões teve o objetivo de identificar áreas de capacidade que podem ser analisadas de maneira específica, direcionando esforços de melhoria das estruturas de controle interno, conforme preconizado por De Bruin et al. (2005). A definição das subdimensões levou em consideração a relação entre os elementos textuais de estruturação do framework COSO (componentes, princípios, pontos de foco, títulos e subtítulos do manual) e do Green Book GAO (componentes, princípios e atributos) com as variáveis do modelo de maturidade, demonstrada no apêndice D deste trabalho.

O quadro a seguir sintetiza as dimensões, subdimensões e variáveis do modelo de maturidade antes dos procedimentos de validação:

Quadro 3 - Dimensões, Subdimensões e Variáveis da Proposta de Modelo de Maturidade (pré-avaliação)

\begin{tabular}{|c|c|c|}
\hline Dimensão & Subdimensão & Variável \\
\hline \multirow{13}{*}{$\begin{array}{l}\text { 1. Ambiente de } \\
\text { Controle }\end{array}$} & \multirow{3}{*}{ 1.1. Padrões de Conduta } & 1.1.1 Destinatários dos Padrões de Conduta \\
\hline & & $\begin{array}{l}\text { 1.1.2. Treinamento sobre Valores de Ética e Padrões de } \\
\text { Conduta }\end{array}$ \\
\hline & & 1.1.3. Avaliação da Aderência aos Padrões de Conduta \\
\hline & \multirow{2}{*}{$\begin{array}{l}\text { 1.2. Independência e } \\
\text { Competência do Corpo } \\
\text { Diretivo }\end{array}$} & 1.2.1. Políticas de Due Diligence para o Corpo Diretivo \\
\hline & & 1.2.2. Requisitos de Competência do Corpo Diretivo \\
\hline & \multirow{2}{*}{$\begin{array}{l}\text { 1.3. Responsabilidades de } \\
\text { Controle Interno e Requisitos } \\
\text { de Competências }\end{array}$} & $\begin{array}{l}\text { 1.3.1. Responsabilidades de Controle Interno na } \\
\text { Organização }\end{array}$ \\
\hline & & 1.3.2. Requisitos de Competências na Organização \\
\hline & $\begin{array}{l}\text { 1.4. Atração, } \\
\text { Desenvolvimento e Retenção } \\
\text { de Indivíduos }\end{array}$ & 1.4.1. Programa de Desenvolvimento de Competências \\
\hline & \multirow{5}{*}{$\begin{array}{l}\text { 1.5. Avaliação de } \\
\text { Desempenho }\end{array}$} & $\begin{array}{l}\text { 1.5.1. Aspectos Analisados pela Avaliação de } \\
\text { Desempenho }\end{array}$ \\
\hline & & 1.5.2. Destinatários da Avaliação de Desempenho \\
\hline & & 1.5.3. Destinatários das Metas de Desempenho \\
\hline & & 1.5.4. Consequências da Avaliação de Desempenho \\
\hline & & 1.5.5. Frequência da Avaliação de Desempenho \\
\hline
\end{tabular}

Continua na página seguinte. 
Continuação do Quadro 3 - Dimensões, Subdimensões e Variáveis da Proposta de Modelo de Maturidade

\begin{tabular}{|c|c|c|}
\hline \multirow{9}{*}{$\begin{array}{l}\text { 2. Avaliação de } \\
\text { Riscos }\end{array}$} & \multirow{5}{*}{ 2.1. Definição de Objetivos } & 2.1.1. Processo de Formulação de Objetivos \\
\hline & & $\begin{array}{l}\text { 2.1.2. Participantes do Processo de Formulação de } \\
\text { Objetivos }\end{array}$ \\
\hline & & 2.1.3. Tipos de Objetivos \\
\hline & & 2.1.4. Níveis Organizacionais dos Objetivos \\
\hline & & 2.1.5. Mensuração dos Objetivos \\
\hline & \multirow{4}{*}{$\begin{array}{l}\text { 2.2. Identificação, Análise e } \\
\text { Resposta aos Riscos }\end{array}$} & 2.2.1. Processo de Avaliação de Riscos \\
\hline & & 2.2.2. Participantes da Avaliação de Riscos \\
\hline & & 2.2.3. Fatores Considerados na Avaliação de Riscos \\
\hline & & 2.2.4. Níveos Organizacionais da Avaliação de Riscos \\
\hline \multirow{8}{*}{$\begin{array}{l}\text { 3. Atividades de } \\
\text { Controle }\end{array}$} & \multirow{4}{*}{$\begin{array}{l}\text { 3.1. Projeto de Controles para } \\
\text { Mitigação de Riscos }\end{array}$} & 3.1.1. Documentação das Atividades de Controle \\
\hline & & 3.1.2. Níveis das Atividades de Controle \\
\hline & & $\begin{array}{l}\text { 3.1.3. Representação Fidedigna da Informação Contábil- } \\
\text { Financeira }\end{array}$ \\
\hline & & 3.1.4. Segregação de Funções \\
\hline & 3.2. Implantação de Controles & 3.2.1. Políticas e Procedimentos de Controle \\
\hline & \multirow{3}{*}{$\begin{array}{l}\text { 3.3. Projeto de Controles } \\
\text { sobre a Tecnologia }\end{array}$} & 3.3.1. Uso da Computação de Usuário Final \\
\hline & & 3.3.2. Políticas de Segurança de TI \\
\hline & & $\begin{array}{l}\text { 3.3.3. Processos de Aquisição, Desenvolvimento e } \\
\text { Manutenção da TI }\end{array}$ \\
\hline \multirow{2}{*}{$\begin{array}{l}\text { 4. Informação e } \\
\text { Comunicação }\end{array}$} & \multirow{2}{*}{$\begin{array}{l}\text { 4.1. Sistema de Informação } \\
\text { da Entidade }\end{array}$} & 4.1.1. Relevância e Qualidade da Informação \\
\hline & & 4.1.2. Comunicação Interna e Externa \\
\hline \multirow{3}{*}{$\begin{array}{l}5 . \\
\text { Monitoramento }\end{array}$} & \multirow{3}{*}{$\begin{array}{l}\text { 5.1. Monitoramento da } \\
\text { Estrutura de Controle Interno }\end{array}$} & 5.1.1. Monitoramento Contínuo \\
\hline & & 5.1.2. Avaliações Avulsas \\
\hline & & $\begin{array}{l}\text { 5.1.3. Comunicação das Deficiências de Controle } \\
\text { Interno e Acompanhamento das Ações Corretivas }\end{array}$ \\
\hline
\end{tabular}

Fonte: Elaboração do autor, a partir dos procedimentos do estudo.

O passo seguinte foi a definição da escala dos níveis de maturidade do modelo proposto. Analisando a definição de controle interno segundo o COSO (2013), observa-se que a lógica subjacente à evolução abrange diferentes pontos de alavancagem da mudança, incluindo: a estrutura organizacional; as políticas, processos e procedimentos; e as pessoas. Assim, considerando a complexidade do domínio do modelo de maturidade pretendido e a noção ainda incipiente do estudo da evolução da maturidade das variáveis identificadas e boas práticas de controles internos relacionadas, optou-se por utilizar uma escala com apenas quatro níveis de maturidade, representando estágios de um processo de implantação de uma estrutura de controle interno nas entidades, com os seguintes descritores: (0) Inexistente; (1) Inicial; (2) Em Formação; e (3) Estabelecido. A descrição das características da estrutura de controle interno em cada nível de maturidade é apresentada no item 3.4.1 deste trabalho.

Após a definição dos níveis de maturidade, foram elaborados os critérios de enquadramento de cada nível de maturidade, dentro de cada variável da proposta. Os critérios foram elaborados a partir das boas práticas de controles internos relacionadas a cada variável (conforme o apêndice B), propondo uma lógica evolutiva em termos de complexidade, abrangência, detalhamento, integração, periodicidade e automatização para o objeto de cada 
variável. Outra referência para a lógica dos critérios foi a descrição dos níveis do modelo de maturidade do Cobit, apresentada no anexo B do presente trabalho.

As dimensões, subdimensões, variáveis e critérios de enquadramento do modelo de maturidade, antes dos procedimentos de validação, são descritos a seguir. A primeira dimensão do modelo de maturidade proposto é o Ambiente de Controle. Segundo o COSO (2013):

O ambiente de controle abrange a integridade e os valores éticos da organização; os parâmetros que permitem ao corpo diretivo cumprir com suas responsabilidades de supervisão; a estrutura organizacional e a delegação de autoridade e responsabilidade; o processo de atrair, desenvolver e reter pessoas competentes; e o rigor quanto às medidas de desempenho, incentivos e recompensas para direcionar a accountability pelo desempenho. ${ }^{56}$

As subdimensões definidas para a dimensão Ambiente de Controle são: Padrões de Conduta; Independência e Competência do Corpo Diretivo; Responsabilidades de Controle Interno e Requisitos de Competência; Atração, Desenvolvimento e Retenção de Indivíduos; e Avaliação de Desempenho. Essas subdimensões e suas respectivas variáveis são apresentadas nos itens a seguir.

\subsubsection{Subdimensão 1.1: Padrões de Conduta}

Pode-se definir padrões de conduta como todas as normas que estabelecem os parâmetros de integridade, ética, moral e valores esperados da conduta dos indivíduos da entidade. O COSO (2013) afirma que o estabelecimento de padrões de conduta é uma característica relevante para a demonstração do comprometimento de uma organização com a integridade e valores éticos.

Para esta subdimensão foram propostas três variáveis: Destinatários dos Padrões de Conduta; Treinamento sobre Valores de Ética e Padrões de Conduta; e Avaliação da Aderência aos Padrões de Conduta. Essas variáveis são descritas nos itens a seguir.

\subsubsection{Variável 1.1.1: Destinatários dos Padrões de Conduta}

Segundo o COSO (2013), "as expectativas do corpo diretivo e alta gerência a respeito de integridade e valores éticos são definidas nos padrões de conduta da entidade e entendidas por todos os níveis da organização e por prestadores de serviços terceirizados e

\footnotetext{
${ }^{56}$ The control environment comprises the integrity and ethical values of the organization; the parameters enabling the board of directors to carry out its oversight responsibilities; the organizational structure and assignment of authority and responsibility; the process for attracting, developing, and retaining competent individuals; and the rigor around performance measures, incentives, and rewards to drive accountability for performance.
} 
parceiros de negócios"57. O COSO (2013b) sugere ainda o estabelecimento de padrões específicos para os indivíduos responsáveis pela elaboração dos relatórios financeiros externos e padrões específicos para aplicação em situações e localidades geográficas de alto risco.

O objetivo da variável é identificar a existência de padrões de conduta próprios da entidade e a presença de disposições específicas para indivíduos ou grupos responsáveis por funções ou atividades significativas para os objetivos e riscos da entidade, inclusive terceiros relacionados. Os critérios para o estabelecimento do nível de maturidade da variável foram definidos nos seguintes termos:

(0) Inexistente - Ausência de padrões de conduta próprios da entidade;

(1) Inicial - A entidade possui padrões de conduta próprios, com disposições gerais, aplicáveis a todos os empregados;

(2) Em Formação - Padrões de conduta da entidade incluem disposições específicas para gerentes, indivíduos do corpo diretivo e empregados de funções relevantes para a realização dos objetivos e tratamento dos riscos corporativos;

(3) Estabelecido - Padrões de conduta da entidade incluem disposições específicas para terceiros (fornecedores de produtos e serviços e empregados terceirizados que atuam em nome da entidade), exigidas contratualmente ou por SLA.

\subsubsection{Variável 1.1.2: Treinamento sobre Valores de Ética e Padrões de Conduta}

O COSO (2013) destaca a importância de regularmente comunicar e prover treinamento sobre os valores de integridade e ética e os padrões de conduta da organização. O COSO (2013b) sugere ainda a educação continuada de todos os empregados (recém-contratados e existentes) e o fornecimento de orientações para terceiros envolvidos em negócios com a entidade.

O objetivo da variável é verificar a inserção dos padrões de conduta da entidade e de temas ligados a ética e valores no programa de capacitação dos empregados da entidade, além da frequência e abrangência dos treinamentos realizados. Os critérios para o estabelecimento do nível de maturidade da variável foram definidos nos seguintes termos:

\footnotetext{
57 The expectations of the board of directors and senior management concerning integrity and ethical values are defined in the entity's standards of conduct and understood at all levels of the organization and by outsourced service providers and business partners.
} 
(0) Inexistente - Ausência dos padrões de conduta e temas ligados a integridade, ética, moral e valores no programa de capacitação da entidade;

(1) Inicial - A entidade dispõe de um programa de capacitação que inclui treinamentos sobre os padrões de conduta da entidade e assuntos de ética e valores;

(2) Em Formação - Política da entidade determina que todos os empregados da entidade devem realizar os treinamentos sobre os padrões de conduta da entidade e assuntos de ética e valores;

(3) Estabelecido - Programa de capacitação da entidade inclui orientações para terceiros sobre os padrões de conduta da entidade.

\subsubsection{Variável 1.1.3: Avaliação da Aderência aos Padrões de Conduta \\ O COSO (2013) afirma que:}

As avaliações podem ser conduzidas por um processo contínuo da gerência e/ou por uma parte independente. Indivíduos podem também avaliar e relatar irregularidades por canais de comunicação formais e informais, como um programa de denúncias, uma linha telefônica de ética, processos de feedback acima e reuniões regulares de equipe. ${ }^{58}$

O Decreto $n^{\circ}$ 1.171/1994, que aprova o Código de Ética Profissional do Servidor Público Civil do Poder Executivo Federal, determina a instalação de comissão de ética em todos os órgãos e entidades da Administração Pública Federal direta, indireta autárquica e fundacional, ou em qualquer órgão ou entidade que exerça atribuições delegadas pelo poder público; o Decreto n 6.029/2007, que institui o Sistema de Gestão de Ética do Poder Executivo Federal, define que é dever do titular de entidade ou órgão conduzir em seu âmbito a avaliação da gestão da ética conforme processo coordenado pela Comissão de Ética Pública. As normas de funcionamento e de rito processual, delimitando competências, atribuições, procedimentos das Comissões de Ética foram aprovadas pela Resolução CEP nº 10/2008.

O COSO (2013b) sugere ainda a disponibilização de canal de comunicação para denúncias anônimas e a realização de auditorias de ética, destacando a importância de agir tempestivamente quando são identificados desvios aos padrões de conduta da entidade.

O objetivo da variável é verificar a existência da Comissão de Ética, as atividades por ela desempenhadas e a existência de política que determine a realização periódica de

\footnotetext{
${ }^{58}$ Evaluations may be conducted by an ongoing management process and/or by an independent party. Individuals can also assess and report irregularities through formal and informal communication channels, such as a whistleblowing program, an ethics hotline, upward feedback processes, and regular staff meetings.
} 
auditoria de ética pela auditoria interna ou auditor independente. Os critérios para o estabelecimento do nível de maturidade da variável foram definidos nos seguintes termos:

(0) Inexistente - Ausência de estrutura organizacional para avaliação da aderência aos padrões de conduta da entidade;

(1) Inicial - A entidade instituiu Comissão de Ética e avalia a gestão da ética conforme processo coordenado pela Comissão de Ética Pública - CEP, nos termos do Decreto nº 6.029/2007;

(2) Em Formação - A Comissão de Ética da entidade realiza a apuração dos desvios conforme a Resolução CEP nº 10/2008 e dispõe de canal de comunicação para denúncias anônimas;

(3) Estabelecido - Política de entidade determina a realização periódica de auditoria de ética, conduzida pela auditoria interna ou auditor independente.

\subsubsection{Subdimensão 1.2: Independência e Competência do Corpo Diretivo}

Segundo o COSO (2013), o corpo diretivo da entidade deve ser independente da gerência e demonstrar habilidades e perícia relevantes no cumprimento de suas responsabilidades de supervisão. O GAO (2014) acrescenta que os membros do corpo diretivo devem entender os objetivos da entidade, os riscos relacionados e as expectativas das partes interessadas, além de possuir conhecimentos especializados para a realização de críticas construtivas à gerência e a tomada de decisões de supervisão adequadas.

Para esta subdimensão foram propostas duas variáveis: Políticas de Due Diligence para o Corpo Diretivo e Requisitos de Competências do Corpo Diretivo. Essas variáveis são descritas nos itens a seguir.

\subsubsection{Variável 1.2.1: Políticas de Due Diligence para o Corpo Diretivo}

O COSO (2013b) sugere a realização de procedimentos de due diligence para verificar a independência e competência dos candidatos a integrar o corpo diretivo da entidade, e a divulgação dos resultados. Essa avaliação pode ser conduzida pelo próprio corpo diretivo (autoavaliação) ou supervisionada por um comitê de nominação ou outra parte independente. O COSO (2013) afirma ainda a necessidade de avaliar regularmente a competência e independência do corpo diretivo, levando em consideração a evolução das necessidades da entidade.

O objetivo da variável é identificar a existência de políticas e processos para a verificação da independência e competência de membros do corpo diretivo da entidade, a 
oportunidade e a frequência de sua realização, além da supervisão dos procedimentos e divulgação dos resultados. Os critérios para o estabelecimento do nível de maturidade da variável foram definidos nos seguintes termos:

(0) Inexistente - Ausência de políticas de due diligence para os indivíduos do corpo diretivo da entidade;

(1) Inicial - Políticas da entidade estabelecem a realização de procedimentos de due diligence como parte do processo de seleção dos candidatos ao corpo diretivo;

(2) Em Formação - Políticas da entidade estabelecem a realização periódica de procedimentos de due diligence para a confirmação da competência e independência dos membros do corpo diretivo;

(3) Estabelecido - Políticas da entidade estabelecem que os procedimentos de due diligence sejam supervisionados por um comitê de nominação independente ou firma de contratação e os resultados devem ser divulgados.

\subsubsection{Variável 1.2.2: Requisitos de Competências do Corpo Diretivo}

O COSO (2013) afirma que a composição do corpo diretivo deve levar em consideração as competências necessárias para supervisionar, questionar e avaliar adequadamente a alta gerência, incluindo padrões de integridade e ética, liderança, pensamento crítico e solução de problemas, além de conhecimentos e habilidades especializados em assuntos como controle interno, mercado, finanças, leis e regulamentos, responsabilidade social e ambiental, incentivos e compensação e tecnologia e sistemas relevantes. Os integrantes do corpo diretivo devem receber treinamentos para manter a relevância e atualidade de suas capacidades.

O objetivo da variável é verificar a existência de políticas que definam os requisitos de competência dos indivíduos que integram o corpo diretivo da entidade, inclusive a exigência de indivíduos com conhecimentos especializados, e a existência de um programa de capacitação para manutenção das competências necessárias ao cumprimento das responsabilidades de supervisão. Os critérios para o estabelecimento do nível de maturidade da variável foram definidos nos seguintes termos:

(0) Inexistente - Ausência de políticas definindo os requisitos de competências dos integrantes do corpo diretivo da entidade; 
(1) Inicial - Políticas da entidade definem os requisitos de competências exigidos de todos os integrantes do corpo diretivo;

(2) Em Formação - Políticas da entidade exigem que o corpo diretivo disponha de membros com conhecimentos especializados em controle interno, planejamento e orçamento, finanças, TI, leis e regulamentos e outros, conforme necessário para a supervisão;

(3) Estabelecido - Políticas da entidade exigem que os integrantes do corpo diretivo cumpram um programa de capacitação para manutenção de um conjunto de conhecimentos adequado para suas responsabilidades de supervisão.

\subsubsection{Subdimensão 1.3: Responsabilidades de Controle Interno e Requisitos de Competência}

O COSO (2013) afirma que as responsabilidades de controle interno geralmente constituem três linhas de defesa contra a falha na realização dos objetivos da entidade: gerência e equipes (primeira linha), funções de suporte aos negócios (segunda linha) e auditoria interna (terceira linha).

Para esta subdimensão foram propostas duas variáveis: Responsabilidades de Controle Interno na Organização e Requisitos de Competências na Organização. Essas variáveis são descritas nos itens a seguir.

\subsubsection{Variável 1.3.1: Responsabilidades de Controle Interno na Organização}

Segundo o COSO (2013), a delegação de autoridades e atribuição de responsabilidades ao longo da organização deve habilitar os gerentes e as equipes a tomar decisões de acordo com as diretrizes da gerência para a realização dos objetivos da entidade; limites devem ser estabelecidos para que a autoridade não exceda o necessário para a realização dos objetivos e riscos desnecessários não sejam acatados.

O objetivo da variável é verificar a existência de definição de autoridades e responsabilidades de controle interno ao longo dos níveis organizacionais da entidade, desde a alta gerência até os empregados de departamentos ou funções relevantes para os objetivos e riscos da entidade, inclusive terceirizados. Os critérios para o estabelecimento do nível de maturidade da variável foram definidos nos seguintes termos:

(0) Inexistente - Ausência de descrição de cargos ou ausência de definição das autoridades e responsabilidades de controle interno nas descrições de cargos da entidade; 
(1) Inicial - Definição das autoridades e responsabilidades de controle interno para a alta gerência ( $2^{\circ}$ escalão) e a auditoria interna da entidade;

(2) Em Formação - Definição das autoridades e responsabilidades de controle interno para os gerentes das divisões, unidades operacionais ( $3^{\circ}$ escalão) e funções de suporte relevantes, considerando os objetivos e riscos da entidade;

(3) Estabelecido - Definição das autoridades e responsabilidades de controle interno para os empregados das divisões, unidades operacionais e funções de suporte, e prestadores de serviços terceirizados relevantes, considerando os objetivos e riscos da entidade.

\subsubsection{Variável 1.3.2: Requisitos de Competências na Organização}

O COSO (2013) afirma que a competência é a qualificação para cumprir as responsabilidades atribuídas, expressada na atitude, conhecimento e comportamento dos indivíduos.

O objetivo da variável é verificar a existência de definição de requisitos de competências ao longo dos níveis organizacionais da entidade, desde a alta gerência até os empregados de departamentos ou funções relevantes para os objetivos e riscos da entidade, inclusive terceirizados. Os critérios para o estabelecimento do nível de maturidade da variável foram definidos nos seguintes termos:

(0) Inexistente - Ausência de descrição de cargos ou ausência de definição dos requisitos de competências nas descrições de cargos da entidade;

(1) Inicial - Definição dos requisitos de competências para a alta gerência ( $2^{\circ}$ escalão) e a auditoria interna da entidade;

(2) Em Formação - Definição dos requisitos de competências para os gerentes das divisões, unidades operacionais ( $3^{\circ}$ escalão) e funções de suporte relevantes, considerando os objetivos e riscos da entidade;

(3) Estabelecido - Definição dos requisitos de competências para os empregados das divisões, unidades operacionais e funções de suporte, e prestadores de serviços terceirizados relevantes, considerando os objetivos e riscos da entidade. 


\subsubsection{Subdimensão 1.4: Atração, Desenvolvimento e Retenção de Indivíduos}

O COSO (2013) afirma que o comprometimento com a competência é apoiado e está embutido nos processos de gerenciamento de recursos humanos para a atração, desenvolvimento, avaliação e retenção de pessoal adequado, inclusive terceirizados.

Para esta subdimensão foi proposta a variável Programa de Desenvolvimento de Competências, descrita no item a seguir.

\subsubsection{Variável 1.4.1: Programa de Desenvolvimento de Competências \\ O COSO (2013) afirma que:}

A gerência em diferentes níveis estabelece as estruturas e processos para: [...] Treinar - Habilitar indivíduos a desenvolver competências adequadas para os papéis e responsabilidades atribuídos, reforçar padrões de conduta e níveis de competência esperados para atribuições específicas, ajustar o treinamento com base nos papéis e necessidades, e considerar uma mescla de técnicas de entrega, incluindo instrução em sala de aula, autoestudo e treinamento no trabalho. ${ }^{59}$

O objetivo da variável é verificar a existência de um programa de desenvolvimento de competências para os empregados da entidade, e as características do programa. Os critérios para o estabelecimento do nível de maturidade da variável foram definidos nos seguintes termos:

(0) Inexistente - Ausência de programa de desenvolvimento de competências para os empregados da entidade;

(1) Inicial - A entidade possui um programa de desenvolvimento de competências;

(2) Em Formação - O programa de desenvolvimento de competências inclui o desenvolvimento de competências específicas para o desempenho de funções e atividades significativas para a realização dos objetivos e tratamento dos riscos da entidade;

(3) Estabelecido - O programa de desenvolvimento de competências da entidade inclui múltiplas técnicas de entrega (ações instrucionais em sala de aula, autoestudo e treinamento no trabalho).

\footnotetext{
${ }^{59}$ Management at different levels establishes the structures and processes to: [...] Train - Enable individuals to develop competencies appropriate for assigned roles and responsibilities, reinforce standards of conduct and expected levels of competence for particular assignments, tailor training based on roles and needs, and consider a mix of delivery techniques, including classroom instruction, self-study, and on-the-job training.
} 


\subsubsection{Subdimensão 1.5: Avaliação de Desempenho}

O GAO (2014) afirma que a avaliação de desempenho é um dos recursos utilizados pela gerência para promover o accountability do pessoal da entidade por suas responsabilidades de controle interno. Para tanto, o COSO (2013) destaca a necessidade de avaliar a aderência aos padrões de conduta e níveis esperados de competência, além do desempenho dos indivíduos na realização dos objetivos e metas definidos em todos os níveis da organização.

Para esta subdimensão foram propostas cinco variáveis: Aspectos Analisados na Avaliação de Desempenho; Destinatários da Avaliação de Desempenho; Destinatários das Metas de Desempenho; Consequências da Avaliação de Desempenho; e Frequência da Avaliação de Desempenho. Essas variáveis são descritas nos itens a seguir.

\subsubsection{Variável 1.5.1: Aspectos Analisados na Avaliação de Desempenho}

Segundo o COSO (2013), "a gerência e o corpo diretivo avaliam cumprimento das responsabilidades de controle interno, incluindo a aderência a padrões de conduta e níveis esperados de competência e proveem recompensas ou exercem ação disciplinar conforme adequado"60.

O objetivo da variável é identificar os aspectos analisados no processo de avaliação de desempenho da entidade (produtividade, conduta ética e competências). Os critérios para o estabelecimento do nível de maturidade da variável foram definidos nos seguintes termos:

(0) Inexistente - Ausência de avaliação de desempenho;

(1) Inicial - Avaliação da produtividade dos empregados da entidade;

(2) Em Formação - Avaliação da produtividade e conduta ética dos empregados da entidade;

(3) Estabelecido - Avaliação da produtividade, conduta ética e competências dos empregados da entidade.

\footnotetext{
${ }^{60}$ Management and the board of directors evaluate performance of internal control responsibilities, including adherence to standards of conduct and expected levels of competence and provide rewards or exercise disciplinary action as appropriate.
} 


\subsubsection{Variável 1.5.2: Destinatários da Avaliação de Desempenho}

A avaliação de desempenho deve ser conduzida em todos os níveis da organização. Segundo o COSO (2013), "o corpo diretivo avalia o desempenho do diretor executivo, que por sua vez avalia a equipe da alta gerência, e assim por diante" 61 .

O objetivo da variável é identificar os níveis organizacionais para os quais é realizado o processo de avaliação de desempenho, desde os empregados até a alta gerência da entidade. Os critérios para o estabelecimento do nível de maturidade da variável foram definidos nos seguintes termos:

(0) Inexistente - Ausência de avaliação de desempenho;

(1) Inicial - Avaliação de desempenho dos empregados e gerência da entidade (até o $3^{\circ}$ nível organizacional);

(2) Em Formação - Avaliação de desempenho dos empregados, gerência e alta gerência da entidade (até o $2^{\circ}$ nível organizacional);

(3) Estabelecido - Avaliação de desempenho dos empregados, gerência e direção executiva da entidade.

\subsubsection{Variável 1.5.3: Destinatários das Metas de Desempenho}

O COSO (2013) afirma que a entidade deve definir metas de desempenho em todos os níveis da organização, desde o corpo diretivo até o diretor executivo, alta gerência e equipes.

O objetivo da variável é identificar os níveis organizacionais da entidade para os quais são estabelecidas metas de desempenho, desde a definição de metas em nível de entidade até a definição de metas individuais, para cada empregado. Os critérios para o estabelecimento do nível de maturidade da variável foram definidos nos seguintes termos:

(0) Inexistente - Ausência de metas de desempenho;

(1) Inicial - Definição de metas de desempenho para a organização, como um todo;

(2) Em Formação - Definição de metas de desempenho para as unidades e subunidades organizacionais da entidade;

\footnotetext{
${ }^{61}$ The board of directors evaluates the performance of the chief executive officer, who in turn evaluates that of the senior management team, and so on.
} 
(3) Estabelecido - Definição de metas de desempenho individuais, para cada empregado da entidade.

\subsubsection{Variável 1.5.4: Consequências da Avaliação de Desempenho \\ O COSO (2013) destaca a importância de vincular recompensas e ações} disciplinares ao desempenho dos indivíduos na realização de suas responsabilidades de controle interno e dos objetivos da entidade.

O objetivo da variável é identificar as consequências de uma avaliação de desempenho inferior às expectativas definidas pela entidade. Os critérios para o estabelecimento do nível de maturidade da variável foram definidos nos seguintes termos:

(0) Inexistente - Ausência de avaliação de desempenho;

(1) Inicial - Consequências de caráter disciplinar;

(2) Em Formação - Parcela variável da remuneração dos empregados é afetada;

(3) Estabelecido - Promoção (evolução nos níveis da carreira) e movimentação (inclusive remoção) levam em consideração as avaliações de desempenho do empregado.

\subsubsection{Variável 1.5.5: Frequência da Avaliação de Desempenho}

O GAO (2001) e o COSO (2013b) sugerem que a avaliação de desempenho dos indivíduos seja realizada periodicamente, propiciando recompensas individuais ou ações disciplinares, conforme necessário.

O objetivo da variável é identificar a frequência com a qual a entidade realiza o processo de avaliação de desempenho. Os critérios para o estabelecimento do nível de maturidade da variável foram definidos nos seguintes termos:

(0) Inexistente - Ausência de avaliação de desempenho;

(1) Inicial - Avaliação de desempenho realizada anualmente;

(2) Em Formação - Avaliação de desempenho realizada semestralmente;

(3) Estabelecido - Avaliação de desempenho realizada quadrimestralmente (ou frequência maior). 
A segunda dimensão do modelo de maturidade proposto é a Avaliação de Riscos. Segundo o COSO (2013), "a avaliação de riscos envolve um processo dinâmico e interativo para identificar e avaliar os riscos para a concretização dos objetivos". ${ }^{6}$

As subdimensões definidas para a dimensão Avaliação de Riscos são: Definição de Objetivos; e Identificação, Análise e Resposta a Riscos. Essas subdimensões e suas respectivas variáveis são apresentadas nos itens a seguir.

\subsubsection{Subdimensão 2.1: Definição de Objetivos}

Segundo o GAO (2014), a gerência deve definir objetivos em termos específicos e mensuráveis, estabelecer métricas para a avaliação do desempenho na sua realização e reavaliar periodicamente os objetivos definidos para manter a consistência com os requisitos legais e regulamentares e as expectativas de partes externas e internas à organização.

Para esta subdimensão foram propostas cinco variáveis: Processo de Formulação de Objetivos; Participantes do Processo de Formulação de Objetivos; Tipos de Objetivos; Níveis Organizacionais dos Objetivos; e Mensuração de Objetivos. Essas variáveis são descritas nos itens a seguir.

\subsubsection{Variável 2.1.1: Processo de Formulação de Objetivos}

O GAO (2014) afirma que a entidade estabelece um processo para a definição inicial dos objetivos, enquanto o refinamento dos objetivos ocorre conforme a sua incorporação na estrutura de controle interno, e destaca a necessidade de reavaliação periódica da relevância e consistência dos objetivos definidos.

O objetivo da variável é verificar a existência de um processo para a formulação dos objetivos da entidade, a formalização desse processo e a repetição periódica do processo para reavaliação dos objetivos. Os critérios para o estabelecimento do nível de maturidade da variável foram definidos nos seguintes termos:

(0) Inexistente - Ausência de processo para a formulação de objetivos;

(1) Inicial - Entidade possui objetivos formulados em processo casuístico;

(2) Em Formação - Entidade possui objetivos formulados em processo formalmente estabelecido;

\footnotetext{
${ }^{62}$ Risk assessment involves a dynamic and iterative process for identifying and assessing risks to the achievement of objectives.
} 
(3) Estabelecido - Processo de formulação de objetivos é realizado periodicamente (mínimo de uma vez ao ano), para a reavaliação dos objetivos.

\subsubsection{Variável 2.1.2: Participantes do Processo de Formulação de Objetivos}

O GAO (2014) afirma que o processo de formulação de objetivos deve levar em consideração as expectativas internas e requisitos legais e regulatórios externos.

O objetivo da variável é identificar os níveis organizacionais que participam do processo de formulação dos objetivos da entidade, desde a participação exclusiva de corpo diretivo e alta gerência até a participação ampla, inclusive de partes interessadas externas. Os critérios para o estabelecimento do nível de maturidade da variável foram definidos nos seguintes termos:

(0) Inexistente - Ausência de processo para a formulação de objetivos;

(1) Inicial - Corpo diretivo e alta gerência;

(2) Em Formação - Todos os empregados da entidade;

(3) Estabelecido - Ampla participação, inclusive de partes interessadas externas.

\subsubsection{Variável 2.1.3: Tipos de Objetivos}

O COSO (2004) classifica os objetivos de uma organização em objetivos estratégicos e objetivos correlatos; os objetivos correlatos são categorizados em objetivos operacionais, objetivos de comunicação e objetivos de conformidade.

Segundo o COSO (2013), os objetivos operacionais devem refletir as escolhas da gerência dentro dos ambientes particulares de negócios, indústria e econômico em que a entidade funciona, estabelecendo a base para o comprometimento dos recursos necessários para a realização das metas de desempenho, inclusive o desempenho financeiro; os objetivos de comunicação se referem à confiabilidade, tempestividade, transparência de relatórios financeiros e não financeiros, internos e externos, conforme as exigências de reguladores, padronizadores ou das políticas da entidade; e os objetivos de conformidade são estabelecidos de acordo com as exigências mínimas estabelecidas pela lei e regulamentos para as atividades da entidade.

O GAO (2014, p. 35) afirma que "os objetivos são definidos inicialmente como parte do processo de definição de objetivos e então refinados conforme eles são incorporados 
na estrutura de controle interno quando a gerência os utiliza para estabelecer o ambiente de controle" 63 .

O objetivo da variável é identificar os tipos de objetivos que são definidos no processo de formulação de objetivos da entidade, entre os objetivos estratégicos, operacionais, de conformidade e de relatórios. Os critérios para o estabelecimento do nível de maturidade da variável foram definidos nos seguintes termos:

(0) Inexistente - Ausência de definição de objetivos;

(1) Inicial - Definição de objetivos estratégicos;

(2) Em Formação - Definição de objetivos de operacionais, a partir dos objetivos estratégicos;

(3) Estabelecido - Definição de objetivos de conformidade e objetivos de comunicação (relatórios internos e externos).

\subsubsection{Variável 2.1.4: Níveis Organizacionais dos Objetivos}

O COSO (2013, 2013b) sugere o "cascateamento" dos objetivos ao longo da entidade e suas subunidades, em todos os níveis da organização. O GAO (2001) destaca a importância do suporte dado pelo planejamento estratégico (priorização, alocação de recursos) aos objetivos definidos em nível de entidade, além da definição de objetivos em nível de atividade e sua vinculação com os objetivos em nível de entidade.

O objetivo da variável é identificar os níveis organizacionais da entidade para os quais são definidos objetivos, desde a definição de objetivos em nível de entidade até a definição de objetivos para as atividades dos processos mais relevantes para os objetivos e riscos da entidade. Os critérios para o estabelecimento do nível de maturidade da variável foram definidos nos seguintes termos:

(0) Inexistente - Ausência de definição de objetivos;

(1) Inicial - Objetivos são estabelecidos para a organização como um todo;

(2) Em Formação - Objetivos são estabelecidos para as unidades e subunidades organizacionais, ou divididos em objetivos específicos;

\footnotetext{
${ }^{63}$ Objectives are initially set as part of the objective-setting process and then refined as they are incorporated into the internal control system when management uses them to establish the control environment.
} 
(3) Estabelecido - Objetivos são estabelecidos em nível de atividade, para os processos mais relevantes para os objetivos e riscos da entidade.

\subsubsection{Variável 2.1.5: Mensuração dos Objetivos}

O GAO (2014, p. 35) afirma que:

A gerência define objetivos em termos mensuráveis de modo que o desempenho na realização desses objetivos possa ser avaliado. Objetivos mensuráveis são geralmente livres de viés e não requerem julgamentos subjetivos para dominar sua mensuração. Objetivos mensuráveis também são declarados numa forma quantitativa ou qualitativa que permita mensuração razoavelmente consistente. ${ }^{64}$

O COSO (2013) e o GAO (2014) destacam ainda que podem ser definidas variações aceitáveis no desempenho no cumprimento dos objetivos, chamadas de tolerâncias a risco. Destaca-se ainda a importância da definição de prazos e da atribuição de recursos adequados para a realização dos objetivos da entidade.

O objetivo da variável é verificar se a realização dos objetivos da entidade é mensurada, se há metas definidas e se os objetivos da entidade possuem cronograma e orçamento definidos. Os critérios para o estabelecimento do nível de maturidade da variável foram definidos nos seguintes termos:

(0) Inexistente - Ausência de definição de objetivos, ou os objetivos não são mensurados;

(1) Inicial - Os objetivos da entidade são mensurados;

(2) Em Formação - Os objetivos da entidade possuem metas associadas;

(3) Estabelecido - Os objetivos da entidade possuem cronograma e orçamento definidos para a sua realização.

\subsubsection{Subdimensão 2.2: Identificação, Análise e Resposta aos Riscos}

O GAO (2014) afirma que a gerência analisa os riscos identificados para estimar sua significância, que é a base para as respostas; a gerência projeta respostas aos riscos analisados de modo que os riscos estejam dentro da tolerância a risco definida para o objetivo.

\footnotetext{
${ }^{64}$ Management defines objectives in measurable terms so that performance toward achieving those objectives can be assessed. Measurable objectives are generally free of bias and do not require subjective judgments to dominate their measurement. Measurable objectives are also stated in a quantitative or qualitative form that permits reasonably consistent measurement.
} 
Para esta subdimensão foram propostas quatro variáveis: Processo de Avaliação de Riscos; Participantes da Avaliação de Riscos; Fatores Considerados na Avaliação de Riscos; e Níveis Organizacionais da Avaliação de Riscos. Essas variáveis são descritas nos itens a seguir.

\subsubsection{Variável 2.2.1: Processo de Avaliação de Riscos}

Segundo o COSO (2013), “a identificação e análise de risco é um processo contínuo e iterativo conduzido para melhorar a capacidade de uma entidade de realizar seus objetivos" 65 . O GAO (2001) acrescenta que a identificação de riscos pode ocorrer como parte de atividades de planejamento de curto e longo prazo, e do planejamento estratégico da entidade, e que deve ser realizada de maneira periódica e programada.

O objetivo da variável é verificar a existência de um processo para a avaliação dos riscos da entidade, a formalização desse processo e a repetição periódica do processo para reavaliação dos riscos. Os critérios para o estabelecimento do nível de maturidade da variável foram definidos nos seguintes termos:

(0) Inexistente - Ausência de processo para avaliação de riscos;

(1) Inicial - Entidade possui avaliação de riscos realizada em processo casuístico;

(2) Em Formação - Entidade possui avaliação de riscos realizada em processo formalmente estabelecido;

(3) Estabelecido - Processo de avaliação de riscos é realizado periodicamente (mínimo de uma vez ao ano), para a reavaliação dos riscos.

\subsubsection{Variável 2.2.2: Participantes da Avaliação de Riscos}

O COSO (2013) afirma que mecanismos eficazes de avaliação de riscos envolvem níveis adequados da gerência da entidade, com o conhecimento necessário. A responsabilidade pela identificação e análise dos riscos pertence à alta gerência da entidade e suas subunidades; o GAO (2001) destaca a necessidade de envolvimento de empregados e gerência de nível médio da entidade no processo, e que os riscos identificados por tais partes sejam levados ao conhecimento da alta gerência.

O objetivo da variável é identificar os níveis organizacionais que participam do processo de avaliação de riscos da entidade, desde a participação exclusiva de corpo diretivo e

\footnotetext{
${ }^{65}$ Identifying and analyzing risk is an ongoing iterative process conducted to enhance the entity's ability to achieve its objectives.
} 
alta gerência até a participação de auditor ou especialista externo. Os critérios para o estabelecimento do nível de maturidade da variável foram definidos nos seguintes termos:

(0) Inexistente - Ausência de avaliação de riscos;

(1) Inicial - O processo de avaliação de riscos é realizado pelo corpo diretivo e alta gerência da entidade;

(2) Em Formação - O processo de avaliação de riscos tem a participação de empregados das funções e departamentos mais relevantes para a realização dos objetivos e tratamento dos riscos da entidade;

(3) Estabelecido - O processo de avaliação de riscos inclui a obtenção da opinião de auditor ou especialista externo à entidade.

\subsubsection{Variável 2.2.3: Fatores Considerados na Avaliação de Riscos}

O COSO (2013) afirma que a avaliação de riscos deve considerar fatores internos e externos à organização, como os exemplificados pelo GAO (2001):

Quadro 4 - Fatores de Riscos Internos e Externos

\begin{tabular}{|c|c|}
\hline Fatores Internos & Fatores Externos \\
\hline 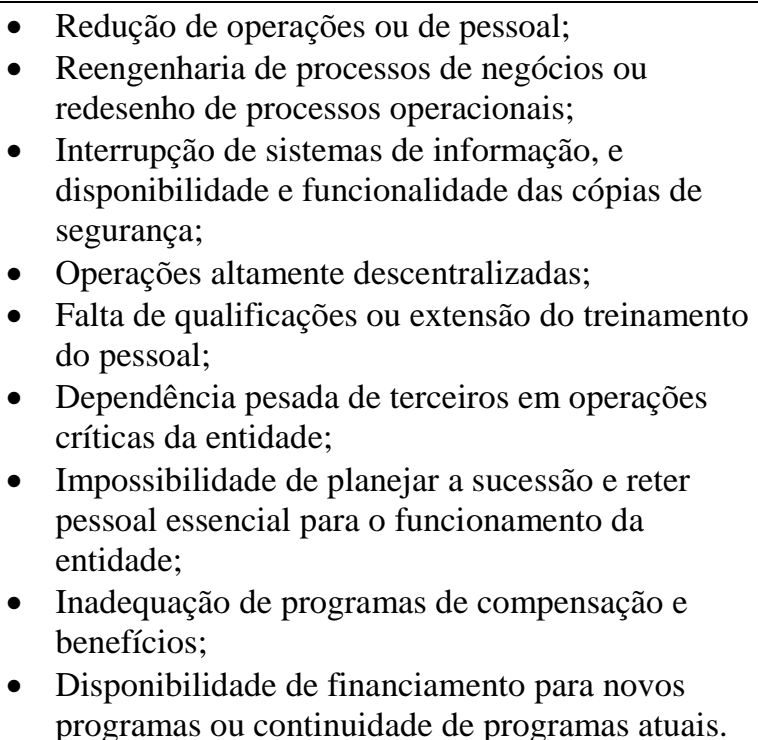 & $\begin{array}{l}\text { - Avanços e desenvolvimentos tecnológicos; } \\
\text { - Mudanças nas expectativas do Congresso e } \\
\text { cidadãos; } \\
\text { - Novas leis e regulamentos; } \\
\text { - Catástrofes naturas e atividade criminosa ou } \\
\text { terrorista; } \\
\text { - Grandes fornecedores e contratados; } \\
\text { - Interação com outras entidades do Governo e fora } \\
\text { dele. }\end{array}$ \\
\hline
\end{tabular}

Fonte: GAO (2001).

O COSO (2013) afirma que devem ser considerados os riscos decorrentes de mudanças significativas no ambiente externo, no modelo de negócios ou na liderança da entidade, além da análise do potencial para fraudes de diferentes tipos, como relatórios fraudulentos, salvaguarda de ativos, corrupção e management override, levando em consideração os fatores que impactam o risco de fraude, como incentivos e pressões, oportunidades, atitudes e racionalizações. 
O objetivo da variável é verificar a abrangência dos fatores considerados no processo de avaliação de riscos da entidade. Os critérios para o estabelecimento do nível de maturidade da variável foram definidos nos seguintes termos:

(0) Inexistente - Ausência de avaliação de riscos;

(1) Inicial - O processo de avaliação de riscos considera fatores internos e externos à entidade;

(2) Em Formação - O processo de avaliação de riscos da entidade inclui o risco decorrente de mudanças no ambiente externo, modelo de negócios e liderança da entidade;

(3) Estabelecido - O processo de avaliação de riscos inclui o risco de fraude, incluindo incentivos e pressões, oportunidades, atitudes e racionalizações, além de abordagens para burlar controles.

\subsubsection{Variável 2.2.4: Níveis Organizacionais da Avaliação de Riscos}

O COSO (2013) afirma que os riscos devem ser identificados em nível de entidade e em nível de transação ou atividade. Além disso, a avaliação de riscos em nível de entidade deve levar em consideração os vários níveis da estrutura organizacional, incluindo a entidade geral e suas subunidades.

O objetivo da variável é verificar os níveis organizacionais da entidade para os quais é realizado o processo de avaliação de riscos, desde a avaliação de riscos em nível de entidade até a avaliação de riscos em nível de atividade, para os processos relevantes para os objetivos e riscos da entidade. Os critérios para o estabelecimento do nível de maturidade da variável foram definidos nos seguintes termos:

(0) Inexistente - Ausência de avaliação de riscos;

(1) Inicial - Avaliação de riscos da organização como um todo;

(2) Em Formação - Avaliação de riscos levando em consideração os vários níveis da estrutura organizacional;

(3) Estabelecido - Avaliação de riscos em nível de atividade, para os processos internos mais relevantes para os objetivos e riscos da entidade.

A terceira dimensão do modelo de maturidade proposto é Atividades de Controle. De acordo com o COSO (2013), "as atividades de controle são as ações estabelecidas por meio 
de políticas e procedimentos que ajudam a garantir o cumprimento das diretrizes da administração para mitigar os riscos à realização dos objetivos". ${ }^{66}$

As subdimensões definidas para a dimensão Atividades de Controle são: Projeto de Controles para Mitigação de Riscos; Implantação de Controles; e Projeto de Controles sobre a Tecnologia. Essas subdimensões e suas respectivas variáveis são apresentadas nos itens a seguir.

\subsubsection{Subdimensão 3.1: Projeto de Controles para Mitigação de Riscos}

Segundo o GAO (2014), a gerência projeta tipos adequados de atividades de controle, que irão auxiliar no cumprimento de suas responsabilidades e tratar as respostas aos riscos identificados na estrutura de controle interno. Entre as categorias de atividades de controle possíveis, o GAO menciona: revisões de alto nível do desempenho atual; revisões pela gerência no nível de atividade ou função; administração do capital humano; controles sobre o processamento das transações; controle físico sobre ativos vulneráveis; estabelecimento e revisão de métricas e indicadores de desempenho; segregação de funções; execução adequada das transações; registro preciso e tempestivo das transações; restrição de acesso e accountability por recursos e registros; e documentação adequada das transações e do controle interno.

Para esta subdimensão foram propostas quatro variáveis: Documentação das Atividades de Controle; Níveis das Atividades de Controle; Representação Fidedigna da Informação Contábil-Financeira; e Segregação de Funções. Essas variáveis são descritas nos itens a seguir.

\subsubsection{Variável 3.1.1: Documentação das Atividades de Controle}

O GAO (2001) destaca a importância da documentação do controle interno, todas as transações e outros eventos significativos; o COSO (2013b) sugere o uso de uma matriz ou inventário para mapear os riscos identificados aos controles estabelecidos para a resposta, documentando informações como o nível, a frequência, a descrição e a classificação ou tipificação dos controles; além disso, sugere a documentação dos controles por meio de fluxogramas ou narrativas, incluindo a tecnologia subjacente que suporta a atividade de controle.

\footnotetext{
${ }^{66}$ Control activities are the actions established through policies and procedures that help ensure that management's directives to mitigate risks to the achievement of objectives are carried out.
} 
O GAO (2001, p. 43) acrescenta que a documentação "inclui a identificação das funções da agência em nível de atividade, objetivos relacionados e atividades de controle e aparece nas diretrizes da gerência, políticas administrativas, manuais de contabilidade e outros manuais". 67

O objetivo da variável é verificar a existência e o detalhamento da documentação a respeito das atividades de controle interno da entidade. Os critérios para o estabelecimento do nível de maturidade da variável foram definidos nos seguintes termos:

(0) Inexistente - Ausência de documentação das atividades de controle;

(1) Inicial - Elaboração de Matriz de Riscos e Controles;

(2) Em Formação - Documentação das atividades de controle, incluindo a infraestrutura de tecnologia que provê suporte ao funcionamento dos controles, seguindo modelos padronizados pela entidade;

(3) Estabelecido - Mapeamento dos processos relevantes para os objetivos e riscos da entidade, em nível de atividade.

\subsubsection{Variável 3.1.2: Níveis das Atividades de Controle}

O GAO (2014) afirma que a gerência projeta atividades de controle em níveis adequados da organização, para a devida cobertura dos objetivos e riscos de suas operações. Segundo o COSO (2013), as atividades de controles em níveis mais altos da organização são mais abrangentes, geralmente na forma de revisões analíticas ou de desempenho dos negócios.

O objetivo da variável é identificar os níveis organizacionais para os quais são elaboradas atividades de controle, desde o nível de transações até o nível de entidade, inclusive de prestadores de serviços terceirizados. Os critérios para o estabelecimento do nível de maturidade da variável foram definidos nos seguintes termos:

(0) Inexistente - Ausência de documentação das atividades de controle;

(1) Inicial - Atividades de controle em nível de transações para os processos internos relevantes para os objetivos e riscos da entidade;

(2) Em Formação - Atividades de controle em nível de departamento;

\footnotetext{
${ }^{67}$ The documentation for internal control includes identification of the agency's activity-level functions and related objectives and control activities and appears in management directives, administrative policies, accounting manuals, and other such manuals.
} 
(3) Estabelecido - Atividades de controle em nível de entidade e controles para os prestadores de serviços terceirizados que realizam funções relevantes para os objetivos e riscos da entidade.

\subsubsection{Variável 3.1.3: Representação Fidedigna da Informação Contábil-Financeira}

O COSO (2013b) sugere a definição de responsabilidades pela revisão das demonstrações financeiras; o estabelecimento de controles para a mitigação do risco de avaliação das estimativas contábeis significativas (perdas estimadas com créditos de liquidação duvidosa, obsolescência de estoque, ajustes para avaliação de ativos e passivos ao valor justo, depreciação, amortização e outros); e a reconciliação das demonstrações financeiras.

O objetivo da variável é verificar a existência e formalização de processos para promover a representação fidedigna das informações em relatórios financeiros internos e externos da entidade. Os critérios para o estabelecimento do nível de maturidade da variável foram definidos nos seguintes termos:

(0) Inexistente - Ausência de processos para a representação fidedigna da informação contábilfinanceira;

(1) Inicial - Processos formalmente estabelecidos para a realização dos Procedimentos Contábeis Patrimoniais (MCASP Parte II);

(2) Em Formação - Processo formalmente estabelecidos para a conformidade contábil das demonstrações financeiras;

(3) Estabelecido - Processo formalmente estabelecidos para a conciliação entre os dados registrados no SIAFI e outros sistemas da Administração Pública Federal (SPIUNET, SIASG, $\mathrm{RMB})$.

\subsubsection{Variável 3.1.4: Segregação de Funções}

O COSO (2013) afirma que a gerência deve avaliar a necessidade de separar as responsabilidades pelo registro, autorização e aprovação das transações e a custódia dos respectivos bens, para reduzir o risco de erro ou fraude, levando em consideração ainda os requisitos legais e regulatórios e as expectativas das partes interessadas; se a segregação não for viável, atividades de controle alternativas devem ser elaboradas.

O objetivo da variável é verificar a existência de uma matriz de controle de acesso e segregação de funções (autorização, aprovação e verificação) para os processos, políticas e procedimentos relevantes para os objetivos e riscos da entidade, a existência de controles 
alternativos quando a segregação de funções não é adequada, e a reavaliação periódica da segregação de funções. Os critérios para o estabelecimento do nível de maturidade da variável foram definidos nos seguintes termos:

(0) Inexistente - Ausência de matriz de controle de acesso e segregação de funções;

(1) Inicial - A entidade elabora matriz de controle de acesso e segregação de funções (autorização, aprovação e verificação) para os processos, políticas e procedimentos relevantes para os objetivos e riscos da entidade;

(2) Em Formação - Projeto de controles alternativos para os processos, políticas e procedimentos relevantes para os objetivos e riscos da entidade que não podem ter a segregação de funções adequada;

(3) Estabelecido - Política da entidade determina a reavaliação periódica da matriz de controle de acesso e segregação de funções.

\subsubsection{Subdimensão 3.2: Implantação de Controles}

Segundo o COSO (2013), “a organização implanta atividades de controle por meio de políticas que estabelecem o que é esperado e procedimentos que colocam as políticas em ação" $"$.

Para esta subdimensão foi proposta a variável Políticas e Procedimentos de Controle, descrita no item a seguir.

\subsubsection{Variável 3.2.1: Políticas e Procedimentos de Controle}

O GAO (2014) afirma que a gerência deve documentar em políticas a responsabilidade de cada unidade da organização pelos objetivos e riscos de um processo operacional, além do projeto, implantação e eficácia operacional das atividades de controle; cada unidade também documenta políticas em nível de detalhe adequado para permitir que a gerência monitore eficazmente a atividade de controle. A gerência deve revisar periodicamente as políticas, procedimentos e atividades de controle relacionadas para a continuidade da relevância e eficácia na realização dos objetivos da entidade ou tratamento dos riscos relacionados.

\footnotetext{
${ }^{68}$ The organization deploys control activities through policies that establish what is expected and procedures that put policies into action.
} 
O objetivo da variável é identificar a existência, a complexidade e a reavaliação periódica das políticas e procedimentos para definição de responsabilidades e implantação das atividades de controle na entidade. Os critérios para o estabelecimento do nível de maturidade da variável foram definidos nos seguintes termos:

(0) Inexistente - Ausência de políticas e procedimentos para definição de responsabilidades e implantação dos controles da entidade;

(1) Inicial - Entidade elabora políticas e procedimentos para a definição de responsabilidades e implantação dos controles de todos os processos relevantes para os objetivos e riscos da entidade e documenta seguindo modelos padronizados pela entidade;

(2) Em Formação - Políticas e procedimentos especificam a tempestividade (frequência ou oportunidade) na execução dos controles, as ações corretivas caso sejam identificados problemas e o nível de competência e autoridade necessária para a execução adequada;

(3) Estabelecido - Política da entidade determina a reavaliação periódica das políticas e procedimentos de controles da entidade, ou sempre que forem identificadas mudanças nas atividades de negócios ou sistemas e processos relevantes para os objetivos e riscos da entidade.

\subsubsection{Subdimensão 3.3: Projeto de Controles sobre a Tecnologia}

O GAO (2014) identifica dois tipos de atividades de controle para sistemas de informação: controles gerais e controles de aplicação. Os controles gerais são as políticas e procedimentos que se aplicam a todos ou a grande parte dos sistemas de informação de uma entidade, como o gerenciamento da segurança, acesso físico e lógico, o gerenciamento da configuração, a segregação de funções e o planejamento de contingência; os controles de aplicação (ou controles de processos de negócios) são incorporados nas aplicações de computador para obter a validade, completude, precisão e confidencialidade das transações e dados durante o processamento, como os controles sobre a entrada, processamento, saída, arquivo mestre, interface e sistema de gerenciamento de dados.

Para esta subdimensão foram propostas três variáveis: Uso da Computação de Usuário Final; Políticas de Segurança de TI; e Processos de Aquisição, Desenvolvimento e Manutenção de TI. Essas variáveis são descritas nos itens a seguir.

\subsubsection{Variável 3.3.1: Uso da Computação de Usuário Final}

Segundo o COSO (2013b), a gerência da entidade deve compreender o uso da computação do usuário final (inclusive planilhas) no suporte a processos significativos e 
respectivas atividades de controle, avaliar os riscos decorrentes e elaborar atividades de controle adicionais ou converter para uma aplicação de TI.

O objetivo da variável é identificar o tratamento dado à computação do usuário final nos processos, políticas e procedimentos relevantes para os objetivos e riscos da entidade e nas atividades de controle associadas. Os critérios para o estabelecimento do nível de maturidade da variável foram definidos nos seguintes termos:

(0) Inexistente - Ausência de documentação do uso de computação do usuário final nos processos, políticas e procedimentos relevantes para os objetivos e riscos da entidade e nas atividades de controle associadas;

(1) Inicial - O uso de computação do usuário final nos processos, políticas e procedimentos relevantes os objetivos e riscos da entidade e nas atividades de controle associadas é mapeado e documentado;

(2) Em Formação - Gerência avalia os riscos decorrentes do uso de computação do usuário final nos processos, políticas e procedimentos relevantes para os objetivos e riscos da entidade e nas atividades de controle associadas e elabora controles adicionais conforme necessário;

(3) Estabelecido - As atividades de controle dos processos, políticas e procedimentos relevantes para os objetivos e riscos da entidade não dependem de computação do usuário final.

\subsubsection{Variável 3.3.2: Políticas de Segurança de TI}

Segundo o GAO (2014), a gerência projeta o gerenciamento da segurança para proteger o sistema de informação da entidade do acesso não autorizado e inadequado por parte de ameaças externas e internas, mantendo a confidencialidade, integridade e disponibilidade do sistema.

O objetivo da variável é verificar a existência e a formalização de políticas de segurança e controle de acesso à informação e aos recursos de TI, e a existência de plano de continuidade de serviços e recuperação de desastres para a infraestrutura de TI da entidade. Os critérios para o estabelecimento do nível de maturidade da variável foram definidos nos seguintes termos:

(0) Inexistente - Ausência de políticas de segurança de TI;

(1) Inicial - A entidade possui política de segurança de TI formalmente estabelecida; 
(2) Em Formação - A entidade possui política de controle de acesso à informação e aos recursos de TI formalmente estabelecida, consistente com as funções do trabalho e com a segregação de funções;

(3) Estabelecido - A infraestrutura de TI que suporta os processos, políticas e procedimentos relevantes para os objetivos e riscos da entidade possui plano de continuidade de serviços e recuperação de desastres.

\subsubsection{Variável 3.3.3: Processos de Aquisição, Desenvolvimento e Manutenção da TI}

O GAO (2014) afirma que a gerência da entidade deve projetar atividades de controle sobre a aquisição, desenvolvimento e manutenção da TI, o que pode incluir a adoção de um ciclo de vida de desenvolvimento de sistemas (SDLC) para as aplicações desenvolvidas internamente (inclusive por terceiros contratados) e pacotes de software adquiridos. O COSO (2013) descreve o SDLC como "uma metodologia de desenvolvimento de tecnologia" que provê "uma estrutura para projeto e implementação de sistemas, delineando fases específicas, requisitos de documentação, aprovações e pontos de verificação com controles sobre a aquisição, desenvolvimento e manutenção da tecnologia"69.

O objetivo da variável é identificar a existência de processos para a aquisição, desenvolvimento e manutenção da infraestrutura de TI da entidade, incluindo o gerenciamento de configuração e mudança para a infraestrutura de TI que suporta os processos, políticas e procedimentos relevantes para os objetivos e riscos da entidade e o ciclo de vida de desenvolvimento para os sistemas e suas características. Os critérios para o estabelecimento do nível de maturidade da variável foram definidos nos seguintes termos:

(0) Inexistente - Ausência de processos de gerenciamento de configuração e mudança para a infraestrutura de TI da entidade;

(1) Inicial - Processos formalmente estabelecidos para o gerenciamento de configuração e mudança da infraestrutura de TI que suporta os processos, políticas e procedimentos relevantes para os objetivos e riscos da entidade;

(2) Em Formação - Entidade adota um SDLC completo, tanto para o software desenvolvido internamente quanto para os pacotes adquiridos;

69 For example, a technology development methodology provides a structure for system design and implementation, outlining specific phases, documentation requirements, approvals, and checkpoints with controls over the acquisition, development, and maintenance of technology. 
(3) Estabelecido - Fases e controles previstos no SDLC da entidade são definidos em função de uma classificação de riscos da mudança, definida conforme o tamanho, esforço, complexidade e impactos em processos e controles relevantes para os objetivos e riscos da entidade.

A quarta dimensão do modelo de maturidade proposto é Informação e Comunicação. O COSO (2013) afirma que "a administração obtém ou produz e utiliza informações relevantes e de qualidade, a partir de fontes internas e externas, para apoiar o funcionamento do controle interno. A comunicação é o processo contínuo e interativo de fornecer, compartilhar e obter as informações necessárias". ${ }^{70}$

A subdimensão definida para a dimensão Informação e Comunicação é: Sistema de Informação da Entidade. Essa subdimensão e suas variáveis são apresentadas nos itens a seguir.

\subsubsection{Subdimensão 4.1: Sistema de Informação da Entidade}

O GAO (2014, p. 51-52) afirma que:

A gerência projeta o sistema de informação da entidade para obter e processar informação para atender os requisitos de informação de cada processo operacional e para responder aos riscos e objetivos da entidade. Um sistema de informação são as pessoas, processos, dados, e tecnologia que a gerência utiliza para obter, comunicar ou descartar informação. Um sistema de informação representa o ciclo de vida da informação usada pelos processos operacionais da entidade que habilita a entidade a obter, armazenar e processar informação de qualidade. ${ }^{71}$

Para esta subdimensão foram propostas duas variáveis: Relevância e Qualidade da Informação; e Comunicação Interna e Externa. Essas variáveis são descritas nos itens a seguir.

\subsubsection{Variável 4.1.1: Relevância e Qualidade da Informação}

O COSO (2013) afirma que a entidade deve obter ou gerar informações relevantes e de qualidade para apoiar o funcionamento do controle interno, identificando as necessidades de informações, capturando dados de fontes internas e externas e processando em informações.

Segundo o COSO (2013), "um processo está posto para identificar a informação requerida e esperada para apoiar o funcionamento dos outros componentes do controle interno

\footnotetext{
${ }^{70}$ Management obtains or generates and uses relevant and quality information from both internal and external sources to support the functioning of internal control. Communication is the continual, iterative process of providing, sharing, and obtaining necessary information.

${ }^{71}$ Management designs the entity's information system to obtain and process information to meet each operational process's information requirements and to respond to the entity's objectives and risks. An information system is the people, processes, data, and technology that management organizes to obtain, communicate, or dispose of information. An information system represents the life cycle of information used for the entity's operational processes that enables the entity to obtain, store, and process quality information.
} 
e a realização dos objetivos da entidade" ${ }^{\text {72 }}$. O GAO (2014) afirma que esse processo deve levar em consideração as expectativas de usuários internos e externos, e ser iterativo e contínuo, para identificar mudanças nas necessidades de informações conforme os objetivos e riscos da entidade se modificam.

O objetivo da variável é verificar a existência e a formalização de processos para identificar e documentar as necessidades de informações, bem como produzir, coletar, tratar, armazenar, processar e descartar dados e informações necessárias para apoiar o funcionamento o controle interno da entidade. Os critérios para o estabelecimento do nível de maturidade da variável foram definidos nos seguintes termos:

(0) Inexistente - Ausência de processos para identificar e documentar as necessidades, produzir, coletar, tratar, armazenar, processar e descartar dados e informações necessárias para apoiar o funcionamento o controle interno da entidade;

(1) Inicial - Processo formalmente estabelecido para identificar e documentar as informações necessárias para apoiar o funcionamento do controle interno da entidade;

(2) Em Formação - Processos formalmente estabelecidos para produção, coleta, tratamento, armazenamento, processamento e descarte dos dados e informações que apoiam o funcionamento do controle interno da entidade;

(3) Estabelecido - A entidade estabelece um programa de governança para a manutenção da qualidade dos dados e informações que apoiam o funcionamento do controle interno da entidade.

\subsubsection{Variável 4.1.2: Comunicação Interna e Externa}

De acordo com o GAO (2014), a gerência obtém e comunica informações de qualidade para partes externas e internas, em todos os níveis da entidade, para que o pessoal cumpra suas funções na realização dos objetivos, tratamento dos riscos e apoio à estrutura de controle interno.

O objetivo da variável é identificar a existência, a formalização e a complexidade dos processos de comunicação interna e externa da entidade. Os critérios para o estabelecimento do nível de maturidade da variável foram definidos nos seguintes termos:

\footnotetext{
${ }^{72} \mathrm{~A}$ process is in place to identify the information required and expected to support the functioning of the other components of internal control and the achievement of the entity's objectives.
} 
(0) Inexistente - Ausência de processos de comunicação interna e externa;

(1) Inicial - Processos formalmente estabelecidos para comunicar tempestivamente ao público interno e externo as informações necessárias e esperadas;

(2) Em Formação - Processos de comunicação interna e externa incluem a seleção dos métodos de comunicação, levando em consideração a tempestividade, audiência, natureza da comunicação e requisitos, expectativas legais, regulatórias e contratuais, e a relação custo x benefício;

(3) Estabelecido - A entidade define canais de comunicação internos e externos múltiplos e bidirecionais para evitar a perda de informações relevantes, incluindo canal de denúncias com garantia de anonimato para a comunicação de questões significativas relacionadas ao controle interno.

A quinta dimensão do modelo de maturidade proposto é o Monitoramento, definido pelo COSO (2013) nos seguintes termos: "avaliações contínuas, avaliações avulsas ou alguma combinação das duas são usadas para verificar se cada um dos cinco componentes de controle interno, inclusive os controles para concretizar os princípios relativos a cada componente, está presente e em funcionamento". ${ }^{73}$

A subdimensão definida para a dimensão Monitoramento é: Monitoramento da Estrutura de Controle Interno. Essa subdimensão e suas variáveis são apresentadas nos itens a seguir.

\subsubsection{Subdimensão 5.1: Monitoramento da Estrutura de Controle Interno}

O COSO (2013) afirma que as atividades de monitoramento avaliam a presença e funcionamento dos cinco componentes da estrutura de controles internos e princípios relevantes, por meio de monitoramento contínuo e avaliações avulsas.

Para esta subdimensão foram propostas três variáveis: Monitoramento Contínuo; Avaliações Avulsas; e Comunicação das Deficiências de Controle Interno e Acompanhamento das Ações Corretivas. Essas variáveis são descritas nos itens a seguir.

\footnotetext{
${ }^{73}$ Ongoing evaluations, separate evaluations, or some combination of the two are used to ascertain whether each of the five components of internal control, including controls to effect the principles within each component, is present and functioning.
} 


\subsubsection{Variável 5.1.1: Monitoramento Contínuo}

O GAO (2014) afirma que o monitoramento contínuo está embutido nas operações normais da entidade, e inclui atividades de supervisão regulares da gerência, comparações, reconciliações e outras atividades de rotina, podendo incluir ferramentas automatizadas, que podem aumentar a objetividade e eficiência pela compilação eletrônica de avaliações de controles e transações.

O objetivo da variável é verificar a existência, documentação e automatização das atividades de monitoramento contínuo dos processos, políticas e procedimentos relevantes para os objetivos e riscos da entidade. Os critérios para o estabelecimento do nível de maturidade da variável foram definidos nos seguintes termos:

(0) Inexistente - Ausência de atividades de monitoramento contínuo dos processos, políticas e procedimentos relevantes para os objetivos e riscos da entidade;

(1) Inicial - Os processos, políticas e procedimentos relevantes para os objetivos e riscos da entidade possuem atividades de monitoramento integradas;

(2) Em Formação - As atividades de monitoramento são documentadas seguindo modelos padronizados pela entidade;

(3) Estabelecido - As atividades de monitoramento dos processos, políticas e procedimentos relevantes para os objetivos e riscos da entidade são automatizadas, com o uso de tecnologia.

\subsubsection{Variável 5.1.2: Avaliações Avulsas}

O GAO (2014) afirma que as avaliações avulsas são utilizadas para monitorar a eficácia da estrutura de controle interno num momento específico ou para uma função ou processo específico, na forma de autoavaliações, auditorias e outras avaliações que incluam testes diretos do controle interno. Essas auditorias e outras avaliações podem ser obrigatórias em razão da lei e realizadas por auditores internos, externos ou outros revisores.

O objetivo da variável é verificar a realização e identificar os responsáveis pela condução das avaliações avulsas da estrutura de controle interno da entidade. Os critérios para o estabelecimento do nível de maturidade da variável foram definidos nos seguintes termos:

(0) Inexistente - Ausência de avaliações avulsas da estrutura de controle interno da entidade;

(1) Inicial - Avaliações avulsas da estrutura de controle interno são realizadas pela gerência da entidade; 
(2) Em Formação - Avaliações avulsas da estrutura de controle interno são realizadas pela gerência da entidade e pela auditoria interna;

(3) Estabelecido - Avaliações avulsas da estrutura de controle interno são realizadas pela gerência da entidade, pela auditoria interna e por auditoria independente ou consultores externos.

\subsubsection{Variável 5.1.3: Comunicação das Deficiências de Controle Interno e Acompanhamento das Ações Corretivas}

O COSO (2013) afirma que a comunicação das deficiências de controles internos para as partes corretas, para que adotem medidas corretivas, é primordial para a realização dos objetivos da entidade. Segundo o GAO (2014), os empregados da entidade relatam problemas de controle interno pelas linhas hierárquicas estabelecidas, para partes internas e externas adequadas, de maneira tempestiva para que a entidade avalie prontamente esses problemas; a gerência finaliza e documenta as ações corretivas para remediar as deficiências de controle interno de maneira tempestiva.

O objetivo da variável é verificar a existência e formalização de políticas e processos para a comunicação das deficiências de controle interno e acompanhamento das ações corretivas na entidade. Os critérios para o estabelecimento do nível de maturidade da variável foram definidos nos seguintes termos:

(0) Inexistente - Ausência de políticas e processos para a comunicação das deficiências de controle interno e acompanhamento das ações corretivas;

(1) Inicial - A entidade possui políticas formalmente estabelecidas definindo a classificação dos problemas identificados nas atividades de monitoramento, além do nível de detalhe da documentação, as responsabilidades pelas ações corretivas e as partes que devem ser comunicadas, conforme a classificação;

(2) Em Formação - A entidade possui processos formalmente estabelecidos para o acompanhamento das ações corretivas para as deficiências identificadas nos controles internos;

(3) Estabelecido - A entidade possui processos formalmente estabelecidos para a verificação da eficácia das ações corretivas adotadas para deficiências de controles internos significativas. 
A proposta de modelo de maturidade foi submetida a procedimento de validação, por meio de avaliação de juízes (especialistas), com o objetivo de obter contribuições para o aperfeiçoamento da clareza e pertinência das variáveis e dos critérios de enquadramento em cada nível de maturidade. Coy e Dixon (2004) entendem que a avaliação de juízes é necessária para assegurar a compreensibilidade dos itens que compõem um constructo, permitindo sua validação e testes em momento posterior.

Para tanto, foram elaborados questionários de avaliação. Os especialistas analisaram a clareza dos critérios das variáveis (se os termos escolhidos para a redação dos critérios são compreensíveis e se o padrão evolutivo estabelecido pelos critérios foi adequado) e a pertinência das variáveis (se a variável se relaciona com o componente da estrutura de controles internos e é característica de entidades do setor governamental). Os questionários utilizaram uma escala tipo Likert, de cinco pontos, para a atribuição de pontuação aos quesitos avaliados. Os questionários incluíram instruções detalhadas de como responder à pesquisa (modelo dos questionários no apêndice E), tendo sido encaminhados aos juízes via correio eletrônico (modelo das comunicações no apêndice F).

Os juízes foram selecionados dentre o quadro de Auditores Federais de Controle Externo do Tribunal de Contas da União, com conhecimento e experiência em controles internos e domínios de conhecimento conexos, identificados no currículo dos juízes, conforme cadastro no sistema de gestão de competências do TCU.

Considerando que o modelo de maturidade proposto inclui 35 variáveis distribuídas entre as dimensões e subdimensões, optou-se pela divisão do questionário de avaliação, de modo a evitar excessivo esforço de resposta por parte dos juízes e a possibilitar um melhor aproveitamento de seus conhecimentos. Desse modo, foram elaborados nove questionários, com seu conteúdo definido nos termos do quadro a seguir:

Quadro 5 - Divisão dos Questionários de Avaliação

\begin{tabular}{|c|l|c|}
\hline Número & \multicolumn{1}{|c|}{ Escopo (Dimensões, Subdimensões e Variáveis) } & Respostas / Convidados \\
\hline \multirow{2}{*}{1} & $\begin{array}{l}\text { (1) Ambiente de Controle } \\
\text { (1.1) Padrões de Conduta } \\
\text { (1.2) Independência e Competência do Corpo Diretivo }\end{array}$ & $2 / 3$ \\
\hline 2 & $\begin{array}{l}\text { (1) Ambiente de Controle } \\
\text { (1.3) Responsabilidades de Controle Interno e Requisitos de } \\
\text { Competência } \\
\text { (1.4) Atração, Desenvolvimento e Retenção de Indivíduos }\end{array}$ & $2 / 3$ \\
\hline
\end{tabular}

Continua na página seguinte. 
Continuação do Quadro 5 - Divisão dos Questionários de Avaliação

\begin{tabular}{|c|l|c|}
\hline Número & \multicolumn{1}{|c|}{ Escopo (Dimensões, Subdimensões e Variáveis) } & Respostas / Convidados \\
\hline 3 & $\begin{array}{l}\text { (1) Ambiente de Controle } \\
\text { (1.5) Avaliação de Desempenho }\end{array}$ & $3 / 4$ \\
\hline 4 & $\begin{array}{l}\text { (2) Avaliação de Riscos } \\
\text { (2.1) Definição de Objetivos }\end{array}$ & $3 / 4$ \\
\hline 5 & $\begin{array}{l}\text { (2) Avaliação de Riscos } \\
\text { (2.2) Identificação, Análise e Resposta aos Riscos }\end{array}$ & $5 / 5$ \\
\hline 6 & $\begin{array}{l}\text { (3) Atividades de Controle } \\
\text { (3.1) Projeto de Controles para Mitigação de Riscos } \\
\text { (3.2) Implantação de Controles }\end{array}$ & $5 / 13$ \\
\hline 7 & $\begin{array}{l}\text { (3) Atividades de Controle } \\
\text { (3.3) Projeto de Controles sobre a Tecnologia }\end{array}$ & $2 / 5$ \\
\hline 8 & $\begin{array}{l}\text { (4) Informação e Comunicação } \\
\text { (4.1) Sistema de Informação da Entidade }\end{array}$ & $2 / 4$ \\
\hline 9 & $\begin{array}{l}\text { (5) Monitoramento } \\
\text { (5.1) Monitoramento da Estrutura de Controle Interno }\end{array}$ & \\
\hline
\end{tabular}

Fonte: Elaboração pelo autor, a partir dos procedimentos do estudo.

No quadro a seguir, são apresentados os resultados da avaliação dos juízes:

Quadro 6 - Resultados da avaliação de juízes especialistas

\begin{tabular}{|c|c|c|c|}
\hline \multirow{2}{*}{ Questionário } & \multirow{2}{*}{ Variável } & \multicolumn{2}{|c|}{ Média da Avaliação } \\
\hline & & Clareza & Pertinência \\
\hline \multirow{5}{*}{1} & 1.1 .1 & 4,5 & 5 \\
\hline & 1.1 .2 & 4 & 3,5 \\
\hline & 1.1 .3 & 4 & 5 \\
\hline & 1.2 .1 & 4,5 & 5 \\
\hline & 1.2 .2 & 3 & 4,5 \\
\hline \multirow{3}{*}{2} & 1.3 .1 & 4 & 4,5 \\
\hline & 1.3 .2 & 3 & 5 \\
\hline & 1.4 .1 & 4 & 5 \\
\hline \multirow{5}{*}{3} & 1.5 .1 & 5 & 3,5 \\
\hline & 1.5 .2 & 5 & 3,5 \\
\hline & 1.5 .3 & 4 & 4,5 \\
\hline & 1.5 .4 & 4,5 & 3,5 \\
\hline & 1.5 .5 & 5 & 4 \\
\hline \multirow{5}{*}{4} & 2.1 .1 & 3,33 & 5 \\
\hline & 2.1 .2 & 3,33 & 5 \\
\hline & 2.1 .3 & 3 & 5 \\
\hline & 2.1 .4 & 3,67 & 5 \\
\hline & 2.1 .5 & 4 & 5 \\
\hline \multirow{4}{*}{5} & 2.2 .1 & 4,5 & 5 \\
\hline & 2.2 .2 & 4 & 4,5 \\
\hline & 2.2 .3 & 3,5 & 4,5 \\
\hline & 2.2 .4 & 4 & 4,5 \\
\hline \multirow{5}{*}{6} & 3.1 .1 & 3,8 & 4,8 \\
\hline & 3.1 .2 & 3,6 & 4,4 \\
\hline & 3.1 .3 & 5 & 5 \\
\hline & 3.1 .4 & 4,2 & 4,4 \\
\hline & 3.2 .1 & 3,8 & 4,8 \\
\hline
\end{tabular}

Continua na página seguinte. 
Continuação do Quadro 6 - Resultados da avaliação de juízes especialistas

\begin{tabular}{|c|c|c|c|}
\hline \multirow{2}{*}{ Questionário } & \multirow{2}{*}{ Variável } & \multicolumn{2}{|c|}{ Média da Avaliação } \\
\cline { 2 - 4 } & & Clareza & Pertinência \\
\hline \multirow{3}{*}{7} & 3.3 .1 & 2,6 & 3,8 \\
\cline { 2 - 4 } & 3.3 .2 & 3,6 & 4,8 \\
\cline { 2 - 4 } & 3.3 .3 & 3,4 & 4,2 \\
\hline \multirow{2}{*}{8} & 4.1 .1 & 2,5 & 3 \\
\cline { 2 - 4 } & 4.1 .2 & 3 & 3 \\
\hline \multirow{2}{*}{9} & 5.1 .1 & 3 & 5 \\
\cline { 2 - 4 } & 5.1 .2 & 5 & 5,5 \\
\cline { 2 - 4 } & 5.1 .3 & 4 & \multicolumn{2}{c}{} \\
\hline
\end{tabular}

Fonte: Dados da pesquisa.

Além da pontuação aos quesitos de clareza e pertinência, os especialistas foram estimulados a fazer comentários adicionais para esclarecer a pontuação atribuída e oferecer outras contribuições. As críticas e sugestões de cada especialista foram sintetizadas em quadros de avaliação, e incorporadas ao modelo de maturidade conforme o ajustamento aos fundamentos teóricos da variável relacionada. Os resultados desse procedimento são apresentados no apêndice G.

O modelo de maturidade final, utilizado para avaliar a maturidade das estruturas de controle interno das entidades que participaram deste estudo, é apresentado no apêndice I desde trabalho. O quadro a seguir sintetiza as dimensões, subdimensões e variáveis do modelo de maturidade após dos procedimentos de validação:

Quadro 7 - Dimensões, subdimensões e variáveis da proposta de modelo de maturidade (pós-avaliação)

\begin{tabular}{|c|c|c|}
\hline Dimensão & Subdimensão & Variável \\
\hline \multirow{13}{*}{$\begin{array}{l}\text { 1. Ambiente de } \\
\text { Controle }\end{array}$} & \multirow{3}{*}{ 1.1. Padrões de Conduta } & 1.1.1. Destinatários dos Padrões de Conduta \\
\hline & & $\begin{array}{l}\text { 1.1.2. Disseminação dos Padrões de Conduta, Ética e } \\
\text { Valores }\end{array}$ \\
\hline & & $\begin{array}{l}\text { 1.1.3. Estrutura Organizacional para Avaliação da } \\
\text { Aderência aos Padrões de Conduta }\end{array}$ \\
\hline & \multirow{2}{*}{$\begin{array}{l}\text { 1.2. Independência e } \\
\text { Competência do Corpo } \\
\text { Diretivo }\end{array}$} & 1.2.1. Políticas de Due Diligence para o Corpo Diretivo \\
\hline & & 1.2.2. Requisitos de Competência do Corpo Diretivo \\
\hline & \multirow{2}{*}{$\begin{array}{l}\text { 1.3. Responsabilidades de } \\
\text { Controle Interno e } \\
\text { Requisitos de Competências }\end{array}$} & $\begin{array}{l}\text { 1.3.1. Responsabilidades de } \\
\text { Organização }\end{array}$ \\
\hline & & 1.3.2. Requisitos de Competências na Organização \\
\hline & $\begin{array}{l}\text { 1.4. Atração, } \\
\text { Desenvolvimento e } \\
\text { Retenção de Indivíduos }\end{array}$ & 1.4.1. Programa de Desenvolvimento de Competências \\
\hline & \multirow{5}{*}{$\begin{array}{l}\text { 1.5. Avaliação de } \\
\text { Desempenho }\end{array}$} & 1.5.1. Fatores da Avaliação de Desempenho \\
\hline & & $\begin{array}{l}\text { 1.5.2. Níveis Organizacionais da Avaliação de } \\
\text { Desempenho }\end{array}$ \\
\hline & & 1.5.3. Níveis Organizacionais das Metas de Desempenho \\
\hline & & $\begin{array}{l}\text { 1.5.4. Recompensas e Sanções da Avaliação de } \\
\text { Desempenho }\end{array}$ \\
\hline & & 1.5.5. Frequência da Avaliação de Desempenho \\
\hline
\end{tabular}

Continua na página seguinte. 
Continuação do Quadro 7 - Dimensões, subdimensões e variáveis da proposta de modelo de maturidade (pós-avaliação)

\begin{tabular}{|c|c|c|}
\hline Dimensão & Subdimensão & Variável \\
\hline \multirow{9}{*}{$\begin{array}{l}\text { 2. Avaliação de } \\
\text { Riscos }\end{array}$} & \multirow{5}{*}{ 2.1. Definição de Objetivos } & 2.1.1. Processo de Formulação de Objetivos \\
\hline & & $\begin{array}{l}\text { 2.1.2. Participantes do Processo de Formulação de } \\
\text { Objetivos }\end{array}$ \\
\hline & & 2.1.3. Tipos de Objetivos \\
\hline & & 2.1.4. Níveis Organizacionais dos Objetivos \\
\hline & & 2.1.5. Mensuração dos Objetivos \\
\hline & \multirow{4}{*}{$\begin{array}{l}\text { 2.2. Identificação, Análise e } \\
\text { Resposta aos Riscos }\end{array}$} & 2.2.1. Processo de Avaliação de Riscos \\
\hline & & 2.2.2. Participantes da Avaliação de Riscos \\
\hline & & 2.2.3. Fatores Considerados na Avaliação de Riscos \\
\hline & & 2.2.4. Níveos Organizacionais da Avaliação de Riscos \\
\hline \multirow{8}{*}{$\begin{array}{l}\text { 3. Atividades de } \\
\text { Controle }\end{array}$} & \multirow{4}{*}{$\begin{array}{l}\text { 3.1. Projeto de Controles } \\
\text { para Mitigação de Riscos }\end{array}$} & 3.1.1. Documentação das Atividades de Controle \\
\hline & & 3.1.2. Níveis Organizacionais das Atividades de Controle \\
\hline & & $\begin{array}{l}\text { 3.1.3. Representação Fidedigna da Informação Contábil- } \\
\text { Financeira }\end{array}$ \\
\hline & & 3.1.4. Segregação de Funções \\
\hline & $\begin{array}{l}\text { 3.2. Implantação de } \\
\text { Controles }\end{array}$ & 3.2.1. Políticas e Procedimentos de Controle \\
\hline & \multirow{3}{*}{$\begin{array}{l}\text { 3.3. Projeto de Controles } \\
\text { sobre a Tecnologia }\end{array}$} & 3.3.1. Uso da Computação de Usuário Final \\
\hline & & 3.3.2. Políticas de Segurança de TI \\
\hline & & $\begin{array}{l}\text { 3.3.3. Processos de Aquisição, Desenvolvimento e } \\
\text { Manutenção da TI }\end{array}$ \\
\hline \multirow{2}{*}{$\begin{array}{l}\text { 4. Informação e } \\
\text { Comunicação }\end{array}$} & \multirow{2}{*}{$\begin{array}{l}\text { 4.1. Sistema de Informação } \\
\text { da Entidade }\end{array}$} & 4.1.1. Relevância e Qualidade da Informação \\
\hline & & 4.1.2. Comunicação Interna e Externa \\
\hline \multirow{3}{*}{$\begin{array}{l}5 . \\
\text { Monitoramento }\end{array}$} & \multirow{3}{*}{$\begin{array}{l}\text { 5.1. Monitoramento da } \\
\text { Estrutura de Controle } \\
\text { Interno }\end{array}$} & 5.1.1. Monitoramento Contínuo \\
\hline & & 5.1.2. Avaliações Avulsas \\
\hline & & $\begin{array}{l}\text { 5.1.3. Comunicação das Deficiências de Controle Interno e } \\
\text { Acompanhamento das Ações Corretivas }\end{array}$ \\
\hline
\end{tabular}

Fonte: Elaboração do autor, a partir dos procedimentos do estudo.

\subsubsection{Caracterização dos Níveis de Maturidade}

As características finais dos níveis do modelo de maturidade, após os procedimentos de validação, são apresentadas nas seções a seguir.

\subsubsection{Nível de Maturidade 0: Incipiente}

O nível de maturidade (0) Incipiente (anteriormente denominado Inexistente) é caracterizado pela ausência ou incipiência dos elementos que caracterizam a presença e funcionamento de uma estrutura de controle interno na organização.

\subsubsection{Nível de Maturidade 1: Inicial}

O nível de maturidade (1) Inicial tem suas características nos termos do quadro a seguir: 


\section{Quadro 8 - Características do Nível de Maturidade (1) Inicial}

\begin{tabular}{|c|c|}
\hline Dimensão & Características \\
\hline $\begin{array}{l}\text { Ambiente de } \\
\text { Controle }\end{array}$ & $\begin{array}{l}\text { Organização possui padrões de conduta próprios, com disposições gerais para } \\
\text { todos os empregados; comissão de ética constituída e avaliação anual da gestão } \\
\text { da ética; due diligence na seleção para o corpo diretivo; definição de requisitos } \\
\text { de competências para o corpo diretivo; definição de responsabilidades de controle } \\
\text { interno e requisitos de competências para alta gerência e auditoria interna; } \\
\text { avaliação anual de desempenho dos empregados e gerência, com foco na } \\
\text { produtividade, tendo metas definidas para a organização como um todo e } \\
\text { consequências de natureza disciplinar para o baixo desempenho. }\end{array}$ \\
\hline $\begin{array}{l}\text { Avaliação de } \\
\text { Riscos }\end{array}$ & $\begin{array}{l}\text { Objetivos estratégicos, definidos de forma casuística, com a participação apenas } \\
\text { de corpo diretivo e alta gerência, definidos em nível de entidade e mensurados; } \\
\text { riscos avaliados de forma casuística, abordando fatores internos e externos à } \\
\text { entidade, com a participação apenas de corpo diretivo e alta gerência, avaliados } \\
\text { em nível de entidade. }\end{array}$ \\
\hline $\begin{array}{l}\text { Atividades de } \\
\text { Controle }\end{array}$ & $\begin{array}{l}\text { Matriz de riscos e controles; controles em nível de transação nos processos } \\
\text { relevantes para os objetivos da entidade; processos para realização dos } \\
\text { Procedimentos Contábeis Patrimoniais (MCASP parte II); matriz de } \\
\text { responsabilidades ou segregação de funções para os processos, políticas e } \\
\text { procedimentos relevantes para os objetivos da entidade; documentação do uso da } \\
\text { computação de usuários final nos processos relevantes para os objetivos da } \\
\text { entidade e atividades de controle associadas; política de segurança de TI } \\
\text { estabelecida; processos estabelecidos para gerenciamento de configuração e } \\
\text { mudança da infraestrutura de TI que suporta os processos, políticas e } \\
\text { procedimentos relevantes os dos objetivos da entidade. }\end{array}$ \\
\hline $\begin{array}{l}\text { Informação e } \\
\text { Comunicação }\end{array}$ & $\begin{array}{l}\text { Processos estabelecidos para identificar as informações necessárias para o } \\
\text { funcionamento dos controles internos e para realizar a comunicação interna e } \\
\text { externa. }\end{array}$ \\
\hline Monitoramento & $\begin{array}{l}\text { Atividades de monitoramento integradas aos processos, políticas e procedimentos } \\
\text { relevantes os objetivos da entidade; avaliações avulsas periódicas da estrutura de } \\
\text { controle interno pela gerência da entidade; políticas estabelecidas para a } \\
\text { classificação dos problemas identificados no monitoramento e respectiva } \\
\text { documentação, ações corretivas e as partes comunicadas. }\end{array}$ \\
\hline
\end{tabular}

Fonte: Elaborado pelo autor, a partir dos procedimentos do estudo.

\subsubsection{Nível de Maturidade 2: Em Formação}

O nível de maturidade (2) Em Formação tem suas características nos termos do quadro a seguir:

\begin{tabular}{|c|c|}
\hline Dimensão & Características \\
\hline $\begin{array}{l}\text { Ambiente de } \\
\text { Controle }\end{array}$ & $\begin{array}{l}\text { Padrões de conduta específicos para gerência, corpo diretivo e pessoal de funções } \\
\text { relevantes para os objetivos da organização; comissão de ética com plano de } \\
\text { trabalho e apuração de incidentes de ética; due diligence periódico para } \\
\text { continuidade da competência e independência do corpo diretivo; corpo diretivo } \\
\text { possui membros com conhecimentos especializados; definição de } \\
\text { responsabilidades de controle interno e requisitos de competências para gerentes } \\
\text { de funções relevantes para os objetivos da organização; avaliação semestral de } \\
\text { desempenho, incluindo a alta gerência, incluindo nos fatores a conduta ética, tendo } \\
\text { metas definidas para as subunidades organizacionais e consequências financeiras } \\
\text { para o baixo desempenho. }\end{array}$ \\
\hline
\end{tabular}

Continua na página seguinte. 
Continuação do Quadro 9 - Características do Nível de Maturidade (2) Em Formação

\begin{tabular}{|c|c|}
\hline Dimensão & Características \\
\hline $\begin{array}{l}\text { Avaliação de } \\
\text { Riscos }\end{array}$ & $\begin{array}{l}\text { Objetivos operacionais, definidos em processo formal, com a participação de } \\
\text { empregados de funções relevantes para os objetivos da organização, definidos em } \\
\text { nível de subunidade organizacional, com metas associadas; riscos avaliados em } \\
\text { processo formal, abordando riscos decorrentes de mudanças (ambiente externo, } \\
\text { modelo de negócios e liderança), com a participação de empregados de funções } \\
\text { relevantes para os objetivos da organização, avaliados em nível de subunidade } \\
\text { organizacional. }\end{array}$ \\
\hline $\begin{array}{r}\text { Ativida } \\
\text { Cont }\end{array}$ & $\begin{array}{l}\text { Documentação das atividades de controle, incluindo a tecnologia subjacente; } \\
\text { controles em nível de departamento; processos para conformidade contábil das } \\
\text { demonstrações financeiras; identificação de incompatibilidades nas matrizes de } \\
\text { responsabilidades ou segregação de funções e elaboração de controles } \\
\text { alternativos; avaliação de riscos do uso da computação de usuários final nos } \\
\text { processos relevantes para os objetivos da entidade e elaboração de controles } \\
\text { adicionais; política de controle de acesso aos recursos de TI estabelecida; adoção } \\
\text { de SDLC para software adquirido ou desenvolvido pela própria entidade. }\end{array}$ \\
\hline $\begin{array}{l}\text { Informação e } \\
\text { Comunicação }\end{array}$ & $\begin{array}{l}\text { Processos estabelecidos para produção, coleta, tratamento, armazenamento, } \\
\text { processamento e descarte dos dados e informações para o funcionamento dos } \\
\text { controles internos; seleção de métodos de comunicação nos processos de } \\
\text { comunicação interna e externa. }\end{array}$ \\
\hline Monitorament & $\begin{array}{l}\text { Documentação das atividades de monitoramento; avaliações avulsas periódicas } \\
\text { pela auditoria interna; processos estabelecidos para o acompanhamento das ações } \\
\text { corretivas para os problemas identificados no monitoramento. }\end{array}$ \\
\hline
\end{tabular}

Fonte: Elaborado pelo autor, a partir dos procedimentos do estudo.

\subsubsection{Nível de Maturidade 3: Elaborado}

O nível de maturidade Elaborado (3) tem suas características nos termos do quadro a seguir:

Quadro 10 - Características do Nível de Maturidade Elaborado (3)

\begin{tabular}{|c|l|}
\hline Dimensão & \multicolumn{1}{c|}{ Características } \\
\hline & $\begin{array}{l}\text { Padrões de conduta para terceiros relacionados; auditoria periódica de ética por auditor } \\
\text { independente; supervisão dos procedimentos de due diligence e transparência dos } \\
\text { resultados; programa de capacitação para membros do corpo diretivo; definição de } \\
\text { responsabilidades de controle interno e requisitos de competências para empregados e } \\
\text { Ambiente de } \\
\text { Controle } \\
\text { terceirizados de funções relevantes para os objetivos da organização; avaliação } \\
\text { frequente de desempenho, incluindo a direção executiva, incluindo nos fatores as } \\
\text { competências, tendo metas definidas individualmente e consequências de promoção e } \\
\text { movimentação para o baixo desempenho. }\end{array}$ \\
\hline Avaliação de \\
Riscos & $\begin{array}{l}\text { Objetivos de relatórios e conformidade, definidos em processo formal periódico, com } \\
\text { a participação de partes interessadas externas, definidos em nível de atividade, com } \\
\text { cronograma e orçamento; riscos avaliados em processo formal periódico, abordando } \\
\text { risco de fraude, com a participação de auditor independente, avaliados em nível de } \\
\text { atividade. }\end{array}$ \\
\hline
\end{tabular}

Continua na página seguinte. 
Continuação do Quadro 10 - Características do Nível de Maturidade Elaborado (3)

\begin{tabular}{|c|l|}
\hline $\begin{array}{c}\text { Atividades de } \\
\text { Controle }\end{array}$ & $\begin{array}{l}\text { Mapeamento dos processos relevantes para os objetivos da entidade; controles } \\
\text { em nível de entidade e controles para terceirizados de funções relevantes para os } \\
\text { objetivos da entidade; processos para conciliação das informações contábeis; } \\
\text { reavaliação periódica das matrizes de responsabilidades ou segregação de funções } \\
\text { e controle de acesso; eliminação da computação de usuário final nos processos } \\
\text { relevantes para os objetivos da entidade; plano de continuidade e recuperação de } \\
\text { desastres para a TI que suporta os processos relevantes para a entidade; adoção } \\
\text { de SDLC com fases e controles definidos conforme classificação de risco da } \\
\text { mudança. }\end{array}$ \\
\hline $\begin{array}{c}\text { Informação e } \\
\text { Comunicação }\end{array}$ & $\begin{array}{l}\text { Programa de governança para dados e informações que apoiam o funcionamento } \\
\text { dos controles internos; canais múltiplos e bidirecionais para comunicação interna } \\
\text { e externa, com garantia de anonimato. }\end{array}$ \\
\hline Monitoramento & $\begin{array}{l}\text { Atividades de monitoramento automatizadas; avaliações avulsas periódicas por } \\
\text { auditor independente; processos estabelecidos para avaliação da eficácia das } \\
\text { ações corretivas para deficiências significativas de controles internos. }\end{array}$ \\
\hline
\end{tabular}

Fonte: Elaborado pelo autor, a partir dos procedimentos do estudo.

\subsection{PROCEDIMENTOS PARA A AVALIAÇÃO DA MATURIDADE DAS ESTRUTURAS DE CONTROLE INTERNO DAS ENTIDADES GOVERNAMENTAIS ESTUDADAS}

Nessa fase foram realizados os estudos de caso no Ministério da Agricultura, Pecuária e Abastecimento - MAPA, no Instituto de Colonização e Reforma Agrária - Incra e na Companhia Nacional de Abastecimento - Conab. As razões para a escolha dessas entidades estão apresentadas no item 3.2 deste trabalho. No MAPA, a interlocução se deu com o Assessor Especial de Controle Interno; no Incra, com o Chefe da Auditoria Interna; e na Conab, com o Superintendente de Controladoria e Riscos.

O primeiro passo do estudo de caso foi a solicitação de um conjunto de documentos, elaborado com embasamento nos critérios de enquadramento das variáveis do modelo de maturidade. O conjunto foi integrado por oitenta e cinco documentos, e o modelo das solicitações pode ser encontrado no apêndice $\mathrm{H}$ deste trabalho. A documentação foi entregue pelos interlocutores em arquivos de formato digital, encaminhados por correio eletrônico e mídia física.

Em seguida, foi realizado procedimento de análise documental, com o objetivo de identificar evidências que sustentassem um juízo quanto ao atendimento aos critérios de enquadramento de cada variável. Bardin (2011, p. 51) define a análise documental como "uma operação ou um conjunto de operações visando representar o conteúdo de um documento sob a forma diferente do original, a fim de facilitar num estado ulterior, a sua consulta e referenciação". O atendimento aos critérios de enquadramento das variáveis foi tipificado conforme o quadro a seguir: 
Quadro 11 - Tipologia do atendimento aos critérios de enquadramento das variáveis do modelo de maturidade

\begin{tabular}{|c|l|}
\hline Juízo & \multicolumn{1}{|c|}{ Características } \\
\hline Sim & $\begin{array}{l}\text { As evidências encontradas na análise documental foram consideradas suficientes para } \\
\text { afirmar que a estrutura de controle interno da entidade analisada atende integralmente ao } \\
\text { critério definido. }\end{array}$ \\
\hline Parcial & $\begin{array}{l}\text { A análise documental identificou evidências de que a estrutura de controle interno da } \\
\text { entidade analisada atende apenas a parte dos elementos do critério definido, ou identificou } \\
\text { indícios de atendimento ao critério, porém insuficientes para afirmar que o critério definido } \\
\text { seja atendido integralmente. }\end{array}$ \\
\hline Não & $\begin{array}{l}\text { A análise documental não identificou evidências de que a estrutura de controle interno da } \\
\text { entidade analisada atenda ao critério definido, ou identificou evidências suficientes para } \\
\text { afirmar que a estrutura de controle interno da entidade analisada não atende ao critério } \\
\text { definido. }\end{array}$ \\
\hline
\end{tabular}

Fonte: Elaborado pelo autor.

Os resultados dos procedimentos de análise do atendimento aos critérios de enquadramento são apresentados no capítulo 4 deste trabalho.

$\mathrm{O}$ apêndice $\mathrm{J}$ apresenta o resultado dos procedimentos de avaliação do nível de maturidade das estruturas de controle interno das entidades estudadas. A partir do atendimento aos critérios de enquadramento, foi atribuído o peso das variáveis em cada nível de maturidade. A atribuição do peso das variáveis nos níveis de maturidade (1) Inicial, (2) Em Formação e (3) Estabelecido foi tipificada em: $100 \%$, quando o critério do nível de maturidade foi integralmente atendido (Sim); 50\%, quando o critério do nível de maturidade foi parcialmente atendido (Parcial); e 0\%, quando o critério do nível de maturidade não foi atendido (Não).

Quanto ao peso das variáveis no nível de maturidade (0) Incipiente, a atribuição foi tipificada em: $100 \%$, quando nenhum dos critérios dos níveis de maturidade (1), (2) ou (3) foi atendido; ou $0 \%$, quando qualquer um dos critérios dos níveis de maturidade (1), (2) ou (3) foi atendido, mesmo que parcialmente.

A avaliação final quanto à maturidade da estrutura de controle interno das entidades levou em consideração a média do peso das variáveis em cada nível de maturidade e a lógica implícita aos modelos de maturidade, segundo a qual o alcance de determinado estágio depende do cumprimento dos requisitos dos estágios anteriores. O esquema apresentado no quadro a seguir esclarece a lógica aplicada para a avaliação final: 
Quadro 12 - Lógica de avaliação do nível de maturidade das estruturas de controle interno das entidades estudadas

\begin{tabular}{|c|l|}
\hline $\begin{array}{c}\text { Nível de } \\
\text { Maturidade }\end{array}$ & \multicolumn{1}{c|}{ Características } \\
\hline (1) Inicial & $\begin{array}{l}\text { A entidade é classificada no nível de maturidade (1) Inicial quando a média do } \\
\text { peso das variáveis no nível de maturidade (1) for igual ou superior a 50\%. }\end{array}$ \\
\hline $\begin{array}{c}\text { (2) Em } \\
\text { Formação }\end{array}$ & $\begin{array}{l}\text { A entidade é classificada no nível de maturidade (2) Em Formação quando a média } \\
\text { do peso das variáveis nos níveis de maturidade (1) e (2) for igual ou superior a } \\
50 \% .\end{array}$ \\
\hline (3) Estabelecido & $\begin{array}{l}\text { A entidade é classificada no nível de maturidade (3) Estabelecido quando a média } \\
\text { do peso das variáveis nos níveis de maturidade (1), (2) e (3) for igual ou superior } \\
\text { a 50\%. }\end{array}$ \\
\hline (0) Incipiente & $\begin{array}{l}\text { A entidade é classificada no nível de maturidade (0) Incipiente quando não for } \\
\text { classificada em nenhum dos demais níveis de maturidade. }\end{array}$ \\
\hline
\end{tabular}

Fonte: Elaborado pelo autor.

\section{6}

\section{LIMITAÇÕES DA PESQUISA}

Apesar da ampla diversidade de domínios de conhecimento integradas no âmbito de uma estrutura de controle interno ${ }^{74}$, as boas práticas de controles internos que deram embasamento aos procedimentos de construção da matriz de maturidade foram identificadas considerando os frameworks do COSO e os padrões de controle interno do GAO e Intosai. Nesse sentido, é possível que as principais referências de tais domínios de conhecimento defendam práticas diversas das identificadas nos documentos fundamentaram este trabalho.

Os estudos de caso desta pesquisa foram realizados exclusivamente por meio de análise documental, o que pode implicar em vieses no julgamento do nível de maturidade da estrutura de controle interno das entidades analisadas, em razão de dois problemas: primeiro, porque é possível que as estruturas organizacionais ${ }^{75}$ analisadas existam na prática, mas ainda não tenham sido estabelecidas formalmente ou documentadas; segundo, porque é possível que as estruturas organizacionais analisadas não estejam funcionando na prática, apesar de terem sido estabelecidas formalmente ou documentadas.

A identificação das características intermediárias e finais dos níveis de maturidade não aplicou integralmente os procedimentos de análise de conteúdo preconizados por Bardin (2011). A definição do nível de maturidade das estruturas de controle interno das entidades estudadas foi realizada por procedimentos que buscaram a comparação dos resultados das

\footnotetext{
${ }^{74}$ Citando apenas alguns desses domínios: governança corporativa; padrões de ética e conduta; gestão estratégica de recursos humanos; planejamento estratégico; gestão de riscos; gestão por processos; controles; tecnologia da informação; e comunicação.

75 Políticas, processos, procedimentos, atividades, controles, departamentos, responsabilidades, autoridades, comunicações, etc.
} 
variáveis com a características dos níveis de maturidade, conforme descrito nas seções 3.4.1 e 3.5 deste trabalho.

Finalmente, destaca-se que a validação do modelo de maturidade deve ser observada sob a perspectiva de que o modelo se encontra em desenvolvimento, a exemplo de sua ampliação para contemplar todos os princípios do COSO. 
Neste capítulo os resultados do teste empírico do modelo de maturidade são apresentados e discutidos. A organização das seções e subseções do capítulo obedece à estruturação das dimensões, subdimensões e variáveis do modelo de maturidade. Ao final de cada subdimensão é apresentada a análise comparativa dos achados, ressaltando-se as semelhanças e diferenças encontradas, identificando-se ainda os riscos decorrentes dos achados e realizando recomendações às entidades estudadas. Ao final de cada dimensão, são apresentados os resultados dos procedimentos de avaliação do nível de maturidade das estruturas de controle interno das entidades estudadas.

\section{1}

RESULTADOS DA DIMENSÃO 1 - AMBIENTE DE CONTROLE

\subsubsection{Resultados da Subdimensão 1.1 - Padrões de Conduta}

\subsubsection{Resultados da Variável 1.1.1 - Destinatários dos Padrões de Conduta}

Quadro 13 - Resultados da Variável 1.1.1 - Destinatários dos Padrões de Conduta

\begin{tabular}{|c|l|l|l|}
\hline \multicolumn{1}{|c|}{ (0) Incipiente } & \multicolumn{1}{|c|}{ (1) Inicial } & \multicolumn{1}{c|}{ (2) Em Formação } & \multicolumn{1}{c|}{ Estabelecido } \\
\hline $\begin{array}{l}\text { Ausência de padrões de } \\
\text { conduta próprios da } \\
\text { entidade. }\end{array}$ & $\begin{array}{l}\text { A entidade possui } \\
\text { padrões de conduta } \\
\text { próprios, com } \\
\text { disposições gerais, } \\
\text { aplicáveis a todos os } \\
\text { empregados. }\end{array}$ & $\begin{array}{l}\text { Padrões de conduta da } \\
\text { entidade incluem } \\
\text { disposições específicas } \\
\text { para gerentes, indivíduos } \\
\text { do corpo diretivo e } \\
\text { empregados de funções } \\
\text { relevantes para a } \\
\text { realização dos objetivos } \\
\text { da entidade. }\end{array}$ & $\begin{array}{l}\text { Padrões de conduta da } \\
\text { entidade incluem } \\
\text { disposições específicas } \\
\text { para terceiros } \\
\text { fornecedores de } \\
\text { produtos e serviços e } \\
\text { empregados terceirizados } \\
\text { que atuam em nome da } \\
\text { entidade), exigidas } \\
\text { contratualmente ou por } \\
\text { SLA. }\end{array}$ \\
\hline MAPA & Não & Não & Não \\
\hline Incra & Não & Não & Não \\
\hline Conab & \multicolumn{2}{c|}{ Parcial } & Não \\
\hline
\end{tabular}

Fonte: Dados da pesquisa.

Para a análise da maturidade nesta variável foram solicitados às entidades estudadas os seguintes documentos: Normas, regulamentos, padrões ou código de conduta.

O MAPA e o Incra não possuem código ou padrões de conduta próprios, aplicando as disposições do Código de Ética Profissional do Servidor Público Civil do Poder Executivo Federal (Decreto $\mathrm{n}^{\mathrm{o}}$ 1.171/1994), do Código de Conduta Ética dos Agentes Públicos em exercício na Presidência e Vice-Presidência da República (Decreto $n^{\circ}$ 4.081/2002) e das Resoluções da Comissão de Ética Pública. Tais normas são aplicáveis aos empregados de todas as entidades que integram a Administração Pública Federal brasileira. 
A Conab possui também um código de ética próprio, que define princípios e diretrizes aplicáveis à atuação da empresa e seus colaboradores e dispõe sobre as atribuições e competências do comitê de ética da empresa. Os regulamentos de pessoal (NOC 10.105 e 10.106) incluem disposições sobre os deveres e proibições dos empregados, a responsabilidade civil, penal e administrativa dos empregados, o procedimento de notificação em caso de indisciplina ou insubordinação e as sanções aplicáveis. Nesse sentido, entende-se que a Conab atende ao critério do nível de maturidade (1) Inicial.

Os regulamentos de pessoal da Conab definem deveres gerais para ocupantes de funções (comissionados). A Conab possui também uma norma de governança corporativa (NOC 10.111), que define que os conselheiros de administração e conselheiros fiscais devem agir exclusivamente no interesse da empresa, mantendo a objetividade e independência nos julgamentos, além de definir sua responsabilidade por danos resultantes de omissão no cumprimento de seus deveres e atos praticados com culpa ou dolo, ou com violação à Lei ou ao estatuto social da empresa.

Apesar disso, a NOC 10.111 não inclui declaração explicita de deveres e proibições específicos para os conselheiros. Não foram identificadas declarações de deveres e proibições específicos para empregados de funções relevantes para a realização dos objetivos da empresa. Assim, entende-se que a Conab atende parcialmente ao critério do nível de maturidade (2) Em Formação.

O COSO (2013b) recomenda que os padrões de conduta reflitam o diagnóstico e a orientação estratégica das entidades, para a diferenciação em relação aos códigos de conduta genéricos. Assim, a edição de padrões de conduta próprios tende a reforçar a percepção dos empregados quanto ao comprometimento da entidade com a conduta ética, ao incluir previsões específicas para as peculiaridades dos ambientes interno e externo, além dos objetivos e riscos da entidade. Apenas a Conab possui normas de conduta próprias, apesar de não estarem reunidas num código de conduta, o que pode dificultar a sua disseminação na organização. 


\subsubsection{Resultados da Variável 1.1.2 - Disseminação dos Padrões de Conduta, Ética e}

Valores

Quadro 14 - Resultados da Variável 1.1.2 - Disseminação dos Padrões de Conduta, Ética e Valores

\begin{tabular}{|c|l|l|l|}
\hline \multicolumn{1}{|c|}{ (0) Incipiente } & \multicolumn{1}{c|}{ (1) Inicial } & \multicolumn{1}{c|}{ (2) Em Formação } & \multicolumn{1}{c|}{ Estabelecido } \\
\hline $\begin{array}{l}\text { Ausência de ações de } \\
\text { disseminação dos } \\
\text { padrões de conduta e } \\
\text { temas ligados a ética e } \\
\text { valores na entidade. }\end{array}$ & $\begin{array}{l}\text { A entidade realiza ações } \\
\text { de disseminação dos } \\
\text { padrões de conduta e } \\
\text { temas ligados a ética e } \\
\text { valores. }\end{array}$ & $\begin{array}{l}\text { As ações de } \\
\text { disseminação dos } \\
\text { padrões de conduta da } \\
\text { entidade e temas ligados } \\
\text { a ética e valores são } \\
\text { programadas e incluem } \\
\text { treinamento presencial e } \\
\text { ações de sensibilização à } \\
\text { distância por múltiplos } \\
\text { canais de comunicação. }\end{array}$ & $\begin{array}{l}\text { disseminaça dos } \\
\text { padrões de conduta e } \\
\text { temas ligados a ética e } \\
\text { valores incluem a } \\
\text { sensibilização de } \\
\text { terceirizados e parceiros. }\end{array}$ \\
\hline MAPA & Sim & Sim & Não \\
\hline Incra & Não & Não & Não \\
\hline Conab & Não & Não \\
\hline
\end{tabular}

Fonte: Dados da pesquisa.

Para a análise da maturidade nesta variável foram solicitados às entidades estudadas os seguintes documentos: Normas e regulamentos referentes a programas de capacitação ou programas de desenvolvimento de competências dos servidores; Normas e regulamentos que contenham determinações a respeito da realização de treinamentos sobre os padrões de conduta; Planos de trabalho da Comissão de Ética; Relatórios de atividades da Comissão de Ética.

O Incra e a Conab não apresentaram evidências de cumprimento dos critérios da variável. No MAPA, o Plano de Trabalho da Comissão de Ética para 2015 incluiu a "Ação Educativa", com as seguintes metas: "Realizar palestras e videoconferências abrangendo o maior número de Superintendências e unidades operacionais", "Capacitar multiplicadores para a realização das palestras e videoconferências" e "Primar pela conduta ética"; incluiu também a "Produção de material de divulgação", tendo a meta de "Divulgação periódica de princípios éticos" e as ações "Utilização do Intercom, abertura de tela e outros espaços de comunicação do Mapa para divulgação de princípios éticos”, "Atualização da página da Ética no Portal do Mapa" e "Produção de cartilhas". Assim, entende-se que o MAPA atende ao critério do nível de maturidade (2) Em Formação.

A definição de uma estratégia de disseminação dos padrões de conduta é importante porque os empregados devem ter conhecimento das condutas consideradas aceitáveis segundo as expectativas da organização, bem como das condutas inaceitáveis e suas consequências (COSO, 2013). Além disso, a disseminação das referências de conduta, ética e valores contribui para a formação de uma consciência de controle na organização (JOHNSTONE et al., 2012). Apenas o MAPA demonstrou ter planejado ações de disseminação de padrões de conduta, ética 
e valores. Cabe destacar a importância de que a disseminação seja constante, abrangente e planejada, utilizando-se de múltiplos meio de comunicação, de modo a atingir a maior quantidade possível de empregados, reforçando a percepção de que a entidade tem compromisso com a ética e valores.

\subsubsection{Resultados da Variável 1.1.3 - Estrutura Organizacional para Avaliação da} Aderência aos Padrões de Conduta

Quadro 15 - Resultados da Variável 1.1.3 - Estrutura Organizacional para Avaliação da Aderência aos Padrões de Conduta

\begin{tabular}{|c|c|c|c|}
\hline (0) Incipiente & (1) Inicial & (2) Em Formação & (3) Estabelecido \\
\hline $\begin{array}{l}\text { Ausência de estrutura } \\
\text { organizacional para } \\
\text { avaliação da aderência } \\
\text { aos padrões de conduta } \\
\text { da entidade. }\end{array}$ & $\begin{array}{l}\text { A entidade instituiu } \\
\text { Comissão de Ética e } \\
\text { avalia a gestão da ética } \\
\text { conforme processo } \\
\text { coordenado pela } \\
\text { Comissão de Ética } \\
\text { Pública - CEP, nos } \\
\text { termos do Decreto no } \\
6.029 / 2007 .\end{array}$ & $\begin{array}{l}\text { A Comissão de Ética da } \\
\text { entidade realiza a } \\
\text { apuração dos desvios } \\
\text { conforme a Resolução } \\
\text { CEP no } 10 / 2008 \text { e dispõe } \\
\text { de canal de comunicação } \\
\text { para denúncias } \\
\text { anônimas. }\end{array}$ & $\begin{array}{l}\text { Política de entidade } \\
\text { determina a realização } \\
\text { periódica de auditoria de } \\
\text { ética, conduzida pela } \\
\text { auditoria interna ou } \\
\text { auditor independente. }\end{array}$ \\
\hline MAPA & Parcial & Sim & Não \\
\hline Incra & Parcial & Sim & Não \\
\hline Conab & Sim & Não & Não \\
\hline
\end{tabular}

Fonte: Dados da pesquisa.

Para a análise da maturidade nesta variável foram solicitados às entidades estudadas os seguintes documentos: Norma que institui a Comissão de Ética; Relatórios com os resultados dos processos de avaliação da gestão da ética; Planos de trabalho da Comissão de Ética; Regimento ou regulamento da Comissão de Ética; Relatórios de atividades da Comissão de Ética; Normas e regulamentos que contenham determinações a respeito de realização de auditorias de ética.

O MAPA possui Comissão de Ética formalmente instituída; apesar disso, não foram apresentadas evidências de que a Comissão de Ética já tenha conduzido um processo de avaliação da gestão da ética conforme processo coordenado pela CEP, nos termos do Decreto $\mathrm{n}^{\circ}$ 6.029/2007, atendendo parcialmente ao critério do nível de maturidade (1) Inicial. A Comissão de Ética do MAPA realizou o planejamento dos trabalhos para o ano de 2015; o Relatório de Atividades referente ao ano de 2014 informa que as denúncias são apuradas nos termos do Regimento Interno da Comissão, que prevê a possibilidade de realização de denúncia anônima (art. 18, parágrafo único) e rito processual em conformidade com a Resolução CEP n ${ }^{\circ}$ 10/2008 (Capítulo VI). Desse modo, considera-se que o MAPA atende ao critério do nível de maturidade (2) Em Formação. 
O Incra possui comissão de ética, tendo seu Regimento Interno estabelecido pela Portaria $n^{\circ}$ 586/2010; apesar disso, não foram apresentadas evidências de que a Comissão de Ética já tenha conduzido um processo de avaliação da gestão da ética conforme processo coordenado pela CEP, nos termos do Decreto $\mathrm{n}^{\circ}$ 6.029/2007, atendendo parcialmente ao critério do nível de maturidade (1) Inicial. O Regimento inclui normas gerais do procedimento e rito processual compatível com a Resolução CEP no 10/2008 (Capítulo VII), prevê a possibilidade de denúncia anônima (art. 20, parágrafo único) e define entre os princípios fundamentais do trabalho desenvolvido pela comissão a proteção à identidade do denunciante (art. 31, inciso II). Assim, considera-se que o Incra atende ao critério do nível de maturidade (2) Em Formação.

A Conab também possui comissão de ética, instituída em seu Regimento Interno (competências definidas no art. 14), com titulares e suplentes designados nos termos da Portaria $n^{\circ}$ 549, de 13/07/2015, e realizou em 2015 o processo de avaliação da gestão da ética conforme disposto no Decreto $n^{\circ}$ 6.029/2007, atendendo ao critério do nível de maturidade (1) Inicial. A Conab não apresentou evidências de atendimento aos critérios dos demais níveis de maturidade.

O IFAC (2001) recomenda a designação de um membro do corpo diretivo ou gerente sênior para investigar preocupações, relatadas confidencialmente, quanto aos padrões de conduta. É importante ainda “definir procedimentos claros para os empregados reportarem preocupações ou reclamações sobre má administração, violações da lei ou preocupações éticas, num ambiente em que serão apoiados e protegidos de represálias" ${ }^{, 76}$ (IFAC, 2001, p. 29). Nesse sentido, a existência de uma estrutura organizacional para a avaliação da gestão da ética também contribui para a percepção de que a entidade tem compromisso com ética e valores.

\footnotetext{
76 To ensure effective communication with stakeholders, public sector entities may: [...] set in place clear procedures for employees to voice concerns or complaints about maladministration, breaches of the law or ethical concerns, in an environment where they will be supported and protected from reprisals.
} 


\subsubsection{Análise Comparativa da Subdimensão 1.1 - Padrões de Conduta}

Quadro 16 - Análise Comparativa da Subdimensão 1.1 - Padrões de Conduta

\begin{tabular}{|l|l|l|l|}
\hline \multicolumn{1}{|c|}{ Variável } & \multicolumn{1}{|c|}{ MAPA } & \multicolumn{1}{c|}{ Incra } & \multicolumn{1}{c|}{ Conab } \\
\hline $\begin{array}{l}\text { 1.1.1. Destinatários } \\
\text { dos Padrões de } \\
\text { Conduta }\end{array}$ & $\begin{array}{l}\text { Não possui código ou padrões } \\
\text { de conduta próprios. }\end{array}$ & $\begin{array}{l}\text { Não possui código ou } \\
\text { padrões de conduta } \\
\text { próprios. }\end{array}$ & $\begin{array}{l}\text { Possui padrões de conduta } \\
\text { próprios, ainda não } \\
\text { reunidos num código. Há } \\
\text { disposições gerais para os } \\
\text { empregados e gerentes } \\
\text { (comissionados). }\end{array}$ \\
\hline $\begin{array}{l}\text { 1.1.2. Disseminação } \\
\text { dos Padrões de } \\
\text { Conduta, Ética e } \\
\text { Valores }\end{array}$ & $\begin{array}{l}\text { O plano de trabalho da } \\
\text { comissão de ética prevê ações } \\
\text { de disseminação programadas, } \\
\text { incluindo capacitação de } \\
\text { multiplicadores, produção de } \\
\text { cartilhas e divulgação em } \\
\text { múltiplos espaços de } \\
\text { comunicação. }\end{array}$ & $\begin{array}{l}\text { Não apresentou } \\
\text { evidências de } \\
\text { disseminação dos } \\
\text { padrões de conduta e } \\
\text { temas ligados a ética e } \\
\text { valores. }\end{array}$ & $\begin{array}{l}\text { Nâno disseminação dos } \\
\text { padrões de conduta e } \\
\text { temas ligados a ética e } \\
\text { valores. }\end{array}$ \\
\hline $\begin{array}{l}\text { 1.1.3. Estrutura } \\
\text { Organizacional para } \\
\text { Avaliação da } \\
\text { Aderência aos } \\
\text { Padrões de Conduta }\end{array}$ & $\begin{array}{l}\text { Comissão de ética instituída, } \\
\text { sem avaliação da gestão da } \\
\text { ética, apurando desvios e } \\
\text { dispondo de canal para } \\
\text { denúncias anônimas. }\end{array}$ & $\begin{array}{l}\text { Comissão de ética } \\
\text { instituída, sem } \\
\text { avaliação da gestão da } \\
\text { ética, apurando } \\
\text { desvios e dispondo de } \\
\text { canal para denúncias } \\
\text { anônimas. }\end{array}$ & $\begin{array}{l}\text { Comissão de ética } \\
\text { instituída, com avaliação } \\
\text { da gestão da ética. }\end{array}$ \\
\hline
\end{tabular}

Fonte: Dados da pesquisa.

Apenas a Conab possui padrões de conduta próprios. Apenas o MAPA programou ações de disseminação de padrões de conduta, ética e valores. As três entidades instituíram comitê de ética, mas apenas a Conab evidenciou ter avaliado a gestão da ética nos termos definidos pela Comissão de Ética Pública.

O quadro a seguir apresenta os riscos identificados com embasamento nas características da subdimensão, diagnosticadas pela aplicação do modelo de maturidade desenvolvido neste trabalho, e as respectivas recomendações para o aprimoramento das estruturas de controle interno das entidades estudadas.

Quadro 17 - Riscos e Recomendações da Subdimensão 1.1 - Padrões de Conduta

\begin{tabular}{|l|l|}
\hline \multicolumn{1}{|c|}{ Riscos } & \multicolumn{1}{c|}{ Recomendações } \\
\hline $\begin{array}{l}\text { (MAPA, Incra, Conab) A conduta dos empregados } \\
\text { contrarie expectativas de ética e valores das partes } \\
\text { interessadas. }\end{array}$ & $\begin{array}{l}\text { (MAPA, Incra) Desenvolver um código de conduta } \\
\text { próprio. } \\
\text { (Conab) Aperfeiçoar o código de conduta, reunindo } \\
\text { (MAPA, Incra, Conab) A conduta de empregados e } \\
\text { as disposições dos padrões de ética e valores num } \\
\text { único documento. }\end{array}$ \\
$\begin{array}{l}\text { inerente e atividades relevantes para a realização dos } \\
\text { objetivos da entidade contrarie requisitos ética e } \\
\text { valores peculiares à natureza de suas atividades. }\end{array}$ & $\begin{array}{l}\text { (MAPA, Incra, Conab) Incluir no código de conduta } \\
\text { da entidade disposições específicas para empregados } \\
\text { e gerentes que desempenham atividades com alto } \\
\text { (MAPA, Incra, Conab) A conduta de terceirizados } \\
\text { que prestam serviços para a entidade ou atuam em } \\
\text { nome da entidade contrarie as expectativas de ética e e de pessoal, gestão de } \\
\text { alores das pantratos) e atividades relevantes para a } \\
\text { realização dos objetivos da entidade, exigíveis de } \\
\text { terceiros que prestam serviços relevantes ou atuam } \\
\text { em nome da entidade por contrato ou SLA. }\end{array}$ \\
\hline
\end{tabular}

Continua na página seguinte. 
Continuação do Quadro 17 - Riscos e Recomendações da Subdimensão 1.1 - Padrões de Conduta

\begin{tabular}{|c|c|}
\hline Riscos & Recomendações \\
\hline $\begin{array}{l}\text { (MAPA, Incra, Conab) Os empregados e } \\
\text { terceirizados da entidade não incorporem as } \\
\text { expectativas de ética e valores das partes interessadas } \\
\text { à cultura organizacional. }\end{array}$ & $\begin{array}{l}\text { (Incra, Conab) Elaborar e implantar um programa de } \\
\text { disseminação dos padrões de conduta, ética e valores, } \\
\text { utilizando múltiplos canais de comunicação, } \\
\text { inclusive treinamento. } \\
\text { (MAPA, Incra, Conab) Incluir no programa de } \\
\text { disseminação dos padrões de conduta, ética e valores } \\
\text { da entidade ações para sensibilizar a todos os } \\
\text { empregados e terceiros relacionados. }\end{array}$ \\
\hline $\begin{array}{l}\text { (Conab) As violações aos padrões ou código de ética } \\
\text { na entidade não sejam adequadamente investigadas e } \\
\text { sancionadas. } \\
\text { (Conab) Os empregados não tenham confiança de } \\
\text { que a estrutura organizacional estabelecida para a } \\
\text { avaliação da aderência aos padrões de conduta na } \\
\text { entidade irá apoiar denunciantes e protegê-los de } \\
\text { represálias. } \\
\text { (MAPA, Incra, Conab) Descumprimento de } \\
\text { requisitos legais e regulamentares a respeito da } \\
\text { gestão da ética na entidade. }\end{array}$ & $\begin{array}{l}\text { (Conab) Estabelecer formalmente os procedimentos } \\
\text { de apuração de violações aos padrões de ética da } \\
\text { entidade, regulamentando e definindo os canais de } \\
\text { comunicação para apresentação de denúncias } \\
\text { anônimas. } \\
\text { (MAPA, Incra, Conab) Estabelecer políticas e } \\
\text { processos para a avaliação periódica da gestão da } \\
\text { ética (Decreto n } \text { n }^{\circ} \text { 6.029/2007), o planejamento e } \\
\text { acompanhamento de ações de melhoria da gestão da } \\
\text { ética. } \\
\text { (MAPA, Incra, Conab) Estabelecer políticas e } \\
\text { processos para realização periódica de auditorias de } \\
\text { ética pela auditoria interna ou auditor externo ou } \\
\text { independente. }\end{array}$ \\
\hline
\end{tabular}

Fonte: Elaborado pelo autor.

\subsubsection{Resultados da Subdimensão 1.2 - Independência e Competência do Corpo Diretivo}

\subsubsection{Resultados da Variável 1.2.1 - Políticas de Due Diligence para o Corpo Diretivo}

Quadro 18 - Resultados da Variável 1.2.1 - Políticas de Due Diligence para o Corpo Diretivo

\begin{tabular}{|l|l|l|l|}
\hline \multicolumn{1}{|c|}{ (0) Incipiente } & \multicolumn{1}{|c|}{ (1) Inicial } & \multicolumn{1}{c|}{ (2) Em Formação } \\
$\begin{array}{l}\text { Ausência de políticas de } \\
\text { due diligence para os } \\
\text { indivíduos do corpo } \\
\text { diretivo da entidade. }\end{array}$ & $\begin{array}{l}\text { Políticas da entidade } \\
\text { estabelecem a realização } \\
\text { de procedimentos de due } \\
\text { diligence como parte do } \\
\text { processo de seleção dos } \\
\text { candidatos ao corpo } \\
\text { diretivo. }\end{array}$ & $\begin{array}{l}\text { Políticas da entidade } \\
\text { estabelecem a realização } \\
\text { periódica de } \\
\text { procedimentos de due } \\
\text { diligence para a } \\
\text { confirmação da } \\
\text { competência e } \\
\text { independência dos } \\
\text { membros do corpo } \\
\text { diretivo. }\end{array}$ & $\begin{array}{l}\text { Políticas da entidade } \\
\text { estabelecem que os } \\
\text { procedimentos de due } \\
\text { diligence sejam } \\
\text { supervisionados por um } \\
\text { comitê de nominação } \\
\text { independente ou firma de } \\
\text { contratação e os } \\
\text { resultados devem ser } \\
\text { divulgados. }\end{array}$ \\
\hline MAPA & Não & Não & Não \\
\hline Incra & Não & Não & Não \\
\hline Conab & Não & Não \\
\hline
\end{tabular}

Fonte: Dados da pesquisa.

Para a análise da maturidade nesta variável foram solicitados às entidades estudadas os seguintes documentos: Normas e regulamentos referentes à realização de procedimentos de averiguação da independência e competência (due diligence) de indivíduos do corpo diretivo. 
Nenhuma das entidades analisadas apresentou evidências de cumprimento dos critérios da variável.

A independência dos membros do corpo diretivo é importante para a manutenção da objetividade nas avaliações e julgamentos que fazem parte das atividades de supervisão das ações da gerência para a realização dos objetivos da organização. Nesse sentido, o IFAC (2001) recomenda que as entidades do setor público estabeleçam mecanismos adequados para garantir que os membros do corpo diretivo e os empregados não sejam influenciados por preconceito, viés ou conflito de interesse. Esses mecanismos podem incluir a exigência de uma divulgação completa dos interesses, incluindo atividades profissionais e privadas, atividades políticas e negócios.

Cabe observar que o setor governamental comporta organizações com variadas estruturas de governança; muitas dessas organizações não possuem um órgão com as funções de supervisão de um corpo diretivo. Das entidades estudadas, apenas a Conab possui um corpo diretivo, contudo não apresentou evidências da existência de políticas de due diligence e requisitos de competências para os membros do seu conselho de administração.

\subsubsection{Resultados da Variável 1.2.2 - Requisitos de Competências do Corpo Diretivo}

Quadro 19 - Resultados da Variável 1.2.2 - Requisitos de Competências do Corpo Diretivo

\begin{tabular}{|c|c|c|c|}
\hline (0) Incipiente & (1) Inicial & (2) Em Formação & (3) Estabelecido \\
\hline $\begin{array}{l}\text { Ausência de definição de } \\
\text { requisitos de } \\
\text { competências para os } \\
\text { integrantes do corpo } \\
\text { diretivo da entidade. }\end{array}$ & $\begin{array}{l}\text { Definição de requisitos } \\
\text { gerais de competências, } \\
\text { exigidos de todos os } \\
\text { integrantes do corpo } \\
\text { diretivo. }\end{array}$ & $\begin{array}{l}\text { Exigência de indivíduos } \\
\text { com conhecimentos } \\
\text { especializados no corpo } \\
\text { diretivo da entidade, de } \\
\text { acordo com as } \\
\text { necessidades de } \\
\text { supervisão. }\end{array}$ & $\begin{array}{l}\text { Exigência de que os } \\
\text { integrantes do corpo } \\
\text { diretivo cumpram um } \\
\text { programa de capacitação } \\
\text { para manutenção dos } \\
\text { conhecimentos } \\
\text { adequados para as } \\
\text { responsabilidades de } \\
\text { supervisão. }\end{array}$ \\
\hline МАРА & Não & Não & Não \\
\hline Incra & Não & Não & Não \\
\hline Conab & Não & Não & Não \\
\hline
\end{tabular}

Fonte: Dados da pesquisa.

Para a análise da maturidade nesta variável foram solicitados às entidades estudadas os seguintes documentos: Descrições de cargos do corpo diretivo; Normas e regulamentos referentes a requisitos ou expectativas de competências dos indivíduos do corpo diretivo.

Nenhuma das entidades analisadas apresentou evidências de cumprimento dos critérios da variável.

A competência dos membros do corpo diretivo é necessária para o questionamento das ações da gerência para a realização dos objetivos da organização (COSO, 2013). Jensen 
(1993) destaca ainda a importância de ter indivíduos com conhecimentos especializados no corpo diretivo da entidade, adequados às necessidades da supervisão. O treinamento de indução e de sensibilização contínua podem contribuir o desenvolvimento e manutenção das competências dos membros do corpo diretivo (IFAC, 2001). Desse modo, é relevante o estabelecimento de políticas no sentido de prover o corpo diretivo das entidades governamentais de membros com as competências adequadas para o cumprimento de suas responsabilidades de supervisão.

\subsubsection{Analise Comparativa da Subdimensão 1.2 - Independência e Competência do}

\section{Corpo Diretivo}

Quadro 20 - Analise Comparativa da Subdimensão 1.2 - Independência e Competência do Corpo Diretivo

\begin{tabular}{|l|l|l|l|}
\hline \multicolumn{1}{|c|}{ Variável } & \multicolumn{1}{|c|}{ MAPA } & \multicolumn{1}{c|}{ Incra } & \multicolumn{1}{c|}{ Conab } \\
$\begin{array}{l}\text { 1.2.1. Políticas de } \\
\text { Due Diligence para } \\
\text { o Corpo Diretivo }\end{array}$ & $\begin{array}{l}\text { Não apresentou evidências } \\
\text { de políticas de due } \\
\text { diligence para os } \\
\text { indivíduos do corpo } \\
\text { diretivo. }\end{array}$ & $\begin{array}{l}\text { Não apresentou evidências } \\
\text { de políticas de due } \\
\text { diligence para os } \\
\text { indivíduos do corpo } \\
\text { diretivo. }\end{array}$ & $\begin{array}{l}\text { Não apresentou evidências } \\
\text { de políticas de due } \\
\text { diligence para os } \\
\text { indivíduos do corpo } \\
\text { diretivo. }\end{array}$ \\
\hline $\begin{array}{l}\text { 1.2.2. Requisitos de } \\
\text { Competência do } \\
\text { Corpo Diretivo }\end{array}$ & $\begin{array}{l}\text { Não apresentou evidências } \\
\text { de requisitos de } \\
\text { competências para os } \\
\text { integrantes do corpo } \\
\text { diretivo. }\end{array}$ & $\begin{array}{l}\text { Nãosentou evidências } \\
\text { de requisitos de } \\
\text { competências para os } \\
\text { integrantes do corpo } \\
\text { diretivo. }\end{array}$ & $\begin{array}{l}\text { Não apresentou evidências } \\
\text { de requisitos de } \\
\text { competências para os } \\
\text { integrantes do corpo } \\
\text { diretivo. }\end{array}$ \\
\hline
\end{tabular}

Fonte: Dados da pesquisa.

Quanto à independência e competência do corpo diretivo, nenhuma das entidades possui procedimentos de due diligence ou define requisitos de competências para os membros do corpo diretivo. Cabe destacar que apenas a Conab possui um conselho de administração, presidido pelo Secretário-Executivo do MAPA e integrado pelo Presidente da Conab, até três representantes indicados pelo MAPA e um representante indicado pelo Ministério do Planejamento, Orçamento e Gestão. No Incra, esse papel é cumprido pelo seu Conselho Diretor, composto pelo Presidente, pelos Diretores, pelo Diretor de Programa, pelo Chefe de Gabinete e por um representante do Ministério do Desenvolvimento Agrário. No MAPA, esse papel é cumprido pelo Ministro de Estado, cargo de natureza política.

O quadro a seguir apresenta os riscos identificados com embasamento nas características da subdimensão, diagnosticadas pela aplicação do modelo de maturidade desenvolvido neste trabalho, e as respectivas recomendações para o aprimoramento das estruturas de controle interno das entidades estudadas. 
Quadro 21 - Riscos e Recomendações da Subdimensão 1.2 - Independência e Competência do Corpo Diretivo

\begin{tabular}{|l|l|}
\hline \multicolumn{1}{|c|}{ Riscos } & \multicolumn{1}{c|}{ Recomendações } \\
\hline $\begin{array}{l}\text { (MAPA, Incra, Conab) Designação de indivíduos que } \\
\text { não tenham a independência necessária ao } \\
\text { cumprimento de suas responsabilidades de controle } \\
\text { interno para o corpo diretivo da entidade. }\end{array}$ & $\begin{array}{l}\text { (MAPA, Incra, Conab) Estabelecer políticas, } \\
\text { processos e procedimentos para o due diligence dos } \\
\text { indivíduos do corpo diretivo da entidade, incluindo a } \\
\text { repetição periódica dos procedimentos para } \\
\text { confirmação da independência, a supervisão dos } \\
\text { procedimentos por partes independentes e a } \\
\text { divulgação dos resultados do due diligence. }\end{array}$ \\
$\begin{array}{l}\text { que tenham perdido a independência necessária ao } \\
\text { cumprimento de suas responsabilidades de controle } \\
\text { interno no corpo diretivo da entidade. }\end{array}$ & $\begin{array}{l}\text { (MAPA, Incra, Conab) Designação de indivíduos } \\
\text { para o corpo diretivo da entidade que não possuam } \\
\text { competências adequadas para a realização das } \\
\text { atribuições e o cumprimento das responsabilidades de } \\
\text { controle interno. }\end{array}$ \\
$\begin{array}{l}\text { (MAPA, Incra, Conab) Desenvolver os requisitos de } \\
\text { competências para o corpo diretivo da entidade, } \\
\text { incluindo competências gerais, esperadas de todos os } \\
\text { integrantes, e competências especializadas, conforme } \\
\text { as responsabilidades de supervisão. } \\
\text { (MAPA, Incra, Conab) Estabelecer políticas que } \\
\text { exijam quantidade mínima de indivíduos com } \\
\text { competências especializadas no corpo diretivo da } \\
\text { entidade e o cumprimento de um programa de } \\
\text { capacitação para manutenção de competências } \\
\text { adequadas às responsabilidades de supervisão. }\end{array}$ \\
\hline
\end{tabular}

Fonte: Elaborado pelo autor.

\subsubsection{Resultados da Subdimensão 1.3 - Responsabilidades de Controle Interno e}

\section{Requisitos de Competências}

\subsubsection{Resultados da Variável 1.3.1 - Responsabilidades de Controle Interno na Organização}

Quadro 22 - Resultados da Variável 1.3.1 - Responsabilidades de Controle Interno na Organização

\begin{tabular}{|c|l|l|l|}
\hline \multicolumn{1}{|c|}{ (0) Incipiente } & \multicolumn{1}{|c|}{ (1) Inicial } & \multicolumn{1}{c|}{ (2) Em Formação } & \multicolumn{1}{c|}{ Estabelecido } \\
\hline $\begin{array}{l}\text { Ausência de definição } \\
\text { das autoridades e } \\
\text { responsabilidades de } \\
\begin{array}{l}\text { controle interno na } \\
\text { entidade. }\end{array}\end{array}$ & $\begin{array}{l}\text { Definição das } \\
\text { autoridades e } \\
\text { responsabilidades de } \\
\text { controle interno para a } \\
\text { alta gerência e a } \\
\text { auditoria interna da } \\
\text { entidade. }\end{array}$ & $\begin{array}{l}\text { Definiço das } \\
\text { autoridades e } \\
\text { responsabilidades de } \\
\text { controle interno para os } \\
\text { gerentes das divisões, } \\
\text { unidades operacionais e } \\
\text { funções de suporte } \\
\text { relevantes para a } \\
\text { realização dos objetivos } \\
\text { da entidade. }\end{array}$ & $\begin{array}{l}\text { autoridades e } \\
\text { responsabilidades de } \\
\text { controle interno para os } \\
\text { empregados das divisões, } \\
\text { unidades operacionais e } \\
\text { funções de suporte, e } \\
\text { prestadores de serviços } \\
\text { terceirizados relevantes } \\
\text { para a realização dos } \\
\text { objetivos da entidade. }\end{array}$ \\
\hline MAPA & \multicolumn{1}{|c|}{ Sim } & Não \\
\hline Incra & Sim & Sim & Não \\
\hline Conab & Sim & & Sim \\
\hline
\end{tabular}

Fonte: Dados da pesquisa.

Para a análise da maturidade nesta variável foram solicitados às entidades estudadas os seguintes documentos: Descrições de cargos dos servidores; Normas e regulamentos referentes a responsabilidades de controle interno para os servidores. 
Os órgãos que integram a estrutura organizacional do MAPA possuem seus próprios Regimentos Internos, que definem autoridades e responsabilidades de controle para todos os níveis organizacionais, incluindo a alta gerência (Secretários), a gerência (Departamentos, Coordenações-Gerais, Divisões, Serviços e outros) e funções de suporte relevantes (Coordenações-Gerais de Contabilidade, Planejamento, Orçamento e Finanças, Recursos Humanos, Logística e Serviços Gerais, Tecnologia da Informação e outras). O MAPA não possui Auditoria Interna. Assim, entende-se que o MAPA atende aos critérios dos níveis de maturidade (1) Inicial e (2) Em Formação.

O Incra possui Regimento Interno definindo autoridades e responsabilidades de controle para todos os níveis organizacionais, incluindo a alta gerência (Presidente e Diretores), a Auditoria Interna, a gerência (Coordenações-Gerais e Divisões) e funções de suporte relevantes (Coordenações-Gerais de Pessoas, Administração e Serviços Gerais, Orçamento e Finanças, Contabilidade, Tecnologia e Gestão da Informação e outras). Nesse sentido, entendese que o Incra atende aos critérios dos níveis de maturidade (1) Inicial e (2) Em Formação.

Quanto à Conab, o Regimento Interno (NOC 10.104) define autoridades e responsabilidades de controle para todos os níveis organizacionais, incluindo a alta gerência (Presidência, Diretorias e Superintendências), a Auditoria Interna, a gerência (Gerências) e funções de suporte relevantes (Superintendências de Fiscalização de Estoques, Orçamento e Finanças, Contabilidade, Administração, Gestão da TI, Informações do Agronegócio e outras); além disso, o Plano de Cargos, Carreiras e Salários de 2009 define espaços ocupacionais ${ }^{77}$, incluindo a descrição das principais atribuições, requisitos de formação e capacitação para os ocupantes, além das competências exigidas de cada espaço. Desse modo, entende-se que a Conab atende integralmente aos critérios dos níveis de maturidade (1) Inicial, (2) Em Formação e (3) Estabelecido.

Para que uma estrutura de controle interno funcione adequadamente, os empregados devem ter conhecimento de suas responsabilidades (COSO, 2013). Nesse sentido, quanto mais

77 O Glossário de Terminologias do PCCS Conab 2009 define espaço ocupacional como um conjunto de atribuições típicas para um cargo num determinado processo. Para atuar neste espaço ocupacional o profissional precisa desenvolver competências específicas, ou seja, competências técnicas definidas para a Conab. Exemplos: Analista Administrativo; Analista de Comunicação Social; Analista de Contabilidade; Analista de Documentação e Informação; Analista de Mercado; Analista de Operações; Analista de Planejamento; Analista de Recursos Humanos; Analista de Tecnologia da Informação; Analista Financeiro; Analista Organizacional; Arquiteto; Assistente Social; Auditor Interno; Corregedor; Enfermeiro; Engenheiro; Engenheiro Agrônomo / Agrícola; Engenheiro de Segurança do Trabalho; Médico do Trabalho; Médico Veterinário; Nutricionista; Odontólogo; Psicólogo; Procurador. 
claras e completas forem as atribuições de responsabilidades, maior a tendência de que os empregados atuem conforme as expectativas e contribuam para a realização dos objetivos da organização.

\subsubsection{Resultados da Variável 1.3.2 - Requisitos de Competências na Organização}

Quadro 23 - Resultados da Variável 1.3.2 - Requisitos de Competências na Organização

\begin{tabular}{|c|l|l|l|}
\hline \multicolumn{1}{|c|}{ (0) Incipiente } & \multicolumn{1}{|c|}{ (1) Inicial } & \multicolumn{1}{c|}{ (2) Em Formação } \\
\hline $\begin{array}{l}\text { Ausência de definição } \\
\text { dos requisitos de } \\
\begin{array}{l}\text { competências na } \\
\text { entidade. }\end{array}\end{array}$ & $\begin{array}{l}\text { Definição de requisitos } \\
\text { gerais de competências, } \\
\text { exigíveis de todos os } \\
\text { empregados da entidade } \\
\text { e prestadores de serviços } \\
\text { terceirizados. }\end{array}$ & $\begin{array}{l}\text { Definição de requisitos } \\
\text { de competências } \\
\text { específicos para } \\
\text { empregados e gerentes } \\
\text { das divisões, unidades } \\
\text { operacionais e funções } \\
\text { de suporte relevantes } \\
\text { para a realização dos } \\
\text { objetivos da entidade, } \\
\text { inclusive a auditoria } \\
\text { interna. }\end{array}$ & $\begin{array}{l}\text { Definição de requisitos } \\
\text { de competências } \\
\text { específicos para a alta } \\
\text { gerência da entidade. }\end{array}$ \\
\hline MAPA & Não & Não & \\
\hline Incra & Não & Não & Não \\
\hline Conab & Sim & Nimo \\
\hline
\end{tabular}

Fonte: Dados da pesquisa.

Para a análise da maturidade nesta variável foram solicitados às entidades estudadas os seguintes documentos: Descrições de cargos dos servidores; Normas e regulamentos referentes a requisitos ou expectativas de competências para os servidores.

O MAPA e o Incra não apresentaram evidências de cumprimento dos critérios da variável. Na Conab, o modelo de competências estabelecido no Plano de Cargos, Carreiras e Salários de 2009 inclui: competências estratégicas, que influenciam no desempenho do negócio, tendo vínculo direto com a Estratégia da Conab; competências técnicas, focadas nos aspectos técnicos dos processos de trabalho e vinculadas aos espaços ocupacionais preenchidos pelos empregados $^{78}$; e competências de liderança, relacionadas com o papel esperado do líder na implementação da estratégia. As competências estratégicas e técnicas são exigíveis de todos os empregados da organização; as competências de liderança são aplicáveis aos empregados que ocupam função de chefia, em todos os níveis organizacionais. Desse modo, entende-se que a Conab atende integralmente os critérios de todos os níveis de maturidade.

\footnotetext{
${ }^{78}$ As competências técnicas definidas no âmbito do Plano de Cargos, Carreiras e Salários da Conab classificamse em: Gerais; Apoio/Suporte Administrativo; Informações e Operações; Recursos Humanos; Administrativas; Licitações; Tecnologia da Informação; Planejamento e Avaliação; Políticas Públicas; Jurídicas; Financeiras Contábeis; Assessoria; Auditoria Interna; Comunicação.
} 
A falta de competência dos empregados para cumprir com suas atribuições é apontada por Johnstone et al. (2012) como uma das deficiências mais comuns no ambiente de controle das organizações. Para que os postos de trabalho possam ser providos de indivíduos com as competências adequadas, é necessário que os requisitos de competências sejam definidos de forma clara e abrangente. Isso aumenta a tendência de que a estrutura de controle interno funcione conforme o esperado, contribuindo para a realização dos objetivos da organização.

\subsubsection{Análise Comparativa da Subdimensão 1.3 - Responsabilidades de Controle}

\section{Interno e Requisitos de Competências}

Quadro 24 - Análise Comparativa da Subdimensão 1.3 - Responsabilidades de Controle Interno e Requisitos de Competências

\begin{tabular}{|c|c|c|c|}
\hline Variável & МАРА & Incra & Conab \\
\hline $\begin{array}{l}\text { 1.3.1. } \\
\text { Responsabilidades } \\
\text { de Controle Interno } \\
\text { na Organização }\end{array}$ & $\begin{array}{l}\text { Regimentos Internos } \\
\text { do MAPA definem as } \\
\text { atribuições da alta } \\
\text { gerência e da gerência, } \\
\text { inclusive de } \\
\text { departamentos que } \\
\text { desempenham funções } \\
\text { de suporte relevantes } \\
\text { para a realização de } \\
\text { seus objetivos. }\end{array}$ & $\begin{array}{l}\text { Regimento Interno do } \\
\text { Incra define as } \\
\text { atribuições da alta } \\
\text { gerência, da auditoria } \\
\text { interna e da gerência, } \\
\text { inclusive de } \\
\text { departamentos que } \\
\text { desempenham funções } \\
\text { de suporte relevantes } \\
\text { para a realização de } \\
\text { seus objetivos. }\end{array}$ & $\begin{array}{l}\text { Regimento Interno da Conab } \\
\text { define as atribuições da alta } \\
\text { gerência, da auditoria interna e } \\
\text { da gerência, inclusive de } \\
\text { departamentos que } \\
\text { desempenham funções de } \\
\text { suporte relevantes para a } \\
\text { realização de seus objetivos; } \\
\text { Plano de Cargos e Salários da } \\
\text { Conab define as atribuições dos } \\
\text { empregados, conforme a sua } \\
\text { especialidade. }\end{array}$ \\
\hline $\begin{array}{l}\text { 1.3.2. Requisitos de } \\
\text { Competências na } \\
\text { Organização }\end{array}$ & $\begin{array}{l}\text { Não apresentou } \\
\text { evidências de } \\
\text { requisitos de } \\
\text { competências para os } \\
\text { empregados. }\end{array}$ & $\begin{array}{l}\text { Não apresentou } \\
\text { evidências requisitos de } \\
\text { competências para os } \\
\text { empregados. }\end{array}$ & $\begin{array}{l}\text { Plano de Cargos e Salários da } \\
\text { Conab estabelece modelo que } \\
\text { inclui competências estratégicas, } \\
\text { competências técnicas (inclusive } \\
\text { de funções de suporte relevantes } \\
\text { para a realização de seus } \\
\text { objetivos) e competências de } \\
\text { liderança. Competências } \\
\text { estratégicas e técnicas são } \\
\text { exigíveis de todos os } \\
\text { empregados; competências de } \\
\text { liderança são exigíveis dos } \\
\text { ocupantes de cargos } \\
\text { comissionados. }\end{array}$ \\
\hline
\end{tabular}

Fonte: Dados da pesquisa.

Todas as entidades possuem Regimento Interno, definindo as atribuições e responsabilidades de controle até o nível de departamento. Apenas a Conab definiu as responsabilidades de controle e os requisitos de competências de seus empregados.

O quadro a seguir apresenta os riscos identificados com embasamento nas características da subdimensão, diagnosticadas pela aplicação do modelo de maturidade 
desenvolvido neste trabalho, e as respectivas recomendações para o aprimoramento das estruturas de controle interno das entidades estudadas.

Quadro 25 - Riscos e Recomendações da Subdimensão 1.3 - Responsabilidades de Controle Interno e Requisitos de Competências

\begin{tabular}{|l|l|}
\hline \multicolumn{1}{|c|}{ Riscos } & \multicolumn{1}{|c|}{ Recomendações } \\
\hline $\begin{array}{l}\text { (MAPA, Incra) A atuação dos empregados e } \\
\text { terceirizados que desempenham atividades relevantes } \\
\text { para a realização dos objetivos da entidade não } \\
\text { suporte o funcionamento da estrutura de controle } \\
\text { interno. }\end{array}$ & $\begin{array}{l}\text { (MAPA, Incra) Definir as autoridades e } \\
\text { responsabilidades de controle interno dos } \\
\text { empregados e terceiros relacionados que } \\
\text { desempenhem atividades relevantes para a realização } \\
\text { dos objetivos da entidade. }\end{array}$ \\
\hline $\begin{array}{l}\text { (MAPA, Incra) Os empregados da entidade não } \\
\text { possam desenvolver competências adequadas para a } \\
\text { realização de suas atribuições e o cumprimento de } \\
\text { suas responsabilidades de controle interno. }\end{array}$ & $\begin{array}{l}\text { (MAPA, Incra) Desenvolver os requisitos de } \\
\text { competências da entidade, incluindo requisitos gerais } \\
\text { para todos os empregados e terceiros relacionados, } \\
\text { requisitos específicos para empregados e gerentes } \\
\text { que desempenham atividades relevantes para a } \\
\text { (MAPA, Incra) Os empregados e gerentes que } \\
\text { desempenham atividades relevantes para a realização dos objetivos da entidade, e requisitos } \\
\text { dos objetivos da entidade não possam desenvolver } \\
\text { competências adequadas às peculiaridades de suas } \\
\text { atribuições e responsabilidades de controle interno. }\end{array}$ \\
$\begin{array}{l}\text { (MAPA, Incra) Designação de indivíduos para a alta gerência. } \\
\text { gerência da entidade que não possuam competências } \\
\text { adequadas para a realização de suas atribuições e o } \\
\text { cumprimento de suas responsabilidades de controle } \\
\text { interno. }\end{array}$ & \\
\hline
\end{tabular}

Fonte: Elaborado pelo autor.

\subsubsection{Resultados da Subdimensão 1.4 - Atração, Desenvolvimento e Retenção de}

\section{Indivíduos}

\subsubsection{Resultados da Variável 1.4.1 - Programa de Desenvolvimento de}

\section{Competências}

Quadro 26 - Resultados da Variável 1.4.1 - Programa de Desenvolvimento de Competências

\begin{tabular}{|c|c|l|l|}
\hline \multicolumn{1}{|c|}{ (0) Incipiente } & \multicolumn{1}{c|}{ (1) Inicial } & \multicolumn{1}{c|}{ (2) Em Formação } & \multicolumn{1}{c|}{ (3) Estabelecido } \\
\hline $\begin{array}{l}\text { Ausência de programa de } \\
\text { cesenvolvimento de } \\
\text { empretências para os } \\
\text { A entidade possui um } \\
\text { programa de } \\
\text { desenvolvimento de } \\
\text { competências. }\end{array}$ & $\begin{array}{l}\text { O programa de } \\
\text { desenvolvimento de } \\
\text { competências abrange as } \\
\text { funções e atividades } \\
\text { relevantes para a } \\
\text { realização dos objetivos } \\
\text { da entidade. }\end{array}$ & $\begin{array}{l}\text { O programa de } \\
\text { desenvolvimento de } \\
\text { competências da } \\
\text { entidade inclui múltiplas } \\
\text { técnicas de entrega } \\
\text { (ações instrucionais em } \\
\text { sala de aula, autoestudo e } \\
\text { treinamento no trabalho). }\end{array}$ \\
\hline MAPA & Sim & Sim & Sim \\
\hline Incra & Sim & Sim & Sim \\
\hline Conab & Sim & Sim & \\
\hline
\end{tabular}

Fonte: Dados da pesquisa.

Para a análise da maturidade nesta variável foram solicitados às entidades estudadas os seguintes documentos: Normas e regulamentos referentes a programas de capacitação ou programas de desenvolvimento de competências dos servidores. 
No MAPA, a Portaria $n^{\circ}$ 482/2012 dispõe sobre ações de educação continuada na entidade, definindo que as ações devem ter como diretrizes a vinculação com os objetivos e estratégias institucionais e o desenvolvimento de competências críticas para a organização (art. $5^{\circ}$, incisos I e XI). Os eventos de capacitação podem ser presenciais ou à distância, incluída a aprendizagem em serviço (art. $6^{\circ}$, inciso V). No Incra, a Instrução Normativa $n^{\circ}$ 78/2014 regulamenta a participação dos servidores da entidade em eventos de capacitação, com o objetivo de assegurar a formação e o aperfeiçoamento das competências necessárias ao desenvolvimento das atividades institucionais do Incra (art. $2^{\circ}$ ), definindo ainda que as ações de capacitação deverão observar o desenvolvimento das competências institucionais conforme as prioridades definidas pelo Comitê Gestor de Capacitação e o custo-benefício da ação de capacitação (art. $5^{\circ}$, incisos II e III) e que as atividades de capacitação podem ocorrer nas modalidades presencial, semipresencial e à distância (art. $7^{\circ}$, inciso III), incluído o treinamento em serviço (art. $3^{\circ}$, inciso IV).

Na Conab, a Norma de Treinamento, Desenvolvimento e Educação de Recursos Humanos (NOC 60.103) define que as ações de capacitação devem ser definidas pela Companhia para o atendimento da missão, objetivos e metas estabelecidas pelo Planejamento Estratégico, e estruturadas em programas delineados em função das características das ações de treinamento e da natureza das atividades da Companhia, incluindo ações de capacitação podem ser internas, externas, à distância e particulares.

Desse modo, entende-se que MAPA, Incra e Conab atendem aos critérios dos níveis de maturidade (1) Inicial, (2) Em Formação e (3) Estabelecido.

A manutenção de um corpo funcional qualificado é importante para a realização dos objetivos de uma organização (COSO, 2013). O IFAC (2001) destaca ainda a relevância dos programas de treinamento como mecanismo de retenção de pessoal competente. Nesse sentido, a elaboração de mecanismos para a atração, desenvolvimento e retenção de indivíduos competentes aumenta a chance de que a organização realize seus objetivos. 


\subsubsection{Análise Comparativa da Subdimensão 1.4 - Atração, Desenvolvimento e}

\section{Retenção de Indivíduos}

\begin{tabular}{|c|c|c|c|}
\hline Variável & MAPA & Incra & Conab \\
\hline $\begin{array}{l}\text { 1.4.1. Programa de } \\
\text { Desenvolvimento } \\
\text { de Competências }\end{array}$ & $\begin{array}{l}\text { Programa de } \\
\text { desenvolvimento de } \\
\text { competências abrange as } \\
\text { funções e atividades } \\
\text { relevantes para a } \\
\text { realização dos objetivos e } \\
\text { inclui múltiplas técnicas de } \\
\text { entrega. }\end{array}$ & $\begin{array}{l}\text { Programa de } \\
\text { desenvolvimento de } \\
\text { competências abrange as } \\
\text { funções e atividades } \\
\text { relevantes para a } \\
\text { realização dos objetivos e } \\
\text { inclui múltiplas técnicas de } \\
\text { entrega. }\end{array}$ & $\begin{array}{l}\text { Programa de } \\
\text { desenvolvimento de } \\
\text { competências abrange as } \\
\text { funções e atividades } \\
\text { relevantes para a } \\
\text { realização dos objetivos e } \\
\text { inclui múltiplas técnicas de } \\
\text { entrega. }\end{array}$ \\
\hline
\end{tabular}

Fonte: Dados da pesquisa.

Todas as entidades possuem programa para o desenvolvimento das competências de seus empregados, incluindo o desenvolvimento de competências críticas para a entidade e múltiplos meios de entrega. As características diagnosticadas nesta subdimensão por meio da aplicação do modelo de maturidade desenvolvido neste trabalho não ensejaram a identificação de riscos e proposta de recomendações para as entidades estudadas.

\subsubsection{Resultados da Subdimensão 1.5 - Avaliação de Desempenho}

\subsubsection{Resultados da Variável 1.5.1 - Fatores da Avaliação de Desempenho}

Quadro 27 - Resultados da Variável 1.5.1 - Fatores da Avaliação de Desempenho

\begin{tabular}{|c|c|c|c|}
\hline \multicolumn{1}{|c|}{ (0) Incipiente } & \multicolumn{1}{c|}{ (1) Inicial } & \multicolumn{1}{c|}{ (2) Em Formação } & Estabelecido \\
\hline $\begin{array}{l}\text { Ausência de definição de } \\
\text { fatores de avaliação de } \\
\text { desempenho. }\end{array}$ & $\begin{array}{l}\text { Avaliação da } \\
\text { produtividade dos } \\
\text { empregados da entidade. }\end{array}$ & $\begin{array}{l}\text { Avaliação da conduta } \\
\text { ética dos empregados da } \\
\text { entidade. }\end{array}$ & $\begin{array}{l}\text { Avaliação das } \\
\text { competências dos } \\
\text { empregados da entidade. }\end{array}$ \\
\hline MAPA & Sim & Sim & Sim \\
\hline Incra & Sim & Sim & Sim \\
\hline Conab & Sim & Não & Sim \\
\hline
\end{tabular}

Fonte: Dados da pesquisa.

Para a análise da maturidade nesta variável foram solicitados às entidades estudadas os seguintes documentos: Normas e regulamentos referentes à avaliação de desempenho dos servidores.

A avaliação de desempenho individual dos servidores do MAPA é baseada em fatores de competência, conforme o art. 17, inciso III da Portaria MAPA n 499/2012. Os fatores de competência avaliados são: produtividade e qualidade no trabalho; conhecimento de métodos e técnicas; trabalho em equipe; comprometimento com o trabalho; ética e disciplina; autodesenvolvimento; capacidade de iniciativa; relacionamento interpessoal; e flexibilidade a mudanças.

Os fatores de avaliação de desempenho individual dos servidores do Incra, nos termos do art. 13 da Portaria MDA n 26/2012, são: produtividade e qualidade no trabalho; 
conhecimento de métodos e técnicas; trabalho em equipe; comprometimento com o trabalho; e cumprimento das normas de procedimento e de conduta. Nesse sentido, o MAPA e o Incra atendem aos critérios dos níveis de maturidade (1) Inicial, (2) Em Formação e (3) Estabelecido.

A Política de Gestão do Desempenho da Conab informa no item "8.3 Critérios de Avaliação" que a avaliação é realizada tendo como critério o desempenho dos empregados em “Competências Estratégicas" (1. Trabalho em Equipe, 2. Adaptação à Mudança, 3. Iniciativa e dinamismo, 4. Conhecimento da Organização, 5. Aquisição e Transferência de Conhecimentos e 6. Foco no Cliente). Os gestores da entidade são avaliados também considerando seu desempenho em "Competências de Liderança" (1. Gestão Estratégica, 2. Orientação para Resultados, 3. Gestão de Processos, 4. Liderança e Gestão de Equipes e 5. Negociação). Nesse sentido, entende-se que a avaliação de desempenho da Conab inclui critérios para a avaliação da produtividade e das competências de seus empregados, mas não há na avaliação de desempenho critérios relacionados à conduta ética dos empregados, de modo que a Conab atende aos critérios dos níveis de maturidade (1) Inicial e (3) Estabelecido.

A avaliação de desempenho é um mecanismo importante para estimular o cumprimento das responsabilidades de controle interno por parte dos empregados da organização (COSO, 2013). Nesse sentido, é um elemento relevante para o estabelecimento de um ambiente de controle favorável ao funcionamento da estrutura de controle interno, contribuindo para a realização dos objetivos da organização. Johnstone et al. (2012) relacionam a falta de cobrança de um comportamento ético e a falta de competência do pessoal para a realização de suas atribuições entre as deficiências mais comuns no ambiente de controle das organizações. Assim, é importante também que a avaliação de desempenho inclua entre seus fatores a conduta ética e a manutenção das competências necessárias.

\subsubsection{Resultados da Variável 1.5.2 - Níveis Organizacionais da Avaliação de}

\section{Desempenho}

Quadro 28 - Resultados da Variável 1.5.2 - Níveis Organizacionais da Avaliação de Desempenho

\begin{tabular}{|c|c|c|c|}
\hline \multicolumn{1}{|c|}{ (0) Incipiente } & \multicolumn{1}{c|}{ (1) Inicial } & \multicolumn{1}{c|}{ (2) Em Formação } & Estabelecido \\
\hline $\begin{array}{l}\text { Ausência de definição de } \\
\text { níveis organizacionais na } \\
\text { avaliação de } \\
\text { desempenho de }\end{array}$ & $\begin{array}{l}\text { Avaliação de } \\
\text { desempenho dos } \\
\text { empregados e gerência } \\
\text { da entidade. }\end{array}$ & $\begin{array}{l}\text { Avaliação de } \\
\text { gerência da entidade. }\end{array}$ & $\begin{array}{l}\text { desempenho da direção } \\
\text { executiva e corpo } \\
\text { diretivo da entidade. }\end{array}$ \\
\hline MAPA & Sim & Parcial & Não \\
\hline Incra & Sim & Parcial & Não \\
\hline Conab & Sim & Não & Não \\
\hline
\end{tabular}

Fonte: Dados da pesquisa. 
Para a análise da maturidade nesta variável foram solicitados às entidades estudadas os seguintes documentos: Normas e regulamentos referentes à avaliação de desempenho dos servidores.

A avaliação de desempenho dos servidores do MAPA (Portaria MAPA $n^{\circ}$ 499/2012) e do Incra (Portaria MDA n 26/2012) não ocupantes de cargo em comissão e dos servidores ocupantes de cargos DAS 1, 2 e 3 leva em consideração o desempenho institucional (cumprimento de metas globais e intermediárias) e o desempenho individual (pontuação atribuída pela chefia imediata, pares e pelo próprio servidor a fatores de produtividade, conhecimento, colaboração, comprometimento e comportamento do servidor). Os ocupantes de cargos DAS 4, 5 e 6 são avaliados com base apenas no desempenho institucional.

A Política de Gestão do Desempenho da Conab orienta o processo de avaliação de desempenho de empregados e gestores. O gestor é definido como “o empregado responsável pela gestão técnico-administrativa de determinadas áreas da Companhia, liderando as respectivas equipes de trabalho sob sua hierarquia, percebendo, para tanto, gratificação de função de confiança". O Relatório Anual de Auditoria de Contas da Conab, do exercício de 2014, informa que a Conab ainda não havia implantado a avaliação formal de desempenho da Diretoria e do Conselho de Administração.

Desse modo, entende-se que as três entidades atendem integralmente ao critério do nível de maturidade (1) Inicial. O MAPA e o Incra atendem parcialmente ao critério do nível de maturidade (2) Em Formação.

Considerando que a avaliação de desempenho é fator de alinhamento da atuação dos empregados com as expectativas da organização, é necessário que ela seja abrangente, incluindo a alta gerência e a direção executiva, que definem as diretrizes para o trabalho dos empregados dos demais níveis da organização e estabelecem o ambiente de controle pelo exemplo de suas atitudes (COSO, 2013b). A ausência da alta gerência e direção executiva na avaliação de desempenho resulta na ausência de feedback, prejudicando sua atuação na realização dos objetivos da entidade, e pode transmitir uma ideia de ausência de compromisso dos níveis organizacionais superiores com a ética e valores, prejudicando o ambiente de controle. 


\subsubsection{Resultados da Variável 1.5.3 - Níveis Organizacionais das Metas de Desempenho}

Quadro 29 - Resultados da Variável 1.5.3 - Níveis Organizacionais das Metas de Desempenho

\begin{tabular}{|c|c|l|c|}
\hline \multicolumn{1}{|c|}{ (0) Incipiente } & \multicolumn{1}{|c|}{ (1) Inicial } & \multicolumn{1}{|c|}{ (2) Em Formação } & \multicolumn{1}{c|}{ Estabelecido } \\
\hline $\begin{array}{l}\text { Ausência de definição de } \\
\text { níveis organizacionais } \\
\text { nas metas de } \\
\text { desempenho. }\end{array}$ & $\begin{array}{l}\text { Definição de metas de } \\
\text { desempenho em nível de } \\
\text { entidade. }\end{array}$ & $\begin{array}{l}\text { Definição de metas de } \\
\text { desempenho para as } \\
\text { unidades e subunidades } \\
\text { organizacionais da } \\
\text { entidade. }\end{array}$ & $\begin{array}{l}\text { Definiça de metas de } \\
\text { desempenho individuais, } \\
\text { para cada empregado da } \\
\text { entidade. }\end{array}$ \\
\hline MAPA & Sim & Sim & Sim \\
\hline Incra & Sim & Não & Sim \\
\hline Conab & Não & & Não \\
\hline
\end{tabular}

Fonte: Dados da pesquisa.

Para a análise da maturidade nesta variável foram solicitados às entidades estudadas os seguintes documentos: Normas e regulamentos referentes à avaliação de desempenho dos servidores.

No MAPA (Portaria MAPA n 499/2012) e no Incra (Portaria MDA nº 26/2012), a avaliação de desempenho institucional é segmentada em metas globais (aplicáveis ao ente como um todo, fixadas levando em consideração o Planejamento Estratégico, o Plano Plurianual, a Lei de Diretrizes Orçamentárias e a Lei Orçamentária) e metas intermediárias (estabelecidas no plano de trabalho de cada unidade de avaliação). Além disso, os planos de trabalho incluem as metas de desempenho individual (pactuadas entre o servidor e a respectiva chefia, em consonância com as demais metas). Desse modo, ambos atendem aos critérios dos níveis de maturidade (1) Inicial e (2) Em Formação. A Conab não apresentou evidências de cumprimento dos critérios da variável.

A definição de metas é importante para que os empregados da organização avaliem seu próprio desempenho e ajustem o seu comportamento conforme necessário para atender às expectativas da organização. Assim, é importante que as metas sejam definidas não apenas em nível de entidade, mas também para cada empregado da organização. 


\subsubsection{Resultados da Variável 1.5.4 - Recompensas e Sanções da Avaliação de Desempenho}

Quadro 30 - Resultados da Variável 1.5.4 - Recompensas e Sanções da Avaliação de Desempenho

\begin{tabular}{|c|l|l|l|}
\hline \multicolumn{1}{|c|}{ (0) Incipiente } & \multicolumn{1}{|c|}{ (1) Inicial } & \multicolumn{1}{|c|}{ (3) Em Estabelecido } \\
\hline $\begin{array}{l}\text { Ausência de definição de } \\
\text { recompensas e sanções } \\
\text { na avaliação de } \\
\text { desempenho. }\end{array}$ & $\begin{array}{l}\text { Recompensas e sanções } \\
\text { de caráter administrativo } \\
\text { e disciplinar. }\end{array}$ & $\begin{array}{l}\text { Parcela variável da } \\
\text { remuneração dos } \\
\text { empregados é afetada. }\end{array}$ & $\begin{array}{l}\text { Promoção (evolução nos } \\
\text { níveis da carreira) e } \\
\text { movimentação (inclusive } \\
\text { remoção) levam em } \\
\text { consideração as } \\
\text { avaliações de } \\
\text { desempenho do } \\
\text { empregado. }\end{array}$ \\
\hline MAPA & Sim & Sim & Parcial \\
\hline Incra & Não & Sim & Parcial \\
\hline Conab & Sim & Não & Parcial \\
\hline
\end{tabular}

Fonte: Dados da pesquisa.

Para a análise da maturidade nesta variável foram solicitados às entidades estudadas os seguintes documentos: Normas e regulamentos referentes à avaliação de desempenho dos servidores; Normas e regulamentos referentes às principais rubricas remuneratórias dos servidores (parcelas fixas e variáveis); Normas e regulamentos referentes à progressão funcional e promoção dos servidores; Normas e regulamentos referentes à lotação, movimentação e remoção dos servidores.

A Portaria MAPA nº 499/2012 regula os critérios e procedimentos para a avaliação de desempenho para fins de concessão das gratificações dos servidores do MAPA. Além disso, a Portaria dispõe em seu art. 25 que os servidores que obtiverem avaliação de desempenho individual inferior a cinquenta por cento da pontuação máxima prevista serão submetidos a processo de capacitação ou de análise da adequação funcional. Nesse sentido, o MAPA cumpre os critérios dos níveis de maturidade (1) Inicial e (2) Em Formação.

O Incra não apresentou evidência de cumprimento do critério do nível (1) Inicial. Contudo, a Portaria MDA n 26/2012 regula os critérios e procedimentos para a avaliação de desempenho para fins de concessão das gratificações dos servidores do Incra, atendendo ao critério do nível de maturidade (2) Em Formação.

A Lei $\mathrm{n}^{\circ} 11.090 / 2005$, que dispõe sobre os planos de carreira de servidores do MAPA e do Incra, define que o desenvolvimento na carreira (progressão funcional e promoção) deve observar a avalição de desempenho. Apesar disso, não foram identificadas evidências de que os processos de movimentação dos servidores de MAPA e Incra tenham de observar a avaliação de desempenho. Assim, ambos atendem parcialmente ao critério do nível de maturidade (3) Estabelecido. 
A Política de Gestão do Desempenho da Conab informa no item "9.2 Treinamento e Desenvolvimento" que os empregados que apresentarem desempenho mediano ou inferior deverão cumprir as horas de treinamento definidas pela GECAP para o desenvolvimento de cada competência. Ainda, a Política informa no item "8.5 Promoção por Mérito" que a nota final inferior a 70 na avaliação de desempenho torna o empregado inelegível ao processo de promoção por mérito. Assim, entende-se que a Conab cumpre integralmente o critério do nível de maturidade (1) Inicial e parcialmente o critério do nível de maturidade (3) Estabelecido.

Para que surta o efeito esperado sobre a conduta dos empregados, a avaliação de desempenho deve estar ligada a um sistema de incentivos e recompensas (COSO, 2013). Os empregados devem ter conhecimento dos benefícios que não lhes serão facultados e das sanções a que estarão sujeitos em caso de desempenho repetidamente abaixo das expectativas da entidade, e tais benefícios e sanções devem ser relevantes o suficiente para influenciar a conduta dos empregados.

\subsubsection{Resultados da Variável 1.5.5 - Frequência da Avaliação de Desempenho}

Quadro 31 - Resultados da Variável 1.5.5 - Frequência da Avaliação de Desempenho

\begin{tabular}{|c|c|l|c|}
\hline \multicolumn{1}{|c|}{ (0) Incipiente } & \multicolumn{1}{c|}{ (1) Inicial } & \multicolumn{1}{c|}{ (2) Em Formação } & \multicolumn{1}{c|}{ Estabelecido } \\
\hline $\begin{array}{l}\text { Ausência de definição da } \\
\text { frequência da avaliação } \\
\text { de desempenho. }\end{array}$ & $\begin{array}{l}\text { Avaliação de } \\
\text { desempenho realizada } \\
\text { anualmente. }\end{array}$ & $\begin{array}{l}\text { Avaliação de } \\
\text { desempenho realizada } \\
\text { semestralmente. }\end{array}$ & $\begin{array}{l}\text { Avaliação de } \\
\text { desempenho realizada } \\
\text { quadrimestralmente (ou } \\
\text { frequência maior). }\end{array}$ \\
\hline MAPA & Sim & Não & Não \\
\hline Incra & Sim & Não & Não \\
\hline Conab & Sim & Não & \\
\hline
\end{tabular}

Fonte: Dados da pesquisa.

Para a análise da maturidade nesta variável foram solicitados às entidades estudadas os seguintes documentos: Normas e regulamentos referentes à avaliação de desempenho dos servidores.

Em todas as entidades avaliadas, o ciclo de avaliação de desempenho é anual, atendendo ao critério do nível de maturidade (1) Inicial.

A avaliação de desempenho deve ser realizada em periodicidade adequada para que os empregados tenham feedback tempestivo a respeito de sua atuação na realização dos objetivos da entidade e façam os ajustes necessários para atender às expectativas da organização (COSO, 2013). A adequação da frequência é questão de julgamento, e cada organização pode definir qual é a periodicidade adequada levando em consideração fatores como a dinâmica da sua área de atuação e os custos do processo de avaliação de desempenho; não obstante, admite- 
se como pressuposto que, quanto mais frequente o feedback, melhor o alinhamento entre a conduta dos empregados e as expectativas de desempenho da organização.

\subsubsection{Análise Comparativa da Subdimensão 1.5 - Avaliação de Desempenho}

Quadro 32 - Análise Comparativa da Subdimensão 1.5 - Avaliação de Desempenho

\begin{tabular}{|c|c|c|c|}
\hline Variável & MAPA & Incra & Conab \\
\hline $\begin{array}{l}\text { 1.5.1. Fatores da } \\
\text { Avaliação de } \\
\text { Desempenho }\end{array}$ & $\begin{array}{l}\text { Produtividade e qualidade no } \\
\text { trabalho, conhecimento de } \\
\text { métodos e técnicas, trabalho em } \\
\text { equipe, comprometimento com } \\
\text { o trabalho, ética e disciplina, } \\
\text { autodesenvolvimento, } \\
\text { capacidade de iniciativa, } \\
\text { relacionamento interpessoal, e } \\
\text { flexibilidade a mudanças. }\end{array}$ & $\begin{array}{l}\text { Produtividade e } \\
\text { qualidade no trabalho, } \\
\text { conhecimento de } \\
\text { métodos e técnicas, } \\
\text { trabalho em equipe, } \\
\text { comprometimento com o } \\
\text { trabalho, e cumprimento } \\
\text { das normas de } \\
\text { procedimento e de } \\
\text { conduta. }\end{array}$ & $\begin{array}{l}\text { Estratégicos (trabalho em } \\
\text { equipe, adaptação à } \\
\text { mudança, iniciativa e } \\
\text { dinamismo, conhecimento } \\
\text { da organização, aquisição } \\
\text { e transferência de } \\
\text { conhecimentos, e foco no } \\
\text { cliente); Liderança (gestão } \\
\text { estratégica, orientação } \\
\text { para resultados, gestão de } \\
\text { processos, liderança e } \\
\text { gestão de equipes, e } \\
\text { negociação). }\end{array}$ \\
\hline $\begin{array}{l}\text { 1.5.2. Níveis } \\
\text { Organizacionais } \\
\text { da Avaliação de } \\
\text { Desempenho }\end{array}$ & $\begin{array}{l}\text { Empregados e gerentes } \\
\text { (desempenho pessoal) e alta } \\
\text { gerência (desempenho } \\
\text { institucional). }\end{array}$ & $\begin{array}{l}\text { Empregados e gerentes } \\
\text { (desempenho pessoal) e } \\
\text { alta gerência } \\
\text { (desempenho } \\
\text { institucional). }\end{array}$ & $\begin{array}{l}\text { Empregados e gerentes } \\
\text { (desempenho pessoal). }\end{array}$ \\
\hline $\begin{array}{l}\text { 1.5.3. Níveis } \\
\text { Organizacionais } \\
\text { das Metas de } \\
\text { Desempenho }\end{array}$ & $\begin{array}{l}\text { Metas globais, metas } \\
\text { intermediárias para equipes de } \\
\text { trabalho e metas individuais } \\
\text { para os empregados. }\end{array}$ & $\begin{array}{l}\text { Metas globais, metas } \\
\text { intermediárias para } \\
\text { equipes de trabalho e } \\
\text { metas individuais para } \\
\text { os empregados. }\end{array}$ & $\begin{array}{l}\text { Não apresentou evidências } \\
\text { de níveis organizacionais } \\
\text { de metas de desempenho. }\end{array}$ \\
\hline $\begin{array}{l}\text { 1.5.4. } \\
\text { Recompensas e } \\
\text { Sanções da } \\
\text { Avaliação de } \\
\text { Desempenho }\end{array}$ & $\begin{array}{l}\text { Baixo desempenho individual } \\
\text { sujeita o empregado a processo } \\
\text { de capacitação ou de análise da } \\
\text { adequação funcional; avaliação } \\
\text { influencia o valor da } \\
\text { gratificação de desempenho; } \\
\text { desenvolvimento na carreira } \\
\text { (progressão funcional e } \\
\text { promoção) deve observar a } \\
\text { avaliação de desempenho. }\end{array}$ & $\begin{array}{l}\text { Avaliação influencia o } \\
\text { valor da gratificação de } \\
\text { desempenho; } \\
\text { desenvolvimento na } \\
\text { carreira (progressão } \\
\text { funcional e promoção) } \\
\text { deve observar a } \\
\text { avaliação de } \\
\text { desempenho. }\end{array}$ & $\begin{array}{l}\text { Baixo desempenho } \\
\text { individual sujeita o } \\
\text { empregado a processo de } \\
\text { capacitação; promoção } \\
\text { por mérito deve observar a } \\
\text { avaliação de desempenho. }\end{array}$ \\
\hline $\begin{array}{l}\text { 1.5.5. Frequência } \\
\text { da Avaliação de } \\
\text { Desempenho }\end{array}$ & Anual. & Anual. & Anual. \\
\hline
\end{tabular}

Fonte: Dados da pesquisa.

Quanto à avaliação de desempenho, todas as entidades estudadas instituíram processo de avaliação e observam sistemática semelhante. Não obstante, há oportunidades de melhoria. Cabe observar que apenas o MAPA e o Incra incluíram a conduta ética entre os fatores de avaliação; nas três entidades, a avaliação do desempenho da alta gerência e direção executiva é restrita aos indicadores de desempenho institucional; enquanto as normas do MAPA e do Incra preveem a definição de metas de desempenho em nível de entidade, em nível de equipe e até metas individuais, não existe previsão para metas de desempenho na Conab; no MAPA e 
no Incra, a avaliação de desempenho é realizada com foco na definição do valor da parcela variável da remuneração dos empregados. As normas do MAPA e da Conab prescrevem a realização de capacitação de empregados com baixo desempenho; apenas na Conab o baixo desempenho pode influir no processo de promoção. Em todas as entidades, o ciclo de avaliação de desempenho é anual.

O quadro a seguir apresenta os riscos identificados com embasamento nas características da subdimensão, diagnosticadas pela aplicação do modelo de maturidade desenvolvido neste trabalho, e as respectivas recomendações para o aprimoramento das estruturas de controle interno das entidades estudadas.

Quadro 33 - Riscos e Recomendações da Subdimensão 1.5 - Avaliação de Desempenho

\begin{tabular}{|c|c|}
\hline Riscos & Recomendações \\
\hline $\begin{array}{l}\text { (Conab) A avaliação de desempenho não promova a } \\
\text { ética e os valores esperados do comportamento dos } \\
\text { empregados da entidade. }\end{array}$ & $\begin{array}{l}\text { (Conab) Incluir a conduta ética entre os fatores da } \\
\text { avaliação de desempenho. }\end{array}$ \\
\hline $\begin{array}{l}\text { (MAPA, Incra, Conab) Corpo diretivo e alta gerência } \\
\text { não recebam feedback a respeito do seu desempenho } \\
\text { na realização dos objetivos da entidade. }\end{array}$ & $\begin{array}{l}\text { (MAPA, Incra, Conab) Desenvolver procedimentos } \\
\text { para a avaliação de desempenho do corpo diretivo e } \\
\text { alta gerência da entidade. }\end{array}$ \\
\hline $\begin{array}{l}\text { (Conab) Os empregados não tenham desempenho } \\
\text { adequado na realização dos objetivos da entidade em } \\
\text { razão da ausência de metas. }\end{array}$ & $\begin{array}{l}\text { (Conab) Definir metas de desempenho em nível de } \\
\text { entidade, metas para as unidades e subunidades } \\
\text { organizacionais e metas individuais para os } \\
\text { empregados da entidade. }\end{array}$ \\
\hline $\begin{array}{l}\text { (MAPA, Incra, Conab) As sanções e recompensas } \\
\text { relacionadas à avaliação de desempenho não } \\
\text { representem incentivo eficaz para que os empregados } \\
\text { tenham desempenho adequado na realização dos } \\
\text { objetivos da entidade. }\end{array}$ & $\begin{array}{l}\text { (Incra) Vincular recompensas e sanções de caráter } \\
\text { administrativo e disciplinar à avaliação de } \\
\text { desempenho da entidade. } \\
\text { (Conab) Estabelecer parcela variável à remuneração } \\
\text { dos empregados, vinculada à avaliação de } \\
\text { desempenho da entidade. } \\
\text { (MAPA, Incra, Conab) Incluir a movimentação dos } \\
\text { empregados no sistema de recompensas e sanções da } \\
\text { entidade. }\end{array}$ \\
\hline $\begin{array}{l}\text { (MAPA, Incra, Conab) Empregados recebam } \\
\text { feedback intempestivo a respeito do seu desempenho } \\
\text { na realização dos objetivos da entidade. }\end{array}$ & $\begin{array}{l}\text { (MAPA, Incra, Conab) Aumentar a frequência da } \\
\text { avaliação de desempenho. }\end{array}$ \\
\hline
\end{tabular}

Fonte: Elaborado pelo autor.

\subsubsection{Avaliação do Nível de Maturidade das Entidades na Dimensão 1 - Ambiente de Controle}

O quadro a seguir apresenta o resultado final dos procedimentos de avaliação do nível de maturidade das entidades estudadas na dimensão Ambiente de Controle, considerando o peso de cada nível de maturidade, definido pela média dos pesos estabelecidos pelo atendimento dos critérios dentro das variáveis da dimensão, conforme o apêndice $\mathrm{J}$ deste trabalho. 
Quadro 34 - Avaliação do Nível de Maturidade das Entidades na Dimensão 1 - Ambiente de Controle

\begin{tabular}{|c|c|c|c|}
\hline Nível de Maturidade & MAPA & Incra & Conab \\
\hline (0) Incipiente & $30,8 \%$ & $38,5 \%$ & $30,8 \%$ \\
\hline (1) Inicial & $65,4 \%$ & $50 \%$ & $69,2 \%$ \\
\hline (2) Em Formação & $57,7 \%$ & $50 \%$ & $26,9 \%$ \\
\hline (3) Estabelecido & $26,9 \%$ & $26,9 \%$ & $34,6 \%$ \\
\hline Avaliação & (2) Em Formação & (2) Em Formação & (1) Inicial \\
\hline
\end{tabular}

Fonte: Dados da pesquisa.

O Ambiente de Controle é a dimensão mais desenvolvida nas entidades estudadas, apesar de algumas restrições, como a incipiente disseminação de padrões de ética e a ausência de políticas de due diligence e requisitos de competência para os membros do corpo diretivo. O MAPA obteve avaliação destacada no processo de avaliação de desempenho. A Conab, na definição de responsabilidades de controle interno e requisitos de competências para os empregados.

\subsection{RESULTADOS DA DIMENSÃO 2 - AVALIAÇÃO DE RISCOS}

\subsubsection{Resultados da Subdimensão 2.1 - Definição de Objetivos}

\subsubsection{Resultados da Variável 2.1.1 - Processo de Formulação de Objetivos}

Quadro 35 - Resultados da Variável 2.1.1 - Processo de Formulação de Objetivos

\begin{tabular}{|c|l|l|c|}
\hline \multicolumn{1}{|c|}{ (0) Incipiente } & \multicolumn{1}{c|}{ (1) Inicial } & \multicolumn{1}{c|}{ (2) Em Formação } & Estabelecido \\
\hline $\begin{array}{l}\text { Ausência de processos } \\
\text { para a definição de } \\
\text { objetivos. }\end{array}$ & $\begin{array}{l}\text { Entidade possui } \\
\text { objetivos definidos de } \\
\text { forma casuística, sem } \\
\text { processo formalmente } \\
\text { estabelecido. }\end{array}$ & $\begin{array}{l}\text { Processo formalmente } \\
\text { estabelecido para } \\
\text { definição dos objetivos } \\
\text { da entidade. }\end{array}$ & $\begin{array}{l}\text { Processo de definiço de } \\
\text { objetivos é realizado } \\
\text { periodicamente (mínimo } \\
\text { de uma vez ao ano) para } \\
\text { a reavaliação dos } \\
\text { objetivos da entidade. }\end{array}$ \\
\hline MAPA & Sim & Parcial & Parcial \\
\hline Incra & Sim & Não & Não \\
\hline Conab & Sim & Parcial & Não \\
\hline
\end{tabular}

Fonte: Dados da pesquisa.

Para a análise da maturidade nesta variável foram solicitados às entidades estudadas os seguintes documentos: Planos Estratégicos; Planos Táticos; Planos Operacionais; Normas e regulamentos referentes aos processos de planejamento estratégico, tático e operacional.

No MAPA, O Plano Estratégico 2006-2015 foi elaborado a partir da metodologia do Balanced Scorecard - BSC. Ele define 25 objetivos estratégicos, nas perspectivas de "Sociedade", "Agronegócio e Parceiros", "Processos Internos" e "Pessoas, Aprendizado e Crescimento", atendendo ao critério do nível de maturidade (1) Inicial. A Portaria MAPA n 423/2005 institui o processo de gestão estratégica, que prevê a realização do planejamento estratégico a cada quatro anos e sua revisão a partir do segundo ano de execução; apesar disso, a referida Portaria não estabelece um processo para a elaboração do planejamento estratégico, 
e não define a periodicidade das revisões do plano. Assim, o MAPA cumpre apenas parcialmente os requisitos dos níveis de maturidade (2) Em Formação e (3) Estabelecido.

Os objetivos estratégicos do Incra estão integrados ao Plano Estratégico 2015-2018 do Ministério do Desenvolvimento Agrário - MDA. São definidos 34 objetivos estratégicos, nas perspectivas "Resultados Institucionais", "Processos Internos", "Recursos Humanos e Infraestrutura" e "Orçamento". Apesar disso, não foram encontradas evidências de que esse planejamento estratégico seja realizado num processo formalmente estabelecido, nem da previsão de um processo de revisão dos objetivos estratégicos, razão pela qual se entende que o Incra atende apenas ao critério do nível de maturidade (1) Inicial.

A Conab também possui plano estratégico, estabelecido a partir da metodologia do Balanced Scorecard - BSC, definindo 21 objetivos estratégicos nas perspectivas de sociedade, processos internos, excelência organizacional interna, integração e perspectiva financeira. Além disso, o mapa do Macroprocesso de Gestão Administrativa inclui o processo "5.1 Realizar planejamento estratégico e tático", indicando ainda os departamentos responsáveis por sua realização: PRESI / SUORG, DIRAB, DIPAI, DIGEP e DIAFI. Apesar disso, não foi demonstrado o estabelecimento formal de um processo de planejamento estratégico, nem de um processo de revisão dos objetivos estratégicos, razão pela qual se entende que a Conab atende integralmente ao critério do nível de maturidade (1) Inicial e cumpre apenas parcialmente os requisitos dos níveis de maturidade (2) Em Formação.

É necessário que os objetivos sejam avaliados e aprovados, para que possam servir de base para a alocação de recursos na entidade, e para que possam ser considerados adequados para a avaliação de riscos (COSO, 2013). A ambiguidade de objetivos prejudica o desempenho das entidades e programas governamentais (CHUN; RAINEY, 2005; JUNG, 2014). A existência de um processo formalmente estabelecido para a definição dos objetivos garante a realização ordenada de todos os procedimentos necessários à sua aprovação, tendendo a diminuir a ambiguidade.

A revisão periódica é importante para manutenção da relevância dos objetivos perante mudanças no ambiente de negócios, e nas leis e regulamentos aplicáveis à organização (COSO, 2013). Modificações no ambiente, nas atribuições legais e nas políticas públicas de responsabilidade das entidades governamentais podem resultar na perda da relevância de seus objetivos. 


\subsubsection{Resultados da Variável 2.1.2 - Participantes do Processo de Formulação de}

Objetivos

Quadro 36 - Resultados da Variável 2.1.2 - Participantes do Processo de Formulação de Objetivos

\begin{tabular}{|c|l|l|l|}
\hline \multicolumn{1}{|c|}{ (0) Incipiente } & \multicolumn{1}{c|}{ (1) Inicial } & \multicolumn{1}{c|}{ (2) Em Formação } & Estabelecido \\
\hline $\begin{array}{l}\text { Ausência de definição } \\
\text { dos participantes do } \\
\text { processo de formulação } \\
\text { de objetivos. }\end{array}$ & $\begin{array}{l}\text { Processo para a } \\
\text { formulação de objetivos } \\
\text { envolve apenas o corpo } \\
\text { diretivo e alta gerência } \\
\text { da entidade. }\end{array}$ & $\begin{array}{l}\text { Processo para a } \\
\text { formulação de objetivos } \\
\text { envolve ampla } \\
\text { participação dos } \\
\text { empregados da entidade. }\end{array}$ & $\begin{array}{l}\text { Processo para a } \\
\text { formulação de objetivos } \\
\text { envolve ampla } \\
\text { participação, inclusive de } \\
\text { partes interessadas } \\
\text { externas. }\end{array}$ \\
\hline MAPA & Sim & Parcial & Parcial \\
\hline Incra & Sim & Parcial & Parcial \\
\hline Conab & Sim & Não & Não \\
\hline
\end{tabular}

Fonte: Dados da pesquisa.

Para a análise da maturidade nesta variável foram solicitados às entidades estudadas os seguintes documentos: Planos Estratégicos; Planos Táticos; Planos Operacionais; Normas e regulamentos referentes aos processos de planejamento estratégico, tático e operacional.

A Portaria n 423/2005 do MAPA determina que "a coordenação do processo de elaboração e avaliação do Plano ficará a cargo da Assessoria de Gestão Estratégica - AGE” (art. 1º parágrafo único); que “a elaboração do Plano contará com o apoio dos Órgãos de Assistência Direta ao Ministro, Secretarias, SFAs, INMET, CEPLAC, Empresas Públicas e de Economia Mista, Laboratórios Nacionais e organizações do agronegócio brasileiro" (art. $3^{\circ}$, $\S 2^{\circ}$ ); que "a AGE poderá contar com técnicos das unidades listadas no $\S 2^{\circ}$ do art. $3^{\circ}$ para a elaboração, acompanhamento e avaliação dos resultados do Plano" (art. $5^{\circ}$, parágrafo único); e que "o Plano Estratégico e os instrumentos de sua gestão serão aprovados pelo Ministro de Estado da Agricultura, Pecuária e Abastecimento" (art. $6^{\circ}$ ). Considerando o teor de tais disposições, verifica-se que as diretrizes do processo de planejamento estratégico do MAPA atendem ao critério do nível de maturidade (1) Inicial, mas satisfazem apenas parcialmente os critérios definidos para os níveis (2) Em Formação e (3) Estabelecido.

Quanto ao Incra, o Plano Estratégico 2015-2018 do MDA informa que foi realizado numa dinâmica de oficinas que reuniu colaboradores do MDA e do Incra, com a apreciação do Conselho de Desenvolvimento Rural Sustentável e Solidário - Condraf e exposição dos resultados parciais para todos os funcionários. Com embasamento nessa informação, entendese que o planejamento estratégico do Incra satisfaz integralmente o critério do nível de maturidade (1) Inicial, atendendo parcialmente os critérios definidos para os níveis (2) Em Formação e (3) Estabelecido. 
Na Conab, o mapa do Macroprocesso de Gestão Administrativa inclui o processo "5.1 Realizar planejamento estratégico e tático", indicando ainda os departamentos responsáveis por sua realização: PRESI / SUORG, DIRAB, DIPAI, DIGEP e DIAFI. O Regimento Interno da Conab atribui à Superintendência de Estratégia e Organização (SUORG) responsabilidades como: "desenvolver estudos visando à melhoria da gestão e ao alinhamento entre o planejamento estratégico e a gestão operacional da Companhia"; "coordenar a elaboração e acompanhar a execução do Planejamento Estratégico"; "reportar-se à Diretoria Colegiada e ao Conselho de Administração sobre o andamento do Planejamento Estratégico"; e "desenvolver atividades específicas atribuídas pela Presidência, que tenham correlação com planejamento estratégico e a gestão da Companhia”. Os Superintendentes de Área e Superintendentes Regionais também devem "colaborar nos processos de planejamento estratégico da Companhia e de elaboração dos planos de ação relativos à sua área de competência”. Assim, a Conab atende ao critério do nível de maturidade (1) Inicial.

O GAO (2001) destaca a necessidade de participação de todos os níveis da gerência da definição dos objetivos da entidade, de modo a obter o comprometimento com a sua realização. A participação de empregados no planejamento estratégico também pode propiciar benefícios para a estrutura de controle interno. Os empregados podem ter mais clareza quanto aos objetivos, metas e planos para sua implantação; podem compreender melhor seu papel na implantação; podem aumentar sua influência sobre o ambiente organizacional (DANIELS; BAILEY, 1999, apud KIM, 2000). Kim (2002) identificou uma relação positiva entre um planejamento estratégico participativo e a satisfação dos empregados, o que pode influenciar positivamente o Ambiente de Controle. A participação de partes externas na formulação dos objetivos tende a promover maior alinhamento entre a atuação da entidade e os interesses da sociedade.

\subsubsection{Resultados da Variável 2.1.3 - Tipos de Objetivos}

Quadro 37 - Resultados da Variável 2.1.3 - Tipos de Objetivos

\begin{tabular}{|c|l|l|l|}
\hline \multicolumn{1}{|c|}{ (0) Incipiente } & \multicolumn{1}{|c|}{ (1) Inicial } & \multicolumn{1}{|c|}{ (2) Em Formação } & Estabelecido \\
\hline $\begin{array}{l}\text { Ausência de definição de } \\
\text { tipos de objetivos. }\end{array}$ & $\begin{array}{l}\text { Os objetivos são } \\
\text { definidos no nível } \\
\text { estratégico, mas não são } \\
\text { desdobrados no nível } \\
\text { operacional. }\end{array}$ & $\begin{array}{l}\text { Os objetivos são } \\
\text { definidos até o nível } \\
\text { operacional, a partir do } \\
\text { desdobramento dos } \\
\text { objetivos estratégicos. }\end{array}$ & $\begin{array}{l}\text { Além dos objerionais, também } \\
\text { são definidos objetivos } \\
\text { de conformidade e } \\
\text { objetivos de } \\
\text { comunicação (relatórios } \\
\text { internos e externos). }\end{array}$ \\
\hline MAPA & Sim & Não & Não \\
\hline Incra & Sim & Não & Não \\
\hline Conab & Sim & Não & . \\
\hline
\end{tabular}

Fonte: Dados da pesquisa. 
Para a análise da maturidade nesta variável foram solicitados às entidades estudadas os seguintes documentos: Planos Estratégicos; Planos Táticos; Planos Operacionais; Normas e regulamentos referentes aos processos de planejamento estratégico, tático e operacional.

Todas as entidades possuem objetivos estratégicos estabelecidos, ausente o desdobramento em objetivos operacionais, de conformidade e relatórios. Nesse sentido, atendem ao critério do nível de maturidade (1) Inicial.

O desdobramento dos objetivos estratégicos em objetivos operacionais, de conformidade e de comunicação é relevante para a coerência entre os diferentes tipos de objetivos (COSO, 2013). A ausência desse desdobramento pode resultar na definição de objetivos incongruentes ou conflitantes, com prejuízos ao desempenho das entidades governamentais.

\subsubsection{Resultados da Variável 2.1.4 - Níveis Organizacionais dos Objetivos}

Quadro 38 - Resultados da Variável 2.1.4 - Níveis Organizacionais dos Objetivos

\begin{tabular}{|c|l|l|l|}
\hline \multicolumn{1}{|c|}{ (0) Incipiente } & \multicolumn{1}{c|}{ (1) Inicial } & \multicolumn{1}{c|}{ (2) Em Formação } & \multicolumn{1}{c|}{ Estabelecido } \\
\hline $\begin{array}{l}\text { Ausência de definição de } \\
\text { níveis organizacionais } \\
\text { nos objetivos. }\end{array}$ & $\begin{array}{l}\text { Definição apenas de } \\
\text { objetivos gerais, em } \\
\text { nível de entidade. }\end{array}$ & $\begin{array}{l}\text { Definição de objetivos } \\
\text { para as unidades e } \\
\text { subunidades } \\
\text { organizacionais, ou } \\
\text { desdobramento dos } \\
\text { objetivos gerais em } \\
\text { objetivos específicos. }\end{array}$ & $\begin{array}{l}\text { Definiços } \\
\text { para as atividades dos } \\
\text { processos relevantes para } \\
\text { a realização dos } \\
\text { objetivos da entidade. }\end{array}$ \\
\hline MAPA & Sim & Não & Não \\
\hline Incra & Sim & Não & Não \\
\hline Conab & Sim & & Não \\
\hline
\end{tabular}

Fonte: Dados da pesquisa.

Para a análise da maturidade nesta variável foram solicitados às entidades estudadas os seguintes documentos: Planos Estratégicos; Planos Táticos; Planos Operacionais; Normas e regulamentos referentes aos processos de planejamento estratégico, tático e operacional.

Todas as entidades possuem objetivos estratégicos estabelecidos, aplicáveis à entidade como um todo, ausente o desdobramento ao longo dos níveis organizacionais. Nesse sentido, atendem ao critério do nível de maturidade (1) Inicial.

O desdobramento dos objetivos em nível de entidade até o nível de atividade é importante para garantir a coesão entre os objetivos das unidades e subunidades organizacionais e dos processos e atividades com os objetivos gerais da entidade (COSO, 2013). A ausência desse desdobramento pode resultar na definição de objetivos desconexos ou contraditórios, prejudicando o desempenho da entidade. 


\subsubsection{Resultados da Variável 2.1.5 - Mensuração dos Objetivos}

Quadro 39 - Resultados da Variável 2.1.5 - Mensuração dos Objetivos

\begin{tabular}{|c|c|l|c|}
\hline \multicolumn{1}{|c|}{ (0) Incipiente } & \multicolumn{1}{|c|}{ (1) Inicial } & \multicolumn{1}{c|}{ (2) Em Formação } & \multicolumn{1}{c|}{ (3) Estabelecido } \\
\hline $\begin{array}{l}\text { Ausência de mensuração } \\
\text { dos objetivos da } \\
\text { entidade. }\end{array}$ & $\begin{array}{l}\text { Os objetivos da entidade } \\
\text { são mensurados. }\end{array}$ & $\begin{array}{l}\text { Os objetivos da entidade } \\
\text { possuem metas } \\
\text { associadas. }\end{array}$ & $\begin{array}{l}\text { Os objetivos da entidade } \\
\text { possuem cronograma e } \\
\text { orçamento definidos para } \\
\text { a sua realização. }\end{array}$ \\
\hline MAPA & Parcial & Parcial & Não \\
\hline Incra & Sim & Sim & Não \\
\hline Conab & Parcial & Parcial & Não \\
\hline
\end{tabular}

Fonte: Dados da pesquisa.

Para a análise da maturidade nesta variável foram solicitados às entidades estudadas os seguintes documentos: Planos Estratégicos; Planos Táticos; Planos Operacionais; Normas e regulamentos referentes aos processos de planejamento estratégico, tático e operacional; Relatórios com os resultados dos processos de acompanhamento ou avaliação do desempenho institucional.

O Relatório de Gestão do MAPA do exercício de 2015 informa que, dos 25 objetivos estratégicos, apenas quinze (60\%) tiveram ao menos um indicador de desempenho mensurado em 2015; sete objetivos estratégicos (28\%) não possuem nenhum indicador de desempenho relacionado. As perspectivas "Agronegócio e Parceiros" e "Processos Internos Articulação e Promoção" não tiveram nenhum objetivo estratégico mensurado. Desse modo, entende-se que o MAPA atende apenas parcialmente aos critérios dos níveis de maturidade (1) Inicial e (2) Em formação.

O Relatório de Gestão do Incra do exercício de 2015 apresenta os resultados dos objetivos estratégicos do Incra no Plano Estratégico MDA 2013-2014. Todos os objetivos estratégicos do Incra possuem ao menos um indicador de desempenho, mensurados e com meta definida para o exercício de 2015. Nesse sentido, entende-se que o Incra atende ao critério do nível de maturidade (2) Em Formação.

A análise do Relatório de Gestão da Conab, exercício de 2014, permite constatar que os quinze objetivos estratégicos das perspectivas "Processos Internos" e "Excelência Organizacional Interna" (71,5\%) possuem ao menos um indicador de desempenho mensurado no exercício, além de metas associadas; contudo, os seis objetivos estratégicos das perspectivas "Sociedade", "Integração" e "Financeira" (28,5\%) não possuem indicadores de desempenho para sua mensuração. Desse modo, a Conab atende apenas parcialmente aos critérios dos níveis de maturidade (1) Inicial e (2) Em formação. 
O COSO (2013) ressalta a importância que os objetivos sejam definidos em termos mensuráveis, definindo-se metas, cronograma e orçamento para a sua realização. De outro modo não é possível averiguar a evolução da entidade na realização de seus objetivos e adotar medidas corretivas caso necessário.

\subsubsection{Análise Comparativa da Subdimensão 2.1 - Definição de Objetivos}

Quadro 40 - Análise Comparativa da Subdimensão 2.1 - Definição de Objetivos

\begin{tabular}{|c|c|c|c|}
\hline Variáveis & MAPA & Incra & Conab \\
\hline $\begin{array}{l}\text { 2.1.1. Processo de } \\
\text { Formulação de } \\
\text { Objetivos }\end{array}$ & $\begin{array}{l}\text { Objetivos definidos de } \\
\text { forma casuística; definição } \\
\text { de diretrizes para um } \\
\text { processo de planejamento } \\
\text { estratégico e para a revisão } \\
\text { do plano. }\end{array}$ & $\begin{array}{l}\text { Objetivos definidos de } \\
\text { forma casuística. }\end{array}$ & $\begin{array}{l}\text { Objetivos definidos de } \\
\text { forma casuística; } \\
\text { definição de um } \\
\text { macroprocesso para o } \\
\text { planejamento } \\
\text { estratégico. }\end{array}$ \\
\hline $\begin{array}{l}\text { 2.1.2. Participantes } \\
\text { do Processo de } \\
\text { Formulação de } \\
\text { Objetivos }\end{array}$ & $\begin{array}{l}\text { Corpo diretivo, alta } \\
\text { gerência, empregados } \\
\text { (técnicos especializados) e } \\
\text { organizações do } \\
\text { agronegócio brasileiro. }\end{array}$ & $\begin{array}{l}\text { Corpo diretivo, alta } \\
\text { gerência, empregados } \\
\text { (selecionados) e Conselho } \\
\text { de Desenvolvimento Rural } \\
\text { Sustentável e Solidário. } \\
\end{array}$ & $\begin{array}{l}\text { Corpo diretivo e alta } \\
\text { gerência. }\end{array}$ \\
\hline $\begin{array}{l}\text { 2.1.3. Tipos de } \\
\text { Objetivos }\end{array}$ & Objetivos estratégicos. & Objetivos estratégicos. & Objetivos estratégicos. \\
\hline $\begin{array}{l}\text { 2.1.4. Níveis } \\
\text { Organizacionais dos } \\
\text { Objetivos }\end{array}$ & $\begin{array}{l}\text { Objetivos em nível de } \\
\text { entidade. }\end{array}$ & $\begin{array}{l}\text { Objetivos em nível de } \\
\text { entidade. }\end{array}$ & $\begin{array}{l}\text { Objetivos em nível de } \\
\text { entidade. }\end{array}$ \\
\hline $\begin{array}{l}\text { 2.1.5. Mensuração } \\
\text { dos Objetivos }\end{array}$ & $\begin{array}{l}\text { Parte dos objetivos } \\
\text { estratégicos possui } \\
\text { indicadores de desempenho } \\
\text { mensurados e metas } \\
\text { definidas. }\end{array}$ & $\begin{array}{l}\text { Todos os objetivos } \\
\text { estratégicos possuem } \\
\text { indicadores de desempenho } \\
\text { mensurados e metas } \\
\text { definidas. }\end{array}$ & $\begin{array}{l}\text { Parte dos objetivos } \\
\text { estratégicos possui } \\
\text { indicadores de } \\
\text { desempenho } \\
\text { mensurados e metas } \\
\text { definidas. }\end{array}$ \\
\hline
\end{tabular}

Fonte: Dados da pesquisa.

A definição de objetivos de forma clara e completa é primordial para o cumprimento da missão de uma organização. Todas as entidades possuem objetivos estabelecidos; contudo, em todas as entidades a definição dos objetivos se deu em processos $a d$ hoc de planejamento estratégico, inexistindo definição de processo nas entidades para a definição e revisão dos objetivos; trata-se de objetivos estratégicos, estabelecidos em nível de entidade, ausente o desdobramento em objetivos operacionais, de conformidade e relatórios, bem como o desdobramento até o nível de atividades. A participação dos empregados e terceiros interessados também é restrita. Destacou-se a mensuração dos objetivos do Incra, que incluiu ao menos um indicador de desempenho para mensurar os objetivos em todas as dimensões da sua estratégia.

O quadro a seguir apresenta os riscos identificados com embasamento nas características da subdimensão, diagnosticadas pela aplicação do modelo de maturidade 
desenvolvido neste trabalho, e as respectivas recomendações para o aprimoramento das estruturas de controle interno das entidades estudadas.

Quadro 41 - Riscos e Recomendações da Subdimensão 2.1 - Definição de Objetivos

\begin{tabular}{|c|c|}
\hline Riscos & Recomendações \\
\hline $\begin{array}{l}\text { (MAPA, Incra, Conab) Os objetivos da entidade não } \\
\text { sejam definidos em razão da ausência de um processo } \\
\text { formalmente definido. } \\
\text { (MAPA, Incra, Conab) Os objetivos da entidade não } \\
\text { sejam definidos em termos acurados, completos e } \\
\text { claros por não terem sido definidos de maneira } \\
\text { ordenada. } \\
\text { (MAPA, Incra, Conab) Os objetivos da entidade } \\
\text { deixem de ser relevantes em razão de mudanças no } \\
\text { ambiente de atuação, nas atividades realizadas, nas } \\
\text { atribuições legais ou nas políticas públicas de sua } \\
\text { responsabilidade. }\end{array}$ & $\begin{array}{l}\text { (MAPA, Incra, Conab) Estabelecer um processo } \\
\text { formal para a definição de objetivos na entidade, } \\
\text { determinando a sua repetição periódica para a análise } \\
\text { da relevância e ajuste dos objetivos definidos. }\end{array}$ \\
\hline $\begin{array}{l}\text { (MAPA, Incra, Conab) Ausência ou falta de clareza } \\
\text { dos objetivos das unidades, departamentos e } \\
\text { processos e atividades relevantes para a realização } \\
\text { dos objetivos da entidade. } \\
\text { (MAPA, Incra, Conab) Falta de coesão entre os } \\
\text { objetivos gerais da entidade e os objetivos das } \\
\text { unidades, departamentos, e processos e atividades } \\
\text { relevantes para a realização de seus objetivos. }\end{array}$ & $\begin{array}{l}\text { (MAPA, Incra, Conab) Incluir no processo de } \\
\text { definição de objetivos da entidade o desdobramento } \\
\text { dos objetivos gerais em objetivos para as unidades e } \\
\text { departamentos que desempenham funções finalísticas } \\
\text { e de suporte relevantes, e o desdobramento em } \\
\text { objetivos para os processos e atividades relevantes } \\
\text { para a realização de seus objetivos. }\end{array}$ \\
\hline $\begin{array}{l}\text { (MAPA, Incra, Conab) Ausência ou falta de clareza } \\
\text { dos objetivos operacionais, de comunicação e de } \\
\text { conformidade da entidade. } \\
\text { (MAPA, Incra, Conab) Falta de coesão entre os } \\
\text { objetivos estratégicos da entidade e os objetivos } \\
\text { operacionais, de comunicação e de conformidade. }\end{array}$ & $\begin{array}{l}\text { (MAPA, Incra, Conab) Incluir no processo de } \\
\text { definição de objetivos da entidade o desdobramento } \\
\text { dos objetivos estratégicos em objetivos operacionais, } \\
\text { de comunicação e de conformidade. }\end{array}$ \\
\hline $\begin{array}{l}\text { (MAPA, Incra, Conab) Os objetivos da entidade não } \\
\text { sejam definidos de forma acurada, completa e clara } \\
\text { em razão da desconsideração das expectativas das } \\
\text { partes interessadas nas suas atividades e nas políticas } \\
\text { públicas de sua responsabilidade. }\end{array}$ & $\begin{array}{l}\text { (MAPA, Incra, Conab) Incluir no processo de } \\
\text { definição de objetivos da entidade a participação de } \\
\text { corpo diretivo, gerência, empregados e outras partes } \\
\text { interessadas. }\end{array}$ \\
\hline $\begin{array}{l}\text { (MAPA, Conab) Impossibilidade de mensurar o } \\
\text { progresso da entidade na realização de seus objetivos. } \\
\text { (MAPA, Incra, Conab) Descumprimento das } \\
\text { expectativas de prazo na realização dos objetivos da } \\
\text { entidade. } \\
\text { (MAPA, Incra, Conab) Indisponibilidade ou } \\
\text { insuficiência de recursos para a realização dos } \\
\text { objetivos da entidade. }\end{array}$ & $\begin{array}{l}\text { (MAPA, Conab) Incluir no processo de definição de } \\
\text { objetivos da entidade a definição de indicadores e } \\
\text { metas de desempenho. } \\
\text { (MAPA, Incra, Conab) Incluir no processo de } \\
\text { definição de objetivos da entidade a definição de } \\
\text { cronograma e orçamento para a realização dos } \\
\text { objetivos. }\end{array}$ \\
\hline
\end{tabular}

Fonte: Elaborado pelo autor. 


\subsubsection{Resultados da Variável 2.2.1 - Processo de Avaliação de Riscos}

Quadro 42 - Resultados da Variável 2.2.1 - Processo de Avaliação de Riscos

\begin{tabular}{|c|l|l|l|}
\hline \multicolumn{1}{|c|}{ (0) Incipiente } & \multicolumn{1}{c|}{ (1) Inicial } & \multicolumn{1}{c|}{ (2) Em Formação } & \multicolumn{1}{c|}{ (3) Estabelecido } \\
\hline $\begin{array}{l}\text { Ausência de processo } \\
\text { para a avaliação de } \\
\text { riscos. }\end{array}$ & $\begin{array}{l}\text { Entidade possui } \\
\text { avaliação de riscos } \\
\text { realizada de forma } \\
\text { casuística, sem processo } \\
\text { formalmente } \\
\text { estabelecido. }\end{array}$ & $\begin{array}{l}\text { Entidade possui processo } \\
\text { formalmente } \\
\text { estabelecido para a } \\
\text { avaliação de riscos. }\end{array}$ & $\begin{array}{l}\text { Processo de avaliação de } \\
\text { riscos é realizado } \\
\text { periodicamente (mínimo } \\
\text { de uma vez ao ano), para } \\
\text { a reavaliação dos riscos. }\end{array}$ \\
\hline MAPA & Não & Não & Não \\
\hline Incra & Não & Não & Não \\
\hline Conab & Sim & Não \\
\hline
\end{tabular}

Fonte: Dados da pesquisa.

Para a análise da maturidade nesta variável foram solicitados às entidades estudadas os seguintes documentos: Normas e regulamentos referentes aos processos de avaliação de riscos corporativos; Relatórios de avaliação de riscos corporativos; Relatórios de avaliação de riscos das atividades dos principais processos.

O MAPA criou em 2015 o Grupo Executivo de Controle de Risco Operacional GECRO (Portaria SE n 1.674/2015), que tem entre suas atribuições "identificar os processos de trabalho e rotinas que apresentem maior sensibilidade à incidência de desconformidade no cumprimento dos atos normativos e legais vigentes". Não obstante, ainda não existe evidência da realização de uma avaliação de risco.

O Incra não apresentou documentos para evidenciar o atendimento aos critérios da variável.

A Conab apresentou relatório de implantação da gestão de riscos na Superintendência de Operações Comerciais - SUOPE, no ano de 2015. De acordo com o relatório, os gestores da SUOPE receberam capacitação para a gestão de riscos, oportunidade em que foram realizados os procedimentos de identificação dos riscos, análise da significância e definição das respostas aos riscos de parte dos processos da Superintendência. Assim, a Conab atende ao critério do nível de maturidade (1) Inicial.

A existência de um processo formalmente estabelecido é necessária para que a avaliação de riscos seguindo um procedimento ordenado e sistemático, capaz de responder aos riscos decorrentes das exigências de desempenho e accountability da administração pública gerencial (BARRETT, 2000). 
A revisão periódica é importante para verificação da relevância e identificação de novos riscos decorrentes de mudanças no ambiente, atribuições legais e políticas públicas de responsabilidade da entidade (COSO, 2013). A ausência de um processo formal para a avaliação de riscos e sua revisão periódica pode resultar em riscos não identificados, vieses na análise da significância e ausência de resposta aos riscos, prejudicando a realização dos objetivos da entidade.

\subsubsection{Resultados da Variável 2.2.2 - Participantes da Avaliação de Riscos}

Quadro 43 - Resultados da Variável 2.2.2 - Participantes da Avaliação de Riscos

\begin{tabular}{|c|l|l|l|}
\hline \multicolumn{1}{|c|}{ (0) Incipiente } & \multicolumn{1}{c|}{ (1) Inicial } & \multicolumn{1}{c|}{ (2) Em Formação } & \multicolumn{1}{c|}{ Estabelecido } \\
\hline $\begin{array}{l}\text { Ausência de definição } \\
\text { dos participantes do } \\
\text { processo de avaliação de } \\
\text { riscos. }\end{array}$ & $\begin{array}{l}\text { O processo de avaliação } \\
\text { de riscos tem a } \\
\text { participação do corpo } \\
\text { diretivo e alta gerência } \\
\text { da entidade. }\end{array}$ & $\begin{array}{l}\text { O processo de avaliação } \\
\text { de riscos tem a } \\
\text { participação da gerência } \\
\text { e empregados, inclusive } \\
\text { das funções de suporte } \\
\text { relevantes para a } \\
\text { realização dos objetivos } \\
\text { da entidade. }\end{array}$ & $\begin{array}{l}\text { O processo de riscos inclui } \\
\text { bencharking ou } \\
\text { participação de auditor } \\
\text { ou especialista externo à } \\
\text { entidade. }\end{array}$ \\
\hline MAPA & Não & Não & Não \\
\hline Incra & Não & Sim & Não \\
\hline Conab & Não & & Não \\
\hline
\end{tabular}

Fonte: Dados da pesquisa.

Para a análise da maturidade nesta variável foram solicitados às entidades estudadas os seguintes documentos: Normas e regulamentos referentes aos processos de avaliação de riscos corporativos; Relatórios de avaliação de riscos corporativos; Relatórios de avaliação de riscos das atividades dos principais processos.

O MAPA e o Incra não apresentaram evidências de realização de avaliação de riscos. Na Conab, o relatório de implantação da gestão de riscos na SUOPE informa que a avaliação dos riscos foi realizada no âmbito de uma ação de capacitação que envolveu gerentes e empregados indicados de cada área da SUOPE. Nesse sentido, embora não tenha evidenciado o atendimento ao critério do nível de maturidade (1) Inicial, a avaliação de riscos da Conab atende ao critério do nível de maturidade (2) Em Formação.

A participação de um amplo conjunto de interessados na avaliação dos riscos da organização é necessária para que a identificação, análise e resposta aos riscos seja feita por indivíduos com diferentes perspectivas, experiência e conhecimento (GAO, 2001). Empregados e gerentes de níveis organizacionais inferiores possuem conhecimento e experiência em razão da realização cotidiana dos processos e atividades pelos quais são responsáveis. A alta gerência agrega a visão das conexões entre os processos e dos requisitos do produto final a ser entregue pela organização. O envolvimento da alta gerência e direção executiva na avaliação de riscos é 
importante também para a definição das respostas aos riscos. Desse modo, uma avaliação de riscos que envolva apenas um conjunto restrito de participantes pode resultar em riscos não identificados, vieses na análise da significância e ausência de resposta aos riscos, prejudicando a realização dos objetivos da entidade.

\subsubsection{Resultados da Variável 2.2.3 - Fatores Considerados na Avaliação de Riscos}

Quadro 44 - Resultados da Variável 2.2.3 - Fatores Considerados na Avaliação de Riscos

\begin{tabular}{|c|c|c|c|}
\hline (0) Incipiente & (1) Inicial & (2) Em Formação & (3) Estabelecido \\
\hline $\begin{array}{l}\text { Ausência de definição } \\
\text { dos fatores que devem } \\
\text { ser considerados na } \\
\text { avaliação de riscos. }\end{array}$ & $\begin{array}{l}\text { O processo de avaliação } \\
\text { de riscos considera } \\
\text { fatores internos e } \\
\text { externos à entidade. }\end{array}$ & $\begin{array}{l}\text { O processo de avaliação } \\
\text { de riscos da entidade } \\
\text { inclui mecanismos para a } \\
\text { antecipar a identificação, } \\
\text { análise e resposta a riscos } \\
\text { decorrentes de mudanças } \\
\text { (no ambiente externo, } \\
\text { nas políticas públicas de } \\
\text { responsabilidade da } \\
\text { entidade e na liderança } \\
\text { da entidade). }\end{array}$ & $\begin{array}{l}\text { O processo de avaliação } \\
\text { de riscos inclui o risco de } \\
\text { fraude (incentivos e } \\
\text { pressões, oportunidades, } \\
\text { atitudes e } \\
\text { racionalizações, } \\
\text { abordagens para burlar } \\
\text { controles). }\end{array}$ \\
\hline MAPA & Não & Não & Não \\
\hline Incra & Não & Não & Não \\
\hline Conab & Sim & Não & Não \\
\hline
\end{tabular}

Fonte: Dados da pesquisa.

Para a análise da maturidade nesta variável foram solicitados às entidades estudadas os seguintes documentos: Normas e regulamentos referentes aos processos de avaliação de riscos corporativos; Relatórios de avaliação de riscos corporativos; Relatórios de avaliação de riscos das atividades dos principais processos.

O MAPA e o Incra não apresentaram evidências de realização de avaliação de riscos. Na Conab, o relatório de implantação da gestão de riscos na SUOPE informa que a metodologia aplicada na avaliação de riscos considera os fatores infraestrutura, pessoal, processo, tecnologia e ambiente externo, atendendo ao critério do nível de maturidade (1) Inicial.

O COSO (2013) ressalta a importância de que a avaliação de riscos leve em consideração um amplo conjunto de fatores internos e externos, inclusive decorrentes de fraude, e a importância de antecipar-se a riscos decorrentes de mudanças que podem causar grande impacto na organização. De outro modo, riscos significativos podem deixar de ser identificados, analisados e respondidos, prejudicando a realização dos objetivos da entidade. 


\subsubsection{Resultados da Variável 2.2.4 - Níveis Organizacionais da Avaliação de Riscos}

Quadro 45 - Resultados da Variável 2.2.4 - Níveis Organizacionais da Avaliação de Riscos

\begin{tabular}{|c|l|l|c|}
\hline \multicolumn{1}{|c|}{ (0) Incipiente } & \multicolumn{1}{|c|}{ (1) Inicial } & \multicolumn{1}{c|}{ (2) Em Formação } & \multicolumn{1}{c|}{ Estabelecido } \\
\hline $\begin{array}{l}\text { Ausência de definição de } \\
\text { níveis organizacionais na } \\
\text { avaliação de riscos. }\end{array}$ & $\begin{array}{l}\text { Avaliação de riscos em } \\
\text { nível de atividade, para } \\
\text { os processos mais } \\
\text { relevantes para a } \\
\text { realização dos objetivos } \\
\text { da entidade. }\end{array}$ & $\begin{array}{l}\text { Avaliação de riscos } \\
\text { levando em consideração } \\
\text { as unidades e } \\
\text { subunidades } \\
\text { organizacionais. }\end{array}$ & $\begin{array}{l}\text { Avaliaçol de entidade. } \\
\text { nível }\end{array}$ \\
\hline MAPA & Não & Não & Não \\
\hline Incra & Não & Não & Não \\
\hline Conab & Parcial & Não \\
\hline
\end{tabular}

Fonte: Dados da pesquisa.

Para a análise da maturidade nesta variável foram solicitados às entidades estudadas os seguintes documentos: Normas e regulamentos referentes aos processos de avaliação de riscos corporativos; Relatórios de avaliação de riscos corporativos; Relatórios de avaliação de riscos das atividades dos principais processos.

O MAPA e o Incra não apresentaram evidências de realização de avaliação de riscos. Na Conab, o relatório de implantação da gestão de riscos na SUOPE informa que a avaliação de risco foi feita em nível de atividade. Apesar disso, realizou-se apenas em parte das atividades de um dos processos da SUOPE. Assim, entende-se que a Conab atende apenas parcialmente ao critério do nível de maturidade (1) Inicial.

De acordo com o GAO (2001), é importante que os riscos sejam avaliados nos diversos níveis organizacionais. Enquanto os gerentes operacionais e funcionais possuem a visão dos processos e atividades pelas quais são responsáveis, os gerentes de unidade e a alta gerência possuem a visão das conexões entre os diferentes processos e sua influência nas entregas para as partes interessadas. A avaliação de riscos em nível de unidades e subunidades organizacionais deve incluir ainda considerações relacionadas ao âmbito de sua atuação, como leis e regulamentos locais, e características sociais e culturais específicas (COSO, 2013). Assim, a avaliação de riscos nesses níveis vai além da compilação dos riscos identificados nos níveis organizacionais inferiores. A ausência de avaliação de riscos nos níveis de entidade, unidades e subunidades pode resultar numa identificação de riscos incompleta, permitindo prejuízos à realização dos objetivos da organização. 


\subsubsection{Análise Comparativa da Subdimensão 2.2 - Identificação, Análise e Resposta}

aos Riscos

Quadro 46 - Análise Comparativa da Subdimensão 2.2 - Identificação, Análise e Resposta aos Riscos

\begin{tabular}{|l|l|l|l|}
\hline \multicolumn{1}{|c|}{ Variáveis } & \multicolumn{1}{|c|}{ MAPA } & \multicolumn{1}{c|}{ Incra } & \multicolumn{1}{c|}{ Conab } \\
\hline $\begin{array}{l}\text { 2.2.1. Processo de } \\
\text { Avaliação de Riscos }\end{array}$ & $\begin{array}{l}\text { Não apresentou evidências } \\
\text { de processo para a } \\
\text { avaliação de riscos. }\end{array}$ & $\begin{array}{l}\text { Não apresentou evidências } \\
\text { de processo para a } \\
\text { avaliação de riscos. }\end{array}$ & $\begin{array}{l}\text { Avaliação de riscos } \\
\text { realizada de forma } \\
\text { casuística. }\end{array}$ \\
\hline $\begin{array}{l}\text { 2.2.2. Participantes da } \\
\text { Avaliação de Riscos }\end{array}$ & $\begin{array}{l}\text { Não apresentou evidências } \\
\text { de participantes na } \\
\text { avaliação de riscos. }\end{array}$ & $\begin{array}{l}\text { Não apresentou evidências } \\
\text { de participantes na } \\
\text { avaliação de riscos. }\end{array}$ & $\begin{array}{l}\text { Gerentes dos } \\
\text { processos e } \\
\text { atividades avaliados. }\end{array}$ \\
\hline $\begin{array}{l}\text { 2.2.3. Fatores } \\
\text { Considerados na } \\
\text { Avaliação de Riscos }\end{array}$ & $\begin{array}{l}\text { Não apresentou evidências } \\
\text { de fatores de avaliação de } \\
\text { riscos. }\end{array}$ & $\begin{array}{l}\text { Não apresentou evidências } \\
\text { de fatores de avaliação de } \\
\text { riscos. }\end{array}$ & $\begin{array}{l}\text { Fatores de risco } \\
\text { internos e externos. }\end{array}$ \\
\hline $\begin{array}{l}\text { 2.2.4. Níveis } \\
\text { Organizacionais da } \\
\text { Avaliação de Riscos }\end{array}$ & $\begin{array}{l}\text { Não apresentou evidências } \\
\text { de níveis organizacionais } \\
\text { de avaliação de riscos. }\end{array}$ & $\begin{array}{l}\text { Não apresentou evidências } \\
\text { de níveis organizacionais } \\
\text { de avaliação de riscos. }\end{array}$ & $\begin{array}{l}\text { Avaliação em nível } \\
\text { de atividade, para um } \\
\text { dos principais } \\
\text { processos. }\end{array}$ \\
\hline
\end{tabular}

Fonte: Dados da pesquisa.

A avaliação de riscos é importante para que uma organização cumpra seus objetivos, dando embasamento à elaboração dos controles internos, os quais devem concretizar a resposta aos riscos, conforme a sua avaliação. Constatou-se que MAPA e Incra ainda não realizam avaliações de riscos, enquanto a Conab apenas iniciou a implantação do seu processo. A ausência de um processo estruturado para a avaliação de riscos deixa os controles sem referência dos eventos que podem causar prejuízos a realização dos objetivos da entidade, diminuindo a eficácia da estrutura de controle interno.

O quadro a seguir apresenta os riscos identificados com embasamento nas características da subdimensão, diagnosticadas pela aplicação do modelo de maturidade desenvolvido neste trabalho, e as respectivas recomendações para o aprimoramento das estruturas de controle interno das entidades estudadas.

Quadro 47 - Riscos e Recomendações da Subdimensão 2.2 - Identificação, Análise e Resposta aos Riscos

\begin{tabular}{|l|l|}
\hline \multicolumn{1}{|c|}{ Riscos } & \multicolumn{1}{c|}{ Recomendações } \\
\hline $\begin{array}{l}\text { (MAPA, Incra, Conab) Os riscos da entidade não } \\
\text { sejam avaliados em razão da ausência de um } \\
\text { processo formalmente definido. }\end{array}$ & $\begin{array}{l}\text { (MAPA, Incra, Conab) Estabelecer um processo } \\
\text { formal para a identificação, análise e resposta a riscos } \\
\text { no âmbito da entidade, determinando a sua repetição } \\
\text { periódica para a análise da relevância e ajuste da } \\
\text { avaliação de riscos. }\end{array}$ \\
$\begin{array}{l}\text { resposta dos riscos da entidade não produzam } \\
\text { resultados adequados por não terem sido realizadas } \\
\text { de forma ordenada. }\end{array}$ & \\
$\begin{array}{l}\text { (MAPA, Incra, Conab) A avaliação de riscos da } \\
\text { entidade deixe de ser relevante em razão de } \\
\text { mudanças no ambiente de atuação, nas atividades } \\
\text { realizadas, nas atribuições legais ou nas políticas } \\
\text { públicas de sua responsabilidade. }\end{array}$ & \\
\hline
\end{tabular}

Continua na página seguinte. 
Continuação do Quadro 47 - Riscos e Recomendações da Subdimensão 2.2 - Identificação, Análise e Resposta aos Riscos

\begin{tabular}{|c|c|}
\hline Riscos & Recomendações \\
\hline $\begin{array}{l}\text { (MAPA, Incra, Conab) Não sejam identificados } \\
\text { riscos significativos da entidade em razão da ausência } \\
\text { de avaliação de riscos em parte dos níveis } \\
\text { organizacionais da entidade. } \\
\text { (MAPA, Incra, Conab) Não sejam identificados } \\
\text { riscos significativos da entidade em razão da falta de } \\
\text { coordenação entre as avaliações de riscos realizadas } \\
\text { nos diversos níveis organizacionais da entidade. }\end{array}$ & $\begin{array}{l}\text { (MAPA, Incra, Conab) Incluir no processo de } \\
\text { avaliação de riscos da entidade a avaliação de riscos } \\
\text { dos processos e atividades relevantes para a } \\
\text { realização de seus objetivos, a avaliação de riscos das } \\
\text { unidades e departamentos que desempenham funções } \\
\text { finalísticas e de suporte relevantes, e a avaliação de } \\
\text { riscos em nível de entidade. }\end{array}$ \\
\hline $\begin{array}{l}\text { (MAPA, Incra) Não sejam definidas respostas } \\
\text { adequadas a riscos significativos da entidade em } \\
\text { razão da desconsideração de fatores internos e } \\
\text { externos. } \\
\text { (MAPA, Incra, Conab) Não sejam definidas respostas } \\
\text { adequadas a riscos significativos da entidade em } \\
\text { razão da desconsideração de fatores de risco } \\
\text { decorrentes de mudanças relevantes e fatores } \\
\text { relacionados a fraude. }\end{array}$ & $\begin{array}{l}\text { (MAPA, Incra) Incluir no processo de avaliação de } \\
\text { riscos da entidade a consideração de fatores de risco } \\
\text { internos e externos. } \\
\text { (MAPA, Incra, Conab) Incluir no processo de } \\
\text { avaliação de riscos da entidade a antecipação da } \\
\text { identificação, análise e resposta a mudanças } \\
\text { relevantes e a consideração de fatores de risco de } \\
\text { fraude (incentivos, pressões, oportunidades, } \\
\text { racionalizações e abordagens para burlar controles). }\end{array}$ \\
\hline $\begin{array}{l}\text { (MAPA, Incra, Conab) Não sejam identificados } \\
\text { riscos significativos para a entidade em razão da } \\
\text { ausência de participantes com conhecimento, } \\
\text { experiência e objetividade no processo de avaliação } \\
\text { de riscos. } \\
\text { (MAPA, Incra, Conab) A significância dos riscos da } \\
\text { entidade não seja analisada de forma acurada em } \\
\text { razão da ausência de participantes com } \\
\text { conhecimento, experiência e objetividade no } \\
\text { processo de avaliação de riscos. } \\
\text { (MAPA, Incra, Conab) Parte das respostas definidas } \\
\text { para os riscos da entidade não sejam concretizadas } \\
\text { em razão da ausência de participantes com autoridade } \\
\text { para comprometer os recursos necessários no } \\
\text { processo de avaliação de riscos. }\end{array}$ & $\begin{array}{l}\text { (MAPA, Incra, Conab) Incluir no processo de } \\
\text { avaliação de riscos da entidade a participação de } \\
\text { corpo diretivo, gerência, empregados e terceiros } \\
\text { interessados. }\end{array}$ \\
\hline
\end{tabular}

Fonte: Elaborado pelo autor.

\subsubsection{Avaliação do Nível de Maturidade das Entidades na Dimensão 2 - Avaliação de Riscos}

O quadro a seguir apresenta o resultado dos procedimentos de avaliação do nível de maturidade das entidades estudadas na dimensão Avaliação de Riscos, considerando o peso de cada nível de maturidade, definido pela média dos pesos estabelecidos pelo atendimento dos critérios dentro das variáveis da dimensão, conforme o apêndice $\mathrm{J}$ deste trabalho. 
Quadro 48 - Avaliação do Nível de Maturidade das Entidades na Dimensão 2 - Avaliação de Riscos

\begin{tabular}{|c|c|c|c|}
\hline Nível de Maturidade & MAPA & Incra & Conab \\
\hline (0) Incipiente & $44,4 \%$ & $44,4 \%$ & $0,0 \%$ \\
\hline (1) Inicial & $50,0 \%$ & $55,6 \%$ & $77,8 \%$ \\
\hline (2) Em Formação & $16,7 \%$ & $16,7 \%$ & $22,2 \%$ \\
\hline (3) Estabelecido & $11,1 \%$ & $5,6 \%$ & $0,0 \%$ \\
\hline Avaliação & (1) Inicial & (1) Inicial & (1) Inicial \\
\hline
\end{tabular}

Fonte: Dados da pesquisa.

Apesar de os procedimentos de avaliação terem conferido a todas as entidades estudadas o nível de maturidade (1) Inicial, cabe observar que MAPA e Incra não apresentaram evidencias de terem realizado avaliações de riscos, tendo alcançado este nível de maturidade em razão das características de definição de objetivos. Nesse sentido, a implantação de processos de gestão de riscos é a principal recomendação para o aperfeiçoamento das estruturas de controle interno de MAPA e Incra.

\subsection{RESULTADOS DA DIMENSÃO 3 - ATIVIDADES DE CONTROLE}

\subsubsection{Resultados da Subdimensão 3.1 - Projeto de Controles para Mitigação de} Riscos

\subsubsection{Resultados da Variável 3.1.1 - Documentação das Atividades de Controle}

Quadro 49 - Resultados da Variável 3.1.1 - Documentação das Atividades de Controle

\begin{tabular}{|c|c|l|l|}
\hline \multicolumn{1}{|c|}{ (0) Incipiente } & \multicolumn{1}{c|}{ (1) Inicial } & \multicolumn{1}{c|}{ (2) Em Formação } \\
\hline $\begin{array}{l}\text { Ausência de } \\
\text { documentação das } \\
\text { atividades de controle. }\end{array}$ & $\begin{array}{l}\text { Elaboração de Matriz de } \\
\text { Riscos e Controles. }\end{array}$ & $\begin{array}{l}\text { Documentação das } \\
\text { atividades de controle, } \\
\text { incluindo a infraestrutura } \\
\text { de tecnologia que provê } \\
\text { suporte ao } \\
\text { funcionamento dos } \\
\text { controles, seguindo } \\
\text { modelos padronizados } \\
\text { pela entidade. }\end{array}$ & $\begin{array}{l}\text { Mapeamento dos } \\
\text { processos relevantes para } \\
\text { a realização dos } \\
\text { objetivos da entidade, em } \\
\text { nível de atividade. }\end{array}$ \\
\hline MAPA & Não & Não & Não \\
\hline Incra & Não & Não & Não \\
\hline Conab & Não & Não \\
\hline
\end{tabular}

Fonte: Dados da pesquisa.

Para a análise da maturidade nesta variável foram solicitados às entidades estudadas os seguintes documentos: Matrizes de riscos e controles; Mapas dos principais processos; Descrição dos principais processos; Descrição das atividades dos principais processos; Manuais de procedimentos das atividades dos principais processos; Inventários de atividades de controle; Descrição das atividades de controle; Descrição das atividades de controle dos principais processos; Manuais de procedimentos das atividades de controle dos principais processos. 
O MAPA e o Incra não apresentaram evidências do cumprimento dos critérios da variável; a Conab possui mapeamento de 14 macroprocessos, mas não há mapeamento em nível de atividade e não foi identificada a relação entre os macroprocessos e os objetivos da entidade.

O COSO (2013b) recomenda que a gerência das entidades utilize métodos diversos (matrizes, oficinas, inventários) para mapear as atividades de controle aos riscos identificados, descrevendo as atividades de controle em detalhe suficiente para a avaliação de sua suficiência para responder aos riscos identificados. Assim, a documentação das atividades de controle é importante para que as entidades compreendam o estado atual de seus sistemas de controle interno, quais riscos estão sendo abordados, quais são os requisitos para o seu adequado funcionamento, inclusive a dependência da tecnologia, como os controles concretizam a resposta aos riscos e quais são os resultados esperados dos controles.

\subsubsection{Resultados da Variável 3.1.2 - Níveis Organizacionais das Atividades de Controle}

Quadro 50 - Resultados da Variável 3.1.2 - Níveis Organizacionais das Atividades de Controle

\begin{tabular}{|c|l|l|l|}
\hline \multicolumn{1}{|c|}{ (0) Incipiente } & \multicolumn{1}{c|}{ (1) Inicial } & \multicolumn{1}{c|}{ (2) Em Formação } & \multicolumn{1}{c|}{ Estabelecido } \\
\hline $\begin{array}{l}\text { Ausência de diagnóstico } \\
\text { dos níveis } \\
\text { organizacionais das } \\
\text { atividades de controle. }\end{array}$ & $\begin{array}{l}\text { Atividades de controle } \\
\text { em nível de transações, } \\
\text { para os processos } \\
\text { relevantes para a } \\
\text { realização dos objetivos } \\
\text { da entidade. }\end{array}$ & $\begin{array}{l}\text { Atividades de controle } \\
\text { em nível de unidades e } \\
\text { subunidades } \\
\text { organizacionais. }\end{array}$ & $\begin{array}{l}\text { Atividades de controle } \\
\text { em nível de entidade e } \\
\text { controles para terceiros } \\
\text { que realizam funções } \\
\text { relevantes para a } \\
\text { realização dos objetivos } \\
\text { da entidade. }\end{array}$ \\
\hline MAPA & Não & Não & Não \\
\hline Incra & Não & Não & Não \\
\hline Conab & Não & Não & \\
\hline
\end{tabular}

Fonte: Dados da pesquisa.

Para a análise da maturidade nesta variável foram solicitados às entidades estudadas os seguintes documentos: Mapas dos principais processos; Descrição dos principais processos; Descrição das atividades dos principais processos; Manuais de procedimentos das atividades dos principais processos; Inventários de atividades de controle; Descrição das atividades de controle; Descrição das atividades de controle dos principais processos; Manuais de procedimentos das atividades de controle dos principais processos.

Nenhuma das entidades estudadas apresentou evidências de cumprimento dos critérios da variável.

Os controles são a forma de concretizar a resposta aos riscos da entidade. O COSO (2013) entende que, além dos controles em nível de transação, é necessário que as entidades estabeleçam controles mais abrangentes, como revisões de desempenho de negócios e revisões 
analíticas, em níveis organizacionais mais altos. Assim, é necessária a definição de atividades de controle nos diversos níveis organizacionais da entidade, respondendo aos riscos identificados e analisados especificamente em cada nível organizacional.

\subsubsection{Resultados da Variável 3.1.3 - Representação Fidedigna da Informação}

\section{Contábil-Financeira}

Quadro 51 - Resultados da Variável 3.1.3 - Representação Fidedigna da Informação Contábil-Financeira

\begin{tabular}{|l|l|l|l|}
\hline \multicolumn{1}{|c|}{ (0) Incipiente } & \multicolumn{1}{|c|}{ (1) Inicial } & \multicolumn{1}{c|}{ (2) Em Formação } & \multicolumn{1}{c|}{ Estabelecido } \\
\hline $\begin{array}{l}\text { Ausência de processos } \\
\text { para a representação } \\
\text { fidedigna da informação } \\
\text { contábil-financeira. }\end{array}$ & $\begin{array}{l}\text { Processos formalmente } \\
\text { estabelecidos para a } \\
\text { realização dos } \\
\text { Procedimentos Contábeis } \\
\text { Patrimoniais (MCASP } \\
\text { Parte II). }\end{array}$ & $\begin{array}{l}\text { Processo formalmente } \\
\text { estabelecidos para a } \\
\text { conformidade contábil } \\
\text { das demonstrações } \\
\text { financeiras. }\end{array}$ & $\begin{array}{l}\text { Processo formalmente } \\
\text { estabelecidos para a } \\
\text { conciliação entre os } \\
\text { dados registrados no } \\
\text { SIAFI e outros sistemas } \\
\text { da Administração } \\
\text { Pública Federal } \\
\text { (SPIUNET, SIASG, } \\
\text { RMB). }\end{array}$ \\
\hline MAPA & Parcial & Não \\
\hline Incra & Parcial & Parcial & Não \\
\hline Conab & Parcial & Parcial & Não \\
\hline
\end{tabular}

Fonte: Dados da pesquisa.

Para a análise da maturidade nesta variável foram solicitados às entidades estudadas os seguintes documentos: Normas e regulamentos referentes aos processos para a realização dos procedimentos contábeis patrimoniais (MCASP Parte II); Mapas dos processos para a realização dos procedimentos contábeis patrimoniais (MCASP Parte II); Demonstrações contábeis; Normas e regulamentos referentes aos processos para a conformidade das demonstrações contábeis (conformidade contábil); Mapas dos processos para a conformidade das demonstrações contábeis (conformidade contábil); Normas e regulamentos referentes aos processos para a conciliação das informações contábeis; Mapas dos processos para a conciliação das informações contábeis.

O MAPA informa no Relatório de Gestão do exercício de 2015 que realiza a depreciação e amortização dos bens registrados no ativo imobilizado, conforme a macro função do SIAFI “02.03.30 - Reavaliação, Redução a Valor Recuperável, Depreciação, Amortização e Exaustão na Administração Direta da União, Autarquia e Fundações”. As demonstrações contábeis do MAPA, do exercício de 2015, apresentam as seguintes contas contábeis e valores: Depreciação/Amortização/Exaustão Acumulada de Bens Móveis (R \$ 93.269.458,95); Redução ao Valor Recuperável de Bens Móveis ( $\mathrm{R}$ \$ 22.198.503,36); Depreciação / Amortização / Exaustão Acumulada de Bens Imóveis (R \$ 2.209.540,59); e Amortização Acumulada de 
Softwares ( $\mathrm{R} \$ 4.338 .133,75)$. Assim, entende-se que o MAPA atende parcialmente ao critério do nível de maturidade (1) Inicial.

O Incra informa no Relatório de Gestão do exercício de 2015 que adota o mesmo procedimento realizado pelo MAPA para depreciação, amortização e exaustão, acrescentando que realiza procedimentos de reavaliação de bens imóveis por meio do sistema SPIUnet. As demonstrações contábeis do Incra, do exercício de 2015, apresentam as seguintes contas contábeis e valores: Depreciação/Amortização/Exaustão Acumulada de Bens Móveis (R\$ 47.891.146,80); Depreciação/Amortização/Exaustão Acumulada de Bens Imóveis (R\$ 1.481.666,53); e Amortização Acumulada de Marcas, Direitos e Patentes Industriais (R\$ 200,75). Assim, entende-se que o Incra atende parcialmente ao critério do nível de maturidade (1) Inicial.

As demonstrações contábeis da Conab, do exercício de 2015, apresentam as seguintes contas contábeis e valores: Redução ao Valor Recuperável de Participações Permanentes (R\$ 8.047.210,53); Depreciação Acumulada de Propriedades para Investimentos (R \$ 4.447.991,78); Depreciação/Amortização/Exaustão Acumulada de Bens Móveis (R\$ 77.843.751,48); Depreciação/Amortização/Exaustão Acumulada de Bens Imóveis (R 170.851.036,76); e Amortização Acumulada de Softwares (R\$ 181.958,98). Assim, entende-se que a Conab cumpre parcialmente o critério do nível de maturidade (1) Inicial.

Consulta ao SIAFI informa que o MAPA, o Incra e a Conab efetuaram o registro da conformidade contábil das demonstrações em todos os meses do exercício de 2015. Apesar disso, como nenhuma das entidades apresentou evidência de estabelecimento de um processo para a realização da conformidade contábil, entende-se que atende apenas parcialmente ao critério do nível de maturidade (2) Em Formação.

Nenhuma das entidades apresentou evidências de cumprimento do critério do nível de maturidade (3) Estabelecido.

Com a adoção de padrões contábeis convergentes às normas internacionais, a contabilidade governamental brasileira deixa de ter foco exclusivo no orçamento público, resgatando o foco patrimonial (AMARAL; DE LIMA, 2013). Assim, é importante que as organizações governamentais adotem processos para que as informações contábeis e financeiras sejam elaboradas e evidenciadas de forma relevante e fidedigna, propiciando melhor fundamentação para a tomada de decisão da gerência e para a avaliação da gestão pelas instâncias de controle. 


\subsubsection{Resultados da Variável 3.1.4 - Segregação de Funções}

\section{Quadro 52 - Resultados da Variável 3.1.4 - Segregação de Funções}

\begin{tabular}{|c|c|c|c|}
\hline (0) Incipiente & (1) Inicial & (2) Em Formação & (3) Estabelecido \\
\hline $\begin{array}{l}\text { Ausência de diagnóstico } \\
\text { da segregação de funções } \\
\text { nos processos, políticas e } \\
\text { procedimentos relevantes } \\
\text { para a realização dos } \\
\text { objetivos da entidade. }\end{array}$ & $\begin{array}{l}\text { A entidade elabora } \\
\text { matriz de controle de } \\
\text { acesso e segregação de } \\
\text { funções (autorização, } \\
\text { aprovação e verificação) } \\
\text { para os processos, } \\
\text { políticas e procedimentos } \\
\text { relevantes para a } \\
\text { realização dos objetivos } \\
\text { da entidade. }\end{array}$ & $\begin{array}{l}\text { A entidade identifica os } \\
\text { processos, políticas e } \\
\text { procedimentos relevantes } \\
\text { para a realização dos } \\
\text { objetivos que não podem } \\
\text { ter a segregação de } \\
\text { funções adequada e } \\
\text { elabora atividades de } \\
\text { controle alternativas. }\end{array}$ & $\begin{array}{l}\text { Política da entidade } \\
\text { determina a reavaliação } \\
\text { periódica da matriz de } \\
\text { controle de acesso e } \\
\text { segregação de funções. }\end{array}$ \\
\hline MAPA & Não & Não & Não \\
\hline Incra & Não & Não & Não \\
\hline Conab & Não & Não & Não \\
\hline
\end{tabular}

Fonte: Dados da pesquisa.

Para a análise da maturidade nesta variável foram solicitados às entidades estudadas os seguintes documentos: Mapas dos principais processos; Descrição dos principais processos; Descrição das atividades dos principais processos; Manuais de procedimentos das atividades dos principais processos; Matrizes de responsabilidades ou segregação de funções e controle de acesso dos principais processos; Norma que determina a reavaliação periódica das matrizes de responsabilidades ou segregação de funções e controle de acesso dos principais processos.

Nenhuma das entidades estudadas apresentou evidências de cumprimento dos critérios da variável.

A segregação de funções é mecanismo de controle de destacada relevância, em razão de sua eficácia na redução do risco de erros e ações fraudulentas, especialmente o management override. Desse modo, os principais processos da entidade devem ter segregadas as responsabilidades pela autorização, aprovação, registro e revisão das transações, além da guarda dos respectivos ativos, quando for o caso. Quando a segregação de funções for inviável, atividades de controle adicionais devem ser estabelecidas para reduzir o risco de erro ou fraude (COSO, 2013). 


\subsubsection{Análise Comparativa da Subdimensão 3.1 - Projeto de Controles para Mitigação de Riscos}

Quadro 53 - Análise Comparativa da Subdimensão 3.1 - Projeto de Controles para Mitigação de Riscos

\begin{tabular}{|c|c|c|c|}
\hline Variáveis & MAPA & Incra & Conab \\
\hline $\begin{array}{l}\text { 3.1.1. } \\
\text { Documentação das } \\
\text { Atividades de } \\
\text { Controle }\end{array}$ & $\begin{array}{l}\text { Não apresentou evidências } \\
\text { de documentação das } \\
\text { atividades de controle. }\end{array}$ & $\begin{array}{l}\text { Não apresentou evidências } \\
\text { de documentação das } \\
\text { atividades de controle. }\end{array}$ & $\begin{array}{l}\text { Não apresentou evidências } \\
\text { de documentação das } \\
\text { atividades de controle. }\end{array}$ \\
\hline $\begin{array}{l}\text { 3.1.2. Níveis } \\
\text { Organizacionais das } \\
\text { Atividades de } \\
\text { Controle }\end{array}$ & $\begin{array}{l}\text { Não apresentou evidências } \\
\text { dos níveis organizacionais } \\
\text { das atividades de controle. }\end{array}$ & $\begin{array}{l}\text { Não apresentou evidências } \\
\text { dos níveis organizacionais } \\
\text { das atividades de controle. }\end{array}$ & $\begin{array}{l}\text { Não apresentou evidências } \\
\text { dos níveis organizacionais } \\
\text { das atividades de controle. }\end{array}$ \\
\hline $\begin{array}{l}3.1 .3 . \\
\text { Representação } \\
\text { Fidedigna da } \\
\text { Informação } \\
\text { Contábil-Financeira }\end{array}$ & $\begin{array}{l}\text { Realização de } \\
\text { procedimentos contábeis } \\
\text { patrimoniais e registro da } \\
\text { conformidade das } \\
\text { demonstrações contábeis, } \\
\text { ambas sem processo } \\
\text { estabelecido. }\end{array}$ & $\begin{array}{l}\text { Realização de } \\
\text { procedimentos contábeis } \\
\text { patrimoniais e registro da } \\
\text { conformidade das } \\
\text { demonstrações contábeis, } \\
\text { ambas sem processo } \\
\text { estabelecido. }\end{array}$ & $\begin{array}{l}\text { Realização de } \\
\text { procedimentos contábeis } \\
\text { patrimoniais e registro da } \\
\text { conformidade das } \\
\text { demonstrações contábeis, } \\
\text { ambas sem processo } \\
\text { estabelecido. }\end{array}$ \\
\hline $\begin{array}{l}\text { 3.1.4. Segregação de } \\
\text { Funções }\end{array}$ & $\begin{array}{l}\text { Não apresentou evidências } \\
\text { da segregação de funções. }\end{array}$ & $\begin{array}{l}\text { Não apresentou evidências } \\
\text { da segregação de funções. }\end{array}$ & $\begin{array}{l}\text { Não apresentou evidências } \\
\text { da segregação de funções. }\end{array}$ \\
\hline
\end{tabular}

Fonte: Dados da pesquisa.

As organizações necessitam estabelecer controles internos para responder aos riscos que ameaçam a realização de seus objetivos. Os controles devem ser estabelecidos em todos os processos relevantes para a realização dos objetivos organizacionais, sem que seja desprezada a relação entre custo e benefício que existe em cada controle. A documentação incipiente das atividades de controle dificulta a avaliação da eficácia dos controles em responder adequadamente aos riscos das entidades.

O quadro a seguir apresenta os riscos identificados com embasamento nas características da subdimensão, diagnosticadas pela aplicação do modelo de maturidade desenvolvido neste trabalho, e as respectivas recomendações para o aprimoramento das estruturas de controle interno das entidades estudadas.

Quadro 54 - Riscos e Recomendações da Subdimensão 3.1 - Projeto de Controles para Mitigação de Riscos

\begin{tabular}{|c|c|}
\hline Riscos & Recomendações \\
\hline $\begin{array}{l}\text { (MAPA, Incra, Conab) As atividades de controle da } \\
\text { entidade não estabeleçam resposta a riscos significativos. } \\
\text { (MAPA, Incra, Conab) Os processos relevantes para a } \\
\text { realização dos objetivos da entidade não possuam } \\
\text { atividades de controle, ou possuam atividades de } \\
\text { controle inadequadas. } \\
\text { (MAPA, Incra, Conab) As atividades de controle da } \\
\text { entidade não sejam adequadamente executadas, deixando } \\
\text { de produzir os resultados esperados. } \\
\text { (MAPA, Incra, Conab) A infraestrutura de TI da } \\
\text { entidade que suporta o funcionamento das atividades de } \\
\text { controle não seja identificada e protegida. }\end{array}$ & $\begin{array}{l}\text { (MAPA, Incra, Conab) Documentar as atividades } \\
\text { de controle da entidade, incluindo matriz de } \\
\text { riscos e controles, mapeamento dos processos } \\
\text { relevantes para a realização dos objetivos da } \\
\text { entidade e descrição das atividades de controle, } \\
\text { inclusive da infraestrutura de TI que apoia o seu } \\
\text { funcionamento. }\end{array}$ \\
\hline
\end{tabular}

Continua na página seguinte. 


\begin{tabular}{|c|c|}
\hline Riscos & Recomendações \\
\hline $\begin{array}{l}\text { (MAPA, Incra, Conab) Riscos significativos dos } \\
\text { diversos níveis organizacionais da entidade não } \\
\text { possuam atividades de controle estabelecendo } \\
\text { respostas adequadas. }\end{array}$ & $\begin{array}{l}\text { (MAPA, Incra, Conab) Estabelecer atividades de } \\
\text { controle em todos os níveis organizacionais da } \\
\text { entidade, incluindo atividades de controle das } \\
\text { transações dos processos relevantes para a realização } \\
\text { de seus objetivos, atividades de controle nas unidades } \\
\text { e departamentos que desempenham funções } \\
\text { finalísticas e de suporte relevantes, e atividades de } \\
\text { controle em nível de entidade, inclusive para } \\
\text { terceiros relevantes. }\end{array}$ \\
\hline $\begin{array}{l}\text { (MAPA, Incra, Conab) Distorções relevantes nas } \\
\text { informações dos relatórios contábeis e financeiros da } \\
\text { entidade em razão da ausência de processo para a } \\
\text { execução adequada dos procedimentos contábeis } \\
\text { patrimoniais, da conformidade contábil e da } \\
\text { conciliação com as informações de sistemas externos } \\
\text { relevantes. }\end{array}$ & $\begin{array}{l}\text { (MAPA, Incra, Conab) Estabelecer processos formais } \\
\text { na entidade para a realização dos procedimentos } \\
\text { contábeis patrimoniais, a conformidade contábil das } \\
\text { demonstrações financeiras e a conciliação dos dados } \\
\text { registrados nos sistemas informatizados de } \\
\text { contabilidade e os dados dos sistemas informatizados } \\
\text { de aquisições, bens móveis e imóveis. }\end{array}$ \\
\hline $\begin{array}{l}\text { (MAPA, Incra, Conab) Os processos, políticas e } \\
\text { procedimentos relevantes para a realização dos } \\
\text { objetivos da entidade não tenham a segregação de } \\
\text { funções adequada. } \\
\text { (MAPA, Incra, Conab) A segregação de funções dos } \\
\text { processos, políticas e procedimentos relevantes para } \\
\text { a realização dos objetivos da entidade não atenda a } \\
\text { requisitos e expectativas decorrentes de mudanças no } \\
\text { ambiente de atuação, nas atividades realizadas, nas } \\
\text { atribuições legais ou nas políticas públicas de sua } \\
\text { responsabilidade. }\end{array}$ & $\begin{array}{l}\text { (MAPA, Incra, Conab) Realizar o diagnóstico da } \\
\text { segregação de funções nos processos, políticas e } \\
\text { procedimentos relevantes para a realização dos } \\
\text { objetivos da entidade, incluindo a elaboração de } \\
\text { matrizes de segregação de funções e controle de } \\
\text { acesso, a elaboração de atividades de controle } \\
\text { alternativas para os processos, políticas e } \\
\text { procedimentos que não podem ter a segregação de } \\
\text { funções adequada e a reavaliação periódica das } \\
\text { matrizes de segregação de funções e controle de } \\
\text { acesso. }\end{array}$ \\
\hline
\end{tabular}

Fonte: Elaborado pelo autor.

\subsubsection{Resultados da Subdimensão 3.2 - Implantação de Controles}

\subsubsection{Resultados da Variável 3.2.1 - Políticas e Procedimentos de Controle}

Quadro 55 - Resultados da Variável 3.2.1 - Políticas e Procedimentos de Controle

\begin{tabular}{|c|c|c|c|}
\hline (0) Incipiente & (1) Inicial & (2) Em Formação & (3) Estabelecido \\
\hline $\begin{array}{l}\text { Ausência de políticas e } \\
\text { procedimentos para } \\
\text { definir responsabilidades } \\
\text { e orientar a implantação } \\
\text { dos controles da } \\
\text { entidade. }\end{array}$ & $\begin{array}{l}\text { A entidade elabora } \\
\text { políticas e procedimentos } \\
\text { para definir as } \\
\text { responsabilidades e } \\
\text { orientar a implantação } \\
\text { dos controles dos } \\
\text { processos relevantes para } \\
\text { a realização dos } \\
\text { objetivos entidade. }\end{array}$ & $\begin{array}{l}\text { As políticas e } \\
\text { procedimentos } \\
\text { especificam a } \\
\text { tempestividade } \\
\text { (frequência ou } \\
\text { oportunidade) na } \\
\text { execução dos controles, } \\
\text { as ações corretivas caso } \\
\text { sejam identificados } \\
\text { problemas e o nível de } \\
\text { competência e autoridade } \\
\text { necessária para a } \\
\text { execução adequada. }\end{array}$ & $\begin{array}{l}\text { Política da entidade } \\
\text { determina a revisão } \\
\text { periódica das políticas e } \\
\text { procedimentos de } \\
\text { controles da entidade, ou } \\
\text { sempre que forem } \\
\text { identificadas mudanças } \\
\text { nas atividades, sistemas } \\
\text { e processos relevantes } \\
\text { para a realização dos } \\
\text { objetivos da entidade. }\end{array}$ \\
\hline MAPA & Sim & Não & Não \\
\hline Incra & Sim & Não & Não \\
\hline Conab & Sim & Sim & Sim \\
\hline
\end{tabular}

Fonte: Dados da pesquisa. 
Para a análise da maturidade nesta variável foram solicitados às entidades estudadas os seguintes documentos: Normas e regulamentos referentes aos principais processos; Norma que determina a reavaliação periódica das normas, regulamentos e controles dos principais processos.

No MAPA, a regulamentação das principais atividades e respectivos controles é realizada principalmente por meio de Instruções Normativas e Resoluções. No Incra, são utilizadas Portarias, Resoluções, Instruções Normativas e Normas de Execução. Desse modo, entende-se que ambos atendem ao critério do nível de maturidade (1) Inicial. MAPA e Incra não apresentaram evidencia do atendimento aos demais critérios da variável.

As funções e atividades da Conab possuem suas regras e procedimentos de realização estabelecidos nas Normas da Organização da Conab - NOC $^{79}$ e no Manual de Operações da Conab $-\mathrm{MOC}^{80}$. As NOC e o MOC orientam a definição de responsabilidades e implantação de controles nos processos da Conab. A Norma de Gestão Normativa da Conab (NOC 60.304) define que as normas da Conab devem conter "o processo e fluxo detalhado para atendimento da norma", exceto quando não aplicável. Considerando que o processo e o fluxo demonstram a responsabilidade pela execução dos controles, a oportunidade da sua execução e as ações caso sejam identificados problemas. Além disso, a NOC 60.304 define que

As Normas deverão ser atualizadas sempre que houver legislação nova que obrigue a sua atualização, quando produto ou serviço novo for criado, quando algum defeito ou erro for constatado por qualquer pessoa, sendo de exclusiva responsabilidade do gestor a sua atualização, respondendo como responsável solidário em caso de sua inobservância. [...]

A área de Controles Internos deve assegurar que as áreas Gestoras das Normas as mantenham atualizadas e as mudanças sejam observadas pelos usuários.

Desse modo, entende-se que a Conab atende aos critérios dos níveis de maturidade (1) Inicial, (2) Em Formação e (3) Estabelecido.

O estabelecimento de políticas e procedimentos de controle é necessário para definir o que é esperado dos controles internos (COSO, 2013). A ausência de políticas e procedimentos dificulta a avaliação quanto ao funcionamento e adequação dos controles

79 Segundo a Norma de Gestão Normativa da Conab (NOC 60.304), as NOC estabelecem os princípios orientadores das funções e atividades da Conab, observadas as políticas e diretrizes emanadas da Alta Administração que impõem regras e estabelecem procedimentos a serem seguidos na Conab. Tem como principal objetivo organizar administrativamente a Companhia e regular processos, subprocessos e atividades.

${ }^{80}$ Segundo a Norma de Gestão Normativa da Conab (NOC 60.304), o MOC tem o objetivo de divulgar para o público externo e interno informações, programas e instrumentos utilizados para o desenvolvimento das atividades fins da Conab. É composto de títulos, podendo acompanhar-se de procedimentos para utilização dos programas da Conab, documentos com modelos de formulários, de contratos e outros. 
internos, colocando em risco a realização dos objetivos da organização. Considerando que as organizações governamentais são regidas pelos princípios da administração pública, é esperado que as atividades realizadas pelas entidades estudadas e respectivos controles sejam regulamentados em normas, que servirão para dar embasamento às avaliações quanto ao seu funcionamento.

\subsubsection{Análise Comparativa da Subdimensão 3.2 - Implantação de Controles}

Quadro 56 - Análise Comparativa da Subdimensão 3.2 - Implantação de Controles

\begin{tabular}{|c|c|c|c|}
\hline Variáveis & МАРА & Incra & Conab \\
\hline $\begin{array}{l}\text { 3.2.1. Políticas e } \\
\text { Procedimentos } \\
\text { de Controle }\end{array}$ & $\begin{array}{l}\text { Regulamenta as } \\
\text { principais atividades } \\
\text { e respectivos } \\
\text { controles por meio } \\
\text { de Instruções } \\
\text { Normativas e } \\
\text { Resoluções. }\end{array}$ & $\begin{array}{l}\text { Regulamenta as } \\
\text { principais atividades e } \\
\text { respectivos controles } \\
\text { por meio de Portarias, } \\
\text { Resoluções, Instruções } \\
\text { Normativas e Normas } \\
\text { de Execução. }\end{array}$ & $\begin{array}{l}\text { NOC e MOC definem os processos, } \\
\text { incluindo responsabilidades e execução } \\
\text { de procedimentos de controle. NOC } \\
60.304 \text { determina a inclusão de processo } \\
\text { e fluxograma detalhado nas normas da } \\
\text { entidade, e determina a atualização das } \\
\text { normas quando surge nova legislação ou } \\
\text { na criação de produto ou serviço novo. }\end{array}$ \\
\hline
\end{tabular}

Fonte: Dados da pesquisa.

O quadro a seguir apresenta os riscos identificados com embasamento nas características da subdimensão, diagnosticadas pela aplicação do modelo de maturidade desenvolvido neste trabalho, e as respectivas recomendações para o aprimoramento das estruturas de controle interno das entidades estudadas.

Quadro 57 - Riscos e Recomendações da Subdimensão 3.2 - Implantação de Controles

\begin{tabular}{|c|c|}
\hline Riscos & Recomendações \\
\hline $\begin{array}{l}\text { (MAPA, Incra) As atividades de controle da entidade } \\
\text { sejam executadas por indivíduos que não tenham } \\
\text { autoridade e competências adequadas. } \\
\text { (MAPA, Incra) As atividades de controle da entidade } \\
\text { sejam executadas de forma intempestiva ou com } \\
\text { periodicidade insuficiente para produzir os resultados } \\
\text { esperados. } \\
\text { (MAPA, Incra) Os problemas identificados nas } \\
\text { atividades de controle da entidade não sejam } \\
\text { comunicados a indivíduos que tenham a autoridade e } \\
\text { competência adequada para solucioná-los. } \\
\text { (MAPA, Incra) As atividades de controle da entidade } \\
\text { não atendam a requisitos e expectativas decorrentes } \\
\text { de mudanças no ambiente de atuação, nas atividades } \\
\text { realizadas, nas atribuições legais ou nas políticas } \\
\text { públicas de sua responsabilidade. }\end{array}$ & $\begin{array}{l}\text { (MAPA, Incra) Definir nas políticas e procedimentos } \\
\text { que orientam as atividades de controle dos processos } \\
\text { relevantes para a realização dos objetivos da entidade } \\
\text { as competências e o nível de autoridade necessários à } \\
\text { execução das atividades de controle, a oportunidade } \\
\text { ou frequência da execução das atividades de controle } \\
\text { e as ações corretivas em caso de problemas. } \\
\text { (MAPA, Incra) Estabelecer a revisão periódica das } \\
\text { políticas e procedimentos que orientam as atividades } \\
\text { de controle dos processos relevantes para a realização } \\
\text { dos objetivos da entidade. }\end{array}$ \\
\hline
\end{tabular}

Fonte: Elaborado pelo autor. 


\subsubsection{Resultados da Subdimensão 3.3 - Projeto de Controles sobre a Tecnologia}

\subsubsection{Resultados da Variável 3.3.1 - Uso da Computação de Usuário Final}

Quadro 58 - Resultados da Variável 3.3.1 - Uso da Computação de Usuário Final

\begin{tabular}{|l|l|l|l|}
\hline \multicolumn{1}{|c|}{ (0) Incipiente } & \multicolumn{1}{c|}{ (1) Inicial } & \multicolumn{1}{c|}{ (2) Em Formação } & \multicolumn{1}{c|}{ (3) Estabelecido } \\
\hline $\begin{array}{l}\text { Ausência de diagnóstico } \\
\text { do uso de computação do } \\
\text { usuário final nos } \\
\text { processos, políticas e } \\
\text { procedimentos relevantes } \\
\text { para a realização dos } \\
\text { objetivos da entidade. }\end{array}$ & $\begin{array}{l}\text { O uso de computação do } \\
\text { usuário final nos } \\
\text { processos, políticas e } \\
\text { procedimentos relevantes } \\
\text { para a realização dos } \\
\text { objetivos da entidade e } \\
\text { nas atividades de } \\
\text { controle associadas é } \\
\text { ientificado e } \\
\text { documentado. }\end{array}$ & $\begin{array}{l}\text { Gerência avalia os riscos } \\
\text { decorrentes do uso de } \\
\text { computação do usuário } \\
\text { final nos processos, } \\
\text { políticas e procedimentos } \\
\text { relevantes para a } \\
\text { realização dos objetivos } \\
\text { da entidade e nas } \\
\text { atividades de controle } \\
\text { associadas e elabora } \\
\text { controles adicionais } \\
\text { conforme necessário. }\end{array}$ & $\begin{array}{l}\text { dos } \\
\text { procedimentos relevantes } \\
\text { para a realização dos } \\
\text { objetivos da entidade são } \\
\text { automatizadas com o } \\
\text { apoio de aplicativos, } \\
\text { sistemas de informações } \\
\text { outros recursos de } \\
\text { tecnologia. }\end{array}$ \\
\hline MAPA & Não & Não & Não \\
\hline Incra & Não & Não & Não \\
\hline Conab & Não & Não \\
\hline
\end{tabular}

Fonte: Dados da pesquisa.

Para a análise da maturidade nesta variável foram solicitados às entidades estudadas os seguintes documentos: Mapas dos principais processos; Descrição dos principais processos; Descrição das atividades dos principais processos; Manuais de procedimentos das atividades dos principais processos; Inventários de atividades de controle; Descrição das atividades de controle; Descrição das atividades de controle dos principais processos; Manuais de procedimentos das atividades de controle dos principais processos; Relatórios de avaliação de riscos das atividades de controle dos principais processos.

Nenhuma das entidades estudadas apresentou evidências de cumprimento dos critérios da variável.

O uso de computação de usuário final nos principais processos da entidade, especialmente nas atividades de controle, pode colocar em risco a eficácia dos controles (COSO, 2013). Nesse sentido, é importante que as entidades avaliem os riscos decorrentes da utilização de tais recursos em seus processos e controles e definam respostas a tais riscos quando necessário. A situação ideal é que os principais processos tenham seus controles automatizados, evitando que erros e perda de informações coloquem em risco a realização dos objetivos da entidade. 


\subsubsection{Resultados da Variável 3.3.2 - Políticas de Segurança de TI}

\section{Quadro 59 - Resultados da Variável 3.3.2 - Políticas de Segurança de TI}

\begin{tabular}{|c|l|l|l|}
\hline \multicolumn{1}{|c|}{ (0) Incipiente } & \multicolumn{1}{|c|}{ (1) Inicial } & \multicolumn{1}{c|}{ (2) Em Formação } & \multicolumn{1}{c|}{ Estabelecido } \\
\hline $\begin{array}{c}\text { Ausência de políticas de } \\
\text { segurança de TI. }\end{array}$ & $\begin{array}{l}\text { A entidade possui } \\
\text { políticas de segurança de } \\
\text { TI formalmente } \\
\text { estabelecidas. }\end{array}$ & $\begin{array}{l}\text { A entidade possui } \\
\text { política de controle de } \\
\text { acesso à informação e } \\
\text { aos recursos de TI } \\
\text { formalmente } \\
\text { estabelecida, consistente } \\
\text { com as funções do } \\
\text { trabalho e com a } \\
\text { segregação de funções. }\end{array}$ & $\begin{array}{l}\text { A infraestrutura de TI } \\
\text { que suporta os processos, } \\
\text { políticas e procedimentos } \\
\text { relevantes para a } \\
\text { realização dos objetivos } \\
\text { da entidade possui plano } \\
\text { de continuidade de } \\
\text { serviços e plano de } \\
\text { recuperação de desastres. }\end{array}$ \\
\hline MAPA & Sim & Não & Não \\
\hline Incra & Sim & Parcial & Não \\
\hline Conab & Sim & & Não \\
\hline
\end{tabular}

Fonte: Dados da pesquisa.

Para a análise da maturidade nesta variável foram solicitados às entidades estudadas os seguintes documentos: Política de segurança de TI; Política de controle de acesso à TI; Plano de continuidade de serviços de TI; Plano de recuperação de desastres para a infraestrutura de TI.

No MAPA, a Portaria $n^{\circ}$ 147/2015 estabeleceu a Política de Segurança da Informação e Comunicações - PoSIC/MAPA, atendendo ao critério do nível de maturidade (1) Inicial.

No Incra, a Portaria $n^{\circ}$ 587/2013 disciplina a utilização dos recursos de TI, estabelecendo os princípios e diretrizes para a gestão da segurança da informação. Assim, o Incra também atende ao critério do nível de maturidade (1) Inicial.

Na Conab, a Norma de Recursos Computacionais (NOC 60.213) inclui o capítulo III "Política de Segurança - Diretrizes". Apesar da ausência de alguns assuntos relevantes, como classificação das informações, consequências de violações das normas de segurança da informação e gestão da continuidade do negócio, o referido capítulo estabelece um conjunto de princípios que norteiam a gestão de segurança de informações, que deve ser observado pelo corpo técnico e gerencial e pelos usuários internos e externos, cumprindo o critério do nível de maturidade (1) Inicial.

A referida Norma estabelece ainda uma política de controle de acesso aos recursos da rede de computadores da Conab, incluindo o uso da estação de trabalho e dispositivos móveis, e o uso de alguns serviços como correio eletrônico, antivírus, colaboração de informações, VPN, rede, banco de dados e protocolos internet. Não há, contudo, política para controle de acesso a informações e sistemas corporativos, nem consideração a funções de 
trabalho e segregação de funções. Assim, entende-se que a Conab atende parcialmente o critério do nível de maturidade (2) Em Formação.

O estabelecimento e cumprimento de políticas de segurança de TI rigorosas garante a integridade, confidencialidade e disponibilidade das informações que apoiam o funcionamento da estrutura de controle interno das entidades (COSO, 2013). A ausência ou debilidade das políticas de segurança pode expor a organização a riscos de origem interna e externa, prejudicando a eficácia dos controles internos e a realização dos objetivos da entidade.

\subsubsection{Resultados da Variável 3.3.3 - Processos de Aquisição, Desenvolvimento e Manutenção da TI}

Quadro 60 - Resultados da Variável 3.3.3 - Processos de Aquisição, Desenvolvimento e Manutenção da TI

\begin{tabular}{|c|l|l|l|}
\hline \multicolumn{1}{|c|}{ (0) Incipiente } & \multicolumn{1}{|c|}{ (1) Inicial } & \multicolumn{1}{c|}{ (2) Em Formação } & Estabelecido \\
\hline $\begin{array}{l}\text { Ausência de processos } \\
\text { configuração e mudança } \\
\text { para a infraestrutura de } \\
\text { TI da entidade. }\end{array}$ & $\begin{array}{l}\text { Processos formalmente } \\
\text { estabelecidos para o } \\
\text { gerenciamento de } \\
\text { configuração e mudança } \\
\text { da infraestrutura de TI } \\
\text { que suporta os processos, } \\
\text { políticas e procedimentos } \\
\text { relevantes para a } \\
\text { realização dos objetivos } \\
\text { da entidade. }\end{array}$ & $\begin{array}{l}\text { Entidade adota um ciclo } \\
\text { de vida de } \\
\text { desenvolvimento de } \\
\text { sistemas completo, tanto } \\
\text { para o software } \\
\text { desenvolvido } \\
\text { internamente quanto para } \\
\text { os pacotes adquiridos. }\end{array}$ & $\begin{array}{l}\text { Fases e controles } \\
\text { previstos no ciclo de vida } \\
\text { de desenvolvimento de } \\
\text { sistemas da entidade são } \\
\text { definidos em função de } \\
\text { uma classificação de } \\
\text { riscos da mudança, } \\
\text { definida conforme o } \\
\text { tamanho, esforço, } \\
\text { complexidade e impactos } \\
\text { em processos e controles } \\
\text { relevantes para a } \\
\text { realização dos objetivos } \\
\text { da entidade. }\end{array}$ \\
\hline MAPA & Não & Não & Narcial \\
\hline Incra & Não & Não & Não \\
\hline Conab & & & \\
\hline
\end{tabular}

Fonte: Dados da pesquisa.

Para a análise da maturidade nesta variável foram solicitados às entidades estudadas os seguintes documentos: Normas e regulamentos referentes a processos de gerenciamento de configuração e mudança da infraestrutura de TI; Mapas dos processos de gerenciamento de configuração e mudança da infraestrutura de TI; Normas e regulamentos referentes a processos de desenvolvimento de sistemas (processo de software); Mapas dos processos de desenvolvimento de sistemas (processo de software).

O Incra e a Conab não apresentaram evidências de cumprimento dos critérios da variável.

O MAPA possui metodologia de desenvolvimento de sistemas baseada no Rational Unified Process, composta pelas fases de iniciação, execução, implementação e transição. Contudo, não se trata de um ciclo de vida completo, considerando, por exemplo, a ausência das 
fases de suporte e manutenção do sistema. Além disso, o processo de software não abrange os pacotes de software de mercado adquiridos pelo MAPA. Assim, entende-se que o MAPA atende apenas parcialmente o critério do nível de maturidade (2) Em Formação.

O estabelecimento de processos robustos para a aquisição, desenvolvimento e manutenção garante que as mudanças na TI que suporta os principais processos da entidade irão ocorrer de forma planejada e controlada (COSO, 2013). A ausência desses processos pode resultar na realização de mudanças sem o conhecimento adequado dos riscos envolvidos e dos impactos sobre as atividades e processos da entidade. A indisponibilidade ou mau funcionamento da TI pode prejudicar a eficácia dos controles, expondo a entidade a riscos.

\subsubsection{Análise Comparativa da Subdimensão 3.3 - Projeto de Controles sobre a}

\section{Tecnologia}

Quadro 61 - Análise Comparativa da Subdimensão 3.3 - Projeto de Controles sobre a Tecnologia

\begin{tabular}{|c|c|c|c|}
\hline Variáveis & MAPA & Incra & Conab \\
\hline $\begin{array}{l}\text { 3.3.1. Uso da } \\
\text { Computação de } \\
\text { Usuário Final }\end{array}$ & $\begin{array}{l}\text { Não apresentou evidências } \\
\text { do uso da computação de } \\
\text { usuário final em seus } \\
\text { processos, políticas e } \\
\text { procedimentos. }\end{array}$ & $\begin{array}{l}\text { Não apresentou } \\
\text { evidências do uso da } \\
\text { computação de usuário } \\
\text { final em seus processos, } \\
\text { políticas e } \\
\text { procedimentos. }\end{array}$ & $\begin{array}{l}\text { Não apresentou evidências } \\
\text { do uso da computação de } \\
\text { usuário final em seus } \\
\text { processos, políticas e } \\
\text { procedimentos. }\end{array}$ \\
\hline $\begin{array}{l}\text { 3.3.2. Políticas de } \\
\text { Segurança de TI }\end{array}$ & $\begin{array}{l}\text { Políticas de segurança de } \\
\text { TI formalmente } \\
\text { estabelecidas. }\end{array}$ & $\begin{array}{l}\text { Políticas de segurança de } \\
\text { TI formalmente } \\
\text { estabelecidas. }\end{array}$ & $\begin{array}{l}\text { Políticas de segurança de } \\
\text { TI formalmente } \\
\text { estabelecidas; políticas de } \\
\text { controle de acesso } \\
\text { definidas para parte dos } \\
\text { recursos de TI. }\end{array}$ \\
\hline $\begin{array}{l}\text { 3.3.3. Processos de } \\
\text { Aquisição, } \\
\text { Desenvolvimento e } \\
\text { Manutenção da TI }\end{array}$ & $\begin{array}{l}\text { Metodologia de } \\
\text { desenvolvimento de } \\
\text { software inclui fases de } \\
\text { iniciação, execução, } \\
\text { implementação e } \\
\text { transição. }\end{array}$ & $\begin{array}{l}\text { Não apresentou } \\
\text { evidências de processos } \\
\text { para o gerenciamento da } \\
\text { configuração e mudança } \\
\text { da infraestrutura de TI. }\end{array}$ & $\begin{array}{l}\text { Não apresentou evidências } \\
\text { de processos para o } \\
\text { gerenciamento da } \\
\text { configuração e mudança } \\
\text { da infraestrutura de TI. }\end{array}$ \\
\hline
\end{tabular}

Fonte: Dados da pesquisa.

A tecnologia da informação permite minimizar os erros decorrentes da intervenção humana e automatizar operações complexas, realizando, em segundos, análises que seriam impraticáveis sem o apoio de tecnologia. A diminuição dos custos nas últimas décadas fez com que a TI assumisse papel central nas estruturas de controle interno das organizações. As entidades estudadas deram os passos iniciais na governança de TI, tendo implantado política de segurança e processo de software. Contudo, verificou-se a necessidade de aprimoramento das políticas para evitar que a TI se torne fator prejudicial à eficácia das estruturas de controle interno das entidades. 
O quadro a seguir apresenta os riscos identificados com embasamento nas características da subdimensão, diagnosticadas pela aplicação do modelo de maturidade desenvolvido neste trabalho, e as respectivas recomendações para o aprimoramento das estruturas de controle interno das entidades estudadas

Quadro 62 - Riscos e Recomendações da Subdimensão 3.3 - Projeto de Controles sobre a Tecnologia

\begin{tabular}{|c|c|}
\hline Riscos & Recomendações \\
\hline $\begin{array}{l}\text { (MAPA, Incra, Conab) Riscos significativos } \\
\text { decorrentes do uso de computação do usuário final } \\
\text { nos processos, políticas e procedimentos relevantes } \\
\text { para a realização dos objetivos da entidade não sejam } \\
\text { adequadamente respondidos. }\end{array}$ & $\begin{array}{l}\text { (MAPA, Incra, Conab) Realizar o diagnóstico do uso } \\
\text { de computação do usuário final nos processos, } \\
\text { políticas e procedimentos relevantes para a realização } \\
\text { dos objetivos da entidade e nas atividades de controle } \\
\text { relacionadas, incluindo avaliação dos riscos } \\
\text { decorrentes a elaboração de atividades de controle } \\
\text { adicionais para responder a esses riscos. }\end{array}$ \\
\hline $\begin{array}{l}\text { (MAPA, Incra, Conab) As atividades de controle dos } \\
\text { processos, políticas e procedimentos relevantes para } \\
\text { a realização dos objetivos da entidade não produzam } \\
\text { os resultados esperados em razão de problemas } \\
\text { relacionados à computação do usuário final. }\end{array}$ & $\begin{array}{l}\text { (MAPA, Incra, Conab) Implantar atividades de } \\
\text { controle automatizadas com o apoio de recursos de } \\
\text { TI nos processos, políticas e procedimentos } \\
\text { relevantes para a realização dos objetivos da } \\
\text { entidade. }\end{array}$ \\
\hline $\begin{array}{l}\text { (MAPA, Incra, Conab) Empregados e terceirizados } \\
\text { da entidade tenham acesso a informações e recursos } \\
\text { de TI incompatíveis com as suas atribuições e as } \\
\text { atividades que desempenham. } \\
\text { (MAPA, Incra, Conab) Empregados e terceirizados } \\
\text { da entidade não tenham acesso às informações e } \\
\text { recursos de TI necessários ao cumprimento de suas } \\
\text { atribuições e responsabilidades de controle interno. }\end{array}$ & $\begin{array}{l}\text { (MAPA, Incra) Estabelecer política formal de } \\
\text { controle de acesso à informação e aos recursos de TI } \\
\text { da entidade, em conformidade com as atividades } \\
\text { desempenhadas pelos usuários a segregação de } \\
\text { funções. } \\
\text { (Conab) Incluir nas políticas de controle de acesso os } \\
\text { as informações e recursos de TI que ainda não são } \\
\text { cobertos alinhando as políticas com as atividades } \\
\text { desempenhadas pelos usuários a segregação de } \\
\text { funções. }\end{array}$ \\
\hline $\begin{array}{l}\text { (MAPA, Incra, Conab) Acidentes e desastres } \\
\text { resultem na indisponibilidade da infraestrutura de TI } \\
\text { ou na perda de dados e informações necessários para } \\
\text { o funcionamento dos processos, políticas e } \\
\text { procedimentos relevantes para a realização dos } \\
\text { objetivos da entidade e atividades de controle } \\
\text { relacionadas. }\end{array}$ & $\begin{array}{l}\text { (MAPA, Incra, Conab) Estabelecer plano de } \\
\text { continuidade de serviços e plano de recuperação de } \\
\text { desastres para a infraestrutura de TI que suporta os } \\
\text { processos, políticas e procedimentos relevantes para } \\
\text { a realização dos objetivos da entidade. }\end{array}$ \\
\hline $\begin{array}{l}\text { (MAPA, Incra, Conab) Mudanças realizadas de } \\
\text { maneira desordenada resultem na indisponibilidade } \\
\text { da infraestrutura de TI que suporta os processos, } \\
\text { políticas e procedimentos relevantes para a realização } \\
\text { dos objetivos da entidade e atividades de controle } \\
\text { relacionadas. }\end{array}$ & $\begin{array}{l}\text { (MAPA, Incra, Conab) Estabelecer processos de } \\
\text { gerenciamento de configuração e mudança para a } \\
\text { infraestrutura de TI do MAPA que suporta os } \\
\text { processos, políticas e procedimentos relevantes para } \\
\text { a realização de seus objetivos. } \\
\text { (Incra, Conab) Adotar um ciclo de vida de } \\
\text { desenvolvimento de sistemas completo, incluindo o } \\
\text { software desenvolvido internamente e os pacotes } \\
\text { adquiridos, e definindo as fases e controles que } \\
\text { devem ser realizados conforme o risco da mudança. } \\
\text { (MAPA) Aperfeiçoar o ciclo de vida de } \\
\text { desenvolvimento de sistemas da entidade, incluindo } \\
\text { as fases de suporte e manutenção, incluindo o } \\
\text { software desenvolvido internamente e os pacotes } \\
\text { adquiridos, e definindo as fases e controles que } \\
\text { devem ser realizados conforme o risco da mudança. }\end{array}$ \\
\hline
\end{tabular}

Fonte: Elaborado pelo autor. 


\section{de Controle}

O quadro a seguir apresenta o resultado dos procedimentos de avaliação do nível de maturidade das entidades estudadas na dimensão Atividades de Controle, considerando o peso de cada nível de maturidade, definido pela média dos pesos estabelecidos pelo atendimento dos critérios dentro das variáveis da dimensão, conforme o apêndice J deste trabalho.

Quadro 63 - Avaliação do Nível de Maturidade das Entidades na Dimensão 3 - Atividades de Controle

\begin{tabular}{|c|c|c|c|}
\hline Nível de Maturidade & MAPA & Incra & Conab \\
\hline (0) Incipiente & $50,0 \%$ & $62,5 \%$ & $62,5 \%$ \\
\hline (1) Inicial & $31,3 \%$ & $31,3 \%$ & $31,3 \%$ \\
\hline (2) Em Formação & $12,5 \%$ & $6,3 \%$ & $25,0 \%$ \\
\hline (3) Estabelecido & $0,0 \%$ & $0,0 \%$ & $12,5 \%$ \\
\hline Avaliação & (0) Incipiente & (0) Incipiente & (0) Incipiente \\
\hline
\end{tabular}

Fonte: Dados da pesquisa.

Os procedimentos de avaliação conferiram a todas as entidades estudadas o nível de maturidade (0) Incipiente. Além disso, o peso que as entidades obtiveram no nível (0) Incipiente demonstra o baixo nível de estruturação do componente Atividades de Controle em todas as entidades.

\section{RESULTADOS DA DIMENSÃO 4 - INFORMAÇÃO E COMUNICAÇÃO}

\subsubsection{Resultados da Subdimensão 4.1 - Sistema de Informação da Entidade}

\subsubsection{Resultados da Variável 4.1.1 - Relevância e Qualidade da Informação}

Quadro 64 - Resultados da Variável 4.1.1 - Relevância e Qualidade da Informação

\begin{tabular}{|l|l|l|l|}
\hline \multicolumn{1}{|c|}{ (0) Incipiente } & \multicolumn{1}{c|}{ (1) Inicial } & \multicolumn{1}{c|}{ (2) Em Formação } & \multicolumn{1}{c|}{ (3) Estabelecido } \\
\hline $\begin{array}{l}\text { Ausência de diagnóstico } \\
\text { dos processos para a } \\
\text { disponibilização das } \\
\text { informações necessárias } \\
\text { para apoiar o } \\
\text { funcionamento o } \\
\text { controle interno da } \\
\text { entidade. }\end{array}$ & $\begin{array}{l}\text { Processo formalmente } \\
\text { estabelecido para } \\
\text { identificar e documentar } \\
\text { as necessidades de } \\
\text { informações para apoiar } \\
\text { o funcionamento do } \\
\text { controle interno da } \\
\text { entidade. }\end{array}$ & $\begin{array}{l}\text { Processos formalmente } \\
\text { estabelecidos para } \\
\text { produzir ou coletar, } \\
\text { tratar, armazenar, } \\
\text { processar e descartar os } \\
\text { dados e informações que } \\
\text { apoiam o funcionamento } \\
\text { do controle interno da } \\
\text { entidade. }\end{array}$ & $\begin{array}{l}\text { A entidade estabele } \\
\text { um programa de } \\
\text { governança para a } \\
\text { manutenção da qualidade } \\
\text { dos dados e informações } \\
\text { que apoiam o } \\
\text { funcionamento da } \\
\text { estrutura de controle } \\
\text { interno. }\end{array}$ \\
\hline MAPA & \multicolumn{1}{|c|}{ Não } & Não \\
\hline Incra & Não & Não & Não \\
\hline Conab & Não & Não \\
\hline
\end{tabular}

Fonte: Dados da pesquisa.

Para a análise da maturidade nesta variável foram solicitados às entidades estudadas os seguintes documentos: Normas e regulamentos referentes a processos para identificar e documentar as informações necessárias para apoiar o funcionamento do controle interno; Mapas dos processos para identificar e documentar as informações necessárias para apoiar o 
funcionamento do controle interno; Normas e regulamentos referentes a processos de produção, coleta, tratamento, armazenamento, processamento e descarte dos dados e informações que apoiam o funcionamento do controle interno; Mapas dos processos para a produção, coleta, tratamento, armazenamento, processamento e descarte dos dados e informações que apoiam o funcionamento do controle interno; Normas e regulamentos referentes a processos de governança de dados.

Nenhuma das entidades estudadas apresentou evidências de cumprimento dos critérios da variável.

O funcionamento da estrutura de controle interno depende da disponibilização tempestiva de informações relevantes e confiáveis. Nesse sentido, é relevante que seja estabelecido o sistema de informação da entidade, incluindo processos para realizar uma ampla identificação de necessidades de informações, coletando ou produzindo a informação, cuidando da sua qualidade e distribuindo às pessoas corretas, da forma correta e em nível de detalhe adequado, conforme suas tarefas e responsabilidades (GAO, 2001; GAO, 2014). A ausência ou desconexão desses processos pode afetar a eficácia da estrutura de controle interno, prejudicando a realização dos objetivos da entidade.

\subsubsection{Resultados da Variável 4.1.2 - Comunicação Interna e Externa}

Quadro 65 - Resultados da Variável 4.1.2 - Comunicação Interna e Externa

\begin{tabular}{|c|c|c|c|}
\hline (0) Incipiente & (1) Inicial & (2) Em Formação & (3) Estabelecido \\
\hline $\begin{array}{l}\text { Ausência de diagnóstico } \\
\text { dos processos de } \\
\text { comunicação interna e } \\
\text { externa. }\end{array}$ & $\begin{array}{l}\text { Processos formalmente } \\
\text { estabelecidos para } \\
\text { comunicar } \\
\text { tempestivamente ao } \\
\text { público interno e externo } \\
\text { as informações } \\
\text { necessárias e esperadas. }\end{array}$ & $\begin{array}{l}\text { Processos de } \\
\text { comunicação interna e } \\
\text { externa incluem a } \\
\text { seleção dos métodos de } \\
\text { comunicação, levando } \\
\text { em consideração a } \\
\text { tempestividade, } \\
\text { audiência, natureza da } \\
\text { comunicação e } \\
\text { requisitos, expectativas } \\
\text { legais, regulatórias e } \\
\text { contratuais, e a relação } \\
\text { custo x benefício. }\end{array}$ & $\begin{array}{l}\text { A entidade define canais } \\
\text { de comunicação internos } \\
\text { e externos múltiplos e } \\
\text { bidirecionais para evitar } \\
\text { a perda de informações } \\
\text { relevantes, incluindo } \\
\text { canal de denúncias com } \\
\text { garantia de anonimato } \\
\text { para a comunicação de } \\
\text { questões significativas } \\
\text { relacionadas ao controle } \\
\text { interno. }\end{array}$ \\
\hline МАРА & Não & Não & Não \\
\hline Incra & Não & Não & Não \\
\hline Conab & Parcial & Não & Não \\
\hline
\end{tabular}

Fonte: Dados da pesquisa.

Para a análise da maturidade nesta variável foram solicitados às entidades estudadas os seguintes documentos: Normas e regulamentos referentes a processos de comunicação interna e externa; Mapas dos processos para comunicação interna e externa; Normas e regulamentos referentes a canais de comunicação internos e externos. 
O MAPA e o Incra não apresentaram evidências de cumprimento dos critérios da variável. A Conab possui o mapa de um "Macroprocesso de Geração e Disseminação de Informações e Conhecimento", que inclui os processos: "8.1 Definir / planejar escopo", "8.2 Analisar e registrar", "8.3 Coletar dados (fonte Conab ou terceiros)", "8.4 Tratar dados e atualizar Base de Dados", "8.5 Elaborar trabalhos e estudos técnicos", "8.6 Concluir geração de informação e conhecimento", "8.7 Disponibilizar e divulgar". Ao final do macroprocesso, os produtos são entregues a "Usuários de informações e conhecimentos", "Sociedade" e "Inteligência de governo, nas áreas Agrícola, Abastecimento e Segurança Alimentar e Nutricional". Apesar disso, não há mapeamento dos processos mencionados e não foram identificadas outras evidências de seu estabelecimento formal. Entende-se que a Conab atente apenas parcialmente ao critério do nível de maturidade (1) Inicial.

O estabelecimento de processos de comunicação interna e externa é importante para o funcionamento adequado da estrutura de controle interno da entidade. Os processos devem assegurar que as informações necessárias para o funcionamento dos controles sejam disponibilizadas de maneira tempestiva; os canais de comunicação devem permitir que as partes interessadas internas e externas relatem problemas para a alta gerência e o corpo diretivo da entidade (COSO, 2013). A ausência de processos de comunicação pode diminuir a eficácia dos controles internos na resposta aos riscos da entidade.

\subsubsection{Análise Comparativa da Subdimensão 4.1 - Sistema de Informação da Entidade}

Quadro 66 - Análise Comparativa da Subdimensão 4.1 - Sistema de Informação da Entidade

\begin{tabular}{|l|l|l|l|}
\hline \multicolumn{1}{|c|}{ Variáveis } & \multicolumn{1}{|c|}{ MAPA } & \multicolumn{1}{c|}{ Incra } & \multicolumn{1}{c|}{ Conab } \\
\hline $\begin{array}{l}\text { 4.1.1. } \\
\text { Relevância e } \\
\begin{array}{l}\text { Qualidade da } \\
\text { Informação }\end{array}\end{array}$ & $\begin{array}{l}\text { Não apresentou evidências } \\
\text { de processos para a } \\
\text { disponibilização das } \\
\text { informações necessárias } \\
\text { para apoiar o } \\
\text { funcionamento da estrutura } \\
\text { de controle interno. }\end{array}$ & $\begin{array}{l}\text { Não apresentou evidências } \\
\text { de processos para a } \\
\text { disponibilização das } \\
\text { informações necessárias } \\
\text { para apoiar o } \\
\text { funcionamento da estrutura } \\
\text { de controle interno. }\end{array}$ & $\begin{array}{l}\text { Não apresentou evidências } \\
\text { de processos para a } \\
\text { disponibilização das } \\
\text { informações necessárias } \\
\text { para apoiar o } \\
\text { funcionamento da estrutura } \\
\text { de controle interno. }\end{array}$ \\
\hline $\begin{array}{l}\text { 4.1.2. } \\
\text { Comunicação } \\
\text { Interna e } \\
\text { Externa }\end{array}$ & $\begin{array}{l}\text { Não apresentou evidências } \\
\text { de processos de } \\
\text { comunicação interna e } \\
\text { externa. }\end{array}$ & $\begin{array}{l}\text { Não apresentou evidências } \\
\text { de processos de } \\
\text { comunicação interna e } \\
\text { externa. }\end{array}$ & $\begin{array}{l}\text { Definição de um } \\
\text { macroprocesso de geração e } \\
\text { disseminação de } \\
\text { informaçôes e } \\
\text { conhecimento. }\end{array}$ \\
\hline
\end{tabular}

Fonte: Dados da pesquisa.

A ausência de planejamento e investimento é um dos principais fatores que prejudicam a eficácia da comunicação interna nas organizações (CHMIELECKI, 2015). A ausência de um sistema de informações planejado, construído com embasamento num diagnóstico de necessidades informacionais, incluindo processos para o tratamento da 
qualidade da informação e para sua comunicação às partes interessadas, pode afetar o funcionamento dos controles, deixando os riscos da entidade sem a resposta esperada e prejudicando a realização de seus objetivos. Destaca-se ainda a relevância dos processos de informação e comunicação para a transparência e a accountability necessárias para o controle social (IFAC, 2001).

O quadro a seguir apresenta os riscos identificados com embasamento nas características da subdimensão, diagnosticadas pela aplicação do modelo de maturidade desenvolvido neste trabalho, e as respectivas recomendações para o aprimoramento das estruturas de controle interno das entidades estudadas.

Quadro 67 - Riscos e Recomendações da Subdimensão 4.1 - Sistema de Informação da Entidade

\begin{tabular}{|c|c|}
\hline Riscos & Recomendações \\
\hline $\begin{array}{l}\text { (MAPA, Incra, Conab) As atividades de controle da } \\
\text { entidade não disponham das informações necessárias } \\
\text { para o seu funcionamento adequado. } \\
\text { (MAPA, Incra, Conab) As informações } \\
\text { disponibilizadas para as atividades de controle da } \\
\text { entidade são possuam a qualidade necessária. } \\
\text { (MAPA, Incra, Conab) Perda das informações } \\
\text { necessárias para o funcionamento adequado das } \\
\text { atividades de controle da entidade. }\end{array}$ & $\begin{array}{l}\text { (MAPA, Incra, Conab) Estabelecer processos formais } \\
\text { para a identificar, produzir ou coletar, tratar, } \\
\text { armazenar, processar e descartar os dados e } \\
\text { informações necessários para o funcionamento do } \\
\text { controle interno da entidade, incluindo um programa } \\
\text { de governança para a manutenção da qualidade dos } \\
\text { dados e informações. }\end{array}$ \\
\hline $\begin{array}{l}\text { (MAPA, Incra, Conab) As informações necessárias } \\
\text { ao funcionamento da estrutura de controle interno da } \\
\text { entidade não sejam comunicadas às partes } \\
\text { interessadas, ou sejam comunicadas de forma } \\
\text { intempestiva. } \\
\text { (MAPA, Incra, Conab) O método ou canal de } \\
\text { comunicação utilizado pela entidade não seja } \\
\text { adequado para as características da mensagem ou do } \\
\text { público receptor. } \\
\text { (MAPA, Incra, Conab) O método ou canal de } \\
\text { comunicação utilizado pela entidade não propicie } \\
\text { uma relação adequada entre custo e benefício. } \\
\text { (MAPA, Incra, Conab) Indisponibilidade de canal de } \\
\text { comunicação adequado para a transmissão da } \\
\text { mensagem pela entidade, ou para o fornecimento de } \\
\text { feedback. } \\
\text { (MAPA, Incra, Conab) A falta de confiança na } \\
\text { capacidade da entidade de proteger a identidade do } \\
\text { comunicante resulte em perda de informações } \\
\text { relevantes para a identificação de problemas na } \\
\text { estrutura de controle interno da entidade. }\end{array}$ & $\begin{array}{l}\text { (MAPA, Incra, Conab) Estabelecer processos formais } \\
\text { para comunicar ao público interno e externo as } \\
\text { informações necessárias para o funcionamento da } \\
\text { estrutura de controle interno da entidade, incluindo } \\
\text { procedimentos para a seleção dos métodos de } \\
\text { comunicação, a definição de canais de comunicação } \\
\text { internos e externos, múltiplos e bidirecionais, e canal } \\
\text { de denúncias com garantia de anonimato. }\end{array}$ \\
\hline
\end{tabular}

Fonte: Elaborado pelo autor. 


\subsection{2}

Avaliação do Nível de Maturidade das Entidades na Dimensão 4 - Informação

\section{e Comunicação}

O quadro a seguir apresenta o resultado dos procedimentos de avaliação do nível de maturidade das entidades estudadas na dimensão Informação e Comunicação, considerando o peso de cada nível de maturidade, definido pela média dos pesos estabelecidos pelo atendimento dos critérios dentro das variáveis da dimensão, conforme o apêndice $\mathrm{J}$ deste trabalho.

Quadro 68 - Avaliação do Nível de Maturidade das Entidades na Dimensão 4 - Informação e

\begin{tabular}{|c|c|c|c|}
\hline Nível de Maturidade & MAPA & Incra & Conab \\
\hline (0) Incipiente & $100,0 \%$ & $100,0 \%$ & $50,0 \%$ \\
\hline (1) Inicial & $0,0 \%$ & $0,0 \%$ & $25,0 \%$ \\
\hline (2) Em Formação & $0,0 \%$ & $0,0 \%$ & $0,0 \%$ \\
\hline (3) Estabelecido & $0,0 \%$ & $0,0 \%$ & $0,0 \%$ \\
\hline Avaliação & (0) Incipiente & (0) Incipiente & (0) Incipiente \\
\hline
\end{tabular}

Fonte: Dados da pesquisa.

Os procedimentos de avaliação conferiram a todas as entidades estudadas o nível de maturidade (0) Incipiente. Nesse sentido, a implantação de um sistema de informação, incluindo processos para identificar as necessidades de informações e disponibilizar as informações necessárias para o funcionamento da estrutura de controle interno, conforme conceituado pelo GAO (2014), é a principal recomendação para o aperfeiçoamento das estruturas de controle interno de MAPA, Incra e Conab.

\subsection{RESULTAD DA DIMENSÃO 5 - MONITORAMENTO}

\subsubsection{Resultados da Subdimensão 5.1 - Monitoramento da Estrutura de Controle}

\section{Interno}

\subsubsection{Resultados da Variável 5.1.1 - Monitoramento Contínuo}

Quadro 69 - Resultados da Variável 5.1.1 - Monitoramento Contínuo

\begin{tabular}{|l|l|l|l|}
\hline \multicolumn{1}{|c|}{ (0) Incipiente } & \multicolumn{1}{c|}{ (1) Inicial } & \multicolumn{1}{c|}{ (2) Em Formação } & \multicolumn{1}{c|}{ (3) Estabelecido } \\
\hline $\begin{array}{l}\text { Ausência de diagnóstico } \\
\text { das atividades de } \\
\text { monitoramento contínuo } \\
\text { dos processos, políticas e } \\
\text { procedimentos relevantes } \\
\text { para a realização dos } \\
\text { objetivos da entidade. }\end{array}$ & $\begin{array}{l}\text { Os processos, políticas e } \\
\text { procedimentos relevantes } \\
\text { para a realização dos } \\
\text { objetivos da entidade } \\
\text { possuem atividades de } \\
\text { monitoramento } \\
\text { integradas. }\end{array}$ & $\begin{array}{l}\text { As atividades de } \\
\text { monitoramento são } \\
\text { documentadas seguindo } \\
\text { modelos padronizados } \\
\text { pela entidade. }\end{array}$ & $\begin{array}{l}\text { As atividades de } \\
\text { monitoramento dos } \\
\text { processos, políticas e } \\
\text { procedimentos relevantes } \\
\text { para a realização dos } \\
\text { objetivos da entidade são } \\
\text { automatizadas, com o } \\
\text { uso de tecnologia. }\end{array}$ \\
\hline MAPA & Não & Não & Não \\
\hline Incra & Não & Não & Não \\
\hline Conab & Não & Não \\
\hline
\end{tabular}

Fonte: Dados da pesquisa. 
Para a análise da maturidade nesta variável foram solicitados às entidades estudadas os seguintes documentos: Mapas dos principais processos; Descrição dos principais processos; Descrição das atividades dos principais processos; Manuais de procedimentos das atividades dos principais processos; Descrição das atividades de monitoramento dos principais processos; Manuais de procedimentos das atividades de monitoramento dos principais processos.

Nenhuma das entidades estudadas apresentou evidências de cumprimento dos critérios da variável.

A integração de atividades de monitoramento contínuo aos principais processos da entidade é importante em razão de sua tempestividade na identificação de problemas (COSO, 2013). Na ausência de tais atividades, o funcionamento da estrutura de controle interno da entidade é analisado apenas no âmbito das avaliações avulsas, que podem não ter a tempestividade adequada. Mudanças no ambiente ou nos processos da organização podem afetar o funcionamento da estrutura de controle interno, prejudicando a realização dos objetivos da entidade.

\subsubsection{Resultados da Variável 5.1.2 - Avaliações Avulsas}

Quadro 70 - Resultados da Variável 5.1.2 - Avaliações Avulsas

\begin{tabular}{|c|l|l|l|}
\hline \multicolumn{1}{|c|}{ (0) Incipiente } & \multicolumn{1}{c|}{ (1) Inicial } & \multicolumn{1}{c|}{ (2) Em Formação } & \multicolumn{1}{c|}{ Estabelecido } \\
\hline $\begin{array}{l}\text { Ausência de avaliações } \\
\text { avulsas da estrutura de } \\
\text { controle interno da } \\
\text { entidade. }\end{array}$ & $\begin{array}{l}\text { Avaliações avulsas da } \\
\text { estrutura de controle } \\
\text { interno são realizadas } \\
\text { periodicamente pela } \\
\text { gerência da entidade. }\end{array}$ & $\begin{array}{l}\text { Avaliações avulsas da } \\
\text { estrutura de controle } \\
\text { interno são realizadas } \\
\text { periodicamente pela } \\
\text { auditoria interna. }\end{array}$ & $\begin{array}{l}\text { Avaliações avulsas da } \\
\text { estrutura de controle } \\
\text { interno são realizadas } \\
\text { periodicamente por } \\
\text { auditoria independente } \\
\text { ou consultores externos. }\end{array}$ \\
\hline MAPA & Não & Não & Parcial \\
\hline Incra & Não & Parcial & Parcial \\
\hline Conab & Não & Simcial \\
\hline
\end{tabular}

Fonte: Dados da pesquisa.

Para a análise da maturidade nesta variável foram solicitados às entidades estudadas os seguintes documentos: Relatórios de avaliações de controles internos realizadas pelos gerentes; Normas e regulamentos da Entidade referentes à avaliação de controles internos; Mapas dos processos para a avaliação de controles internos; Relatórios de avaliações de controles internos realizadas pela auditoria interna; Relatórios de avaliações de controles internos realizadas por auditor independente ou consultor externo.

No MAPA, os Relatórios Anuais de Auditoria de Contas dos exercícios de 2013 e 2014 demonstraram que a CGU tem realizado a avaliação do sistema de controles internos do Ministério, estruturada conforme os componentes do COSO. Não obstante, considerando que 
essa avaliação é realizada conforme o entendimento da CGU quanto às áreas da gestão que devem ser analisadas na auditoria anual de contas, entende-se que o MAPA atende apenas parcialmente ao critério do nível de maturidade (3). O MAPA não possui uma unidade de auditoria interna, nem departamento com a atribuição de avaliar controles internos; também não apresentou evidências de que a gerência realize avaliações de controles internos, de modo que não atende aos critérios para os níveis de maturidade (1) e (2).

No Incra, os Relatórios Anuais de Atividades de Auditoria Interna - RAINT dos exercícios de 2013 e 2014 informam que a Auditoria Interna não realizou "trabalhos que visassem a sistematização e avaliação de controles internos administrativos [...] permanecendo a conduta de se avaliá-los de forma pontual entre as demandas desta Auditoria e de auditorias da SFC/CGU e TCU”. O Relatório Anual de Auditoria de Contas do Incra, exercício de 2014, demonstra que a CGU avaliou os controles do Programa Nacional de Reforma Agrária e respectivos processos e sistemas informatizados. Não obstante, não se trata de uma avaliação da estrutura de controle interno do Incra. Assim, o Incra não cumpre o critério do nível (1) Inicial, atendendo apenas parcialmente os critérios dos níveis de maturidade (2) e (3).

$\mathrm{Na}$ Conab, o Plano Anual de Atividades da Auditoria Interna - PAINT do exercício de 2015 incluiu a avaliação de controles internos da gestão do Programa de Aquisição de Alimentos da Agricultura Familiar, na modalidade Compra com Doação Simultânea; da folha de pagamento de pessoal; e da gestão de débitos não liquidados de armazenadoras impedidas de operar com a Conab. Além disso, a Auditoria Interna tem a competência regimental de emitir parecer sobre as demonstrações contábeis da Conab, o que implica a análise de controles internos.

O Relatório Anual de Auditoria de Contas da Conab, exercício de 2014, informa que a CGU avaliou os controles sobre a gestão dos imóveis da entidade e os controles do Programa de Vendas em Balcão. O Parecer dos Auditores Independentes sobre as Demonstrações Contábeis da Conab, do exercício de 2015, deixa claro que os trabalhos da auditoria incluem uma avaliação dos controles, mas que não tem o objetivo de expressar uma opinião sobre a eficácia dos controles internos da entidade.

Além disso, a Gerência de Controles Internos da Conab tem entre suas atribuições regimentais manifestar-se sobre o sistema de controles internos da Conab no âmbito das prestações de contas anuais da Companhia. 
Assim, a Conab não atende ao critério do nível de maturidade (1) Inicial, embora atenda integralmente ao critério do nível de maturidade (2), além de atender parcialmente ao critério do nível de maturidade (3) Estabelecido.

As avaliações avulsas também são parte importante da estratégia de monitoramento da estrutura de controle interno, e não devem ser realizadas apenas pela auditoria interna ou função especializada em controle interno da entidade. O IFAC (2001) destaca que cabe à gerência a responsabilidade primária pela eficácia do controle interno, que deve ser revisada e testada regularmente.

As autoavaliações, apesar da restrição na objetividade, podem auxiliar a gerência a identificar deficiências nos controles internos dos processos sob sua responsabilidade, propiciando a melhoria das atividades de monitoramento contínuo. Podem servir também como embasamento para que os gerentes atestem a eficácia dos controles internos, caso tenham essa responsabilidade.

\subsubsection{Resultados da Variável 5.1.3 - Comunicação das Deficiências de Controle} Interno e Acompanhamento das Ações Corretivas

Quadro 71 - Resultados da Variável 5.1.3 - Comunicação das Deficiências de Controle Interno e Acompanhamento das Ações Corretivas

\begin{tabular}{|c|c|c|c|}
\hline (0) Incipiente & (1) Inicial & (2) Em Formação & (3) Estabelecido \\
\hline $\begin{array}{l}\text { Ausência de políticas e } \\
\text { processos para a } \\
\text { comunicação das } \\
\text { deficiências de controle } \\
\text { interno e } \\
\text { acompanhamento das } \\
\text { ações corretivas. }\end{array}$ & $\begin{array}{l}\text { A entidade possui } \\
\text { políticas formalmente } \\
\text { estabelecidas definindo a } \\
\text { classificação dos } \\
\text { problemas identificados } \\
\text { nas atividades de } \\
\text { monitoramento, além do } \\
\text { nível de detalhe da } \\
\text { documentação, as } \\
\text { responsabilidades pelas } \\
\text { ações corretivas e as } \\
\text { partes que devem ser } \\
\text { comunicadas, conforme a } \\
\text { classificação. }\end{array}$ & $\begin{array}{l}\text { A entidade possui } \\
\text { processos formalmente } \\
\text { estabelecidos para o } \\
\text { acompanhamento das } \\
\text { ações corretivas para as } \\
\text { deficiências identificadas } \\
\text { nos controles internos. }\end{array}$ & $\begin{array}{l}\text { A entidade possui } \\
\text { processos formalmente } \\
\text { estabelecidos para a } \\
\text { verificação da eficácia } \\
\text { das ações corretivas } \\
\text { adotadas para } \\
\text { deficiências de controles } \\
\text { internos significativas. }\end{array}$ \\
\hline MAPA & Não & Não & Não \\
\hline Incra & Não & Não & Não \\
\hline Conab & Parcial & Sim & Não \\
\hline
\end{tabular}

Fonte: Dados da pesquisa.

Para a análise da maturidade nesta variável foram solicitados às entidades estudadas os seguintes documentos: Normas e regulamentos referentes à classificação dos problemas identificados nas atividades de monitoramento; Mapas dos processos para a classificação dos problemas identificados nas atividades de monitoramento; Normas e regulamentos referentes a processos de acompanhamento das ações corretivas para as deficiências identificadas nos 
controles internos; Mapas dos processos para o acompanhamento das ações corretivas para as deficiências identificadas nos controles internos; Normas e regulamentos referentes a processos de verificação da eficácia das ações corretivas adotadas para deficiências significativas de controles internos; Mapas dos processos para a verificação da eficácia das ações corretivas adotadas para deficiências significativas de controles internos.

O MAPA e o Incra não apresentaram evidências de cumprimento dos critérios da variável.

Na Conab, a Norma de Gestão de Recomendações da Auditoria Interna (NOC 10.501) institui um processo formal para o monitoramento das recomendações dos relatórios da Auditoria Interna, realizado com o apoio do sistema informatizado SIAUDI. Esse processo prevê a classificação das recomendações em alta, média e baixa, e define critérios para a comunicação de recomendações não atendidas à Diretoria responsável, o Conselho de Administração e do Conselho Fiscal.

O RAINT da Conab do exercício de 2015 demonstra que a Auditoria Interna também realiza procedimentos para acompanhamento de recomendações emanadas da CGU e do TCU, além de decisões e recomendações oriundas do Conselho de Administração e do Conselho Fiscal.

Além disso, a Gerência de Controles Internos da Conab tem entre suas a atribuições regimentais a avaliação da qualidade e adequação dos controles internos existentes nos aspectos de conformidade normativa. $\mathrm{O}$ acompanhamento deve ser sistemático, incluindo a emissão de relatórios anuais incluindo as conclusões dos exames efetuados, as recomendações a respeito de eventuais deficiências e a manifestação dos responsáveis pelas correspondentes áreas a respeito das deficiências encontradas e das medidas saneadoras adotadas (art. 30, parágrafo único).

Considerando as evidências encontradas, entende-se que a Conab atende parcialmente ao critério do nível de maturidade (1) Inicial, e atende integralmente o critério do nível de maturidade (2) Em Formação.

A ausência de políticas sobre o tratamento das deficiências de controle interno pode fazer com que deficiências significativas deixem de ser comunicadas aos níveis organizacionais competentes para o estabelecimento de correções (COSO, 2013). É possível ainda que as correções não sejam adequadamente implantadas, ou que a eficácia das correções não seja 
avaliada. Nesse sentido, a entidade permanece exposta a riscos, com a possibilidade de prejuízos à realização de seus objetivos.

\subsubsection{Análise Comparativa da Subdimensão 5.1 - Monitoramento da Estrutura de}

\section{Controle Interno}

Quadro 72 - Análise Comparativa da Subdimensão 5.1 - Monitoramento da Estrutura de Controle

\begin{tabular}{|c|c|c|c|}
\hline \multicolumn{4}{|c|}{ Interno } \\
\hline Variáveis & MAPA & Incra & Conab \\
\hline $\begin{array}{l}\text { 5.1.1. Monitoramento } \\
\text { Contínuo }\end{array}$ & $\begin{array}{l}\text { Não apresentou } \\
\text { evidências de } \\
\text { atividades de } \\
\text { monitoramento } \\
\text { contínuo de seus } \\
\text { processos, políticas e } \\
\text { procedimentos. }\end{array}$ & $\begin{array}{l}\text { Não apresentou } \\
\text { evidências de } \\
\text { atividades de } \\
\text { monitoramento } \\
\text { contínuo de seus } \\
\text { processos, políticas e } \\
\text { procedimentos. }\end{array}$ & $\begin{array}{l}\text { Não apresentou evidências de } \\
\text { atividades de monitoramento } \\
\text { contínuo de seus processos, } \\
\text { políticas e procedimentos. }\end{array}$ \\
\hline $\begin{array}{l}\text { 5.1.2. Avaliações } \\
\text { Avulsas }\end{array}$ & $\begin{array}{l}\text { Avaliações avulsas da } \\
\text { estrutura de controle } \\
\text { interno realizadas } \\
\text { somente pela CGU. }\end{array}$ & $\begin{array}{l}\text { Avaliações avulsas dos } \\
\text { controles internos de } \\
\text { processos específicos, } \\
\text { realizadas de forma } \\
\text { eventual, somente pela } \\
\text { auditoria interna e } \\
\text { CGU. }\end{array}$ & $\begin{array}{l}\text { Avaliações avulsas da estrutura } \\
\text { de controle interno realizadas de } \\
\text { forma institucional pela auditoria } \\
\text { interna e avaliações avulsas dos } \\
\text { controles internos de processos } \\
\text { específicos realizadas pela } \\
\text { auditoria interna e pela CGU. }\end{array}$ \\
\hline $\begin{array}{l}\text { 5.1.3. Comunicação } \\
\text { das Deficiências de } \\
\text { Controle Interno e } \\
\text { Acompanhamento } \\
\text { das Ações Corretivas }\end{array}$ & $\begin{array}{l}\text { Não apresentou } \\
\text { evidências de políticas } \\
\text { e processos para a } \\
\text { comunicação das } \\
\text { deficiências de } \\
\text { controle interno e } \\
\text { acompanhamento das } \\
\text { ações corretivas. }\end{array}$ & $\begin{array}{l}\text { Não apresentou } \\
\text { evidências de políticas } \\
\text { e processos para a } \\
\text { comunicação das } \\
\text { deficiências de } \\
\text { controle interno e } \\
\text { acompanhamento das } \\
\text { ações corretivas. }\end{array}$ & $\begin{array}{l}\text { Processo formalmente } \\
\text { estabelecidos para o } \\
\text { acompanhamento das ações } \\
\text { corretivas para as recomendações } \\
\text { da auditoria interna, incluindo a } \\
\text { classificação das recomendações } \\
\text { e a comunicação das } \\
\text { recomendações não atendidas ao } \\
\text { corpo diretivo e alta gerência; } \\
\text { acompanhamento eventual de } \\
\text { recomendações oriundas do } \\
\text { Conselho de Administração, } \\
\text { Conselho Fiscal, CGU e TCU. }\end{array}$ \\
\hline
\end{tabular}

Fonte: Dados da pesquisa.

Verificou-se que MAPA, Incra e Conab não possuem estratégia de monitoramento de seus sistemas de controle interno. A ausência de uma estratégia para a verificação da presença e funcionamento dos componentes e princípios do controle interno aumenta o risco de que as deficiências dos controles não sejam tempestivamente identificadas, além do risco de que as atividades de controle deixem de funcionar com o transcorrer do tempo, diminuído a eficácia da estrutura de controle interno e prejudicando a realização dos objetivos da entidade.

O quadro a seguir apresenta os riscos identificados com embasamento nas características da subdimensão, diagnosticadas pela aplicação do modelo de maturidade desenvolvido neste trabalho, e as respectivas recomendações para o aprimoramento das estruturas de controle interno das entidades estudadas: 
Quadro 73 - Riscos e Recomendações da Subdimensão 5.1 - Monitoramento da Estrutura de Controle Interno

\begin{tabular}{|c|c|}
\hline Riscos & Recomendações \\
\hline $\begin{array}{l}\text { (MAPA, Incra, Conab) Os problemas nos } \\
\text { componentes da estrutura de controle interno da } \\
\text { entidade não sejam identificados, ou sejam } \\
\text { identificados de forma intempestiva. }\end{array}$ & $\begin{array}{l}\text { (MAPA, Incra, Conab) Estabelecer atividades de } \\
\text { monitoramento integradas aos processos, políticas e } \\
\text { procedimentos da entidade. }\end{array}$ \\
\hline $\begin{array}{l}\text { (MAPA, Incra, Conab) As limitações das atividades } \\
\text { de monitoramento manuais dificultem ou } \\
\text { impossibilitem a identificação de problemas nos } \\
\text { componentes da estrutura de controle interno da } \\
\text { entidade. }\end{array}$ & $\begin{array}{l}\text { (MAPA, Incra, Conab) Estabelecer atividades de } \\
\text { monitoramento integradas automatizadas com } \\
\text { recursos de TI para o monitoramento contínuo dos } \\
\text { processos, políticas e procedimentos relevantes para } \\
\text { a realização dos objetivos da entidade. }\end{array}$ \\
\hline $\begin{array}{l}\text { (MAPA, Incra, Conab) Os processos, políticas e } \\
\text { procedimentos da entidade não possuam atividades } \\
\text { de monitoramento contínuo, ou sejam as atividades } \\
\text { de monitoramento inadequadas. } \\
\text { (MAPA, Incra, Conab) As atividades de } \\
\text { monitoramento contínuo da entidade não sejam } \\
\text { adequadamente executadas, deixando de produzir os } \\
\text { resultados esperados. } \\
\text { (MAPA, Incra, Conab) A infraestrutura de TI da } \\
\text { entidade que suporta o funcionamento das atividades } \\
\text { de monitoramento contínuo não seja identificada e } \\
\text { protegida. }\end{array}$ & $\begin{array}{l}\text { (MAPA, Incra, Conab) Documentar as atividades de } \\
\text { monitoramento contínuo, inclusive a infraestrutura de } \\
\text { TI que apoia o seu funcionamento. }\end{array}$ \\
\hline $\begin{array}{l}\text { (MAPA, Incra, Conab) A gerência da entidade não } \\
\text { identifique problemas nos componentes da estrutura } \\
\text { de controle interno sob sua responsabilidade. } \\
\text { (MAPA, Incra, Conab) Restrições de objetividade } \\
\text { nas avaliações avulsas dificultem ou impossibilitem a } \\
\text { identificação de problemas nos componentes da } \\
\text { estrutura de controle interno da entidade. }\end{array}$ & $\begin{array}{l}\text { (MAPA, Incra, Conab) Estabelecer políticas, } \\
\text { processos e procedimentos para avaliações avulsas } \\
\text { das estruturas de controle interno por parte da } \\
\text { gerência da entidade, além de política determinado } \\
\text { avaliações avulsas periódicas por auditor ou } \\
\text { consultor externo. } \\
\text { (MAPA) Implantar uma unidade de auditoria interna } \\
\text { na entidade. }\end{array}$ \\
\hline $\begin{array}{l}\text { (MAPA, Incra, Conab) Os problemas identificados } \\
\text { nas atividades de monitoramento da entidade não } \\
\text { sejam adequadamente documentados e priorizados. } \\
\text { (MAPA, Incra, Conab) Os problemas identificados } \\
\text { nas atividades de monitoramento da entidade não } \\
\text { sejam comunicados aos indivíduos que tenham a } \\
\text { autoridade e competência adequada para solucioná- } \\
\text { los. } \\
\text { (MAPA, Incra, Conab) As ações para a correção dos } \\
\text { problemas identificados nas atividades de } \\
\text { monitoramento da entidade não sejam implantadas. } \\
\text { (MAPA, Incra, Conab) As ações implantadas para a } \\
\text { correção dos problemas identificados nas atividades } \\
\text { de monitoramento da entidade não produzam o } \\
\text { resultado esperado. }\end{array}$ & $\begin{array}{l}\text { (MAPA, Incra) Estabelecer formalmente políticas e } \\
\text { processos para a classificação, documentação e } \\
\text { comunicação dos problemas identificados nas } \\
\text { atividades de monitoramento da entidade. } \\
\text { (Conab) Incluir nas políticas e processos a } \\
\text { documentação e comunicação dos problemas } \\
\text { identificados nas atividades de monitoramento da } \\
\text { entidade, incluindo os problemas identificados por } \\
\text { outras partes que não a auditoria interna. } \\
\text { (MAPA, Incra, Conab) Incluir nas políticas e } \\
\text { processos o acompanhamento da implantação das } \\
\text { ações corretivas das e a verificação de sua eficácia. }\end{array}$ \\
\hline
\end{tabular}

Fonte: Elaborado pelo autor. 


\subsubsection{Avaliação do Nível de Maturidade das Entidades na Dimensão 5 -}

\section{Monitoramento}

O quadro a seguir apresenta o resultado dos procedimentos de avaliação do nível de maturidade das entidades estudadas na dimensão Monitoramento, considerando o peso de cada nível de maturidade, definido pela média dos pesos estabelecidos pelo atendimento dos critérios dentro das variáveis da dimensão, conforme o apêndice J deste trabalho.

Quadro 74 - Avaliação do Nível de Maturidade das Entidades na Dimensão 5 - Monitoramento

\begin{tabular}{|c|c|c|c|}
\hline Nível de Maturidade & MAPA & Incra & Conab \\
\hline (0) Incipiente & $66,7 \%$ & $33,3 \%$ & $33,3 \%$ \\
\hline (1) Inicial & $0,0 \%$ & $0,0 \%$ & $16,7 \%$ \\
\hline (2) Em Formação & $0,0 \%$ & $33,3 \%$ & $66,7 \%$ \\
\hline (3) Estabelecido & $16,7 \%$ & $33,3 \%$ & $16,7 \%$ \\
\hline Avaliação & (0) Incipiente & (0) Incipiente & (0) Incipiente \\
\hline
\end{tabular}

Fonte: Dados da pesquisa.

Os procedimentos de avaliação conferiram a todas as entidades estudadas o nível de maturidade (0) Incipiente. Apesar disso, cabe destacar que as características do monitoramento da Conab diferenciam-na do MAPA e do Incra. A auditoria interna da Conab dispõe de mecanismos para o monitoramento de suas próprias recomendações; a Conab dispõe ainda de um departamento que tem a responsabilidade de avaliar anualmente o sistema de controle interno da entidade.

Desse modo, a principal recomendação para o aperfeiçoamento das estruturas de controle interno de MAPA e Incra é a implantação de um sistema de monitoramento. A Conab deve aperfeiçoar o seu sistema de monitoramento, implantando e documentando atividades de monitoramento contínuo, atribuindo à gerencia a responsabilidade pela avaliação de seus controles internos e avaliando a eficácia das correções aos problemas identificados pelo monitoramento.

\subsection{AVALIAÇÃO DO NÍVEL DE MATURIDADE DAS ESTRUTURAS DE CONTROLE INTERNO}

O quadro a seguir apresenta o resultado dos procedimentos de avaliação do nível de maturidade das estruturas de controle interno das entidades estudadas, considerando a média do peso de todas as variáveis do modelo em cada nível de maturidade, conforme o apêndice $\mathbf{J}$ deste trabalho. 
Quadro 75 - Avaliação do Nível de Maturidade das Estruturas de Controle Interno das Entidades

\begin{tabular}{|c|c|c|c|}
\hline Nível de Maturidade & MAPA & Incra & Conab \\
\hline (0) Incipiente & $45,7 \%$ & $48,6 \%$ & $31,4 \%$ \\
\hline (1) Inicial & $44,3 \%$ & $40,0 \%$ & $55,7 \%$ \\
\hline (2) Em Formação & $28,6 \%$ & $27,1 \%$ & $27,1 \%$ \\
\hline (3) Estabelecido & $14,3 \%$ & $14,3 \%$ & $17,1 \%$ \\
\hline Avaliação & (0) INCIPIENTE & (0) INCIPIENTE & (1) INICIAL \\
\hline
\end{tabular}

Fonte: Dados da pesquisa.

Os procedimentos de avaliação conferiram às estruturas de controle interno do MAPA e do Incra o nível de maturidade (0) Incipiente, enquanto a Conab atendeu a critérios suficientes para classificação no nível de maturidade (1) Inicial. Apesar do destaque obtido pela Conab, entende-se que o resultado final demonstra o baixo nível de implementação de estruturas de controle interno nas três organizações. 
Tendo em perspectiva a importância da agricultura para o desenvolvimento econômico e social do Brasil, este trabalho teve como objetivo analisar a maturidade das estruturas de controle interno de organizações governamentais brasileiras que implementam políticas públicas para a agricultura.

A principal contribuição acadêmica do trabalho foi o desenvolvimento e validação de um modelo de maturidade, fundamentado no framework de controle interno do COSO e padrões do GAO, que pode ser utilizado para a avaliação da maturidade de estruturas de controle interno em organizações governamentais.

O modelo foi estruturado em quatro estágios ou níveis de maturidade, representando um processo de implantação gradual de uma estrutura de controle interno nessas organizações: (0) Inicipiente, (1) Inicial, (2) Em Formação e (3) Estabelecido. As cinco dimensões do modelo de maturidade correspondem aos componentes do controle interno, conforme definido pelo framework COSO I: Ambiente de Controle; Avaliação de Riscos; Atividades de Controle; Informação e Comunicação; e Monitoramento (COSO, 2013). As subdimensões foram definidas com embasamento nos princípios e pontos de foco do framework COSO I, e nos atributos dos padrões do GAO. As 35 variáveis e os critérios de enquadramento em cada nível de maturidade foram elaborados com base nas boas práticas de controle interno recomendadas pelo COSO e GAO.

A validação do modelo incluiu a avaliação da clareza e da pertinência das variáveis e critérios de enquadramento por especialistas, por meio de questionário, incorporando-se as contribuições pertinentes ao modelo proposto. A matriz de maturidade final, apresentada no apêndice I, foi empiricamente testada no âmbito do estudo de casos múltiplos (YIN, 2010), que aplicou o modelo para o diagnóstico das capacidades e a avaliação da maturidade das estruturas de controle interno de três organizações governamentais brasileiras ligadas à função agricultura: o MAPA, o Incra e a Conab. Os estudos de caso permitiram uma análise comparativa (CONILL et al., 1991; HORTALE et al., 1999), que identificou as similaridades e diferenças das estruturas de controle interno estudadas, testando a funcionalidade comparativa do modelo de maturidade desenvolvido.

A estrutura de controle interno do MAPA foi classificada no nível de maturidade (0) Incipiente. Na análise por dimensões, o MAPA se destacou na dimensão Ambiente de Controle, em razão das características de suas estruturas organizacionais para a disseminação e 
avaliação da gestão da ética, além das características do seu processo de avaliação de desempenho, alcançando o nível de maturidade (2) Em Formação. O MAPA obteve ainda o nível de maturidade (1) Inicial na dimensão Avaliação de Riscos, mas não conseguiu superar o nível de maturidade (0) Incipiente nas demais dimensões.

As principais recomendações para desenvolvimento da estrutura de controle interno do MAPA incluem: desenvolver um código de conduta próprio; implantar a gestão por competências; desenvolver procedimentos para a avaliação do desempenho da alta gerência e corpo diretivo; estabelecer processos formais para a definição dos objetivos e a avaliação de riscos; mapear os processos relevantes, inventariando e descrevendo as atividades de controle e diagnosticando a segregação de funções; estabelecer processos formais para os procedimentos contábeis patrimoniais, conformidade e conciliação das demonstrações; definir nas políticas das atividades de controle as competências e o nível de autoridade necessários, a tempestividade da execução e ações corretivas em caso de problemas; diagnosticar e avaliar os riscos do uso da computação de usuário final, automatizando os controles dos principais processos; estabelecer políticas de controle de acesso, continuidade de serviços e recuperação de desastres para a infraestrutura de TI; estabelecer processos de gestão de configuração e mudança da TI; estabelecer processos para a obtenção e comunicação interna e externa das informações necessárias ao funcionamento da estrutura de controle interno; estabelecer atividades de monitoramento contínuo nos principais processos; estabelecer uma política de monitoramento avulso, incluindo avaliações periódicas pela gerência; e definir políticas para a comunicação e tratamento dos problemas identificados nas atividades de monitoramento.

A estrutura de controle interno do Incra também foi classificada no nível de maturidade (0) Incipiente. Na análise por dimensões, o Incra alcançou o nível de maturidade (2) Em Formação na dimensão Ambiente de Controle e (1) Inicial na dimensão Avaliação de Riscos, mantendo-se no nível de maturidade (0) Incipiente nas demais dimensões. Destacaramse no Incra as características do seu processo de avaliação de desempenho e as características da mensuração de seus objetivos estratégicos.

As principais recomendações para desenvolvimento da estrutura de controle interno do Incra incluem: desenvolver um código de conduta próprio e um programa para a sua ampla disseminação; implantar a gestão por competências; desenvolver procedimentos para a avaliação do desempenho da alta gerência e corpo diretivo; estabelecer processos formais para a definição dos objetivos e a avaliação de riscos; mapear os processos relevantes, inventariando e descrevendo as atividades de controle e diagnosticando a segregação de funções; estabelecer 
processos formais para os procedimentos contábeis patrimoniais, conformidade e conciliação das demonstrações; definir nas políticas das atividades de controle as competências e o nível de autoridade necessários, a tempestividade da execução e ações corretivas em caso de problemas; diagnosticar e avaliar os riscos do uso da computação de usuário final, automatizando os controles dos principais processos; estabelecer políticas de controle de acesso, continuidade de serviços e recuperação de desastres para a infraestrutura de TI; estabelecer processos de gestão de configuração e mudança da TI; estabelecer processos para a obtenção e comunicação interna e externa das informações necessárias ao funcionamento da estrutura de controle interno; estabelecer atividades de monitoramento contínuo nos principais processos; estabelecer uma política de monitoramento avulso, incluindo avaliações periódicas pela gerência; e definir políticas para a comunicação e tratamento dos problemas identificados nas atividades de monitoramento.

A estrutura de controle interno da Conab foi classificada no nível de maturidade (1) Inicial. Na análise por dimensões, a Conab alcançou o nível de maturidade (1) Inicial nas dimensões Ambiente de Controle e Avaliação de Riscos, não conseguindo superar o nível de maturidade (0) Incipiente nas demais dimensões. Destacaram-se na Conab a definição das responsabilidades de controle interno e requisitos de competências para seus empregados, e a avaliação de riscos.

As principais recomendações para desenvolvimento da estrutura de controle interno da Conab incluem: desenvolver um programa para a ampla disseminação dos padrões de conduta; desenvolver procedimentos para a avaliação do desempenho da alta gerência e corpo diretivo; estabelecer processos formais para a definição dos objetivos e a avaliação de riscos; mapear os processos relevantes, inventariando e descrevendo as atividades de controle e diagnosticando a segregação de funções; estabelecer processos formais para os procedimentos contábeis patrimoniais, conformidade e conciliação das demonstrações; diagnosticar e avaliar os riscos do uso da computação de usuário final, automatizando os controles dos principais processos; estabelecer políticas de continuidade de serviços e recuperação de desastres para a infraestrutura de TI; estabelecer processos de gestão de configuração e mudança da TI; estabelecer processos para a obtenção e comunicação interna e externa das informações necessárias ao funcionamento da estrutura de controle interno; estabelecer atividades de monitoramento contínuo nos principais processos; estabelecer avaliações avulsas periódicas da estrutura de controle interno pela gerência; e aumentar a abrangência das políticas para a comunicação e tratamento dos problemas identificados nas atividades de monitoramento. 
Apesar de todas as entidades terem objetivos estratégicos definidos, a implantação do plano estratégico é incipiente. Não há definição de objetivos para as unidades, departamentos e processos organizacionais; a ausência de definição dos objetivos operacionais, de relatórios e de conformidade dificulta a avaliação de riscos; a ausência da avaliação de riscos pode desordenar a elaboração dos controles internos. Além disso, a ausência de um sistema de informação e comunicação e a incipiência do sistema de monitoramento podem resultar no mau funcionamento dos controles internos. Nesse contexto, os riscos a que as entidades estão expostas podem ficar sem resposta, prejudicando a realização de seus objetivos; os gestores têm mais oportunidades de utilizar os recursos e o patrimônio público em proveito de interesses que divergem dos interesses dos cidadãos.

A principal limitação do trabalho foi a realização dos estudos de caso pela análise documental, implicando possíveis vieses na avaliação do nível de maturidade das estruturas de controle interno estudadas, uma vez que as capacidades analisadas podem existir na prática, apesar da ausência de estabelecimento formal ou registro documental. Além disso, as capacidades analisadas podem não estar implementadas, apesar de terem sido formalmente estabelecidas ou documentadas. Não obstante, cabe observar que o modelo de maturidade proposto não pretende propiciar uma avaliação exata das capacidades da estrutura de controle interno das organizações governamentais, mas estabelecer um diagnóstico da situação atual e apresentar um caminho evolutivo para orientar os gestores dessas organizações em seus esforços de aprimoramento do controle interno.

A aplicação do modelo de maturidade proposto permitiu também uma comparação entre as entidades estudadas. O principal benefício esperado da funcionalidade comparativa do modelo é a sua utilização, por parte de órgãos de controle ou supervisão da administração pública, em iniciativas que estimulem os gestores públicos a aprimorar continuamente as estruturas, contribuindo para que o controle interno das organizações governamentais propicie segurança razoável da realização de seus objetivos e da fidedignidade de suas informações, desestimulando os gestores dessas entidades a utilizar os recursos e o patrimônio público para a realização de interesses particulares, divergentes dos interesses da sociedade.

Possíveis desdobramentos deste trabalho podem incluir: a incorporação de novas práticas, conforme a evolução dos diversos domínios de conhecimento que compõem as estruturas de controle interno; e o aprimoramento da estrutura do modelo de maturidade, dispondo-se as dimensões, subdimensões, variáveis e níveis de maturidade de modo a aumentar o potencial de suas funcionalidades de diagnóstico, prescrição e comparação. 


\section{REFERÊNCIAS}

AMARAL, Guilherme F.; DE LIMA, Diana V. A contribuição da nova contabilidade pública sobre os efeitos dos ciclos políticos no Brasil. Revista Ambiente Contábil, v. 5, n. 2, p. 173, 2013.

AMERICAN INSTITUTE OF ACCOUNTANTS. Internal Control: Elements of a Co-ordinated System and its Importance to Management and the Independent Public Accountant. New York: AIA, 1949.

AMERICAN INSTITUTE OF CERTIFIED PUBLIC ACCOUNTANTS. Statement on Auditing Standards No. 55: Consideration of the Internal Control Structure in a Financial Statement Audit. New York: AICPA, 1988.

AMORIM, Sônia N. D. Ética na esfera pública: a busca de novas relações Estado/sociedade. Revista do Serviço Público, v. 51, n. 2, abr-jun 2000.

ANDERSEN, K.V.; HENRIKSEN, H. Z. E-government maturity models: Extension of the Layne and Lee model. Government Information Quarterly, n. 23, p. 236-248, 2006.

ANTUNES, Jeronimo; ANTUNES, Guilherme M. B.; SONG, Dail D. I. Certificação dos Controles Internos Exigidos pela Sarbanes-Oxley: Análise dos Primeiros Resultados nas Empresas do Índice Dow Jones. In: X SEMEAD, 2007, São Paulo. Anais... São Paulo: FEA-USP, 2007.

BARDIN, Laurence. Análise de Conteúdo. São Paulo: Edições 70, 2011. 279 p. ISBN 978-85-6293804-7.

BARRETT, A. Balancing accountability and efficiency in a more competitive public sector environment. Australian Journal of Public Administration, v. 59, n. 3, p. 58-71, 2000.

BECKER, J.; KNACKSTEDT, R.; PÖPPELBUß, J. Developing Maturity Models for IT Management - A Procedure Model and its Application. Business \& Information Systems Engineering (BISE), v. 1, n. 3, p. 213-222, 2009.

BERLE, A.; MEANS, G. The Modern Corporation and Private Property. New York: Macmillian, 1932. $396 \mathrm{p}$.

BOZEMAN, Barry. A theory of government "red tape". Journal of Public Administration Research and Theory, v. 3, n. 3, p. 273-304, 1993.

BRAMONT, Pedro. Maturidade em governança corporativa: diretrizes para um modelo preliminar. Dissertação apresentada ao Programa de Pós-Graduação Stricto Sensu em Gestão do Conhecimento e da Tecnologia da Informação da Universidade Católica de Brasília, como requisito parcial para obtenção do Título de Mestre em Gestão do Conhecimento e da Tecnologia da Informação. Brasília: 2012.

BRASIL. Ministério da Agricultura, Pecuária e Abastecimento. AGROSTAT - Estatísticas de Comercio Exterior do Agronegócio Brasileiro. Disponível em: <http://www.agricultura.gov.br /internacional/indicadores-e-estatisticas/balanca-comercial>. Acesso em: $1^{\circ}$ abr. 2016.

Ministério de Minas e Energia. Resenha Energética Brasileira: Exercício de 2014. Jun. 2015. Disponível em: <http://www.mme.gov.br/documents/1138787/1732840/Resenha+Energ\%C3\%A9tica +-+Brasil+2015.pdf/4e6b9a34-6b2e-48fa-9ef8-dc7008470bf2>. Acesso em: $1^{\circ}$ abr. 2016.

CASTRO, Domingos Poubel de. Auditoria, Contabilidade e Controle Interno no Setor Público: Integração das Áreas do Ciclo de Gestão: Contabilidade, Orçamento e Auditoria e Organização dos Controles Internos, como suporte à Governança Corporativa. $5^{\mathrm{a}}$ ed. São Paulo: Atlas, 2013. 603 p. ISBN 978-85-224-8027-2

CHMIELECKI, Michał. Factors Influencing Effectiveness of Internal Communication. Management and Business Administration, v. 23, n. 2, p. 24-38, 2015.

CHUN, Young Han; RAINEY, Hal G. Goal ambiguity and organizational performance in US federal agencies. Journal of Public Administration Research and Theory, v. 15, n. 4, p. 529-557, 2005.

COMMITTE OF SPONSORING ORGANIZATIONS OF THE TREADWAY COMMISSION (COSO). COSO Internal Control - Integrated Framework: Framework and Appendices. 2013. 
COSO Internal Control - Integrated Framework: Internal Control over External Financial Reporting: A Compendium of Approaches and Examples. 2013.

COSO Internal Control-Integrated Framework Frequently Asked Questions. May 2013. Disponível em: <http://www.coso.org/documents/COSO\%20FAQs\%20May\%202013\%20branded .pdf>. Acesso em: $1^{\circ}$ abr. 2016.

Enterprise Risk Management - Integrated Framework. Executive Summary. 2004. Disponível em: 〈http://www.coso.org/documents/coso_erm_executivesummary.pdf〉. Acesso em: $1^{\circ}$ jan. 2015.

CONILL, Eleonor M. et al. Organização dos serviços de saúde: a comparação como contribuição. Cadernos de Saúde Pública, v. 7, n. 3, p. 328-346, 1991.

COY, David; DIXON, Keith. The Public Accountability Index: crafting a parametric disclosure index for annual reports. The British Accounting Review, v. 36, 2004, p.79-106.

CREPALDI, Silvio A. Auditoria contábil: teoria e prática. 9a ed. São Paulo: Atlas, 2013. 874 p. ISBN 978-85-224-8082-1

CROSBY, P. Quality is free: The Art of Making Quality Certain. New York: McGraw-Hill, 1979. 270 p.

D'AQUILA, Jill M. Is the control environment related to financial reporting decisions? Managerial Auditing Journal, v. 13, n. 8, p. 472-478, 1998.

DANIELS, Kevin; BAILEY, Andy. Strategy development processes and participation in decision making: predictors of role stressors and job satisfaction. Journal of Applied Management Studies, v. 8, n. 1, p. 27, 1999.

DAVIS, Marcelo D.; BLASCHEK, José R. de S. Deficiências dos sistemas de controle interno governamentais atuais em função da evolução da economia. In: $6^{\circ}$ Congresso USP de Controladoria e Contabilidade. São Paulo: Universidade de São Paulo, 27 e 28 jul. 2006. Disponível em: <http://www.rio.rj.gov.br/dlstatic/10112/3268049/DLFE-259741.pdf/0.2..pdf>. Acesso em: $1^{\circ}$ jan. 2015.

DE BRUIN, T.; ROSEMANN, M.; FREEZE, R.; KULKARNI, U. Understanding the Main Phases of Developing a Maturity Assessment Model. $16^{\text {th }}$ Australasian Conference on Information Systems. Sydney: 2005.

FEDERAL RECORDS COUNCIL; NATIONAL ARCHIVES AND RECORDS ADMINISTRATION. Federal RIM Program Maturity Model User's Guide. 2014. Disponível em: http://www.archives.gov/records-mgmt/prmd/maturity-model-user-guide.pdf. Acesso em: $1^{\mathrm{o}}$ jun. 2015.

FRASER, P.; MOULTRIE, J.; GREGORY, M. The use of maturity models/grids as a tool in assessing product development capability. Engineering Management Conference, 2002. IEMC '02. 2002 IEEE International, v.1, p. 244-249, 2002.

GIL, Antonio de L.; ARIMA, Carlos H.; NAKAMURA, Wilson T. Gestão: controle interno, risco e auditoria. 1. ed. São Paulo: Saraiva, 2013. 158 p. ISBN 978-85-02-19470-0

GOMES, Fábio G. Conflito social e welfare state: Estado e desenvolvimento social no Brasil. RAP, Rio de Janeiro, v. 40, n. 2, p. 201-36, 2006.

GOTTSCHALK, P. Maturity levels for interoperability in digital government. Government Information Quarterly, n. 26, p. 75-81, 2009.

GREINER, L. Evolution and revolution as organizations grow. Harvard Business Review, n. 6, p.3746, 1972.

GUILHOTO, Joaquim J. M. et al. A importância do agronegócio familiar no Brasil. Revista de Economia e Sociologia Rural, v. 44, n. 3, p. 355-382, jul-set. 2006. Disponível em: <http://www.scielo.br/scielo.php?script=sci_arttext\&pid=S0103-20032006000300002>. Acesso em: $1^{\circ}$ abr. 2016. 
HAY, David. Internal Control: How It Evolved in Four English - Speaking Countries. Accounting Historians Journal, v. 20, n. 1, 1993. Disponível em: <http://www.accountingin.com/accountinghistorians-journal/volume-20-number-1/internal-control-how-it-evolved-in-four-english-speakingcountries/>. Acesso em: $1^{\circ}$ abr. 2016.

HORTALE, Virginia A.; CONILL, Eleonor M.; PEDROZA, Manoela. Desafios na construção de um modelo para análise comparada da organização de serviços de saúde . Cad. Saúde Pública, v. 15, n. 1, p. 79-88, 1999.

INTERNATIONAL FEDERATION OF ACCOUNTANTS (IFAC). Internal Controls - A Review of Current Developments. 2006. Disponível em: <http://www.ifac.org/sites/default/files/publications/ files/internal-controls-a-revie.pdf >. Acesso em: $1^{\mathrm{o}}$ jan. 2015.

Study 13 - Governance in the Public Sector: A Governing Body Perspective. 2001. Disponível em: <http://www.ifac.org/sites/default/files/ publications/files/study-13-governance-in-th.pdf>. Acesso em: $1^{\circ}$ jan. 2015.

Study 14 - Transition to the Accrual Basis of Accounting: Guidance for Governments and Government Entities (Third Edition). 2011. Disponível em: <http://www.ifac.org/sites/default/files/ publications/files/IPSASB-study-14-3e.pdf $>$. Acesso em: $1^{\circ}$ out. 2014.

INTERNATIONAL PUBLIC SECTOR ACCOUNTING STANDARDS BOARD. The conceptual framework for general purpose financial reporting by public sector entities. In: 2014 Handbook of International Public Sector Accounting Pronouncements. v. 1. Disponível em: $<$ https://www.ifac.org/publications-resources/2014-handbook-international-public-sector-accountingpronouncements>. Acesso em: $1^{\circ}$ out. 2014.

INTERNATIONAL ORGANISATION OF SUPREME AUDIT INSTITUTIONS (Intosai). International Standards of Supreme Audit Institutions (ISSAI). Disponível em: <http://www.issai.org/>. Acesso em: $1^{\circ}$ out. 2014.

Intosai GOV 9100. Guidelines for Internal Controls Standards for the Public Sector. 2004. Disponível em: 〈http://www.issai.org/media/13329/intosai_gov_9100_e.pdf >. Acesso em: $1^{\circ}$ jan. 2015.

. Intosai GOV 9130. Guidelines for Internal Controls Standards for the Public Sector - Further Information on Entity Risk Management. 2007. Disponível em: < http://www.issai.org/media/ 13341/ intosai_gov_9130_e.pdf>. Acesso em: $1^{\circ}$ jan. 2015.

INFORMATION SYSTEMS AUDIT AND CONTROL ASSOCIATION (ISACA). IT GOVERNANCE INSTITUTE (ITGI). COBIT 4.1: Modelo, Objetivos de Controle, Diretrizes de Gerenciamento, Modelos de Maturidade. 2007. Disponível em: <http://www.isaca.org/>. Acesso em: $1^{\circ}$ jan. 2015.

IVERSEN, Jakob; NIELSEN, Peter A.; NORBJERG, Jacob. Situated assessment of problems in software development. ACM SIGMIS Database, v. 30, n. 2, p. 66-81, 1999.

JENSEN, M.; MECKLING, W. Theory of the Firm: Managerial Behavior, Agency Costs and Ownership Structure. Journal of Financial Economics, v. 3, p. 305-360, 1976. Disponível em: <http://papers.ssrn.com/sol3/papers.cfm?abstract_id=94043>. Acesso em: $1^{\mathrm{o}}$ jan. 2015.

JENSEN, Michael C. The Modern Industrial Revolution, Exit, and The Failure of Internal Control Systems. The Journal of Finance, July, 1993. Disponível em: <http://citeseerx.ist.psu.edu/viewdoc/ download?doi=10.1.1.197.7317\&rep=rep1\&type=pdf $>$. Acesso em: $1^{\circ}$ abr. 2016.

JOHNSTONE, Karla M.; GRAMLING, Audrey A.; RITTENBERG, Larry E. Auditing: a risk-based approach to conducting a quality audit. $9^{a}$ ed. Cengage Learning, 2012. 874 p. ISBN 978-1-133-939153

JUNG, Chan Su. Extending the theory of goal ambiguity to programs: Examining the relationship between goal ambiguity and performance. Public Administration Review, v. 74, n. 2, p. 205-219, 2014.

KIM, Soonhee. Participative management and job satisfaction: Lessons for management leadership. Public administration review, v. 62, n. 2, p. 231-241, 2002. 
KING, J. L.; KRAEMER, K.L. Evolution and Organizational Information Systems: An Assessment of Nolan's Stage Model. Communications of the ACM, v. 27, n. 5, p. 466-475, 1984.

LAYNE, K.; LEE, J. Developing fully functional E-government: A four stage model. Government Information Quarterly, n. 18, p. 122-136, 2001.

LEE, G.; KWAK, Y.H. An Open Government Maturity Model for social media-based public engagement. Government Information Quarterly, n. 29, p. 492-503, 2012.

LOURENÇO, Rui P.; SERRA, Leila. An Online Transparency for Accountability Maturity Model. In: M. Janssen et al. (Eds.). EGOV 2014, LNCS 8653, p. 35-46, 2014.

LUSTOSA DA COSTA, Frederico. Contribuição a um projeto de reforma democrática do Estado. Revista de Administração Pública, Rio de Janeiro, v. 44, n. 2, p. 239-270, 2010.

MAIER, A. M.; MOULTRIE, J.; CLARKSON, P. J. Assessing Organizational Capabilities: Reviewing and Guiding the Development of Maturity Grids. IEEE Transactions on Engineering Management, v. 59, n. 1, p. 138-159, 2012.

MARSON, Priscila R.; MAYER, Verônica F.; NOGUEIRA, Heloisa G. P. Comunicação Interna no Âmbito da Gestão Pública: O Caso de uma Autarquia Pública Federal Brasileira. REGE Revista de Gestão, v. 20, n. 1, p. 43-60, 2013.

MARTINS, Norberto M. Ensaio sobre a "nova" travessia (ou: O programa de ajuste econômico do segundo governo Dilma: uma nova investida neoliberal?). Texto para discussão 021-2015 IE-UFRJ. 2015. Disponível em: <http://www.ie.ufrj.br/images/pesquisa/publicacoes/discussao/2015/TD_IE_ 021_2015_MARTINS-v.fin.pdf>. Acesso em: $1^{\circ}$ mai 2016.

MATIAS-PEREIRA, José. Reforma do Estado e controle da corrupção no Brasil. Revista de Gestão da USP, São Paulo, v. 12, n. 2, p. 1-17, 2005.

METTLER, T.; ROHNER, P. Situational Maturity Models as Instrumental Artifacts for Organizational Design. In: Proceedings of the $4^{\text {th }}$ international conference on design science research in information systems and technology. ACM, 2009.

NOLAN, R. L. Managing the computer resource: a stage hypothesis. Communications of the ACM, v. 16, n. 7, p. 399-405, 1973.

NOLAN, R.L. Managing the crisis in data processing. Harvard Business Review, n. 57, p. 115-126, 1979.

PANDEY, Sanjay K.; GARNETT, James L. Exploring Public Sector Communication Performance: Testing a Model and Drawing Implications. Public Administration Review, v. 66, n. 1, p. 37-51, 2006.

PAULK, M. C.; CURTIS, B.; CHRISSIS, M. B.; WEBER, C. V. Capability Maturity Model for software. version 1.1. Technical Report CMU/SEI-93-TR-024 ESC-TR-93-177. 1993. Disponível em: <http://www.sei.cmu.edu/reports/93tr024.pdf>. Acesso em: $1^{\circ}$ jan. 2015.

PECI, Alketa; PIERANTI, Octavio P.; RODRIGUES, Silvia. Governança e New Public Management: convergências e contradições no contexto brasileiro. Organizações \& Sociedade, v. 15, n. 46, p. 39-55, 2008.

PÖPPELBUß, Jens; RÖGLINGER, Maximilian. What makes a useful maturity model? A framework of general design principles for maturity models and its demonstration in business process management. European Conference on Information Systems 2011 Proceedings, paper 28. Disponível em: <http://aisel.aisnet.org/ecis2011/28/>. Acesso em: $1^{\circ}$ jan. 2015.

PULLEN, William. A public sector HPT maturity model. Performance Improvement, v. 46, n. 4, p. 915, 2007.

RAUPP, Fabiano Maury; BEUREN, Ilse Maria. Metodologia da Pesquisa Aplicável às Ciências Sociais. In: BEUREN, Ilse Maria. Como Elaborar Trabalhos Monográficos em Contabilidade: Teoria e Prática. 3. ed. São Paulo: Atlas, 2006. cap. 3, p. 76-97. 
SANCHEZ, Oscar Adolfo. O poder burocrático e o controle da informação. Lua Nova, n. 58, p. 89-119, 2003.

SCOTT, Judy E. Mobility, business process management, software sourcing, and maturity model trends: propositions for the IS organization of the future. Information Systems Management, v. 24, n. 2, p. 139145, 2007.

SECCHI, Leonardo. Modelos organizacionais e reformas da administração pública. Revista de Administração Pública, Rio de Janeiro, v. 43, n. 2, p. 347-369, 2009.

SENGER, C. A. A necessidade de mudar o enfoque de auditoria: um estudo sobre as "big six". Dissertação (Mestrado em Ciências Contábeis) - Departamento de Contabilidade e Atuária da Faculdade de Economia, Administração e Contabilidade. São Paulo: Universidade de São Paulo, 1998.

SMYTHE, John. The changing role of internal communication in tomorrow's company. Managing Service Quality: An International Journal, v. 6, n. 2, p. 41-44, 1996.

SOLLI-SÆTHER, H.; GOTTSCHALK, P. The Modeling Process for Stage Models. Journal of Organizational Computing and Electronic Commerce, v. 20, n. 3, p. 279-293, 2010.

TEO, T. S. H.; KING, W. R. Integration Between Business Planning and Information Systems Planning: An Evolutionary-Contingency Perspective. Journal of Management Information Systems, v. 14, n. 1, p. 185-214, 1997.

THE INSTITUTE OF INTERNAL AUDITORS. Internal Audit Capability Model (IA-CM) For the Public Sector. 2009. Disponível em: <https://na.theiia.org/iiarf/Public\%20Documents/Internal \%20Audit\%20Capability\%20Model\%20IA-CM\%20for\%20the\%20Public\%20Sector\%20

Overview.pdf >. Acesso em: $1^{\circ}$ jan. 2015.

International Standards for the Professional Practice of Internal Auditing (Standards). Disponível em: < https://na.theiia.org/standards-guidance/mandatory-guidance/Pages/Standards.aspx> . Acesso em: $1^{\circ}$ abr. 2016.

Selecting, Using, and Creating Maturity Models: A Tool for Assurance and Consulting Engagements. 2013. Disponível em: <http://www.iia.no/filestore/Fag_og_tema/Standarder_og_ Guidance/2013PGMaturityModels.pdf>. Acesso em: $1^{\circ}$ jan. 2015.

UNITED STATES GENERAL ACCOUNTING OFFICE (GAO). Internal Control Management and Evaluation Tool. 2001. Disponível em: <http://www.gao.gov/products/GAO-01-1008G>. Acesso em: $1^{\mathrm{o}}$ jul. 2015.

Standards for Internal Control in the Federal Government (The Green Book). 2014. Disponível em: <http://www.gao.gov/products/GAO-14-704G>. Acesso em: $1^{\circ}$ jul. 2015.

UNIVERSIDADE DE SÃO PAULO (USP). Centro de Estudos Avançados em Economia Aplicada ESALQ/USP. PIB do Agronegócio. Disponível em: <http://cepea.esalq.usp.br/pib/>. Acesso em: $1^{\circ}$ abr. 2016.

WENDLER, Roy. The maturity of maturity model research: A systematic mapping study. Information and Software Technology, n. 54, p. 1317-1339, 2012.

WHITTINGTON, Ray; PANY, Kurt. Principles of auditing \& other assurance services. $18^{\mathrm{a}}$ ed. McGraw-Hill/Irwin, 2012. 842 p. ISBN 978-0-07-811103-7

YIN, Robert K. Estudo de caso: planejamento e métodos. $4^{\text {a }}$ ed. Tradução de Ana Thorell; revisão técnica de Cláudio Damacena. Porto Alegre: Bookman, 2010. 248 p. ISBN 978-85-7780-655-3 


\section{APÊNDICE A - INVENTÁRIO DE BOAS PRÁTICAS DE CONTROLES INTERNOS}

Legenda: A (COSO 2013b, Compêndio de Abordagens e Exemplos); B (GAO 2001, Internal Control Management and Evaluation Tool)

\begin{tabular}{|c|c|c|}
\hline $\begin{array}{l}\text { Princípio } \\
\text { COSO }\end{array}$ & Descrição & Fonte \\
\hline 1 & Inclusão de uma seção sobre ética e padrões de conduta no boletim de notícias da entidade. & A \\
\hline 1 & $\begin{array}{l}\text { Estabelecimento de padrões de conduta específicos para os responsáveis pelos principais cargos da entidade, além de funções de risco como aquisições, } \\
\text { contabilidade, controle e auditoria. }\end{array}$ & A \\
\hline 1 & Padrões de conduta da organização alavancam os códigos de conduta profisssionais. & A \\
\hline 1 & Padrões de conduta elaborados considerando os objetivos e riscos da entidade. & A \\
\hline 1 & Padrões de conduta incluem orientações para situações e localidades geográficas de risco. & $\mathrm{A}$ \\
\hline 1 & Estabelecimento de padrões de conduta para os fornecedores da entidade. & A \\
\hline 1 & $\begin{array}{l}\text { Acordos de nível de serviços e contratos com partes externas incluem disposições a respeito do padrão de conduta esperado pela entidade, servindo como } \\
\text { base para avaliação da aderência. }\end{array}$ & A \\
\hline 1 & Padrões de conduta são revisados periodicamente e ajustes são realizados conforme as mudanças no ambiente da entidade exijam. & A \\
\hline 1 & Padrões de conduta são explícitos e claros a respeito das consequências para os desvios de conduta, em qualquer nível da organização. & A \\
\hline 1 & Estabelecimento de um programa de educação continuada sobre ética e os padrões de conduta da entidade, para empregados novos e existentes. & A \\
\hline 1 & $\begin{array}{l}\text { Desenvolvimento de processos de avaliação de desempenho e incentivos que promovam o comportamento correto para a realização dos objetivos da } \\
\text { entidade. }\end{array}$ & A \\
\hline 1 & Análise dos resultados de processos de treinamento e certificação em ética. & A \\
\hline 1 & Realização de auditorias de ética. & A \\
\hline 1 & $\begin{array}{l}\text { Consideração dos indicadores de desempenho e revisão de informações operacionais e financeiras como forma de investigação de fraude nos relatórios } \\
\text { financeiros e outras más condutas. }\end{array}$ & A \\
\hline 1 & Análise de problemas e tendências reportados por canais anônimos de comunicação de desvios de conduta. & A \\
\hline 1 & $\begin{array}{l}\text { Estabelecimento de um processo e um padrão para prontamente investigar, reportar e agir para corrigir violações aos padrões de conduta em todos os } \\
\text { níveis da organização, incluindo terceirizados e fornecedores. }\end{array}$ & A \\
\hline 1 & Investigações conduzidas por indivíduos independentes, e os casos mais graves são investigados por comitês. & A \\
\hline 1 & Definição de critérios para a priorização dos desvios. & A \\
\hline 1 & Identificação dos impactos dos desvios, inclusive sobre os relatórios financeiros, bem como os controles internos que falharam em detectar o problema. & A \\
\hline 1 & Documentação adequada do processo de investigação e tratamento de desvios. & A \\
\hline 1 & Restrição de acesso às informações sensíveis aos indivíduos autorizados a conduzir as investigações. & A \\
\hline 1 & O corpo diretivo é informado dos desvios identificados e de quaisquer exonerações concedidas ou que estejam sendo consideradas. & A \\
\hline 1 & Determinação de como e quando a violação será comunicada e se a violação será tornada pública. & A \\
\hline 1 & Todo o pessoal da organização é comunicado da investigação e das ações corretivas tomadas. & A \\
\hline 1 & Medidas corretivas incluem correções retrospectivas e melhorias prospectivas, conforme necessário. & A \\
\hline
\end{tabular}




\begin{tabular}{|c|c|c|}
\hline $\begin{array}{l}\text { Princípio } \\
\text { COSO }\end{array}$ & Descrição & Fonte \\
\hline 1 & O corpo diretivo revisa e aprova as medidas corretivas, e os relatórios de progresso de sua implantação. & A \\
\hline 1 & $\begin{array}{l}\text { Os padrões de conduta abordam questões como pagamentos indevidos, uso adequado dos recursos, conflitos de interesse, atividades políticas de } \\
\text { funcionários, aceitação de presentes, doações ou condecorações estrangeiras, e uso de zelo profissional devido. }\end{array}$ & B \\
\hline 1 & Os padrões de conduta são periodicamente reconhecidos pela assinatura de todos os funcionários. & $\mathrm{B}$ \\
\hline 1 & $\begin{array}{l}\text { Os empregados indicam saber que tipo de comportamento é aceitável e inaceitável, que sanções comportamento inaceitável poderá trazer, e o que fazer } \\
\text { se tiverem conhecimento de um comportamento inaceitável. }\end{array}$ & B \\
\hline 1 & Os empregados indicam que existe pressão dos pares por comportamento moral e ético adequado. & $\mathrm{B}$ \\
\hline 1 & A entidade tem um processo definido e compreendido para atender a preocupações e queixas de seus empregados de forma tempestiva e adequada. & $\mathrm{B}$ \\
\hline 1 & Existe orientação a respeito das circunstâncias em que o management override é autorizado, e os níveis da gerência podem realizar tal ação. & $\mathrm{B}$ \\
\hline 1 & Qualquer management override do controle interno é totalmente documentado quanto a razões e ações específicas tomadas. & $\mathrm{B}$ \\
\hline 1 & $\begin{array}{l}\text { O management override por parte de níveis inferiores da gerência é autorizado somente em caso de emergências, e imediatamente comunicado à gerência } \\
\text { superior. }\end{array}$ & B \\
\hline 1 & A gerência tem uma base sólida para a definição de metas realistas e exequíveis. & B \\
\hline 1 & $\begin{array}{l}\text { A gerência oferece incentivos justos e moderados (em oposição a tentações injustas e desnecessárias) para ajudar a garantir a integridade e a adesão aos } \\
\text { valores éticos. }\end{array}$ & B \\
\hline 1 & A compensação e a promoção dos empregados são baseadas em resultados e desempenho. & $\mathrm{B}$ \\
\hline 2 & Corpo diretivo realiza uma avaliação independente da eficácia do comitê de auditoria no cumprimento de suas responsabilidades. & A \\
\hline 2 & Corpo diretivo conduz benchmarks das práticas do comitê de auditoria contra as melhores práticas e realiza ajustes conforme adequado. & A \\
\hline 2 & Estabelecimento de fóruns adequados para que os membros do corpo diretivo realizem questionamentos à gerência. & A \\
\hline 2 & Estabelecimento de um calendário definindo a oportunidade e frequência das reuniões com a gerência. & A \\
\hline 2 & Reuniões são adequadamente planejadas. & A \\
\hline 2 & $\begin{array}{l}\text { Estabelecimento de procedimentos para manter os membros do corpo diretivo informados quanto aos padrões de contabilidade adotados e emergentes, } \\
\text { e seu impacto nos relatórios financeiros da entidade. }\end{array}$ & A \\
\hline 2 & Estabelecimento de procedimentos para revisar o desenvolvimento e desempenho da gerência quanto ao controle interno sobre os relatórios financeiros. & A \\
\hline 2 & $\begin{array}{l}\text { Corpo diretivo tem autoridade para envolver especialistas conforme necessário e supervisionar para garantir que a gerência resolva os problemas } \\
\text { identificados pelo corpo diretivo. }\end{array}$ & A \\
\hline 2 & Estabelecimento de procedimentos para convocar reuniões de emergência, conforme necessário. & A \\
\hline 2 & $\begin{array}{l}\text { Alocação de tempo nas reuniões do corpo diretivo para discussões com conselheiros externos, auditores internos e externos e advogados, sem que a } \\
\text { gerência esteja presente. }\end{array}$ & A \\
\hline 2 & $\begin{array}{l}\text { Corpo diretivo efetua periodicamente a autoavaliação e a revisão independente de sua composição, visando a manutenção da independência e das } \\
\text { competências necessárias às suas responsabilidades de supervisão. }\end{array}$ & A \\
\hline 2 & $\begin{array}{l}\text { Identificação de candidatos potenciais ao corpo diretivo inclui procedimentos de due diligence, supervisionados por um comitê de nominação } \\
\text { independente ou firma de contratação. }\end{array}$ & A \\
\hline 2 & Procedimentos de due diligence são realizados periodicamente para a confirmação da competência e independência dos membros do corpo diretivo. & A \\
\hline 2 & Resultados dos procedimentos de due diligence são divulgados. & $\mathrm{A}$ \\
\hline
\end{tabular}




\begin{tabular}{|c|c|c|}
\hline $\begin{array}{l}\text { Princípio } \\
\text { COSO }\end{array}$ & Descrição & Fonte \\
\hline 2 & $\begin{array}{l}\text { Comitê de auditoria busca esclarecimentos e justificativas para as políticas contábeis da entidade, inclusive as principais premissas, julgamentos e } \\
\text { estimativas contábeis, além da avaliação dos riscos que impactam os relatórios financeiros. }\end{array}$ & A \\
\hline 2 & $\begin{array}{l}\text { Comitê de auditoria considera informações obtidas por meio de programas de denúncias da entidade ao monitorar os riscos de distorções nos relatórios } \\
\text { financeiros. }\end{array}$ & A \\
\hline 2 & Investigação das denúncias é feita pela auditoria interna ou outra parte independente do problema. & A \\
\hline 2 & $\begin{array}{l}\text { Comitê de auditoria avalia o potencial de fraude e management override, analisando as motivações, oportunidades e racionalizações, e como tais } \\
\text { atividades podem ser escondidas, para definir as medidas corretivas. }\end{array}$ & A \\
\hline 3 & Políticas da entidade consubstanciam uma matriz de autoridade e aprovação para as principais funções de negócios da organização. & A \\
\hline 3 & $\begin{array}{l}\text { Entidade mantém job descriptions definindo as responsabilidades de controle interno para todos os cargos relevantes, considerando os objetivos e riscos } \\
\text { da organização. }\end{array}$ & A \\
\hline 3 & Entidade revisa periodicamente a matriz de autoridade e aprovação e as job descriptions, ajustando-as conforme necessário. & A \\
\hline 3 & Responsabilidades de controle interno de funções relevantes terceirizadas são definidas e exigidas dentro de acordos de nível de serviços. & A \\
\hline 3 & Auditoria interna é empoderada com acesso direto ao corpo diretivo e comitê de auditoria. & A \\
\hline 3 & Corpo diretivo ou comitê de auditoria revisa o plano anual de auditoria interna, garantindo cobertura adequada aos principais riscos da organização. & A \\
\hline 3 & Plano anual de auditoria interna é revisado e aprovado anualmente pela alta gerência e comitê de auditoria. & A \\
\hline 3 & $\begin{array}{l}\text { Plano anual de auditoria interna inclui o escopo, plano de trabalho, equipe e orçamento para a sua realização, bem como as mudanças necessárias ao } \\
\text { mandato para definição de papéis e responsabilidades. }\end{array}$ & A \\
\hline 3 & Compensação da função de auditoria interna seja estruturada de forma a apoiar a objetividade. & A \\
\hline 3 & Plano anual de auditoria interna é revisado periodicamente em resposta a mudanças relevantes na entidade. & A \\
\hline 3 & Comitê de auditoria avalia regularmente a independência do chefe da auditoria interna e as atividades desempenhadas pela auditoria interna. & A \\
\hline 3 & $\begin{array}{l}\text { As job descriptions e avaliações de desempenho contém referências específicas a deveres, responsabilidades e accountability relacionado a controle } \\
\text { interno. }\end{array}$ & B \\
\hline 3 & Empregados dos níveis organizacionais adequados são empoderados para corrigir problemas ou implantar melhorias. & B \\
\hline 3 & Os executivos no comando das principais atividades ou funções da entidade são plenamente conscientes dos seus deveres e responsabilidades. & $\mathrm{B}$ \\
\hline 3 & $\begin{array}{l}\text { Os executivos e principais gerentes da entidade compreendem suas responsabilidades de controle interno e garantem que sua equipe também compreende } \\
\text { as suas próprias responsabilidades. }\end{array}$ & B \\
\hline 3 & $\begin{array}{l}\text { As relações de comunicação foram estabelecidas e fornecem eficazmente aos gestores as informações de que necessitam para cumprir com suas } \\
\text { responsabilidades e executar seus trabalhos. }\end{array}$ & B \\
\hline 4 & $\begin{array}{l}\text { As competências necessárias são incluídas nas job descriptions, e tais descrições são periodicamente revisadas para garantir sua relevância face à } \\
\text { mudança de expectativas internas e fatores externos. }\end{array}$ & A \\
\hline 4 & Departamento de recursos humanos define e atualiza periodicamente políticas para atrair, treinar, aconselhar, avaliar e reter pessoal. & A \\
\hline 4 & $\begin{array}{l}\text { Políticas de recrutamento, desenvolvimento, avaliação e promoção consideram os padrões de competência e desempenho esperados, conforme as } \\
\text { políticas e práticas da entidade. }\end{array}$ & A \\
\hline 4 & Definição de expectativas de desempenho e metas para cada empregado. & A \\
\hline 4 & $\begin{array}{l}\text { Políticas e práticas contábeis da entidade são periodicamente revisadas e atualizadas conforme as mudanças nos padrões técnicos e requisitos regulatórios, } \\
\text { com o treinamento dos indivíduos responsáveis pela implantação das novas políticas (diretor financeiro, controlador e equipes). }\end{array}$ & A \\
\hline
\end{tabular}




\begin{tabular}{|c|c|c|}
\hline $\begin{array}{l}\text { Princípio } \\
\text { COSO }\end{array}$ & Descrição & Fonte \\
\hline 4 & Procedimentos de seleção de terceirizados observem as exigências de competência definidas nas políticas e procedimentos da entidade. & A \\
\hline 4 & $\begin{array}{l}\text { Terceirizados são contratualmente obrigados a manter os níveis de competência exigidos, e a continuidade de seu comprometimento com a competência } \\
\text { é avaliada periodicamente pela entidade. }\end{array}$ & A \\
\hline 4 & A entidade requer a certificação anual independente dos controles internos dos terceirizados. & A \\
\hline 4 & Procedimentos de avaliação de desempenho dos indivíduos são realizados em todos os níveis da organização, com periodicidade adequada. & A \\
\hline 4 & $\begin{array}{l}\text { Procedimentos de avaliação de desempenho consideram a manutenção e o desenvolvimento das competências necessárias às funções desempenhadas } \\
\text { pelo empregado. }\end{array}$ & A \\
\hline 4 & Sistema de incentivos e recompensas considera as múltiplas dimensões de conduta e desempenho. & A \\
\hline 4 & Objetivos individuais e de equipe são definidos em termos mensuráveis, e comunicados a todos os empregados. & A \\
\hline 4 & Procedimentos de avaliação de desempenho mantém cada empregado informado de seu progresso perante as metas e seu status na organização. & A \\
\hline 4 & Procedimentos de avaliação de desempenho são periodicamente revisados para incorporar lições aprendidas ou mudanças nos objetivos da entidade. & A \\
\hline 4 & Desempenho dos gerentes da entidade é avaliado pelo comitê de auditoria. & A \\
\hline 4 & Entidade avalia a competência e o desempenho do pessoal responsável pelas finanças e relatórios financeiros da entidade. & A \\
\hline 4 & Entidade avalia a adequação da carga de trabalho e da quantidade de pessoal dedicada às funções de finanças e relatórios financeiros da entidade. & A \\
\hline 4 & Um programa de treinamento foi estabelecido e inclui programas de orientação para novos funcionários e formação contínua para todos os funcionários. & B \\
\hline 4 & $\begin{array}{l}\text { Rescisão do contrato, seguindo as políticas estabelecidas, quando o desempenho é consistentemente abaixo dos padrões ou há violações graves das } \\
\text { políticas. }\end{array}$ & B \\
\hline 4 & $\begin{array}{l}\text { A gerência analisa o efeito da saída ou aposentação de um grande número de funcionários esperada em determinado período sobre as operações da } \\
\text { entidade. }\end{array}$ & B \\
\hline 4 & Procedimentos de contratação incluem a investigação de registros criminais e a confirmação de certificações educacionais e profissionais. & B \\
\hline 4 & $\begin{array}{l}\text { A gerência analisou as tarefas que precisam ser executadas por posições específicas e analisou o nível de julgamento requerido e a extensão da supervisão } \\
\text { necessária. }\end{array}$ & B \\
\hline 4 & $\begin{array}{l}\text { Job descriptions formais ou outros meios de identificação e definição de tarefas específicas necessárias para postos de trabalho foram estabelecidas e } \\
\text { são atualizadas. }\end{array}$ & B \\
\hline 4 & Os supervisores têm as competências de gestão necessárias e foram treinados para fornecer aconselhamento eficaz sobre o desempenho no trabalho. & B \\
\hline 4 & $\begin{array}{l}\text { As avaliações de desempenho são baseadas em uma avaliação dos fatores críticos de trabalho e identificam claramente as áreas em que o empregado } \\
\text { tem bom desempenho e as áreas que precisam ser melhoradas. }\end{array}$ & B \\
\hline 5 & Responsabilidades são estabelecidas “em cascata” por toda a organização. & A \\
\hline 5 & Medidas de desempenho, incentivos e recompensas apoiam os valores éticos da entidade. & A \\
\hline 5 & $\begin{array}{l}\text { Medidas de desempenho, incentivos e recompensas são desenvolvidas em todos os níveis da entidade de modo a apoiar a realização dos objetivos de } \\
\text { curto e longo prazo. }\end{array}$ & A \\
\hline 5 & Medidas de desempenho, incentivos e recompensas equilibram medidas financeiras e não financeiras. & A \\
\hline 5 & Medidas de desempenho, incentivos e recompensas são incorporadas no sistema de avaliação e promoção da entidade. & A \\
\hline 5 & $\begin{array}{l}\text { Sistema de recompensas da entidade encoraja os departamentos a monitorar a eficácia de seus controles internos e relatar possíveis deficiências de } \\
\text { controle e oportunidades de melhoria. }\end{array}$ & A \\
\hline
\end{tabular}




\begin{tabular}{|c|c|c|}
\hline $\begin{array}{l}\text { Princípio } \\
\text { COSO }\end{array}$ & Descrição & Fonte \\
\hline 5 & $\begin{array}{l}\text { Corpo diretivo e gerência revisam periodicamente as medidas de desempenho para garantir a manutenção de sua relevância considerando mudanças nos } \\
\text { objetivos da entidade, na regulação e tendências da indústria, desconformidades e violações éticas ocorridas no passado, pressões para burlar controles } \\
\text { e outros. }\end{array}$ & A \\
\hline 5 & Empregados são recompensados por feedback e sugestões que auxiliem a entidade a melhorar sua estrutura de controle interno. & A \\
\hline 6 & $\begin{array}{l}\text { Avaliação de riscos leva em consideração as afirmações contidas nos relatórios financeiros (existência, completude, direitos e obrigações, avaliação ou } \\
\text { alocação, e apresentação e divulgação). }\end{array}$ & A \\
\hline 6 & Objetivos de alto nível formam a base para todos os subobjetivos. & A \\
\hline 6 & Objetivos e subobjetivos são periodicamente revisados para a verificação de sua relevância e adequação em relação às contas e atividades da entidade. & A \\
\hline 6 & $\begin{array}{l}\text { Avaliação da materialidade das contas significativas leva em consideração fatores quantitativos e qualitativos (quem é o usuário, raridade ou sensibilidade } \\
\text { da transação, dificuldades de mensuração, tendências). }\end{array}$ & A \\
\hline 6 & $\begin{array}{l}\text { Entidade atualiza periodicamente suas políticas e procedimentos contábeis de acordo com as mudanças nos padrões aplicáveis e reavalia os objetivos de } \\
\text { relatórios financeiros. }\end{array}$ & A \\
\hline 6 & Entidade revisa periodicamente as atividades para garantir que todas as atividades relevantes da entidade sejam capturadas pelos relatórios financeiros. & A \\
\hline 6 & Objetivos são alinhados com as prioridades estratégicas. & A \\
\hline 6 & Tolerâncias a risco dos objetivos são articuladas. & A \\
\hline 6 & Objetivos estão de acordo com as leis, regulamentos e padrões aplicáveis à entidade. & A \\
\hline 6 & Objetivos são articulados com termos específicos, mensuráveis ou observáveis, atingíveis, relevantes e com delimitação temporal. & $\mathrm{A}$ \\
\hline 6 & Objetivos são cascateados ao longo da entidade e suas subunidades. & A \\
\hline 6 & Objetivos são alinhados com circunstâncias diversas que requeiram foco específico da entidade. & A \\
\hline 6 & Objetivos são submetidos a um processo de avaliação antes de se tornarem a base para o processo de avaliações de risco. & A \\
\hline 6 & A gerência estabelece objetivos globais, em nível de entidade, sob a forma de missão, metas e objetivos estratégicos. & B \\
\hline 6 & Os objetivos em nível de entidade relacionam-se e decorrem de requisitos de programa estabelecidos pela legislação. & $\mathrm{B}$ \\
\hline 6 & $\begin{array}{l}\text { Os objetivos em nível de entidade são específicos o suficiente para serem identificados de forma clara com a entidade, em vez de serem aplicáveis a } \\
\text { todas as agências governamentais. }\end{array}$ & B \\
\hline 6 & Os planos estratégicos apoiam os objetivos em nível de entidade. & $\mathrm{B}$ \\
\hline 6 & Os planos estratégicos abordam as alocações de recursos e prioridades. & $\mathrm{B}$ \\
\hline 6 & Os planos estratégicos e orçamentos são projetados com um nível adequado de detalhe para os vários níveis de gestão. & $\mathrm{B}$ \\
\hline 6 & Os objetivos das atividades relevantes são adequadamente ligados aos objetivos em nível de entidade e objetivos estratégicos & $\mathrm{B}$ \\
\hline 6 & Os objetivos em nível de atividade são revisados periodicamente para verificação de sua relevância. & B \\
\hline 6 & As principais atividades operacionais e atividades de apoio possuem objetivos atribuídos. & B \\
\hline 6 & Os objetivos em nível de atividade incluem critérios de mensuração. & $\mathrm{B}$ \\
\hline 6 & Os recursos para atender os objetivos em nível de atividade foram identificados e, se não estiverem disponíveis, a gerência possui planos para obtê-los. & B \\
\hline 6 & Os objetivos das atividades críticas recebem atenção especial, revisão pela gerência e seu desempenho é monitorado regularmente. & B \\
\hline 6 & Todos os níveis da gerência estão envolvidos na definição dos objetivos em nível de atividade e estão comprometidos com a sua realização. & $\mathrm{B}$ \\
\hline 7 & $\begin{array}{l}\text { Processo de identificação e análise dos riscos envolve a alta gerência e equipes dos departamentos considerados relevantes para os negócios da entidade, } \\
\text { como TI, recursos humanos, jurídico, marketing e produção. }\end{array}$ & A \\
\hline
\end{tabular}




\begin{tabular}{|c|c|c|}
\hline $\begin{array}{l}\text { Princípio } \\
\text { COSO }\end{array}$ & Descrição & Fonte \\
\hline 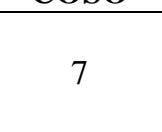 & $\begin{array}{l}\text { Utilização de um sistema de rating (escala de } 1 \text { a } 5 \text {; ou alto, médio e baixo) para classificar os processos operacionais da entidade conforme sua } \\
\text { importância para os negócios, definindo o nível de documentação de riscos que cada classe de processos deve ter, além de classificar os riscos conforme } \\
\text { a significância. }\end{array}$ & A \\
\hline 7 & Métodos qualitativos e quantitativos são usados para identificar riscos e determinar rankings de risco relativos de forma programada e periódica. & B \\
\hline 7 & Os procedimentos para a identificação, classificação, análise e mitigação dos riscos são comunicados ao pessoal adequado. & B \\
\hline 7 & A identificação e discussão dos riscos ocorrem em reuniões da alta gerência. & B \\
\hline 7 & A identificação de riscos ocorre como parte do planejamento estratégico de curto e longo prazos. & B \\
\hline 7 & A identificação de riscos ocorre como resultado da avaliação dos resultados de auditorias e outras avaliações. & $\mathrm{B}$ \\
\hline 7 & Riscos identificados pelos empregados e gerência de nível médio são levados à avaliação da alta gerência. & B \\
\hline 7 & $\begin{array}{l}\text { A entidade identifica riscos que surgem de fatores externos, como: avanços tecnológicos; mudança nas necessidades ou expectativas do Congresso e } \\
\text { sociedade; novas leis e regulamentos; catástrofes naturais, ações criminosas ou terroristas; mudanças nos negócios, política e economia; grandes } \\
\text { fornecedores e prestadores de serviços; e interações com outras entidades governamentais e partes interessadas não governamentais. }\end{array}$ & B \\
\hline 7 & $\begin{array}{l}\text { A entidade identifica riscos que surgem de fatores internos, como: redução das operações e do pessoal da entidade; reengenharia ou redesenho dos } \\
\text { processos operacionais ou de negócios; interrupção de sistemas de informação e disponibilidade de sistemas de backup; operações descentralizadas; falta } \\
\text { de qualificação do pessoal; grande dependência de prestadores de serviços ou outros em atividades críticas para as operações da entidade; grandes } \\
\text { mudanças nas responsabilidades gerenciais; acesso não usual de empregados a ativos vulneráveis; impossibilidade de planejar a sucessão ou reter pessoal } \\
\text { para atividades críticas, inadequação dos programas de recompensa e benefícios para os empregados em contraste com o setor privado; disponibilidade } \\
\text { de recursos atual e futura. }\end{array}$ & $\mathrm{B}$ \\
\hline 7 & $\begin{array}{l}\text { A identificação de riscos leva em consideração o histórico da entidade quanto ao fracasso na realização das missões, objetivos e metas; fracasso em } \\
\text { atender a limites orçamentários; despesas inadequadas, violação de controles e outras não conformidades; riscos inerentes à natureza de sua missão e à } \\
\text { relevância e complexidade de seus programas e atividades. }\end{array}$ & B \\
\hline 7 & A gerência identifica riscos em nível de entidade e para cada atividade relevante da entidade. & $\mathrm{B}$ \\
\hline 7 & A gerência estabeleceu um processo formal para analisar riscos. & $\mathrm{B}$ \\
\hline 7 & Critérios foram estabelecidos para determinar riscos altos, médios e baixos. & $\mathrm{B}$ \\
\hline 7 & Níveis adequados da gerência e empregados são envolvidos na análise de riscos. & B \\
\hline 7 & A análise de risco inclui a estimação da significância e determinação de sua categoria. & $\mathrm{B}$ \\
\hline 7 & Uma determinação é realizada em termos de como administrar o risco e quais ações especificamente devem ser realizadas. & $\mathrm{B}$ \\
\hline 7 & $\begin{array}{l}\text { A estratégia para gerenciamento dos riscos e atividades de controle leva em consideração a quantidade de risco que pode ser prudentemente tolerada } \\
\text { pela entidade. }\end{array}$ & B \\
\hline 8 & Gerência leva em consideração como os indivíduos podem desviar ou burlar os controles destinados a prevenir ou detectar fraudes. & A \\
\hline 8 & Comitê de auditoria revisa periodicamente o processo de avaliação de risco de fraude. & A \\
\hline 8 & Resultados da avaliação do risco de fraude são incorporados ao plano de auditoria interna. & A \\
\hline 8 & A entidade se reúne com o auditor externo e outros especialistas para discutir se há outros riscos de fraude que deveriam ser considerados. & A \\
\hline 8 & $\begin{array}{l}\text { Sistema de avaliação de desempenho e recompensas da entidade é periodicamente revisado pelo comitê de compensação e comitê de auditoria para } \\
\text { verificar a presença de incentivos e pressões para que os empregados cometam fraudes. }\end{array}$ & A \\
\hline 9 & Gerência desenvolve abordagens para observar mudanças no mercado externo. & A \\
\hline
\end{tabular}




\begin{tabular}{|c|c|c|}
\hline $\begin{array}{l}\text { Princípio } \\
\text { COSO }\end{array}$ & Descrição & Fonte \\
\hline 9 & $\begin{array}{l}\text { Mudanças no mercado externo, no modelo de negócios ou na liderança são sucedidas de avaliação do impacto potencial na realização dos objetivos da } \\
\text { entidade e elaboração de respostas adequadas aos riscos decorrentes das mudanças. }\end{array}$ & A \\
\hline 9 & Corpo diretivo estabelece planos para a transição dos principais executivos da entidade, avaliando e desenvolvendo candidatos à sucessão. & A \\
\hline 9 & $\begin{array}{l}\text { A entidade tem mecanismos para se antecipar, identificar e responder a riscos apresentados pelas mudanças nas condições do governo, economia, } \\
\text { indústria, regulamentação, operações e outras que podem afetar a realização dos objetivos e metas em nível de entidade e de atividade. }\end{array}$ & B \\
\hline 9 & $\begin{array}{l}\text { A entidade tem mecanismos para se antecipar a riscos como: contratação de novo pessoal para posições críticas ou alta rotatividade de pessoal em } \\
\text { qualquer área; introdução de novos sistemas de informação; rápida expansão ou retração das atividades; desenvolvimento ou incorporação de novas } \\
\text { tecnologias nos processos operacionais; produção ou provisão de novos bens e serviços; estabelecimento de operações numa nova área geográfica. }\end{array}$ & $\mathrm{B}$ \\
\hline 9 & $\begin{array}{l}\text { Os riscos resultantes de mudanças nas condições são avaliados em nível organizacional suficientemente alto para que a análise e resposta sejam } \\
\text { adequados. }\end{array}$ & $\mathrm{B}$ \\
\hline 10 & Gerência utiliza uma variedade de métodos (matrizes, oficinas, inventários) para mapear as atividades de controle aos riscos identificados. & A \\
\hline 10 & Gerência envolve partes interessadas relevantes para identificar as atividades de controle adequadas. & A \\
\hline 10 & Gerência escolhe atividades de controle automatizadas sempre que os sistemas estabelecidos o permitam. & A \\
\hline 10 & $\begin{array}{l}\text { Riscos e atividades de controle são descritos em detalhe suficiente para permitir que a gerência e outros avaliem se serão suficientes para mitigar os } \\
\text { riscos. }\end{array}$ & A \\
\hline 10 & Matrizes de riscos e controles são periodicamente revisadas e ajustadas conforme a necessidade. & A \\
\hline 10 & $\begin{array}{l}\text { Gerência utiliza inventários padronizados de riscos e atividades de controle como ponto de partida para a elaboração do inventário personalizado da } \\
\text { entidade. }\end{array}$ & A \\
\hline 10 & $\begin{array}{l}\text { Gerência da entidade seleciona e desenvolve controles internos sobre as atividades realizadas por terceirizados, conforme a significância dessas } \\
\text { atividades para os objetivos e riscos da entidade. }\end{array}$ & A \\
\hline 10 & $\begin{array}{l}\text { Gerência da entidade revisa os relatórios de controles apresentados por terceirizados para determinar quais processos significativos para os riscos e } \\
\text { objetivos da entidade estão cobertos, se atividades de controle adequadas estão estabelecidas e quais controles adicionais precisam ser estabelecidos na } \\
\text { própria entidade. }\end{array}$ & A \\
\hline 10 & $\begin{array}{l}\text { Gerência utiliza a auditoria interna da entidade para revisar o conjunto de atividades de controle (as realizadas pela própria organização e as realizadas } \\
\text { por terceirizados) e garantir que são suficientes para mitigar os riscos aos objetivos da entidade. }\end{array}$ & A \\
\hline 10 & Mix de atividades de controle leva em consideração o risco de falha dos controles (a probabilidade de que um controle não funcione conforme esperado). & A \\
\hline 10 & $\begin{array}{l}\text { Gerência define limites de variação de métricas ou indicadores de desempenho das operações da entidade ou contas contábeis que, quando excedidos, } \\
\text { indicam a necessidade de analisar as causas e tomar medidas corretivas. }\end{array}$ & A \\
\hline 10 & Estimativas contábeis significativas estão sujeitas a um mix de atividades de controle para mitigar o risco de avaliação. & A \\
\hline 10 & Gerência estabelece atividades de controle alternativas quando não for adequada a segregação de funções. & A \\
\hline 10 & $\begin{array}{l}\text { Gerência utiliza uma variedade de métodos (ferramentas automatizadas, organogramas, fluxogramas de processos e outros) para identificar } \\
\text { incompatibilidades de funções para a adequada segregação. }\end{array}$ & A \\
\hline 10 & Existe documentação por escrito cobrindo a estrutura de controle interno da entidade e para todos os eventos e transações relevantes. & B \\
\hline 10 & $\begin{array}{l}\text { A documentação do controle interno inclui a descrição e abrangência dos sistemas de informação automatizados, coleta e manipulação de dados, e as } \\
\text { especificidades de controle geral e de aplicação relacionadas com tais sistemas. }\end{array}$ & B \\
\hline 10 & Toda a documentação e registros de controle interno são adequadamente administrados, mantidos e atualizados periodicamente. & B \\
\hline
\end{tabular}




\begin{tabular}{|c|c|c|}
\hline $\begin{array}{l}\text { Princípio } \\
\text { COSO }\end{array}$ & Descrição & Fonte \\
\hline 11 & $\begin{array}{l}\text { Gerência documenta a tecnologia subjacente que apoia as atividades de controle nas matrizes de risco e controle, fluxogramas ou narrativas, } \\
\text { documentando a ligação entre atividades de controle e tecnologia. }\end{array}$ & A \\
\hline 11 & $\begin{array}{l}\text { Gerência entende o uso de computação end-user (ex. planilhas) no apoio aos seus processos significativos e suas atividades de controle associadas, } \\
\text { avaliando os riscos de distorção resultantes de erros em tais aplicações e desenvolvendo controles adicionais. }\end{array}$ & A \\
\hline 11 & $\begin{array}{l}\text { Gerência da entidade seleciona e desenvolve controles internos sobre as atividades de TI realizadas por terceirizados, conforme a significância dessas } \\
\text { atividades para os objetivos e riscos da entidade. }\end{array}$ & A \\
\hline 11 & $\begin{array}{l}\text { Gerência da entidade revisa os relatórios de controles apresentados por terceirizados de TI para determinar quais processos significativos para os riscos } \\
\text { e objetivos da entidade estão cobertos, se atividades de controle adequadas estão estabelecidas e quais controles adicionais precisam ser estabelecidos } \\
\text { na própria entidade. }\end{array}$ & A \\
\hline 11 & $\begin{array}{l}\text { Gerência utiliza a auditoria interna da entidade para revisar o conjunto de controles sobre as atividades de TI (as realizadas pela própria organização e } \\
\text { as realizadas por terceirizados) e garantir que são suficientes para mitigar os riscos aos objetivos da entidade. }\end{array}$ & A \\
\hline 11 & $\begin{array}{l}\text { Infraestrutura de TI (aplicações, bancos de dados, sistemas operacionais e redes) que suporta processos significativos é configurada para restringir o } \\
\text { acesso a aplicações e dados em conformidade com as políticas e procedimentos da organização. }\end{array}$ & A \\
\hline 11 & Gerência seleciona e desenvolve atividades de controle para que o processamento das transações seja completo, preciso e válido. & A \\
\hline 11 & $\begin{array}{l}\text { Gerência estabelece políticas que definem direitos de acesso adequados, consistentes com as funções do trabalho e com a segregação de funções, o } \\
\text { acesso a aplicações e processos relevantes para a entidade. }\end{array}$ & A \\
\hline 11 & $\begin{array}{l}\text { Gerência adota um ciclo de vida de desenvolvimento de sistemas (system development life cycle, ou SDLC) completo, tanto para o software desenvolvido } \\
\text { internamente pela entidade quanto para os pacotes de software adquiridos. }\end{array}$ & A \\
\hline 11 & Gerência segue um processo de controle de mudança para a implantação de atualizações e correções. & A \\
\hline 11 & $\begin{array}{l}\text { Fases e atividades de controle previstas no SDLC da entidade são definidas em função de uma classificação de riscos da mudança, definida conforme o } \\
\text { tamanho, esforço, complexidade e impactos em processos e controles relevantes para os objetivos da entidade. }\end{array}$ & A \\
\hline 11 & A entidade realiza periodicamente uma avaliação abrangente e de alto nível dos riscos de seus sistemas de informação. & $\mathrm{B}$ \\
\hline 11 & A entidade desenvolveu um plano que descreve claramente o programa de segurança em nível de entidade e políticas e procedimentos que o apoiam. & B \\
\hline 11 & $\begin{array}{l}\text { A alta gerência estabeleceu uma estrutura para implantar e gerenciar o programa de segurança em toda a entidade e as responsabilidades de segurança } \\
\text { estão claramente definidas. }\end{array}$ & B \\
\hline 11 & A entidade implementou políticas de pessoal relacionadas com a segurança. & $\mathrm{B}$ \\
\hline 11 & A entidade monitora a eficácia do programa de segurança e faz as alterações necessárias. & $\mathrm{B}$ \\
\hline 11 & A entidade classifica os recursos de informação de acordo com sua criticidade e sensibilidade. & B \\
\hline 11 & Os proprietários dos recursos identificaram os usuários autorizados, e seu acesso à informação é formalmente autorizada. & $\mathrm{B}$ \\
\hline 11 & A entidade estabeleceu controles físicos e lógicos para prevenir ou detectar o acesso não autorizado. & $\mathrm{B}$ \\
\hline 11 & A entidade monitora o acesso de sistemas de informação, investiga violações aparentes, e tomar medidas corretivas e disciplinares adequadas. & $\mathrm{B}$ \\
\hline 11 & Características de processamento de sistemas de informações e alterações nos programas são devidamente autorizadas. & $\mathrm{B}$ \\
\hline 11 & Todo software novo ou modificado é exaustivamente testado e aprovado. & $\mathrm{B}$ \\
\hline 11 & $\begin{array}{l}\text { A entidade estabeleceu procedimentos para assegurar o controle das suas bibliotecas de software, incluindo a rotulagem, as restrições de acesso e uso de } \\
\text { inventários e bibliotecas separadas. }\end{array}$ & B \\
\hline 11 & A criticidade e sensibilidade das operações informatizadas foram avaliadas e priorizadas, e os recursos que as apoiam foram identificados. & $\mathrm{B}$ \\
\hline
\end{tabular}




\begin{tabular}{|c|c|c|}
\hline $\begin{array}{l}\text { Princípio } \\
\text { COSO }\end{array}$ & Descrição & Fonte \\
\hline 11 & $\begin{array}{l}\text { A entidade adota medidas para prevenir e minimizar possíveis danos e interrupção através do uso de procedimentos de backup de dados e sistemas, } \\
\text { incluindo o armazenamento externo de dados de backup, bem como controles ambientais, treinamento de pessoal, e gestão e manutenção de hardware. }\end{array}$ & B \\
\hline 11 & A gerência desenvolveu e documentou um plano de contingência abrangente. & $\mathrm{B}$ \\
\hline 11 & A entidade testa periodicamente o plano de contingência e efetua ajustes conforme necessário. & B \\
\hline 12 & $\begin{array}{l}\text { Gerência desenvolve e documenta, por diversos mecanismos (fluxogramas, matrizes, narrativas), políticas e procedimentos para todas as atividades de } \\
\text { controle dos processos significativos para os objetivos da entidade. }\end{array}$ & A \\
\hline 12 & Políticas são documentadas seguindo modelos padronizados. & A \\
\hline 12 & $\begin{array}{l}\text { Manutenção de registro das mudanças, adições e retiradas de todas as políticas, incluindo data e número de revisão, data de início da vigência, breve } \\
\text { descrição das alterações e pessoa que aprovou a mudança. }\end{array}$ & A \\
\hline 12 & Gerência estabelece nas políticas as responsabilidades pela revisão dos relatórios financeiros externos. & A \\
\hline 12 & Gerência estabelece nas políticas a revisão de transações significativas e excessos de custos. & A \\
\hline 12 & $\begin{array}{l}\text { Líderes de unidades de negócios ou funções implantam atividades de controle em suas áreas de responsabilidade adotando as políticas e procedimentos } \\
\text { da organização nas suas atividades cotidianas. }\end{array}$ & A \\
\hline 12 & $\begin{array}{l}\text { Entidade dispõe de uma função ou equipe de controle centralizado trabalhando com os líderes de unidades de negócios ou funções para ajudar a implantar } \\
\text { as políticas e procedimentos da organização de maneira consistente. }\end{array}$ & A \\
\hline 12 & $\begin{array}{l}\text { Reavaliações das atividades de controle de maneira periódica ou quando os sistemas e processos significativos para os objetivos da entidade são } \\
\text { modificados, efetuando mudanças quando forem identificados controles redundantes, obsoletos ou ineficazes. }\end{array}$ & A \\
\hline 12 & $\begin{array}{l}\text { Gerência estabelece a revisão das políticas e procedimentos da entidade de maneira periódica ou quando ocorrerem mudanças nas atividades de negócios } \\
\text { significativas para os objetivos da entidade. }\end{array}$ & A \\
\hline 12 & Políticas, procedimentos, técnicas e mecanismos adequados existem no que diz respeito a cada uma das atividades da entidade. & B \\
\hline 13 & $\begin{array}{l}\text { Obtenção de informações externas por meio de assinatura de publicações da indústria e atualizações regulatórias, participação em treinamentos, } \\
\text { conferências e outros eventos da indústria, comunicações regulares com fornecedores, clientes e terceirizados, participação em organizações relevantes } \\
\text { (associações, entidades de classe), participação em listas eletrônicas de discussão e mídias sociais pertinentes, relatórios de pesquisa da indústria e outros. }\end{array}$ & A \\
\hline 13 & $\begin{array}{l}\text { Obtenção de informações internas por meio dos departamentos da entidade, que podem fornecer informações não financeiras como mudanças } \\
\text { significativas no conjunto de interessados da entidade (clientes, fornecedores, outros), rotatividade de empregados e seu impacto, tendências inesperadas } \\
\text { (positivas e negativas), indícios de comportamento antiético ou impróprio, comparação entre orçamento e expectativas atuais e previstas, questões } \\
\text { contratuais ou de conformidade, reclamações de clientes e fornecedores, achados da auditoria interna. }\end{array}$ & A \\
\hline 13 & $\begin{array}{l}\text { Utilização de entrevistas periódicas com os chefes dos departamentos, além da disponibilização de relatórios periódicos com métricas operacionais e de } \\
\text { conformidade ao controlador. }\end{array}$ & A \\
\hline 13 & Criação e manutenção de um repositório de informações. & A \\
\hline 13 & $\begin{array}{l}\text { Utilização de programas de computador para processar os dados, transformando-os em informação e automatizando os controles que garantem a } \\
\text { completude, precisão, segurança, validade e ausência de redundância da informação. }\end{array}$ & A \\
\hline
\end{tabular}




\begin{tabular}{|c|c|c|}
\hline $\begin{array}{l}\text { Princípio } \\
\text { COSO }\end{array}$ & Descrição & Fonte \\
\hline 13 & $\begin{array}{l}\text { Alta gerência estabelece um programa de governança de dados para garantir informações confiáveis para apoiar a realização dos objetivos da entidade } \\
\text { e os relatórios financeiros externos. O programa deve incluir políticas e procedimentos para: atribuir papéis e responsabilidades entre um grupo de } \\
\text { administração de dados central, funções de negócios e TI; validação de fontes de informação; estabelecimento de requisitos de qualidade de dados antes } \\
\text { da aceitação de fontes no sistema de informação; direitos de acesso aos dados subjacentes e informações relacionadas produzidas pelo processamento; e } \\
\text { proteção dos dados durante a transmissão e armazenamento. }\end{array}$ & A \\
\hline 13 & Alta gerência elabora políticas de classificação dos dados, auxiliando a definição de requisitos de proteção, retenção e destruição dos dados. & A \\
\hline 13 & Dados são identificados aplicando o padrão extensible Business Reporting Language (XBRL). & A \\
\hline 14 & $\begin{array}{l}\text { Alta administração comunica internamente os objetivos e metas da entidade, as políticas e procedimentos de controle interno e sua relação com as } \\
\text { responsabilidades individuais por meios de comunicação diversos, como: quadros de avisos em áreas de grande tráfego de pessoas ou no sítio internet } \\
\text { da entidade; reuniões e conferências internas; pesquisas periódicas junto aos empregados; intranet; correio eletrônico, boletins de notícias, chamadas de } \\
\text { conferência, webcasts ou reuniões; e visitas pessoais de gerentes executivos e financeiros. }\end{array}$ & A \\
\hline 14 & $\begin{array}{l}\text { Entidade utiliza ferramentas específicas de TI para comunicar objetivos, riscos e responsabilidades de controle interno, e reportar para a gerência a } \\
\text { situação da estrutura de controle interno (ex.: repositório compartilhado de documentação sobre avaliação de riscos, processos de negócios, controles } \\
\text { internos e outros; e solução tecnológica de governança de riscos e conformidade). }\end{array}$ & A \\
\hline 14 & $\begin{array}{l}\text { Corpo diretivo estabelece um quadro que define as orientações para compartilhamento de informações com o corpo diretivo, responsabilidades pela } \\
\text { comunicação e método de comunicação, o que pode incluir a frequência e número de reuniões, inclusive dos comitês, objetivo de cada reunião, natureza } \\
\text { e extensão da informação a ser compartilhada em cada reunião e responsabilidade pela preparação e aprovação das minutas. }\end{array}$ & A \\
\hline 14 & $\begin{array}{l}\text { Informações financeiras, relatórios financeiros e a estrutura de controle interno são regularmente discutidos em reuniões entre a gerência e o corpo } \\
\text { diretivo. }\end{array}$ & A \\
\hline 14 & $\begin{array}{l}\text { Gerência e corpo diretivo estabelecem um programa de denúncias anônimas para que os empregados comuniquem preocupações, más condutas, } \\
\text { problemas relacionados aos relatórios externos, e outras questões significativas relacionadas ao controle interno. }\end{array}$ & A \\
\hline 14 & Ampla publicidade do programa de denúncias, por diversos canais de comunicação. & A \\
\hline 14 & Estabelecimento de canais alternativos de comunicação, como programas de mentoring, reuniões informais e conselho de empregados. & A \\
\hline 14 & $\begin{array}{l}\text { Estabelecimento de processos e fóruns de comunicação transfuncionais e multidirecionais (ex. comitê ou conselho de controles internos, com os donos } \\
\text { de todos os processos de negócios funcionais e de TI da entidade). }\end{array}$ & A \\
\hline 15 & Comitê de divulgação avalia quais informações devem ser divulgadas para partes externas. & A \\
\hline 15 & Entidade estabelece comunicações periódicas com contratantes e terceirizados. & A \\
\hline 15 & $\begin{array}{l}\text { Gerentes de cada unidade de negócios ou grupo funcional identificam meios de receber informações externas da empresa, relevantes para a realização } \\
\text { de seus objetivos, estabelecendo responsabilidades pela obtenção, revisão e compartilhamento das informações com o restante da companhia, conforme } \\
\text { adequado. }\end{array}$ & A \\
\hline 15 & Entidade realiza pesquisas junto a clientes, fornecedores e outros para obter sua percepção quanto à integridade e valores éticos de seu pessoal. & A \\
\hline 15 & $\begin{array}{l}\text { Gerência provê canais de denúncias para facilitar o feedback de clientes, fornecedores, prestadores de serviços terceirizados e outras partes externas } \\
\text { quanto a impropriedades ou problemas nos relatórios financeiros. }\end{array}$ & A \\
\hline 15 & $\begin{array}{l}\text { Corpo diretivo revisa comunicações do auditor externo a respeito de questões financeiras ou problemas com os controles internos da entidade e discute } \\
\text { soluções com a gerência. }\end{array}$ & A \\
\hline 16 & Mix de atividades de monitoramento é periodicamente revisado. & A \\
\hline
\end{tabular}




\begin{tabular}{|c|c|c|}
\hline $\begin{array}{l}\text { Princípio } \\
\text { COSO }\end{array}$ & Descrição & Fonte \\
\hline 16 & Plano de auditoria interna é revisado conforme necessário para adequação das funções de monitoramento da auditoria interna. & A \\
\hline 16 & Alta gerência revisa o projeto e operação dos controles para estabelecer a baseline (descrição de como cada controle deve funcionar). & A \\
\hline 16 & $\begin{array}{l}\text { Auditoria interna realiza periodicamente avaliações avulsas da estrutura de controle interno da entidade em comparação com a baseline para reconfirmar } \\
\text { a eficácia das operações de monitoramento contínuo. }\end{array}$ & A \\
\hline 16 & $\begin{array}{l}\text { Gerência utiliza métricas correlacionadas à completude e precisão das transações, operações e contas contábeis da entidade para monitorar continuamente } \\
\text { as atividades de controle. }\end{array}$ & A \\
\hline 16 & Gerência realiza o projeto e implantação de "painéis de instrumentos" para o uso dos revisores. & A \\
\hline 16 & $\begin{array}{l}\text { Gerência utiliza uma aplicação de monitoramento automatizado para revisar grandes volumes de dados de maneira eficiente e contínua, com baixo custo } \\
\text { e grande padrão de objetividade, e para identificar tendências. }\end{array}$ & A \\
\hline 16 & $\begin{array}{l}\text { Gerência realiza avaliações avulsas da estrutura de controle interno por meio de mecanismos variados, como a investigação e relatório de denúncias } \\
\text { anônimas, revisão dos direitos de acesso a dados e informações sensíveis, realização de visitas presenciais do diretor financeiro a departamentos e } \\
\text { unidades de negócios da entidade, além de autoavaliações. }\end{array}$ & A \\
\hline 16 & $\begin{array}{l}\text { Gerência equipa e treina adequadamente a auditoria interna para realizar avaliações avulsas, provendo uma perspectiva objetiva dos elementos da } \\
\text { estrutura de controle interno. }\end{array}$ & A \\
\hline 16 & Gerência obtém e revisa periodicamente informações sobre os controles internos dos terceirizados. & A \\
\hline 17 & $\begin{array}{l}\text { Gerência desenvolve políticas e práticas para avaliar periodicamente e comunicar as deficiências identificadas pelas atividades de monitoramento e } \\
\text { outras fontes. }\end{array}$ & A \\
\hline 17 & Identificação dos mecanismos de identificação de deficiências na estrutura de controle interno nos relatórios. & A \\
\hline 17 & $\begin{array}{l}\text { Gerência define um protocolo de classificação de deficiências de controles internos, com base nos impactos potenciais para a organização, para orientar } \\
\text { os procedimentos de comunicação das deficiências. }\end{array}$ & A \\
\hline 17 & Protocolo de comunicação de deficiências de controles internos especifica que tipos de deficiência devem ser comunicados para o corpo diretivo. & A \\
\hline 17 & $\begin{array}{l}\text { Gerência estabelece práticas para revisar a situação de ações corretivas para verificar se as deficiências reportadas estão sendo solucionadas de maneira } \\
\text { tempestiva. }\end{array}$ & $\mathrm{A}$ \\
\hline
\end{tabular}

Fonte: Elaborado pelo autor, a partir de COSO (2013b) e GAO (2001). 


\section{APÊNDICE B - VARIÁVEIS IDENTIFICADAS E BOAS PRÁTICAS DE CONTROLES INTERNOS RELACIONADAS}

Legenda: A (COSO, 2013b); B (GAO 2001, Internal Control Management and Evaluation Tool).

\begin{tabular}{|c|c|}
\hline Variável & Boas Práticas de Controles Internos Relacionadas \\
\hline (1) Destinatários dos Padrões de Conduta & $\begin{array}{l}\text { - A, P1: Estabelecimento de padrões de conduta específicos para os responsáveis pelos principais cargos da entidade, além } \\
\text { de funções de risco como aquisições, contabilidade, controle e auditoria. } \\
\text { - A, P1: Padrões de conduta da organização alavancam os códigos de conduta profissionais. } \\
\text { - A, P1: Padrões de conduta elaborados considerando os objetivos e riscos da entidade. } \\
\text { - A, P1: Padrões de conduta incluem orientações para situações e localidades geográficas de risco. } \\
\text { - A, P1: Estabelecimento de padrões de conduta para os fornecedores da entidade. } \\
\text { - A, P1: Acordos de nível de serviços e contratos com partes externas incluem disposições a respeito do padrão de conduta } \\
\text { esperado pela entidade, servindo como base para avaliação da aderência. } \\
\text { - A, P1: Padrões de conduta são revisados periodicamente e ajustes são realizados conforme as mudanças no ambiente da } \\
\text { entidade exijam. } \\
\text { - A, P1: Padrões de conduta são explícitos e claros a respeito das consequências para os desvios de conduta, em qualquer } \\
\text { nível da organização. }\end{array}$ \\
\hline $\begin{array}{l}\text { (2) Treinamento sobre Valores de Ética e } \\
\text { Padrões de Conduta }\end{array}$ & $\begin{array}{l}\text { - A, P1: Inclusão de uma seção sobre ética e padrões de conduta no boletim de notícias da entidade. } \\
\text { - A, P1: Estabelecimento de um programa de educação continuada sobre ética e os padrões de conduta da entidade, para } \\
\text { empregados novos e existentes. } \\
\text { - A, P1: Análise dos resultados de processos de treinamento e certificação em ética. }\end{array}$ \\
\hline
\end{tabular}




\begin{tabular}{|c|c|}
\hline Variável & Boas Práticas de Controles Internos Relacionadas \\
\hline $\begin{array}{l}\text { (3) Avaliação da Aderência aos Padrões } \\
\text { de Conduta }\end{array}$ & $\begin{array}{l}\text { - A, P1: Realização de auditorias de ética. } \\
\text { - A, P1: Consideração dos indicadores de desempenho e revisão de informações operacionais e financeiras como forma de } \\
\text { investigação de fraude nos relatórios financeiros e outras más condutas. } \\
\text { - A, P1: Análise de problemas e tendências reportados por canais anônimos de comunicação de desvios de conduta. } \\
\text { - A, P1: Estabelecimento de um processo e um padrão para prontamente investigar, reportar e agir para corrigir violações } \\
\text { aos padrões de conduta em todos os níveis da organização, incluindo terceirizados e fornecedores. } \\
\text { - A, P1: Investigações conduzidas por indivíduos independentes, e os casos mais graves são investigados por comitês. } \\
\text { - A, P1: Definição de critérios para a priorização dos desvios. } \\
\text { - A, P1: Identificação dos impactos dos desvios, inclusive sobre os relatórios financeiros, bem como os controles internos } \\
\text { - } \text { que falharam em detectar o problema. } \\
\text { - A, P1: Documentação adequada do processo de investigação e tratamento de desvios. } \\
\text { - A, P1: O corpstrição de acesso às informações sensíveis aos indivíduos autorizados a conduzir as investigações. } \\
\text { - } \text { sendo consideradas. } \\
\text { - A, P1: Determinação de como e quando a violação será comunicada e se a violação será tornada pública. } \\
\text { - A, P1: Medidas corretivas incluem correções retrospectivas e melhorias prospectivas, conforme necessário. } \\
\text { - A, P1: O corpo diretivo revisa e aprova as medidas corretivas, e os relatórios de progresso de sua implantação. } \\
\text { - A, P2: Investigação das denúncias é feita pela auditoria interna ou outra parte independente do problema. }\end{array}$ \\
\hline $\begin{array}{l}\text { (4) Políticas de Due Diligence para o } \\
\text { Corpo Diretivo }\end{array}$ & $\begin{array}{l}\text { - A, P2: Identificação de candidatos potenciais ao corpo diretivo inclui procedimentos de due diligence, supervisionados } \\
\text { por um comitê de nominação independente ou firma de contratação. } \\
\text { - A, P2: Procedimentos de due diligence são realizados periodicamente para a confirmação da competência e independência } \\
\text { dos membros do corpo diretivo. } \\
\text { - A, P2: Resultados dos procedimentos de due diligence são divulgados. } \\
\text { - A, P2: Corpo diretivo efetua periodicamente a autoavaliação e a revisão independente de sua composição, visando a } \\
\text { manutenção da independência e do expertise necessários às suas responsabilidades de supervisão. }\end{array}$ \\
\hline $\begin{array}{l}\text { (5) Requisitos de Competências do Corpo } \\
\text { Diretivo }\end{array}$ & $\begin{array}{l}\text { - A, P2: Corpo diretivo efetua periodicamente a autoavaliação e a revisão independente de sua composição, visando a } \\
\text { manutenção da independência e do expertise necessários às suas responsabilidades de supervisão. } \\
\text { - A, P2: Corpo diretivo tem autoridade para envolver especialistas conforme necessário e supervisionar para garantir que a } \\
\text { gerência resolva os problemas identificados pelo corpo diretivo. }\end{array}$ \\
\hline
\end{tabular}




\begin{tabular}{|c|c|}
\hline Variável & Boas Práticas de Controles Internos Relacionadas \\
\hline $\begin{array}{l}\text { (6) Responsabilidades de Controle } \\
\text { Interno na Organização }\end{array}$ & $\begin{array}{l}\text { - A, P3: Políticas da entidade consubstanciam uma matriz de autoridade e aprovação para as principais funções de negócios } \\
\text { da organização. } \\
\text { - A, P3: Entidade revisa periodicamente a matriz de autoridade e aprovação e as job descriptions, ajustando-as conforme } \\
\text { necessário. } \\
\text { - A, P3: Entidade mantém job descriptions definindo as responsabilidades de controle interno para todos os cargos } \\
\text { relevantes, considerando os objetivos e riscos da organização. } \\
\text { - A, P3: Responsabilidades de controle interno de funções relevantes terceirizadas são definidas e exigidas dentro de acordos } \\
\text { de nível de serviços. } \\
\text { - A, P5: Responsabilidades são estabelecidas "em cascata" por toda a organização. }\end{array}$ \\
\hline $\begin{array}{l}\text { (7) Requisitos de Competências na } \\
\text { Organização }\end{array}$ & $\begin{array}{l}\text { - A, P4: As competências necessárias são incluídas nas job descriptions, e tais descrições são periodicamente revisadas para } \\
\text { garantir sua relevância face à mudança de expectativas internas e fatores externos. } \\
\text { - A, P4: Procedimentos de seleção de terceirizados observem as exigências de competência definidas nas políticas e } \\
\text { procedimentos da entidade. } \\
\text { - A, P4: Terceirizados são contratualmente obrigados a manter os níveis de competência exigidos, e a continuidade de seu } \\
\text { comprometimento com a competência é avaliada periodicamente pela entidade. }\end{array}$ \\
\hline $\begin{array}{l}\text { (8) Programa de Desenvolvimento de } \\
\text { Competências }\end{array}$ & $\begin{array}{l}\text { - A, P4: Departamento de recursos humanos define e atualiza periodicamente políticas para atrair, treinar, aconselhar, avaliar } \\
\text { e reter pessoal. } \\
\text { - A, P4: Políticas de recrutamento, desenvolvimento, avaliação e promoção consideram os padrões de competência e } \\
\text { desempenho esperados, conforme as políticas e práticas da entidade. }\end{array}$ \\
\hline $\begin{array}{l}\text { (9) Aspectos Analisados na Avaliação de } \\
\text { Desempenho }\end{array}$ & $\begin{array}{l}\text { - A, P1: Desenvolvimento de processos de avaliação de desempenho e incentivos que promovam o comportamento correto } \\
\text { para a realização dos objetivos da entidade. } \\
\text { - A, P4: Procedimentos de avaliação de desempenho consideram a manutenção e o desenvolvimento das competências } \\
\text { necessárias às funções desempenhadas pelo empregado. } \\
\text { - A, P4: Sistema de incentivos e recompensas considera as múltiplas dimensões de conduta e desempenho. } \\
\text { - A, P5: Medidas de desempenho, incentivos e recompensas apoiam os valores éticos da entidade. }\end{array}$ \\
\hline $\begin{array}{l}\text { (10) Destinatários da Avaliação de } \\
\text { Desempenho }\end{array}$ & $\begin{array}{l}\text { - A, P4: Desempenho dos gerentes da entidade é avaliado pelo comitê de auditoria. } \\
\text { - A, P5: Medidas de desempenho, incentivos e recompensas são desenvolvidas em todos os níveis da entidade de modo a } \\
\text { apoiar a realização dos objetivos de curto e longo prazo. }\end{array}$ \\
\hline $\begin{array}{l}\text { (11) Destinatários das Metas de } \\
\text { Desempenho }\end{array}$ & $\begin{array}{l}\text { - A, P4: Definição de expectativas de desempenho e metas para cada empregado. } \\
\text { - A, P4: Objetivos individuais e de equipe são definidos em termos mensuráveis, e comunicados a todos os empregados. }\end{array}$ \\
\hline $\begin{array}{l}\text { (12) Consequências da Avaliação de } \\
\text { Desempenho }\end{array}$ & $\begin{array}{l}\text { - A, P5: Medidas de desempenho, incentivos e recompensas equilibram medidas financeiras e não financeiras. } \\
\text { - A, P5: Medidas de desempenho, incentivos e recompensas são incorporadas no sistema de avaliação e promoção da } \\
\text { entidade. }\end{array}$ \\
\hline $\begin{array}{l}\text { (13) Frequência da Avaliação de } \\
\text { Desempenho }\end{array}$ & $\begin{array}{l}\text { - A, P4: Procedimentos de avaliação de desempenho dos indivíduos são realizados em todos os níveis da organização, com } \\
\text { periodicidade adequada. }\end{array}$ \\
\hline
\end{tabular}




\begin{tabular}{|c|c|}
\hline Variável & Boas Práticas de Controles Internos Relacionadas \\
\hline (14) Processo de Formulação de Objetivos & $\begin{array}{l}\text { - A, P6: Objetivos e subobjetivos são periodicamente revisados para a verificação de sua relevância e adequação em relação } \\
\text { às contas e atividades da entidade. } \\
\text { - A, P6: Objetivos são submetidos a um processo de avaliação antes de se tornarem a base para o processo de avaliações de } \\
\text { risco. } \\
\text { - A, P6: Objetivos são alinhados com circunstâncias diversas que requeiram foco específico da entidade. }\end{array}$ \\
\hline $\begin{array}{l}\text { (15) Participantes do Processo de } \\
\text { Formulação de Objetivos }\end{array}$ & $\begin{array}{l}\text { - B, P6: Todos os níveis da gerência estão envolvidos na definição dos objetivos em nível de atividade e estão } \\
\text { comprometidos com a sua realização. }\end{array}$ \\
\hline (16) Tipos de Objetivos & $\begin{array}{l}\text { - A, P6: Objetivos são alinhados com as prioridades estratégicas. } \\
\text { - A, P6: Objetivos estão de acordo com as leis, regulamentos e padrões aplicáveis à entidade. }\end{array}$ \\
\hline (17) Níveis Organizacionais dos Objetivos & $\begin{array}{l}\text { - A, P6: Objetivos de alto nível formam a base para todos os subobjetivos. } \\
\text { - A, P6: Objetivos são cascateados ao longo da entidade e suas subunidades. }\end{array}$ \\
\hline (18) Mensuração dos Objetivos & $\begin{array}{l}\text { - A, P6: Tolerâncias a risco dos objetivos são articuladas. } \\
\text { - A, P6: Objetivos são articulados com termos específicos, mensuráveis ou observáveis, atingíveis, relevantes e com } \\
\text { delimitação temporal. }\end{array}$ \\
\hline (19) Processo de Avaliação de Riscos & - A, P8: Comitê de auditoria revisa periodicamente o processo de avaliação de risco de fraude. \\
\hline (20) Participantes da Avaliação de Riscos & $\begin{array}{l}\text { - A, P7: Processo de identificação e análise dos riscos envolve a alta gerência e equipes dos departamentos considerados } \\
\text { relevantes para os negócios da entidade, como TI, recursos humanos, jurídico, marketing e produção. } \\
\text { - A, P8: A entidade se reúne com o auditor externo e outros especialistas para discutir se há outros riscos de fraude que } \\
\text { deveriam ser considerados. }\end{array}$ \\
\hline $\begin{array}{l}\text { (21) Fatores Considerados na Avaliação } \\
\text { de Riscos }\end{array}$ & $\begin{array}{l}\text { - A, P8: Gerência leva em consideração como os indivíduos podem desviar ou burlar os controles destinados a prevenir ou } \\
\text { detectar fraudes. } \\
\text { - A, P8: Sistema de avaliação de desempenho e recompensas da entidade é periodicamente revisado pelo comitê de } \\
\text { compensação e comitê de auditoria para verificar a presença de incentivos e pressões para que os empregados cometam } \\
\text { fraudes. } \\
\text { - A, P9: Gerência desenvolve abordagens para observar mudanças no mercado externo. } \\
\text { - A, P9: Mudanças no mercado externo, no modelo de negócios ou na liderança são sucedidas de avaliação do impacto } \\
\text { potencial na realização dos objetivos da entidade e elaboração de respostas adequadas aos riscos decorrentes das mudanças. }\end{array}$ \\
\hline $\begin{array}{l}\text { (22) Níveis Organizacionais da Avaliação } \\
\text { de Riscos }\end{array}$ & $\begin{array}{l}\text { - B, P7: A identificação e discussão dos riscos ocorrem em reuniões da alta gerência. } \\
\text { - B, P7: Riscos identificados pelos empregados e gerência de nível médio são levados à avaliação da alta gerência. } \\
\text { - B, P7: A gerência identifica riscos em nível de entidade e para cada atividade relevante da entidade. } \\
\text { - B, P7: Níveis adequados da gerência e empregados são envolvidos na análise de riscos. }\end{array}$ \\
\hline
\end{tabular}




\begin{tabular}{|c|c|}
\hline Variável & Boas Práticas de Controles Internos Relacionadas \\
\hline $\begin{array}{l}\text { (23) Documentação das Atividades de } \\
\text { Controle }\end{array}$ & $\begin{array}{l}\text { - A, P10: Gerência utiliza uma variedade de métodos (matrizes, oficinas, inventários) para mapear as atividades de controle } \\
\text { aos riscos identificados. } \\
\text { - A, P10: Riscos e atividades de controle são descritos em detalhe suficiente para permitir que a gerência e outros avaliem } \\
\text { se serão suficientes para mitigar os riscos. } \\
\text { - A, P10: Matrizes de riscos e controles são periodicamente revisadas e ajustadas conforme a necessidade. } \\
\text { - A, P10: Gerência utiliza inventários padronizados de riscos e atividades de controle como ponto de partida para a } \\
\text { elaboração do inventário personalizado da entidade. } \\
\text { - A, P11: Gerência documenta a tecnologia subjacente que apoia as atividades de controle nas matrizes de risco e controle, } \\
\text { fluxogramas ou narrativas, documentando a ligação entre atividades de controle e tecnologia. }\end{array}$ \\
\hline (24) Níveis das Atividades de Controle & $\begin{array}{l}\text { - A, P10: Gerência da entidade seleciona e desenvolve controles internos sobre as atividades realizadas por terceirizados, } \\
\text { conforme a significância dessas atividades para os objetivos e riscos da entidade. } \\
\text { - A, P10: Gerência da entidade revisa os relatórios de controles apresentados por terceirizados para determinar quais } \\
\text { processos significativos para os riscos e objetivos da entidade estão cobertos, se atividades de controle adequadas estão } \\
\text { estabelecidas e quais controles adicionais precisam ser estabelecidos na própria entidade. }\end{array}$ \\
\hline $\begin{array}{l}\text { (25) Representação Fidedigna da } \\
\text { Informação Contábil-Financeira }\end{array}$ & $\begin{array}{l}\text { - A, P10: Estimativas contábeis significativas estão sujeitas a um mix de atividades de controle para mitigar o risco de } \\
\text { avaliação. }\end{array}$ \\
\hline (26) Segregação de Funções & $\begin{array}{l}\text { - A, P10: Gerência estabelece atividades de controle alternativas quando não for adequada a segregação de funções. } \\
\text { - A, P10: Gerência utiliza uma variedade de métodos (ferramentas automatizadas, organogramas, fluxogramas de processos } \\
\text { e outros) para identificar incompatibilidades de funções para a adequada segregação. }\end{array}$ \\
\hline $\begin{array}{l}\text { (27) Políticas e Procedimentos de } \\
\text { Controle }\end{array}$ & $\begin{array}{l}\text { - A, P12: Gerência desenvolve e documenta, por diversos mecanismos (fluxogramas, matrizes, narrativas), políticas e } \\
\text { procedimentos para todas as atividades de controle dos processos significativos para os objetivos da entidade. } \\
\text { - A, P12: Políticas são documentadas seguindo modelos padronizados. } \\
\text { - A, P12: Manutenção de registro das mudanças, adições e retiradas de todas as políticas, incluindo data e número de revisão, } \\
\text { data de início da vigência, breve descrição das alterações e pessoa que aprovou a mudança. } \\
\text { - A, P12: Reavaliações das atividades de controle de maneira periódica ou quando os sistemas e processos significativos } \\
\text { para os objetivos da entidade são modificados, efetuando mudanças quando forem identificados controles redundantes, } \\
\text { obsoletos ou ineficazes. } \\
\text { - A, P12: Gerência estabelece a revisão das políticas e procedimentos da entidade de maneira periódica ou quando ocorrerem } \\
\text { mudanças nas atividades de negócios significativas para os objetivos da entidade. }\end{array}$ \\
\hline (28) Uso da Computação de Usuário & $\begin{array}{l}\text { - A, P11: Gerência entende o uso de computação end-user (ex. planilhas) no apoio aos seus processos significativos e suas } \\
\text { atividades de controle associadas, avaliando os riscos de distorção resultantes de erros em tais aplicações e desenvolvendo } \\
\text { controles adicionais. }\end{array}$ \\
\hline
\end{tabular}




\begin{tabular}{|c|c|}
\hline Variável & Boas Práticas de Controles Internos Relacionadas \\
\hline (29) Políticas de Segurança de TI & $\begin{array}{l}\text { - A, P11: Infraestrutura de TI (aplicações, bancos de dados, sistemas operacionais e redes) que suporta processos } \\
\text { significativos é configurada para restringir o acesso a aplicações e dados em conformidade com as políticas e } \\
\text { procedimentos da organização. } \\
\text { - A, P11: Gerência seleciona e desenvolve atividades de controle para que o processamento das transações seja completo, } \\
\text { preciso e válido. } \\
\text { - A, P11: Gerência estabelece políticas que definem direitos de acesso adequados, consistentes com as funções do trabalho } \\
\text { e com a segregação de funções, o acesso a aplicações e processos relevantes para a entidade. }\end{array}$ \\
\hline $\begin{array}{l}\text { (30) Processos de Aquisição, } \\
\text { Desenvolvimento e Manutenção da TI }\end{array}$ & $\begin{array}{l}\text { - A, P11: Gerência adota um ciclo de vida de desenvolvimento de sistemas (system development life cycle, ou SDLC) } \\
\text { completo, tanto para o software desenvolvido internamente pela entidade quanto para os pacotes de software adquiridos. } \\
\text { - A, P11: Gerência segue um processo de controle de mudança para a implantação de atualizações e correções. } \\
\text { - A, P11: Fases e atividades de controle previstas no SDLC da entidade são definidas em função de uma classificação de } \\
\text { riscos da mudança, definida conforme o tamanho, esforço, complexidade e impactos em processos e controles relevantes } \\
\text { para os objetivos da entidade. }\end{array}$ \\
\hline $\begin{array}{l}\text { (31) Relevância e Qualidade da } \\
\text { Informação }\end{array}$ & $\begin{array}{l}\text { - A, P13: Criação e manutenção de um repositório de informações. } \\
\text { - A, P13: Utilização de programas de computador para processar os dados, transformando-os em informação e } \\
\text { automatizando os controles que garantem a completude, precisão, segurança, validade e ausência de redundância da } \\
\text { informação. }\end{array}$ \\
\hline (32) Comunicação Interna e Externa & $\begin{array}{l}\text { - A, P14: Estabelecimento de canais alternativos de comunicação, como programas de mentoring, reuniões informais e } \\
\text { conselho de empregados. } \\
\text { - A, P14: Estabelecimento de processos e fóruns de comunicação transfuncionais e multidirecionais (ex. comitê ou conselho } \\
\text { de controles internos, com os donos de todos os processos de negócios funcionais e de TI da entidade). } \\
\text { - A, P15: Comitê de divulgação avalia quais informações devem ser divulgadas para partes externas. } \\
\text { - A, P15: Gerência provê canais de denúncias para facilitar o feedback de clientes, fornecedores, prestadores de serviços } \\
\text { terceirizados e outras partes externas quanto a impropriedades ou problemas nos relatórios financeiros. }\end{array}$ \\
\hline (33) Monitoramento Contínuo & $\begin{array}{l}\text { - A, P16: Gerência utiliza métricas correlacionadas à completude e precisão das transações, operações e contas contábeis } \\
\text { da entidade para monitorar continuamente as atividades de controle. }\end{array}$ \\
\hline (34) Avaliações Avulsas & $\begin{array}{l}\text { - A, P16: Auditoria interna realiza periodicamente avaliações avulsas da estrutura de controle interno da entidade em } \\
\text { comparação com a baseline para reconfirmar a eficácia das operações de monitoramento contínuo. } \\
\text { - A, P16: Gerência realiza avaliações avulsas da estrutura de controle interno por meio de mecanismos variados, como a } \\
\text { investigação e relatório de denúncias anônimas, revisão dos direitos de acesso a dados e informações sensíveis, realização } \\
\text { de visitas presenciais do diretor financeiro a departamentos e unidades de negócios da entidade, além de autoavaliaçôes. }\end{array}$ \\
\hline
\end{tabular}




\begin{tabular}{|l|l|}
\hline \multicolumn{1}{|c|}{ Variável } & \multicolumn{1}{c|}{ Boas Práticas de Controles Internos Relacionadas } \\
\hline & $\begin{array}{l}\text { A, P17: Gerência desenvolve políticas e práticas para avaliar periodicamente e comunicar as deficiências identificadas } \\
\text { pelas atividades de monitoramento e outras fontes. }\end{array}$ \\
$\begin{array}{ll}\text { A5) Comunicação das Deficiências de } \\
\text { Controle Interno e Acompanhamento das }\end{array}$ & $\begin{array}{l}\text { A, P17: Gerência define um protocolo de classificação de deficiências de controles internos, com base nos impactos } \\
\text { potenciais para a organização, para orientar os procedimentos de comunicação das deficiências. }\end{array}$ \\
& $\begin{array}{l}\text { A, P17: Protocolo de comunicação de deficiências de controles internos especifica que tipos de deficiência devem ser } \\
\text { comunicados para o corpo diretivo. }\end{array}$ \\
& $\begin{array}{l}\text { A, P17: Gerência estabelece práticas para revisar a situação de ações corretivas para verificar se as deficiências reportadas } \\
\text { estão sendo solucionadas de maneira tempestiva. }\end{array}$ \\
\hline Fonte: Elaborado pelo autor, a partir de $\operatorname{COSO}(2013 \mathrm{~b})$.
\end{tabular}




\section{APÊNDICE C - ELEMENTOS TEXTUAIS DE ESTRUTURAÇÃO DO FRAMEWORK COSO E GREEN BOOK GAO}

\begin{tabular}{|c|c|c|c|}
\hline $\begin{array}{c}\text { Princípios } \\
\text { COSO (2013); GAO (2014) }\end{array}$ & $\begin{array}{l}\text { Pontos de Foco } \\
\text { COSO (2013) }\end{array}$ & $\begin{array}{l}\text { Estrutura de Tópicos } \\
\text { COSO (2013) }\end{array}$ & $\begin{array}{c}\text { Atributos } \\
\text { GAO (2014) }\end{array}$ \\
\hline $\begin{array}{l}\text { (1) A organização demonstra comprometimento } \\
\text { com a integridade e os valores éticos (COSO); } \\
\text { Demonstrar comprometimento com a integridade e } \\
\text { os valores éticos (GAO) }\end{array}$ & $\begin{array}{l}\text { - Define o "tom no topo" } \\
\text { - Estabelece de padrões de conduta } \\
\text { - Avalia a aderência aos padrões de conduta } \\
\text { - Trata os desvios de maneira tempestiva }\end{array}$ & $\begin{array}{l}\text { - Tom no topo e ao longo da } \\
\text { organização } \\
\text { - Padrões de conduta } \\
\text { - Aderência e desvios }\end{array}$ & $\begin{array}{l}\text { - Tom no topo } \\
\text { - Padrões de conduta } \\
\text { - Aderência aos padrões de } \\
\text { conduta }\end{array}$ \\
\hline $\begin{array}{l}\text { (2) O corpo diretivo demonstra independência em } \\
\text { relação à gerência e exerce a supervisão do } \\
\text { desenvolvimento e o desempenho do controle } \\
\text { interno (COSO); Exercer supervisão pelas } \\
\text { responsabilidades (GAO) }\end{array}$ & $\begin{array}{l}\text { - Estabelece responsabilidades de supervisão } \\
\text { - Aplica expertise relevante } \\
\text { - Opera independentemente } \\
\text { - Provê supervisão da estrutura de controle } \\
\text { interno }\end{array}$ & $\begin{array}{l}\text { - } \text { Autoridades e } \\
\text { responsabilidades } \\
\text { - Independência e expertise } \\
\text { relevante } \\
\text { - Supervisão pelo corpo diretivo }\end{array}$ & $\begin{array}{l}\text { - Estrutura de supervisão } \\
\text { - Supervisão da estrutura de } \\
\text { controle interno } \\
\text { - Input para remediar as } \\
\text { deficiências }\end{array}$ \\
\hline $\begin{array}{l}\text { (3) A gerência estabelece, com a supervisão do } \\
\text { corpo diretivo, estruturas, linhas hierárquicas, e } \\
\text { autoridades e responsabilidades adequadas na busca } \\
\text { dos objetivos (COSO); Estabelecer estrutura, } \\
\text { responsabilidade e autoridade (GAO) }\end{array}$ & $\begin{array}{l}\text { - Leva em consideração todas as estruturas da } \\
\text { entidade } \\
\text { - Estabelece linhas hierárquicas } \\
\text { - Define, atribui e limita autoridades e } \\
\text { responsabilidades }\end{array}$ & $\begin{array}{l}\text { - Estruturas organizacionais e } \\
\text { linhas hierárquicas } \\
\text { - Autoridades e } \\
\text { responsabilidades } \\
\text { - Limitação da autoridade }\end{array}$ & $\begin{array}{l}\text { - Estrutura organizacional } \\
\text { - Atribuição de } \\
\text { responsabilidade e } \\
\text { delegação de autoridade } \\
\text { - Documentação da estrutura } \\
\text { de controle interno }\end{array}$ \\
\hline $\begin{array}{l}\text { (4) A organização demonstra comprometimento } \\
\text { com a atração, desenvolvimento e retenção de } \\
\text { indivíduos competentes, em alinhamento com seus } \\
\text { objetivos (COSO); Demonstrar comprometimento } \\
\text { com a competência (GAO) }\end{array}$ & $\begin{array}{l}\text { - Estabelece políticas e práticas } \\
\text { - Avalia competência e trata deficiências } \\
\text { - Atrai, desenvolve e retém indivíduos } \\
\text { - Planeja e se prepara para sucessão }\end{array}$ & $\begin{array}{l}\text { - Políticas e práticas } \\
\text { - Avaliação da competência } \\
\text { - Atração, desenvolvimento e } \\
\text { retenção de indivíduos } \\
\text { - Planeja e se prepara para } \\
\text { sucessão }\end{array}$ & $\begin{array}{l}\text { - Expectativas de } \\
\text { competência } \\
\text { - Recrutamento, } \\
\text { desenvolvimento e retenção } \\
\text { de indivíduos } \\
\text { - Planos e preparação de } \\
\text { contingência e sucessão }\end{array}$ \\
\hline $\begin{array}{l}\text { (5) A organização responsabiliza as pessoas por } \\
\text { suas responsabilidades de controle interno na busca } \\
\text { pelos objetivos (COSO); Impor accountability } \\
\text { (GAO) }\end{array}$ & $\begin{array}{l}\text { - Impõe o accountability por meio das estruturas, } \\
\text { autoridades e responsabilidades } \\
\text { - Estabelece medidas de desempenho, incentivos } \\
\text { e recompensas } \\
\text { - Avalia continuamente a relevância das medidas } \\
\text { de desempenho, incentivos e recompensas } \\
\text { - Leva em consideração as pressões excessivas } \\
\text { - Avalia o desempenho e recompensa ou } \\
\text { disciplina indivíduos }\end{array}$ & $\begin{array}{l}\text { - Accountability pelo controle } \\
\text { interno } \\
\text { - Medidas de desempenho, } \\
\text { incentivos e recompensas } \\
\text { - Pressões } \\
\text { - Avaliação de desempenho e } \\
\text { recompensa }\end{array}$ & $\begin{array}{l}\text { - Imposição de } \\
\text { accountability } \\
\text { - Consideração de pressões } \\
\text { excessivas }\end{array}$ \\
\hline
\end{tabular}




\begin{tabular}{|c|c|c|c|}
\hline $\begin{array}{c}\text { Princípios } \\
\text { COSO (2013); GAO (2014) }\end{array}$ & $\begin{array}{c}\text { Pontos de Foco } \\
\text { COSO (2013) }\end{array}$ & $\begin{array}{c}\text { Estrutura de Tópicos } \\
\text { COSO (2013) }\end{array}$ & $\begin{array}{c}\text { Atributos } \\
\text { GAO (2014) }\end{array}$ \\
\hline $\begin{array}{l}\text { (6) A organização especifica os objetivos com } \\
\text { clareza suficiente para permitir a identificaçãa e a } \\
\text { avaliação dos riscos relacionados aos objetivos } \\
\text { (COSO); Definição de objetivos e tolerâncias de } \\
\text { risco (GAO) }\end{array}$ & $\begin{array}{l}\text { - OBJETIVOS OPERACIONAIS (Refletem as } \\
\text { escolhas da gerência; Consideram tolerâncias a } \\
\text { risco; Incluem metas de desempenho } \\
\text { operacionais e financeiras; Formam uma base } \\
\text { para o comprometimento dos recursos) } \\
\text { - OBJETIVOS DE RELATÓRIOS } \\
\text { FINANCEIROS EXTERNOS (Obedecem aos } \\
\text { padrões de contabilidade aplicáveis; Levam em } \\
\text { consideração a materialidade; Refletem as } \\
\text { atividades da entidade) } \\
\text { - OBJETIVOS DE RELATÓRIOS NÃO } \\
\text { FINANCEIROS EXTERNOS (Obedecem a } \\
\text { padrões e frameworks estabelecidos } \\
\text { externamente; Levam em consideração o nível } \\
\text { requerido de precisão; Refletem as atividades } \\
\text { da entidade) } \\
\text { - OBJETIVOS DE RELATÓRIOS INTERNOS } \\
\text { (Refletem as escolhas da gerência; Levam em } \\
\text { consideração o nível requerido de precisão; } \\
\text { Refletem as atividades da entidade) } \\
\text { - OBJETIVOS DE CONFORMIDADE } \\
\text { (Refletem leis e regulamentos externos; Levam } \\
\text { em consideração tolerâncias a riscos) }\end{array}$ & \begin{tabular}{|l}
- Objetivos operacionais \\
$\circ$ Metas e Recursos \\
- Objetivos de relatórios \\
$\circ$ Objetivos de relatórios \\
financeiros externos \\
- Concordam com padrões \\
de contabilidade \\
- Características \\
qualitativas \\
Objetivos de relatórios não \\
financeiros externos \\
- Concordam com leis, \\
normas, padrões \\
regulatórios e \\
frameworks \\
- Levam em consideração \\
a precisão e refletem as \\
atividades \\
Objetivos de relatórios \\
internos \\
- Objetivos de conformidade
\end{tabular} & $\begin{array}{l}\text { - Definição de objetivos } \\
\text { - Definição de tolerâncias de } \\
\text { risco }\end{array}$ \\
\hline
\end{tabular}




\begin{tabular}{|c|c|c|c|}
\hline $\begin{array}{c}\text { Princípios } \\
\text { COSO (2013); GAO (2014) }\end{array}$ & $\begin{array}{l}\text { Pontos de Foco } \\
\text { COSO (2013) }\end{array}$ & $\begin{array}{c}\text { Estrutura de Tópicos } \\
\text { COSO (2013) } \\
\end{array}$ & $\begin{array}{c}\text { Atributos } \\
\text { GAO (2014) } \\
\end{array}$ \\
\hline $\begin{array}{l}\text { (7) A organização identifica os riscos à realização } \\
\text { de seus objetivos por toda a entidade e analisa os } \\
\text { riscos como uma base para determinar a forma } \\
\text { como os riscos devem ser gerenciados (COSO); } \\
\text { Identificar, analisar e responder aos riscos (GAO) }\end{array}$ & $\begin{array}{l}\text { - Inclui os níveis de entidade, subsidiária, } \\
\text { divisão, unidade operacional e funcional } \\
\text { - Analisa fatores internos e externos } \\
\text { - Envolve níveis adequados da gerência } \\
\text { - Estima a significância dos riscos identificados } \\
\text { - Determina como responder aos riscos }\end{array}$ & \begin{tabular}{|ll} 
- Identificação de riscos \\
$\circ \quad$ Leva em consideração a \\
entidade e subunidades \\
$\circ \quad$ Fatores internos e externos \\
$\circ \quad$ Riscos em nível de entidade \\
$\circ$ Riscos em nível de \\
transação \\
- Análise dos riscos \\
$\circ \quad$ Níveis da gerência \\
$\circ \quad$ Significância do risco \\
$\circ \quad$ Risco inerente e risco \\
residual \\
- Resposta a riscos \\
$\circ \quad$ Avaliação das opções de \\
resposta a riscos \\
$\circ \quad$ Respostas selecionadas
\end{tabular} & $\begin{array}{l}\text { - Identificar riscos } \\
\text { - Analisar riscos } \\
\text { - Responder aos riscos }\end{array}$ \\
\hline $\begin{array}{l}\text { (8) A organização considera o potencial para fraude } \\
\text { na avaliação dos riscos à realização dos objetivos } \\
\text { (COSO); Avaliar Risco de Fraude (GAO) }\end{array}$ & $\begin{array}{l}\text { - Leva em consideração vários tipos de fraude } \\
\text { - Avalia incentivos e pressões } \\
\text { - Avalia oportunidades } \\
\text { - Avalia atitudes e racionalizações }\end{array}$ & $\begin{array}{l}\text { - Tipos de fraude } \\
\circ \text { Relatórios fraudulentos } \\
\circ \text { Salvaguarda de ativos } \\
\circ \text { Corrupção } \\
\text { - Management override } \\
\text { - Fatores que impactam o risco } \\
\text { de fraude } \\
\circ \quad \text { Incentivos e pressões } \\
\circ \text { Oportunidade } \\
\circ \quad \text { Atitudes e racionalizações } \\
\text { - Outras considerações na } \\
\text { avaliação de risco de fraude }\end{array}$ & $\begin{array}{l}\text { - Tipos de fraude } \\
\text { - Fatores de risco de fraude } \\
\text { - Resposta a riscos de fraude }\end{array}$ \\
\hline $\begin{array}{l}\text { (9) A organização identifica e avalia as mudanças } \\
\text { que poderiam afetar significativamente a estrutura } \\
\text { de controle interno (COSO); Identificar, analisar e } \\
\text { responder a mudança (GAO) }\end{array}$ & $\begin{array}{l}\text { - Avalia mudanças no ambiente externo } \\
\text { - Avalia mudanças no modelo de negócios } \\
\text { - Avalia mudanças na liderança }\end{array}$ & $\begin{array}{cl}\text { - Avaliação de mudanças } \\
\circ & \text { Ambiente externo } \\
\circ & \text { Modelo de negócios } \\
\circ & \text { Mudanças de liderança }\end{array}$ & $\begin{array}{l}\text { - Identificação da mudança } \\
\text { - Análise e resposta à } \\
\text { mudança }\end{array}$ \\
\hline
\end{tabular}




\begin{tabular}{|c|c|c|c|}
\hline $\begin{array}{c}\text { Princípios } \\
\text { COSO (2013); GAO (2014) }\end{array}$ & $\begin{array}{l}\text { Pontos de Foco } \\
\text { COSO (2013) }\end{array}$ & $\begin{array}{c}\text { Estrutura de Tópicos } \\
\text { COSO (2013) } \\
\end{array}$ & $\begin{array}{c}\text { Atributos } \\
\text { GAO (2014) } \\
\end{array}$ \\
\hline $\begin{array}{l}\text { (10) A organização seleciona e desenvolve } \\
\text { atividades de controle que contribuem para a } \\
\text { mitigação dos riscos à realização dos objetivos a } \\
\text { níveis aceitáveis (COSO); Desenhar (Projetar) } \\
\text { Atividades de Controle (GAO) }\end{array}$ & $\begin{array}{l}\text { - Integra com a avaliação de riscos } \\
\text { - Leva em consideração fatores específicos da } \\
\text { entidade } \\
\text { - Determina processos de negócio relevantes } \\
\text { - Avalia um mix de tipos de atividades de } \\
\text { controle } \\
\text { - Leva em consideração em que nível as } \\
\text { atividades de controle são aplicadas } \\
\text { - Orienta a segregação de funções }\end{array}$ & $\begin{array}{l}\text { - Integração com a avaliação de } \\
\text { riscos } \\
\text { o Processos de negócios } \\
\text { relevantes } \\
\text { - Fatores específicos da entidade } \\
\text { - Atividades de controle de } \\
\text { processo de negócio } \\
\text { - Tipos de atividades de controle } \\
\text { de transações } \\
\text { - Tecnologia e atividades de } \\
\text { controle } \\
\text { - Atividades de controle em } \\
\text { diferentes níveis } \\
\text { - Segregação de funções }\end{array}$ & $\begin{array}{l}\text { - Resposta a Objetivos e } \\
\text { Riscos } \\
\text { - Desenho (Projeto) de tipos } \\
\text { adequados de atividades de } \\
\text { controle } \\
\text { - Desenho (Projeto) de } \\
\text { atividades de controle em } \\
\text { vários níveis } \\
\text { - Segregação de funções }\end{array}$ \\
\hline $\begin{array}{l}\text { (11) A organização seleciona e desenvolve } \\
\text { atividades gerais de controle sobre a tecnologia } \\
\text { para apoiar a realização dos objetivos (COSO); } \\
\text { Desenhar (Projetar) Atividades de Controle para o } \\
\text { Sistema de Informação (GAO) }\end{array}$ & $\begin{array}{l}\text { - Determina a dependência entre o uso da } \\
\text { tecnologia nos processos de negócios e } \\
\text { controles gerais de tecnologia } \\
\text { - Estabelece atividades relevantes de controle da } \\
\text { infraestrutura de tecnologia } \\
\text { - Estabelece atividades relevantes de controle do } \\
\text { processo de administração da segurança } \\
\text { - Estabelece atividades relevantes de controle dos } \\
\text { processos de aquisição, desenvolvimento e } \\
\text { manutenção da tecnologia }\end{array}$ & $\begin{array}{l}\text { - Dependência entre o uso de } \\
\text { tecnologia nos processos de } \\
\text { negócio e controles gerais de } \\
\text { tecnologia } \\
\text { - Controles gerais de tecnologia } \\
\text { O Infraestrutura de tecnologia } \\
\text { Processos de gerenciamento } \\
\text { de segurança } \\
\text { Processos de aquisição, } \\
\text { desenvolvimento e } \\
\text { manutenção }\end{array}$ & $\begin{array}{l}\text { - Desenho (Projeto) do } \\
\text { Sistema de Informação da } \\
\text { Entidade } \\
\text { - Desenho (Projeto) de tipos } \\
\text { adequados de atividades de } \\
\text { controle } \\
\text { - Desenho (Projeto) da } \\
\text { infraestrutura de tecnologia } \\
\text { da informação } \\
\text { - Desenho (Projeto) da } \\
\text { administração de segurança } \\
\text { - Desenho (Projeto) de } \\
\text { aquisição, desenvolvimento } \\
\text { e manutenção da tecnologia } \\
\text { da informação }\end{array}$ \\
\hline
\end{tabular}




\begin{tabular}{|c|c|c|c|}
\hline $\begin{array}{c}\text { Princípios } \\
\text { COSO (2013); GAO (2014) }\end{array}$ & $\begin{array}{l}\text { Pontos de Foco } \\
\text { COSO (2013) }\end{array}$ & $\begin{array}{l}\text { Estrutura de Tópicos } \\
\text { COSO (2013) }\end{array}$ & $\begin{array}{c}\text { Atributos } \\
\text { GAO (2014) }\end{array}$ \\
\hline $\begin{array}{l}\text { (12) A organização implanta atividades de controle } \\
\text { por meio de políticas que estabelecem o que é } \\
\text { esperado e dos procedimentos que colocam em } \\
\text { prática essas políticas (COSO); Implantar } \\
\text { atividades de controle (GAO) }\end{array}$ & $\begin{array}{l}\text { - Estabelece políticas e procedimentos para } \\
\text { apoiar a implantação das diretrizes da gerência } \\
\text { - Estabelece responsabilidade e accountability } \\
\text { pela execução de políticas e procedimentos } \\
\text { - Executa de maneira tempestiva } \\
\text { - Toma ações corretivas } \\
\text { - Executa usando pessoal competente } \\
\text { - Reavaliação de políticas e procedimentos }\end{array}$ & $\begin{array}{l}\text { - Políticas e procedimentos } \\
\text { ○ Tempestividade } \\
\circ \text { Ação corretiva } \\
\text { ○ Competência } \\
\circ \text { Reavaliação periódica }\end{array}$ & $\begin{array}{l}\text { - Documentação das } \\
\text { responsabilidades por meio } \\
\text { de políticas } \\
\text { - Revisão periódica das } \\
\text { atividades de controle }\end{array}$ \\
\hline $\begin{array}{l}\text { (13) A organização obtém ou produz e utiliza } \\
\text { informações relevantes e de qualidade para apoiar o } \\
\text { funcionamento do controle interno (COSO); Usar } \\
\text { informação de qualidade (GAO) }\end{array}$ & $\begin{array}{l}\text { - Identifica requerimentos de informação } \\
\text { - Captura fontes internas e externas de dados } \\
\text { - Processa dados relevantes em informação } \\
\text { - Mantém a qualidade pelo processamento } \\
\text { - Leva em consideração custos e benefícios }\end{array}$ & $\begin{array}{l}\text { - Requisitos de informação } \\
\text { - Informação de fontes relevantes } \\
\text { - Processamento de dados por } \\
\text { meio de sistemas de informação } \\
\text { - Qualidade da informação }\end{array}$ & $\begin{array}{l}\text { - Identificação de Requisitos } \\
\text { de Informação } \\
\text { - Dados Relevantes de } \\
\text { Fontes Confiáveis } \\
\text { - Dados Processados em } \\
\text { Informações de Qualidade } \\
\end{array}$ \\
\hline $\begin{array}{l}\text { (14) A organização comunica internamente } \\
\text { informações necessárias para apoiar o } \\
\text { funcionamento do controle interno, incluindo } \\
\text { objetivos e responsabilidades pelo controle interno } \\
\text { (COSO); Comunicar internamente (GAO) }\end{array}$ & $\begin{array}{l}\text { - Comunica informações de controle interno } \\
\text { - Comunica com o corpo diretivo } \\
\text { - Provê linhas de comunicação avulsas } \\
\text { - Seleciona método de comunicação relevante }\end{array}$ & $\begin{array}{l}\text { - Comunicação de controle } \\
\text { interno } \\
\text { - Comunicação de controle } \\
\text { interno com o corpo diretivo } \\
\text { - Comunicação além dos canais } \\
\text { normais } \\
\text { - Método de comunicação }\end{array}$ & $\begin{array}{l}\text { - Comunicação ao longo da } \\
\text { entidade } \\
\text { - Métodos de comunicação } \\
\text { adequados }\end{array}$ \\
\hline $\begin{array}{l}\text { (15) A organização comunica-se com partes } \\
\text { externas sobre assuntos que afetam o } \\
\text { funcionamento do controle interno (COSO); } \\
\text { Comunicar externamente (GAO) }\end{array}$ & $\begin{array}{l}\text { - Comunica com partes externas } \\
\text { - Permite comunicações para dentro } \\
\text { - Comunica com o corpo diretivo } \\
\text { - Provê linhas de comunicação avulsas } \\
\text { - Seleção de método de comunicação relevante }\end{array}$ & $\begin{array}{l}\text { - Comunicação externa } \\
\text { ○ Comunicação para fora } \\
\text { ○ Comunicação para dentro } \\
\text { para gerência e corpo } \\
\text { diretivo } \\
\text { - Comunicação além dos canais } \\
\text { normais } \\
\text { - Método de comunicação }\end{array}$ & $\begin{array}{l}\text { - Comunicação com partes } \\
\text { externas } \\
\text { - Métodos de comunicação } \\
\text { adequados }\end{array}$ \\
\hline
\end{tabular}




\begin{tabular}{|c|c|c|c|}
\hline $\begin{array}{c}\text { Princípios } \\
\text { COSO (2013); GAO (2014) }\end{array}$ & $\begin{array}{l}\text { Pontos de Foco } \\
\text { COSO (2013) }\end{array}$ & $\begin{array}{c}\text { Estrutura de Tópicos } \\
\text { COSO (2013) } \\
\end{array}$ & $\begin{array}{c}\text { Atributos } \\
\text { GAO (2014) } \\
\end{array}$ \\
\hline $\begin{array}{l}\text { (16) A organização seleciona, desenvolve e realiza } \\
\text { avaliações contínuas e/ou avulsas para se certificar } \\
\text { de que os componentes do controle interno estão } \\
\text { presentes e funcionando (COSO); Realizar } \\
\text { atividades de monitoramento (GAO) }\end{array}$ & $\begin{array}{l}\text { - Leva em consideração um mix de avaliações } \\
\text { contínuas e avulsas } \\
\text { - Leva em consideração a taxa de mudanças } \\
\text { - Estabelece o entendimento de baseline } \\
\text { - Utiliza pessoal capacitado } \\
\text { - Integra com os processos de negócios } \\
\text { - Ajusta escopo e frequência } \\
\text { - Avalia objetivamente }\end{array}$ & $\begin{array}{l}\text { - Avaliações contínuas e avulsas } \\
\circ \quad \text { Taxa de mudança } \\
\circ \text { Informação de baseline } \\
\text { - Avaliações contínuas } \\
\text { - Avaliações avulsas } \\
\circ \text { Pessoal capacitado } \\
\circ \text { Abordagens e objetividade } \\
\text { da avaliação avulsa } \\
\text { Prestadores de serviços } \\
\text { terceirizados }\end{array}$ & $\begin{array}{l}\text { - Estabelecimento de uma } \\
\text { baseline } \\
\text { - Monitoramento da estrutura } \\
\text { de controle interno } \\
\text { - Avaliação dos resultados }\end{array}$ \\
\hline $\begin{array}{l}\text { (17) A organização avalia e comunica deficiências } \\
\text { no controle interno de maneira oportuna às partes } \\
\text { responsáveis por tomar ações corretivas, inclusive a } \\
\text { alta gerência e o corpo diretivo, conforme adequado } \\
\text { (COSO); Avaliar problemas e remediar deficiências } \\
\text { (GAO) }\end{array}$ & $\begin{array}{l}\text { - Avalia os resultados } \\
\text { - Comunica as deficiências } \\
\text { - Monitora ações corretivas }\end{array}$ & $\begin{array}{l}\text { - Avaliar resultados } \\
\text { - Comunicação das deficiências } \\
\text { de controle interno } \\
\text { - Monitoramento das ações } \\
\text { corretivas }\end{array}$ & $\begin{array}{l}\text { - Relato dos problemas } \\
\text { - Avaliação dos problemas } \\
\text { - Ações corretivas }\end{array}$ \\
\hline
\end{tabular}

Fonte: Elaborado pelo autor, a partir de COSO (2013) e GAO (2014) 
APÊNDICE D - RELAÇÃO ENTRE PRINCÍPIOS COSO, SUBDIMENSÕES E VARIÁVEIS DA PROPOSTA DE MODELO DE MATURIDADE

\begin{tabular}{|c|c|c|}
\hline $\begin{array}{l}\text { Princípio } \\
\text { COSO }\end{array}$ & Subdimensões (Origem) & Variável \\
\hline (1) & Padrões de Conduta (Atributo, Tópico) & $\begin{array}{l}\text { 1. Destinatários dos Padrões de Conduta } \\
\text { 2. Treinamento sobre Valores de Ética e Padrões de Conduta } \\
\text { 3. Avaliação da Aderência aos Padrões de Conduta }\end{array}$ \\
\hline (2) & $\begin{array}{l}\text { Independência e Competência do Corpo Diretivo } \\
\text { (Tópico) }\end{array}$ & $\begin{array}{l}\text { 4. Políticas de Due Diligence para o Corpo Diretivo } \\
\text { 5. Requisitos de Competência do Corpo Diretivo }\end{array}$ \\
\hline (3) & $\begin{array}{l}\text { Responsabilidades de Controle Interno e Requisitos de } \\
\text { Competências }\end{array}$ & $\begin{array}{l}\text { 6. Responsabilidades de Controle Interno na Organização } \\
\text { 7. Requisitos de Competências na Organização }\end{array}$ \\
\hline (4) & $\begin{array}{l}\text { Atração, Desenvolvimento e Retenção de Indivíduos } \\
\text { (Tópico) }\end{array}$ & 8. Programa de Desenvolvimento de Competências \\
\hline$(5)$ & Avaliação de Desempenho (Tópico) & $\begin{array}{l}\text { 9. Aspectos Analisados pela Avaliação de Desempenho } \\
\text { 10. Destinatários da Avaliação de Desempenho } \\
\text { 11. Destinatários das Metas de Desempenho } \\
\text { 12. Consequências da Avaliação de Desempenho } \\
\text { 13. Frequência da Avaliação de Desempenho }\end{array}$ \\
\hline (6) & Definição de Objetivos (Atributo) & $\begin{array}{l}\text { 14. Processo de Formulação de Objetivos } \\
\text { 15. Participantes do Processo de Formulação de Objetivos } \\
\text { 16. Tipos de Objetivos } \\
\text { 17. Níveis Organizacionais dos Objetivos } \\
\text { 18. Mensuração dos Objetivos }\end{array}$ \\
\hline (7) $(8)(9)$ & Avaliação de Riscos (Atributo) & $\begin{array}{l}\text { 19. Processo de Avaliação de Riscos } \\
\text { 20. Participantes da Avaliação de Riscos } \\
\text { 21. Fatores Considerados na Avaliação de Riscos } \\
\text { 22. Níveos Organizacionais da Avaliação de Riscos }\end{array}$ \\
\hline$(10)$ & $\begin{array}{l}\text { Projeto de Controles para Mitigação de Riscos } \\
\text { (Princípio) }\end{array}$ & $\begin{array}{l}\text { 23. Documentação das Atividades de Controle } \\
\text { 24. Níveis das Atividades de Controle } \\
\text { 25. Representação Fidedigna da Informação Contábil-Financeira } \\
\text { 26. Segregação de Funções }\end{array}$ \\
\hline$(12)$ & Implantação de Controles (Princípio) & 27. Políticas e Procedimentos de Controle \\
\hline
\end{tabular}




\begin{tabular}{|c|l|l|}
\hline $\begin{array}{c}\text { Princípio } \\
\text { COSO }\end{array}$ & \multicolumn{1}{|c|}{ Subdimensões (Origem) } & \multicolumn{1}{c|}{ Variável } \\
\hline$(11)$ & Projeto de Controles sobre a Tecnologia (Princípio) & $\begin{array}{l}\text { 28. Uso da Computação de Usuário Final } \\
\text { 29. Políticas de Segurança de TI } \\
\text { 30. Processos de Aquisição, Desenvolvimento e Manutenção da TI }\end{array}$ \\
\hline$(13)(14)(15)$ & Sistema de Informação da Entidade & $\begin{array}{l}\text { 31. Relevância e Qualidade da Informação } \\
\text { 32. Comunicação Interna e Externa }\end{array}$ \\
\hline (16) (17) & $\begin{array}{l}\text { Monitoramento da Estrutura de Controle Interno } \\
\text { (Atributo) }\end{array}$ & $\begin{array}{l}\text { 33. Monitoramento Contínuo } \\
\text { 34. Avaliações Avulsas } \\
\text { 35. Comunicação das Deficiências de Controle Interno e Acompanhamento } \\
\text { das Ações Corretivas }\end{array}$ \\
\hline
\end{tabular}

Fonte: Elaborado pelo autor, a partir dos procedimentos do estudo. 


\section{APÊNDICE E - MODELO DE FORMULÁRIO PARA AVALIAÇÃo POR ESPECIALISTAS}

\section{FORMULÁRIO PARA AVALIAÇÃO DE INSTRUMENTO POR ESPECIALISTAS}

Estamos desenvolvendo uma matriz para avaliar o nível de maturidade dos sistemas de controles internos em órgãos e entidades da administração pública federal brasileira.

Uma matriz de maturidade pode ser definida como um modelo que estabelece um caminho lógico ou desejado de evolução das capacidades organizacionais em estágios. Esse modelo pode ser utilizado para a avaliação das capacidades organizacionais, a orientação quanto as necessidades de desenvolvimento de capacidades, e para a comparação das capacidades de diferentes organizações. A matriz ora proposta adota como principal referência a estrutura de controles internos do COSO, que define o controle interno como um processo integrado, desenvolvido para enfrentar os riscos e fornecer razoável segurança de que os objetivos da entidade serão alcançados.

Nesse sentido, uma das dimensões que a matriz de maturidade pretende avaliar é a informação e comunicação, que é a obtenção e compartilhamento de informações relevantes e de qualidade para apoiar o funcionamento do controle interno.

Considerando estas definições, solicitamos que avalie as variáveis a seguir, nos seguintes quesitos:

- Avalie o grau de clareza dos critérios (se os termos dos critérios são compreensíveis e estabelecem um padrão evolutivo bem definido);

- Avalie em que medida a variável é pertinente ao ambiente de controle em órgãos e entidades da Administração Pública Federal (se a variável se relaciona com a informação e comunicação e é característica de entidades do setor governamental).

Ao final deste formulário está reservado espaço para comentários e outras contribuições do especialista.

\section{Avaliador:}

\section{VARIÁVEL 1: RELEVANCIA E QUALIDADE DA INFORMAÇÃO}

Objetivo: Avaliar a existência e a formalização de processos para identificar e documentar as necessidades, produzir, coletar, tratar, armazenar, processar e descartar dados e informações necessárias para apoiar o funcionamento o controle interno da entidade, e a existência de um programa de governança de dados para manutenção da qualidade dos dados. 


\begin{tabular}{|c|c|c|c|c|}
\hline 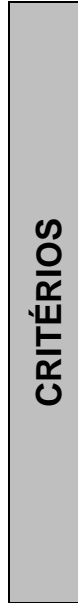 & $\begin{array}{l}\text { Ausência de } \\
\text { processos para } \\
\text { identificar e } \\
\text { documentar as } \\
\text { necessidades, } \\
\text { produzir, coletar, } \\
\text { tratar, armazenar, } \\
\text { processar e } \\
\text { descartar dados e } \\
\text { informações } \\
\text { necessárias para } \\
\text { apoiar o } \\
\text { funcionamento o } \\
\text { controle interno da } \\
\text { entidade. }\end{array}$ & $\begin{array}{l}\text { Processo } \\
\text { formalmente } \\
\text { estabelecido para } \\
\text { identificar e } \\
\text { documentar as } \\
\text { informações } \\
\text { necessárias para } \\
\text { apoiar o } \\
\text { funcionamento do } \\
\text { controle interno da } \\
\text { entidade. }\end{array}$ & $\begin{array}{l}\text { Processos } \\
\text { formalmente } \\
\text { estabelecidos para } \\
\text { produção, coleta, } \\
\text { tratamento, } \\
\text { armazenamento, } \\
\text { processamento e } \\
\text { descarte dos dados e } \\
\text { informações que } \\
\text { apoiam o } \\
\text { funcionamento do } \\
\text { controle interno da } \\
\text { entidade. }\end{array}$ & $\begin{array}{l}\text { A entidade } \\
\text { estabelece um } \\
\text { programa de } \\
\text { governança para a } \\
\text { manutenção da } \\
\text { qualidade dos dados } \\
\text { e informações que } \\
\text { apoiam o } \\
\text { funcionamento do } \\
\text { controle interno da } \\
\text { entidade. }\end{array}$ \\
\hline
\end{tabular}

Avaliação:

\begin{tabular}{|c|c|c|c|c|c|}
\hline Quesito & \multicolumn{3}{|c|}{ Avaliação } & $\begin{array}{c}5 \\
\text { Totalmente } \\
\text { Pertinente }\end{array}$ \\
\hline PERTINÊNCIA DA VARIÀVEL & $\begin{array}{c}1 \\
\text { Pouco Pertinente }\end{array}$ & 2 & 3 & 4 & $\begin{array}{c}5 \\
\text { Totalmente Claro }\end{array}$ \\
\hline CLAREZA DOS CRITÉRIOS & $\begin{array}{c}1 \\
\text { Pouco Claro }\end{array}$ & 2 & 3 & 4 & \\
\hline
\end{tabular}

\section{VARIÁVEL 2: COMUNICAÇÃO INTERNA E EXTERNA}

Objetivo: Avaliar a avaliar a existência, a formalização e a complexidade dos processos de comunicação interna e externa da entidade.

\begin{tabular}{|c|c|c|c|c|}
\hline & \multicolumn{4}{|c|}{ Nível de Maturidade } \\
\hline & Inexistente (0) & Inicial (1) & Em Formação (2) & Estabelecido (3) \\
\hline 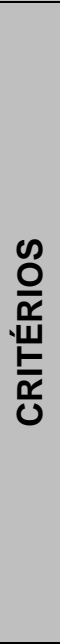 & $\begin{array}{l}\text { Ausência de } \\
\text { processos de } \\
\text { comunicação } \\
\text { interna e externa. }\end{array}$ & $\begin{array}{l}\text { Processos } \\
\text { formalmente } \\
\text { estabelecidos para } \\
\text { comunicar } \\
\text { tempestivamente ao } \\
\text { público interno e } \\
\text { externo as } \\
\text { informações } \\
\text { necessárias e } \\
\text { esperadas. }\end{array}$ & $\begin{array}{l}\text { Processos de } \\
\text { comunicação interna } \\
\text { e externa incluem a } \\
\text { seleção dos métodos } \\
\text { de comunicação, } \\
\text { levando em } \\
\text { consideração a } \\
\text { tempestividade, } \\
\text { audiência, natureza } \\
\text { da comunicação e } \\
\text { requisitos, } \\
\text { expectativas legais, } \\
\text { regulatórias e } \\
\text { contratuais, e a } \\
\text { relação custo x } \\
\text { benefício. }\end{array}$ & $\begin{array}{l}\text { A entidade define } \\
\text { canais de } \\
\text { comunicação internos } \\
\text { e externos múltiplos e } \\
\text { bidirecionais para } \\
\text { evitar a perda de } \\
\text { informações } \\
\text { relevantes, incluindo } \\
\text { canal de denúncias } \\
\text { com garantia de } \\
\text { anonimato para a } \\
\text { comunicação de } \\
\text { questões } \\
\text { significativas } \\
\text { relacionadas ao } \\
\text { controle interno. }\end{array}$ \\
\hline
\end{tabular}

Avaliação:

\begin{tabular}{|c|c|c|c|c|c|}
\hline Quesito & \multicolumn{5}{|c|}{ Avaliação } \\
\hline PERTINÊNCIA DA VARIÀVEL & $\begin{array}{c}1 \\
\text { Pouco Pertinente }\end{array}$ & 2 & 3 & 4 & $\begin{array}{c}5 \\
\text { Totalmente } \\
\text { Pertinente }\end{array}$ \\
\hline CLAREZA DOS CRITÉRIOS & $\begin{array}{c}1 \\
\text { Pouco Claro }\end{array}$ & 2 & 3 & 4 & $\begin{array}{c}5 \\
\text { Totalmente Claro }\end{array}$ \\
\hline
\end{tabular}

\section{Comentários:}




\section{Agradecemos por sua colaboração!}

Ricardo Augusto Capovilla - ricardo capovilla@hotmail.com

Prof. Dr. Rodrigo de Souza Gonçalves - Orientador - rgoncalves@unb.br 


\section{APÊNDICE F - MODELO DE COMUNICAÇÕES COM OS ESPECIALISTAS}

\section{CONVITE}

De: Ricardo Augusto Capovilla

Enviado: segunda-feira, $X$ de $x X X X X$ de $X X X X X X: X X$

Para: ESPECIALISTA

Assunto: Pesquisa - Controles Internos

Caro ESPECIALISTA,

Meu nome é Ricardo Augusto Capovilla, sou Auditor Federal de Controle Externo do TCU (Secex Ambiental) e mestrando do Programa Multi-institucional e Inter-regional de Pós-Graduação em Ciências Contábeis da UnB/UFPB/UFRN.

Gostaria de convidá-lo a participar da pesquisa acadêmica que estou conduzindo na minha dissertação, cujo objetivo é desenvolver um instrumento de avaliação da maturidade dos sistemas de controles internos aplicável aos órgãos e entidades da Administração Pública Federal brasileira, a partir de modelos de maturidade existentes e das recomendações dos principais frameworks de controles internos (COSO). A pesquisa é patrocinada pelo Tribunal e pode contribuir para o aprimoramento do controle e da gestão dessas organizações, provendo um instrumento de avaliação e um roteiro para a melhoria dos sistemas de controles internos.

Sua participação consiste em responder a um teste no qual você dará a sua opinião a respeito da clareza e a pertinência de algumas variáveis da matriz de maturidade. Você foi selecionado em razão de seu conhecimento no tema " $x x x x x x x x x x x x x x x x x$ ", identificado em consulta ao Banco de Competências do TCU.

Caso você concorde em participar, peço que responda a essa mensagem e eu entrarei em contato para apresentar o teste e esclarecer eventuais dúvidas. A resposta ao teste não necessita ser imediata.

Agradeço antecipadamente pela sua colaboração!

Ricardo Augusto Capovilla

AUFC Matrícula 7682-1

Telefones: 3316-5066, 8127-3594

Email: capovillaar@tcu.gov.br, ricardo capovilla@hotmail.com

\section{ENCAMINHAMENTO DO FORMULÁRIO}

De: Ricardo Augusto Capovilla

Enviado: segunda-feira, $X$ de $x X X X X$ de $X X X X X X: X X$

Para: ESPECIALISTA

Assunto: RE: Pesquisa - Controles Internos

Caro ESPECIALISTA,

Encaminho em anexo o formulário do teste, que contém as instruções para a avaliação.

Você irá avaliar algumas das variáveis do componente "Atividades de Controle". 
Sei que você é uma pessoa bastante ocupada mas, se for possível, peço que leia com tranquilidade e se permita alguma reflexão antes de responder. Além disso, falando em termos de contribuição, seus comentários ao final do formulário podem ser muito mais valiosos que a nota dada nos quesitos.

Peço que encaminhe a resposta preferencialmente dentro dos próximos quinze dias.

Muito obrigado!

Ricardo Augusto Capovilla

AUFC Matrícula 7682-1

Telefones: 3316-5066, 8127-3594

Email: capovillaar@tcu.gov.br, ricardo capovilla@hotmail.com 


\section{APÊNDICE G - AVALIAÇÃO DAS VARIÁVEIS DA PROPOSTA DE MODELO DE MATURIDADE}

Dimensão 1 - Ambiente de Controle

Subdimensão 1.1 - Padrões de Conduta

Variável 1.1.1 - Destinatários dos Padrões de Conduta

\begin{tabular}{|c|c|c|c|}
\hline & & & \\
\hline (0) Inexistente & (1) Inicial & (2) Em Formação & (3) Estabelecido \\
\hline $\begin{array}{l}\text { Ausência de padrões de conduta } \\
\text { próprios da entidade. }\end{array}$ & $\begin{array}{l}\text { A entidade possui padrões de conduta } \\
\text { próprios, com disposições gerais, } \\
\text { aplicáveis a todos os empregados. }\end{array}$ & $\begin{array}{l}\text { Padrões de conduta incluem } \\
\text { disposições específicas para gerentes, } \\
\text { corpo diretivo e empregados de } \\
\text { funções relevantes para a realização } \\
\text { dos objetivos e tratamento dos riscos } \\
\text { corporativos. }\end{array}$ & $\begin{array}{l}\text { Padrões de conduta da entidade } \\
\text { incluem disposições específicas para } \\
\text { terceiros (fornecedores de produtos e } \\
\text { serviços e empregados terceirizados } \\
\text { que atuam em nome da entidade), } \\
\text { exigidas contratualmente ou por } \\
\text { SLA. }\end{array}$ \\
\hline \multicolumn{4}{|c|}{ Avaliação dos Juízes Especialistas: Clareza - 4,5; Pertinência - 5 . } \\
\hline \multicolumn{4}{|c|}{$\begin{array}{l}\text { Comentários dos Juízes Especialistas: } \\
\text { Os avaliadores não realizaram críticas adicionais em relação à variável. }\end{array}$} \\
\hline \multicolumn{4}{|c|}{$\begin{array}{l}\text { Parecer: AJUSTE DE TERMOS } \\
\text { Acatando sugestão realizada na avaliação de outras variáveis, admite-se a substituição do termo "funções relevantes para a realização dos objetivos e } \\
\text { tratamento dos riscos corporativos" pelo termo "funções relevantes para a realização dos objetivos da entidade", no critério do nível de maturidade (2), para } \\
\text { simplificação e uniformização. }\end{array}$} \\
\hline
\end{tabular}

Variável 1.1.2 - Treinamento sobre Valores de Ética e Padrões de Conduta

\begin{tabular}{|l|l|l|l|}
\hline \multicolumn{1}{|c|}{$(\mathbf{0})$ Inexistente } & \multicolumn{1}{|c|}{ (1) Inicial } & \multicolumn{1}{c|}{ (2) Em Formação } & \multicolumn{1}{c|}{ (3) Estabelecido } \\
\hline $\begin{array}{l}\text { Ausência dos padrões de conduta e } \\
\text { temas ligados a integridade, ética, } \\
\text { moral e valores no programa de } \\
\text { capacitação da entidade. }\end{array}$ & $\begin{array}{l}\text { A entidade dispõe de um programa } \\
\text { de capacitação que inclui } \\
\text { treinamentos sobre os padrões de } \\
\text { conduta da entidade e assuntos de } \\
\text { ética e valores. }\end{array}$ & $\begin{array}{l}\text { Política da entidade determina que } \\
\text { todos os empregados da entidade } \\
\text { devem realizar os treinamentos sobre } \\
\text { os padrões de conduta da entidade e } \\
\text { assuntos de ética e valores. }\end{array}$ & $\begin{array}{l}\text { Programa de capacitação da entidade } \\
\text { inclui orientações para terceiros } \\
\text { sobre os padrões de conduta da } \\
\text { entidade. }\end{array}$ \\
\hline Avaliação dos Juízes Especialistas: Clareza - 4; Pertinência - 3,5. & & \\
\hline
\end{tabular}




\begin{tabular}{|c|c|c|c|}
\hline \multicolumn{4}{|c|}{$\begin{array}{l}\text { Comentários dos Juízes Especialistas: } \\
\text { O avaliador } 1 \text { entendeu que essa variável seria definida de forma mais adequada em termos de "grau de disseminaç" } \\
\text { observando-se a realização de atividades como: existência de seminários sobre o tema; divulgação do código de cor } \\
\text { comportamentos aceitáveis; campanhas internas; e treinamento. Nesse sentido, a realização de treinamento ou capa } \\
\text { maturidade mais avançado, enquanto as demais estariam enquadradas nos níveis iniciais. } \\
\text { O avaliador } 2 \text { afirma que a diferença entre os critérios definidos para os níveis de maturidade (1) e (2) não é clara. }\end{array}$} \\
\hline \multicolumn{4}{|c|}{$\begin{array}{l}\text { Parecer: REFORMULAÇÃO DA VARIÁ VEL (NOVO NOME E NOVOS CRITÉRIOS) } \\
\text { A proposta do avaliador } 1 \text { encontra respaldo nos frameworks COSO e boas práticas sugeridas. Desse modo, entende-se que a variável 1.1.2 deve ter como } \\
\text { novo nome "Disseminação dos Padrões de Conduta, Ética e Valores" e os critérios devem ser definidos nos termos a seguir: } \\
\text { (0) Incipiente - Ausência de ações de disseminação dos padrões de conduta e temas ligados a ética e valores na entidade. } \\
\text { (1) Inicial - A entidade realiza ações de disseminação dos padrões de conduta e temas ligados a ética e valores. } \\
\text { (2) Em Formação - As ações de disseminação dos padrões de conduta da entidade e temas ligados a ética e valores são programadas e incluem treinamento } \\
\text { presencial e ações de sensibilização à distância por múltiplos canais de comunicação. } \\
\text { (3) Estabelecido - As ações de disseminação dos padrões de conduta e temas ligados a ética e valores incluem a sensibilização de terceirizados e parceiros. }\end{array}$} \\
\hline \multicolumn{4}{|c|}{ Variável 1.1.3 - Avaliação da Aderência aos Padrões de Conduta } \\
\hline (0) Inexistente & (1) Inicial & (2) Em Formação & (3) Estabelecido \\
\hline $\begin{array}{l}\text { Ausência de estrutura organizacional } \\
\text { para avaliação da aderência aos } \\
\text { padrões de conduta da entidade. }\end{array}$ & $\begin{array}{l}\text { A entidade instituiu Comissão de } \\
\text { Ética e avalia a gestão da ética } \\
\text { conforme processo coordenado pela } \\
\text { Comissão de Ética Pública - CEP, } \\
\text { nos termos do Decreto } n^{\circ} 6.029 / 2007 \text {. }\end{array}$ & $\begin{array}{l}\text { A Comissão de Ética da entidade } \\
\text { realiza a apuração dos desvios } \\
\text { conforme a Resolução CEP n } \\
10 / 2008 \text { e dispõe de canal de } \\
\text { comunicação para denúncias } \\
\text { anônimas. }\end{array}$ & $\begin{array}{l}\text { Política de entidade determina a } \\
\text { realização periódica de auditoria de } \\
\text { ética, conduzida pela auditoria } \\
\text { interna ou auditor independente. }\end{array}$ \\
\hline \multicolumn{4}{|c|}{ Avaliação dos Juízes Especialistas: Clareza - 4; Pertinência - 5.} \\
\hline \multicolumn{4}{|c|}{$\begin{array}{l}\text { Comentários dos Juízes Especialistas: } \\
\text { O avaliador } 1 \text { entendeu que o termo “estrutura organizacional” utilizado no critério do nível de maturidade }(0) \text { Inexistente é vago. }\end{array}$} \\
\hline \multicolumn{4}{|c|}{$\begin{array}{l}\text { Parecer: REFORMULAÇÃO DA VARIÁVEL (NOVO NOME) } \\
\text { O significado do termo “estrutura organizacional” pode ser objeto de nota de esclarecimento, não sendo necessária modificação nos critérios da variável; para } \\
\text { maior clareza quanto ao objeto da variável, entende-se que o seu nome deve ser modificado para "Estrutura Organizacional para Avaliação da Aderência aos } \\
\text { Padrões de Conduta". }\end{array}$} \\
\hline
\end{tabular}

Subdimensão 1.2 - Independência e Competência do Corpo Diretivo

Variável 1.2.1 - Políticas de Due Diligence para o Corpo Diretivo 


\begin{tabular}{|c|c|c|c|}
\hline (0) Inexistente & (1) Inicial & (2) Em Formação & (3) Estabelecido \\
\hline \multicolumn{4}{|c|}{ Avaliação dos Juízes Especialistas: Clareza - 4,5; Pertinência - 5.} \\
\hline \multicolumn{4}{|c|}{ Comentários dos Juízes Especialistas: } \\
\hline
\end{tabular}

\section{Variável 1.2.2 - Requisitos de Competências do Corpo Diretivo}

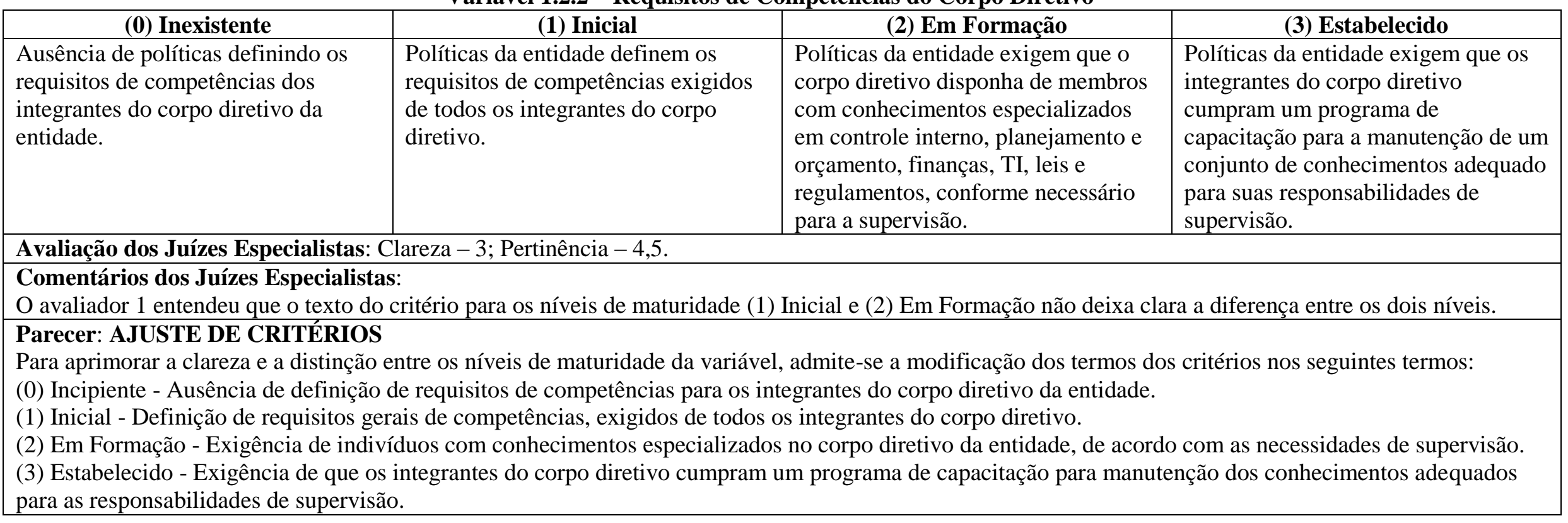


Subdimensão 1.3 - Responsabilidades de Controle Interno e Requisitos de Competência

Variável 1.3.1 - Responsabilidades de Controle Interno na Organização

\begin{tabular}{|c|c|c|c|}
\hline (0) Inexistente & (1) Inicial & (2) Em Formação & (3) Estabelecido \\
\hline $\begin{array}{l}\text { Ausência de descrição de cargos ou } \\
\text { ausência de definição das autoridades } \\
\text { e responsabilidades de controle } \\
\text { interno nas descrições de cargos da } \\
\text { entidade. }\end{array}$ & $\begin{array}{l}\text { Definição das autoridades e } \\
\text { responsabilidades de controle interno } \\
\text { para a alta gerência ( } 2^{\circ} \text { escalão) e a } \\
\text { auditoria interna da entidade. }\end{array}$ & $\begin{array}{l}\text { Definição das autoridades e } \\
\text { responsabilidades de controle interno } \\
\text { para os gerentes das divisões, } \\
\text { unidades operacionais ( } 3^{\circ} \text { escalão) e } \\
\text { funções de suporte relevantes para a } \\
\text { realização dos objetivos da entidade. }\end{array}$ & $\begin{array}{l}\text { Definição das autoridades e } \\
\text { responsabilidades de controle interno } \\
\text { para os empregados das divisões, } \\
\text { unidades operacionais e funções de } \\
\text { suporte, e prestadores de serviços } \\
\text { terceirizados relevantes para a } \\
\text { realização dos objetivos da entidade. }\end{array}$ \\
\hline \multicolumn{4}{|c|}{ Avaliação dos Juízes Especialistas: Clareza - 4; Pertinência - 4,5. } \\
\hline \multicolumn{4}{|c|}{$\begin{array}{l}\text { Comentários dos Juízes Especialistas: } \\
\text { O avaliador } 1 \text { entendeu que o termo “ausência de descrição de cargos" deve ser suprimido do texto do critério do nível de maturidade (0) Inexistente, por } \\
\text { estabelecer foco na existência de um documento ao invés da funcionalidade ou característica desejável. }\end{array}$} \\
\hline \multicolumn{4}{|c|}{$\begin{array}{l}\text { Parecer: AJUSTE DE CRITÉRIOS } \\
\text { O ajuste proposto pelo avaliador } 1 \text { é razoável. Desse modo, admite-se a redefinição do critério do nível de maturidade (0) Incipiente para "Ausência de } \\
\text { definição de autoridades e responsabilidades de controle interno na entidade". } \\
\text { Além disso, acatando sugestão realizada na avaliação de outras variáveis, substitui-se o termo "[...] relevantes, considerando os objetivos e riscos da entidade" } \\
\text { pelo termo "[...] relevantes para a realização dos objetivos da entidade", para simplificação e uniformização. } \\
\text { Finalmente, entende-se adequada a remoção dos termos referentes aos "escalões" específicos, considerando que "gerência" e "alta gerência” podem ter } \\
\text { abrangências específicas nas diferentes estruturas organizacionais das entidades do setor governamental. }\end{array}$} \\
\hline
\end{tabular}

Variável 1.3.2 - Requisitos de Competências na Organização

\begin{tabular}{|l|l|l|l|}
\hline \multicolumn{1}{|c|}{ (0) Inexistente } & \multicolumn{1}{|c|}{ (1) Inicial } & \multicolumn{1}{|c|}{ (2) Em Formação } \\
\hline $\begin{array}{l}\text { Ausência de descrição de cargos ou } \\
\text { ausência de definição dos requisitos } \\
\text { de competências nas descrições de } \\
\text { cargos da entidade. }\end{array}$ & $\begin{array}{l}\text { Definição dos requisitos de } \\
\text { competências para a alta gerência }\left(2^{\circ}\right. \\
\text { escalão) e a auditoria interna da } \\
\text { entidade. }\end{array}$ & $\begin{array}{l}\text { Definição dos requisitos de } \\
\text { competências para os gerentes das } \\
\text { divisões, unidades operacionais (30 } \\
\text { escalão) e funções de suporte } \\
\text { relevantes, considerando os objetivos } \\
\text { e riscos da entidade. }\end{array}$ & $\begin{array}{l}\text { Definição dos requisitos de } \\
\text { das divisões, unidades operacionais e } \\
\text { funções de suporte, e prestadores de } \\
\text { serviços terceirizados relevantes, } \\
\text { considerando os objetivos e riscos da } \\
\text { entidade. }\end{array}$ \\
\hline Avaliação dos Juízes Especialistas: Clareza - 3; Pertinência - 5.
\end{tabular}




\begin{tabular}{|l|}
\hline Comentários dos Juízes Especialistas: \\
O avaliador 1 entendeu que o termo "ausência de descrição de cargos" deve ser suprimido do texto do critério do nível de maturidade (0) Inexistente, por \\
estabelecer foco na existência de um documento ao invés da funcionalidade ou característica desejável. \\
O avaliador 2 manifestou o entendimento de que existe uma inversão de ordem nos critérios estabelecidos, considerando que a definição de requisitos de \\
competência para empregados e terceirizados é mais simples e corriqueira que a definição de requisitos de competência para a alta gerência. \\
Parecer: REFORMULAÇÃO DOS CRITÉRIOS (COM INVERSÃO DA LÓGICA EVOLUTIVA) \\
Acatando sugestão realizada na avaliação de outras variáveis, substitui-se o termo "[...] relevantes, considerando os objetivos e riscos da entidade" pelo termo \\
"[...] relevantes para a realização dos objetivos da entidade", para simplificação e uniformização. \\
Além disso, entende-se adequada a remoção dos termos referentes aos "escalões" específicos, considerando que "gerência" e "alta gerência" podem ter \\
abrangências específicas nas diferentes estruturas organizacionais das entidades do setor governamental. \\
Finalmente, considerando que os ajustes propostos pelos avaliadores são razoáveis, admite-se a modificação dos termos dos critérios nos seguintes termos: \\
(0) Incipiente - Ausência de definição dos requisitos de competências na entidade; \\
(1) Inicial - Definição de requisitos gerais de competências, exigíveis de todos os empregados da entidade e prestadores de serviços terceirizados; \\
(2) Em Formação - Definição de requisitos de competências específicos para empregados e gerentes das divisões, unidades operacionais e funções de suporte \\
relevantes para a realização dos objetivos da entidade, inclusive a auditoria interna; \\
(3) Estabelecido - Defiçição de requisitos de competências específicos para a alta gerência da entidade. \\
\hline
\end{tabular}

Subdimensão 1.4 - Atração, Desenvolvimento e Retenção de Indivíduos

Variável 1.4.1 - Programa de Desenvolvimento de Competências

\begin{tabular}{|l|l|l|l|}
\hline \multicolumn{1}{|c|}{$(\mathbf{0})$ Inexistente } & \multicolumn{1}{|c|}{ (1) Inicial } & \multicolumn{1}{c|}{$\mathbf{( 2 ) \text { Em Formação }}$} & \multicolumn{1}{|c|}{ (3) Estabelecido } \\
\hline $\begin{array}{l}\text { Ausência de programa de } \\
\text { desenvolvimento de competências } \\
\text { para os empregados da entidade. }\end{array}$ & $\begin{array}{l}\text { A entidade possui um programa de } \\
\text { desenvolvimento de competências. }\end{array}$ & $\begin{array}{l}\text { O programa de desenvolvimento de } \\
\text { competências inclui o } \\
\text { desenvolvimento de competências } \\
\text { específicas para o desempenho de } \\
\text { funções e atividades significativas } \\
\text { para a realização dos objetivos e } \\
\text { tratamento dos riscos da entidade. }\end{array}$ & $\begin{array}{l}\text { O programa de desenvolvimento de } \\
\text { múltiplas técnicas de entrega (ações } \\
\text { instrucionais em sala de aula, } \\
\text { autoestudo e treinamento no } \\
\text { trabalho). }\end{array}$ \\
\hline
\end{tabular}




Comentários dos Juízes Especialistas:
O avaliador 1 propôs uma supressão de termos no texto do critério do nível de maturidade (2) Em Formação, adotando-se uma redação final mais simples,
sugerindo: o programa de desenvolvimento de competências inclui funções e atividades significativas da entidade, considerando os objetivos e riscos da
entidade.
Além disso, o avaliador 1 não considerou relevante o critério estabelecido para o nível de maturidade (3) Estabelecido, sugerindo os seguintes critérios: o
programa de desenvolvimento de competências inclui todas as funções e atividades da entidade, considerando os objetivos e riscos da entidade ou a entidade
fornece aconselhamento e subsidia treinamento de forma a ajudar os empregados a manter e melhorar sua competência para o trabalho.
Parecer: AJUSTE DE TERMOS
O ajuste proposto pelo avaliador 1 é razoável, admitindo-se a redefinição do critério do nível de maturidade (2) Em Formação para “O programa de
desenvolvimento de competências abrange as funções e atividades relevantes para a realização dos objetivos da entidade".
Apesar do questionamento quanto ao critério do nível de maturidade (3) Estabelecido, não ficou configurada evidência suficiente de que esse critério necessite
de ajustes.

\section{Subdimensão 1.5 - Avaliação de Desempenho}

\section{Variável 1.5.1 - Aspectos Analisados na Avaliação de Desempenho}

\begin{tabular}{|c|c|c|c|}
\hline (0) Inexistente & (1) Inicial & (2) Em Formação & (3) Estabelecido \\
\hline $\begin{array}{l}\text { Ausência de avaliação de } \\
\text { desempenho. }\end{array}$ & $\begin{array}{l}\text { Avaliação da produtividade dos } \\
\text { empregados da entidade. }\end{array}$ & $\begin{array}{l}\text { Avaliação da produtividade e } \\
\text { conduta ética dos empregados da } \\
\text { entidade. }\end{array}$ & $\begin{array}{l}\text { Avaliação da produtividade, conduta } \\
\text { ética e competências dos empregados } \\
\text { da entidade. }\end{array}$ \\
\hline \multicolumn{4}{|c|}{ Avaliação dos Juízes Especialistas } \\
\hline \multicolumn{4}{|c|}{$\begin{array}{l}\text { Comentários dos Juízes Especialistas: } \\
\text { O avaliador } 1 \text { entende que a evolução da escala não deveria apenas adicionar a avaliação da conduta ética e das competências, sugerindo verificar se avalia } \\
\text { apenas poucas dimensões de desempenho, se avalia um conjunto equilibrado de dimensões de desempenho (qualidade, proatividade, liderança etc.), se } \\
\text { considera carências de capacitação, se existe algum mecanismo de incentivo à correção dos problemas identificados. }\end{array}$} \\
\hline \multicolumn{4}{|c|}{$\begin{array}{l}\text { Parecer: REFORMULAÇÃO DA VARIÁVEL (NOVO NOME) E AJUSTE DE CRITÉRIOS } \\
\text { Apesar do entendimento do avaliador, não ficou configurada evidência suficiente de que os critérios da variável necessitam de ajustes. Para maior clareza } \\
\text { quanto ao objeto da variável, entende-se que o seu nome deve ser modificado para "Fatores da Avaliação de Desempenho". } \\
\text { Além disso, considerando que o caráter cumulativo das características e requisitos está implícito na lógica dos modelos de maturidade, admite-se a } \\
\text { modificação dos termos dos critérios nos seguintes termos: } \\
\text { (0) Incipiente - Ausência de definição dos fatores de avaliação de desempenho; } \\
\text { (1) Inicial - Avaliação da produtividade dos empregados da entidade; } \\
\text { (2) Em Formação - Avaliação da conduta ética dos empregados da entidade; } \\
\text { (3) Estabelecido - Avaliação das competências dos empregados da entidade. }\end{array}$} \\
\hline
\end{tabular}


Variável 1.5.2 - Destinatários da Avaliação de Desempenho

\begin{tabular}{|c|c|c|c|}
\hline (0) Inexistente & (1) Inicial & (2) Em Formação & (3) Estabelecido \\
\hline $\begin{array}{l}\text { Ausência de avaliação de } \\
\text { desempenho. }\end{array}$ & $\begin{array}{l}\text { Avaliação de desempenho dos } \\
\text { empregados e gerência da entidade } \\
\text { (até o } 3^{\circ} \text { nível organizacional). }\end{array}$ & $\begin{array}{l}\text { Avaliação de desempenho dos } \\
\text { empregados, gerência e alta gerência } \\
\text { da entidade (até o } 2^{\circ} \text { nível } \\
\text { organizacional). }\end{array}$ & $\begin{array}{l}\text { Avaliação de desempenho dos } \\
\text { empregados, gerência e direção } \\
\text { executiva da entidade. }\end{array}$ \\
\hline \multicolumn{4}{|c|}{$\begin{array}{l}\text { Comentários dos Juízes Especialistas: } \\
\text { O avaliador } 1 \text { entende que não faz tanta diferença se a organização avalia até o terceiro nível ou até o segundo nível, sugerindo os seguintes critérios: } \\
\text { organizações que não avaliam o desempenho; organizações que o avaliam apenas para certos grupos; organizações que avaliam para todos os servidores sem } \\
\text { função; e organizações que avaliam o desempenho de todos, independentemente do nível hierárquico. }\end{array}$} \\
\hline
\end{tabular}

Variável 1.5.3 - Destinatários das Metas de Desempenho

\begin{tabular}{|l|l|l|l|}
\hline \multicolumn{1}{|c|}{ (0) Inexistente } & \multicolumn{1}{|c|}{ (1) Inicial } & \multicolumn{1}{c|}{ (2) Em Formação } & \multicolumn{1}{|c|}{ (3) Estabelecido } \\
\hline Ausência de metas de desempenho. & $\begin{array}{l}\text { Definição de metas de desempenho } \\
\text { para a organização, como um todo. }\end{array}$ & $\begin{array}{l}\text { Definição de metas de desempenho } \\
\text { para as unidades e subunidades } \\
\text { organizacionais da entidade. }\end{array}$ & $\begin{array}{l}\text { Definição de metas de desempenho } \\
\text { individuais, para cada empregado da } \\
\text { entidade. }\end{array}$ \\
\hline Avaliação dos Juízes Especialistas: Clareza - 4; Pertinência - 4,5. \\
$\begin{array}{l}\text { Comentários dos Juízes Especialistas: } \\
\text { O avaliador 1 comentou o seguinte: tenho dúvidas se designar metas para cada servidor individualmente seja, realmente, o último estágio de evolução dos } \\
\text { sistemas de avaliação de desempenho. }\end{array}$ \\
\hline
\end{tabular}




\section{Parecer: REFORMULAÇÃO DA VARIÁVEL (NOVO NOME) E AJUSTE DE CRITÉRIOS}

Para maior clareza quanto ao objeto da variável, entende-se que o seu nome deve ser modificado para "Níveis Organizacionais das Metas de Desempenho". Apesar do entendimento do avaliador, não ficou configurada evidência suficiente de que os critérios da variável necessitam de ajustes. Para maior clareza, admite-se a modificação dos termos do critério do nível de maturidade (0) Incipiente para "Ausência de definição de níveis organizacionais nas metas de desempenho" e do nível de maturidade (1) Inicial para "Definição de metas de desempenho em nível de entidade".

\begin{tabular}{|c|c|c|c|}
\hline \multicolumn{4}{|c|}{ Variável 1.5.4 - Consequências da Avaliação de Desempenho } \\
\hline (0) Inexistente & (1) Inicial & (2) Em Formação & (3) Estabelecido \\
\hline $\begin{array}{l}\text { Ausência de avaliação de } \\
\text { desempenho. }\end{array}$ & Consequências de caráter disciplinar. & $\begin{array}{l}\text { Parcela variável da remuneração dos } \\
\text { empregados é afetada. }\end{array}$ & $\begin{array}{l}\text { Promoção (evolução nos níveis da } \\
\text { carreira) e movimentação (inclusive } \\
\text { remoção) levam em consideração as } \\
\text { avaliações de desempenho do } \\
\text { empregado. }\end{array}$ \\
\hline \multicolumn{4}{|c|}{ Avaliação dos Juízes Especialistas: Clareza - 4,5; Pertinência - 3,5. } \\
\hline \multicolumn{4}{|c|}{$\begin{array}{l}\text { Comentários dos Juízes Especialistas: } \\
\text { O avaliador } 1 \text { comentou o seguinte: não me parece que a sequência que procura refletir o aumento nível de maturidade esteja adequada. Por exemplo, há } \\
\text { autores que criticam a vinculação da avaliação com os mecanismos de remuneração. }\end{array}$} \\
\hline \multicolumn{4}{|c|}{$\begin{array}{l}\text { Parecer: REFORMULAÇÃO DA VARIÁVEL (NOVO NOME) E AJUSTE DE CRITÉRIOS } \\
\text { Para maior clareza quanto ao objeto da variável, entende-se que o seu nome deve ser modificado para "Recompensas e Sanções da Avaliação de } \\
\text { Desempenho". No mesmo sentido, admite-se ainda a modificação dos termos do critério do nível de maturidade (0) Incipiente para “Ausência de definição de } \\
\text { recompensas e sanções na avaliação de desempenho" e do nível de maturidade (1) Inicial para "Recompensas e sanções de caráter administrativo e } \\
\text { disciplinar". }\end{array}$} \\
\hline
\end{tabular}

Variável 1.5.5 - Frequência da Avaliação de Desempenho

\begin{tabular}{|l|l|l|l|}
\hline \multicolumn{1}{|c|}{ (0) Inexistente } & \multicolumn{1}{|c|}{ (1) Inicial } & \multicolumn{1}{c|}{ (2) Em Formação Estabelecido } & \multicolumn{1}{c|}{ (3) } \\
\hline $\begin{array}{l}\text { Ausência de avaliação de } \\
\text { desempenho. }\end{array}$ & $\begin{array}{l}\text { Avaliação de desempenho realizada } \\
\text { anualmente. }\end{array}$ & $\begin{array}{l}\text { Avaliação de desempenho realizada } \\
\text { semestralmente. }\end{array}$ & $\begin{array}{l}\text { Avaliação de desempenho realizada } \\
\text { quadrimestralmente (ou frequência } \\
\text { maior). }\end{array}$ \\
\hline Avaliação dos Juízes Especialistas: Clareza - 5; Pertinência -4
\end{tabular}




\begin{tabular}{l} 
Comentários dos Juízes Especialistas: \\
O avaliador 1 comentou o seguinte: tenho dúvidas se a organização que avalia seus empregados a cada três meses é mais madura que outra que opta por \\
avaliá-los a cada semestre. \\
O avaliador 2 também questionou a viabilidade ou a relação custo versus benefício de fazer avaliações de desempenho em frequência maior que semestral de \\
determinadas organizações. \\
\hline Parecer: AJUSTE DE TERMOS \\
Apesar do entendimento do avaliador, não ficou configurada evidência suficiente de que os critérios da variável necessitam de ajustes. Para maior clareza, \\
admite-se a modificação dos termos do critério do nível de maturidade $(0)$ Incipiente para "Ausência de definição da frequência da avaliação de desempenho". \\
\hline
\end{tabular}

\section{Dimensão 2 - Avaliação de Riscos}

\section{Subdimensão 2.1 - Definição de Objetivos}

Variável 2.1.1 - Processo de Formulação de Objetivos

\begin{tabular}{|c|c|c|c|}
\hline (0) Inexistente & (1) Inicial & (2) Em Formação & (3) Estabelecido \\
\hline $\begin{array}{l}\text { Ausência de processo pa } \\
\text { formulação de objetivos. }\end{array}$ & $\begin{array}{l}\text { Entidade possui } \\
\text { em processo cas }\end{array}$ & $\begin{array}{l}\text { Entidade } \\
\text { em proces } \\
\text { estabeleci }\end{array}$ & $\begin{array}{l}\text { de objetivos } \\
\text { nte (mínimo } \\
\text { a a } \\
\text { s. }\end{array}$ \\
\hline \multicolumn{4}{|c|}{$\begin{array}{l}\text { Comentários dos Juízes Especialistas: } \\
\text { O avaliador } 1 \text { fez reparos ao texto dos critérios da variável, sugerindo para o nível (0) Inexistente: Processo de formulação de objetivos inexistente; para o } \\
\text { nível (1) Inicial: Processo de formulação de objetivos é casuístico; para o nível (2) Em Formação: Processo de formulação de objetivos é formalmente } \\
\text { estabelecido; e para o nível (3) Estabelecido: Processo de formulação de objetivos é formalmente estabelecido e realizado periodicamente (mínimo de uma } \\
\text { vez ao ano), para a reavaliação dos objetivos. } \\
\text { O avaliador } 2 \text { questionou a possibilidade de uma entidade ter objetivos estabelecidos de forma casuística. } \\
\text { O avaliador } 3 \text { sugeriu o seguinte texto para o critério do nível (2) Em Formação: Existe processo de formulação e revisão de objetivos formalmente } \\
\text { estabelecido. Além disso, o avaliador } 3 \text { sugeriu a inclusão de termos relacionados a resposta a novos desafios no texto do critério do nível (3) Estabelecido, } \\
\text { possivelmente para deixar o critério mais claro. }\end{array}$} \\
\hline \multicolumn{4}{|c|}{$\begin{array}{l}\text { Parecer: AJUSTE DE CRITÉRIOS } \\
\text { As sugestões dos especialistas são razoáveis, razão pela qual se admite a redefinição dos critérios da variável nos seguintes termos: } \\
\text { (0) Incipiente - Ausência de processo para a definição de objetivos; } \\
\text { (1) Inicial - Entidade possui objetivos definidos de forma casuística, sem processo formalmente estabelecido; } \\
\text { (2) Em Formação - Processo formalmente estabelecido para definição dos objetivos da entidade; } \\
\text { (3) Estabelecido - Processo de definição de objetivos é realizado periodicamente (mínimo de uma vez ao ano) para a reavaliação dos objetivos da entidade. }\end{array}$} \\
\hline
\end{tabular}


Variável 2.1.2 - Participantes do Processo de Formulação de Objetivos

\begin{tabular}{|c|c|c|c|}
\hline (0) Inexistente & (1) Inicial & (2) Em Formação & (3) Estabelecido \\
\hline $\begin{array}{l}\text { Ausência de processo para a } \\
\text { formulação de objetivos. }\end{array}$ & $\begin{array}{l}\text { Corpo diretivo e alta gerência da } \\
\text { entidade. }\end{array}$ & Todos os empregados da entidade. & \\
\hline \multicolumn{4}{|l|}{ Avaliação dos Juízes Especia } \\
\hline \multicolumn{4}{|c|}{$\begin{array}{l}\text { Comentários dos Juízes Especialistas: } \\
\text { O avaliador } 1 \text { fez reparos ao texto dos critérios da variável, sugerindo para o nível (0) Inexistente: Processo para a formulação de objetivos inexistente; para o } \\
\text { nível (1) Inicial: Processo para formulação de objetivos envolve apenas o corpo diretivo e alta administração da entidade; para o nível (2) Em Formação: } \\
\text { Processo para formulação de objetivos envolve ampla participação dos empregados da entidade; e para o nível (3) Estabelecido: Processo para formulação } \\
\text { de objetivos envolve ampla participação, inclusive de partes interessadas externas. } \\
\text { O avaliador } 3 \text { manifestou o entendimento de que existiria uma inversão de ordem nos critérios estabelecidos, considerando que o mais corriqueiro nas } \\
\text { entidades do setor público é a formulação de objetivos por parte de especialistas de um departamento específico, e que o envolvimento de corpo diretivo e alta } \\
\text { administração no processo é pouco comum. }\end{array}$} \\
\hline \multicolumn{4}{|c|}{$\begin{array}{l}\text { Parecer: AJUSTE DE CRITÉRIOS } \\
\text { Entende-se que não é razoável a inversão da lógica evolutiva da variável, considerando que a lógica proposta no estudo está respa } \\
\text { COSO e boas práticas de controle interno identificadas. } \\
\text { As sugestões do avaliador } 1 \text { são razoáveis, razão pela qual se admite a redefinição dos critérios da variável nos seguintes termos: } \\
\text { (0) Incipiente - Ausência de definição dos participantes do processo de formulação de objetivos. } \\
\text { (1) Inicial - Processo para formulação de objetivos envolve apenas o corpo diretivo e alta gerência da entidade. } \\
\text { (2) Em Formação - Processo para formulação de objetivos envolve ampla participação dos empregados da entidade. } \\
\text { (3) Estabelecido - Processo para formulação de objetivos envolve ampla participação, inclusive de partes interessadas externas. }\end{array}$} \\
\hline
\end{tabular}

Variável 2.1.3 - Tipos de Objetivos

\begin{tabular}{|l|l|l|}
\hline \multicolumn{1}{|c|}{$(\mathbf{0})$ Inexistente } & \multicolumn{1}{|c|}{ (1) Inicial } & \multicolumn{1}{|c|}{ (2) Em Formação } \\
\hline Ausência de definição de objetivos. & Definição de objetivos estratégicos. & $\begin{array}{l}\text { Definição de objetivos de } \\
\text { operacionais, a partir dos objetivos } \\
\text { estratégicos. }\end{array}$ \\
\hline Avaliação dos Juízes Especialistas: Clareza - 3; Pertinência - 5. & $\begin{array}{l}\text { Definição de objetivos de } \\
\text { conformidade e objetivos de } \\
\text { comunicação (relatórios internos e } \\
\text { externos). }\end{array}$ \\
\hline
\end{tabular}




Comentários dos Juízes Especialistas:
O avaliador 1 fez reparos ao texto dos critérios da variável, sugerindo para o nível (1) Inicial: Os objetivos são definidos no nível estratégico, mas não são
desdobrados no nível operacional; para o nível (2) Em Formação: Os objetivos são definidos até o nível operacional, a partir do desdobramento dos objetivos
estratégicos; e para o nível (3) Estabelecido: Além dos objetivos operacionais, também são definidos objetivos de conformidade e objetivos de comunicação
(relatórios internos e externos).
O avaliador 2 questionou a relevância da definição de objetivos de conformidade, considerando que as entidades do setor público têm seus objetivos
estabelecidos em Lei e não podem extrapolar ou deixar de cumprir duas atribuições legais.
O avaliador 3 fez menção à ausência do nível tático, intermediário entre o estratégico e o operacional, nos critérios da variável; questionou ainda a respeito da
classificação de entidades em estágio inicial de planejamento estratégico, quando estão definidos apenas os direcionadores estratégicos (missão, visão e
valores).
Parecer: AJUSTE DE CRITÉRIOS
As sugestões do avaliador 1 são razoáveis, razão pela qual se admite a redefinição dos critérios da variável nos seguintes termos:
(0) Incipiente - Ausência de definição de tipos de objetivos.
(1) Inicial - Os objetivos são definidos no nível estratégico, mas não são desdobrados no nível operacional.
(2) Em Formação - Os objetivos são definidos até o nível operacional, a partir do desdobramento dos objetivos estratégicos.
(3) Estabelecido - Além dos objetivos operacionais, também são definidos objetivos de conformidade e objetivos de comunicação (relatórios internos e
externos).

Variável 2.1.4 - Níveis Organizacionais dos Objetivos

\begin{tabular}{|c|c|c|c|}
\hline (0) Inexistente & (1) Inicial & (2) Em Formação & (3) Estabelecido \\
\hline Ausência de definição de objetivos. & $\begin{array}{l}\text { Objetivos são estabelecidos para a } \\
\text { organização como um todo. }\end{array}$ & $\begin{array}{l}\text { Objetivos são estabelecidos para as } \\
\text { unidades e subunidades } \\
\text { organizacionais, ou divididos em } \\
\text { objetivos específicos. }\end{array}$ & $\begin{array}{l}\text { Objetivos são estabelecidos em nível } \\
\text { de atividade, para os processos mais } \\
\text { relevantes para os objetivos e riscos } \\
\text { da entidade. }\end{array}$ \\
\hline \multicolumn{4}{|c|}{$\begin{array}{l}\text { Comentários dos Juízes Especialistas: } \\
\text { O avaliador } 1 \text { fez reparos ao texto dos critérios da variável, sugerindo para o nível (1) Inicial: Objetivos são estabelecidos apenas para a organização como } \\
\text { um todo; para o nível (2) Em Formação: Objetivos são estabelecidos para organização como um todo e para as unidades e subunidades organizacionais, ou } \\
\text { divididos em objetivos específicos; e para o nível (3) Estabelecido: Objetivos são estabelecidos em nível de atividades ou processos internos mais relevantes } \\
\text { para os objetivos e riscos da entidade. } \\
\text { O avaliador } 3 \text { entendeu que o texto do critério para o nível (1) Inicial é vago e sugeriu que o critério seja a existência apenas de objetivos estruturais } \\
\text { (regimentais), objetivos apenas para área fim ou somente os objetivos do Plano Plurianual. }\end{array}$} \\
\hline
\end{tabular}




\section{Parecer: AJUSTE DE CRITÉRIOS}

As sugestões do avaliador 1 são razoáveis, razão pela qual se admite a redefinição dos critérios da variável nos seguintes termos:

(0) Incipiente - Ausência de definição de níveis organizacionais nos objetivos.

(1) Inicial - Definição apenas de objetivos gerais, em nível de entidade.

(2) Em Formação - Definição de objetivos para as unidades e subunidades organizacionais, ou desdobramento dos objetivos gerais em objetivos específicos.

(3) Estabelecido - Definição de objetivos para as atividades dos processos relevantes para a realização dos objetivos da entidade.

\section{Variável 2.1.5 - Mensuração dos Objetivos}

\begin{tabular}{|c|c|c|c|}
\hline (0) Inexistente & (1) Inicial & (2) Em Formação & (3) Estabelecido \\
\hline $\begin{array}{l}\text { Ausência de definição de objetivos, } \\
\text { ou os objetivos não são mensurados. }\end{array}$ & $\begin{array}{l}\text { Os objetivos da entidade são } \\
\text { mensurados. }\end{array}$ & $\begin{array}{l}\text { Os objetivos da entidade possuem } \\
\text { metas associadas. }\end{array}$ & $\begin{array}{l}\text { Os objetivos da entidade possuem } \\
\text { cronograma e orçamento definidos } \\
\text { para a sua realização. }\end{array}$ \\
\hline \multicolumn{4}{|c|}{ Avaliação dos Juízes Especialistas: Clareza - 4; Pertinência - 5 . } \\
\hline \multicolumn{4}{|c|}{$\begin{array}{l}\text { Comentários dos Juízes Especialistas: } \\
\text { O avaliador } 2 \text { entendeu que o critério estabelecido para o nível de maturidade (2) Em Formação deveria incluir um processo de avaliação da realização das } \\
\text { metas. } \\
\text { O avaliador } 3 \text { fez objeção aos critérios em razão da existência de objetivos cuja natureza não possibilita a mensuração ou o estabelecimento de metas. }\end{array}$} \\
\hline \multicolumn{4}{|c|}{$\begin{array}{l}\text { Parecer: AJUSTE DE TERMOS } \\
\text { Entende-se que a observação do avaliador } 3 \text { é pertinente, mas deve ser tratada no campo dos procedimentos de avaliação. Para maior clareza, admite-se a } \\
\text { modificação dos termos do critério do nível de maturidade (0) Incipiente para "Ausência de mensuração dos objetivos da entidade". }\end{array}$} \\
\hline
\end{tabular}

\section{Subdimensão 2.2 - Identificação, Análise e Resposta aos Riscos}

\begin{tabular}{|l|l|l|l|}
\multicolumn{1}{|c|}{ (0) Inexistente } & \multicolumn{1}{|c|}{ (1) Inicial } & \multicolumn{1}{c|}{ (2) Em Formação } \\
\hline $\begin{array}{l}\text { Ausência de processo para avaliação } \\
\text { de riscos. }\end{array}$ & $\begin{array}{l}\text { Entidade possui avaliação de riscos } \\
\text { realizada em processo casuístico. }\end{array}$ & $\begin{array}{l}\text { Entidade possui avaliação de riscos } \\
\text { realizada em processo formalmente } \\
\text { estabelecido. }\end{array}$ & $\begin{array}{l}\text { Processo de avaliação de riscos é } \\
\text { realizado periodicamente (mínimo de } \\
\text { uma vez ao ano), para a reavaliação } \\
\text { dos riscos. }\end{array}$ \\
\hline Avaliação dos Juízes Especialistas: Clareza $-4,5 ;$ Pertinência -5. & \\
\hline
\end{tabular}




\begin{tabular}{l} 
Comentários dos Juízes Especialistas: \\
O avaliador 2 questionou a possibilidade de uma entidade ter avaliação de riscos realizada de forma casuística. \\
O avaliador 3 aponta um paradoxo no termo "processo casuístico", sugerindo a troca dessa expressão por "de forma casuísta"; além disso, o avaliador 3 \\
apresenta questionamento a respeito da situação de entidades que possuem avaliação de riscos formalizada e realizada sistematicamente apenas em \\
determinados departamentos e não em toda a organização. \\
O avaliador 4 sugere o uso do termo "atualização da avaliação de riscos" no critério do nível (3) Estabelecido, para transmitir a ideia de que o processo de \\
avaliação necessita de continuidade. \\
\hline Parecer: AJUSTE DOS CRITÉRIOS \\
As sugestões dos avaliadores são razoáveis, razão pela qual se admite a redefinição dos critérios da variável nos seguintes termos: \\
(0) Incipiente - Ausência de processo para a avaliação de riscos. \\
(1) Inicial - Entidade possui avaliação de riscos realizada de forma casuística, sem processo formalmente estabelecido. \\
(2) Em Formação - Entidade possui processo formalmente estabelecido para a avaliação de riscos. \\
(3) Estabelecido - Processo de avaliação de riscos é realizado periodicamente (mínimo de uma vez ao ano), para a reavaliação dos riscos.
\end{tabular}

Variável 2.2.2 - Participantes da Avaliação de Riscos

\begin{tabular}{|c|c|c|c|}
\hline (0) Inexistente & (1) Inicial & (2) Em Formação & (3) Estabelecido \\
\hline Ausência de avaliação de riscos. & $\begin{array}{l}\text { O processo de avaliação de riscos é } \\
\text { realizado pelo corpo diretivo e alta } \\
\text { gerência da entidade. }\end{array}$ & $\begin{array}{l}\text { O processo de avaliação de riscos } \\
\text { tem a participação de empregados } \\
\text { das funções e departamentos mais } \\
\text { relevantes para a realização dos } \\
\text { objetivos e tratamento dos riscos da } \\
\text { entidade. }\end{array}$ & $\begin{array}{l}\text { O processo de avaliação de riscos } \\
\text { inclui a obtenção da opinião de } \\
\text { auditor ou especialista externo à } \\
\text { entidade. }\end{array}$ \\
\hline
\end{tabular}




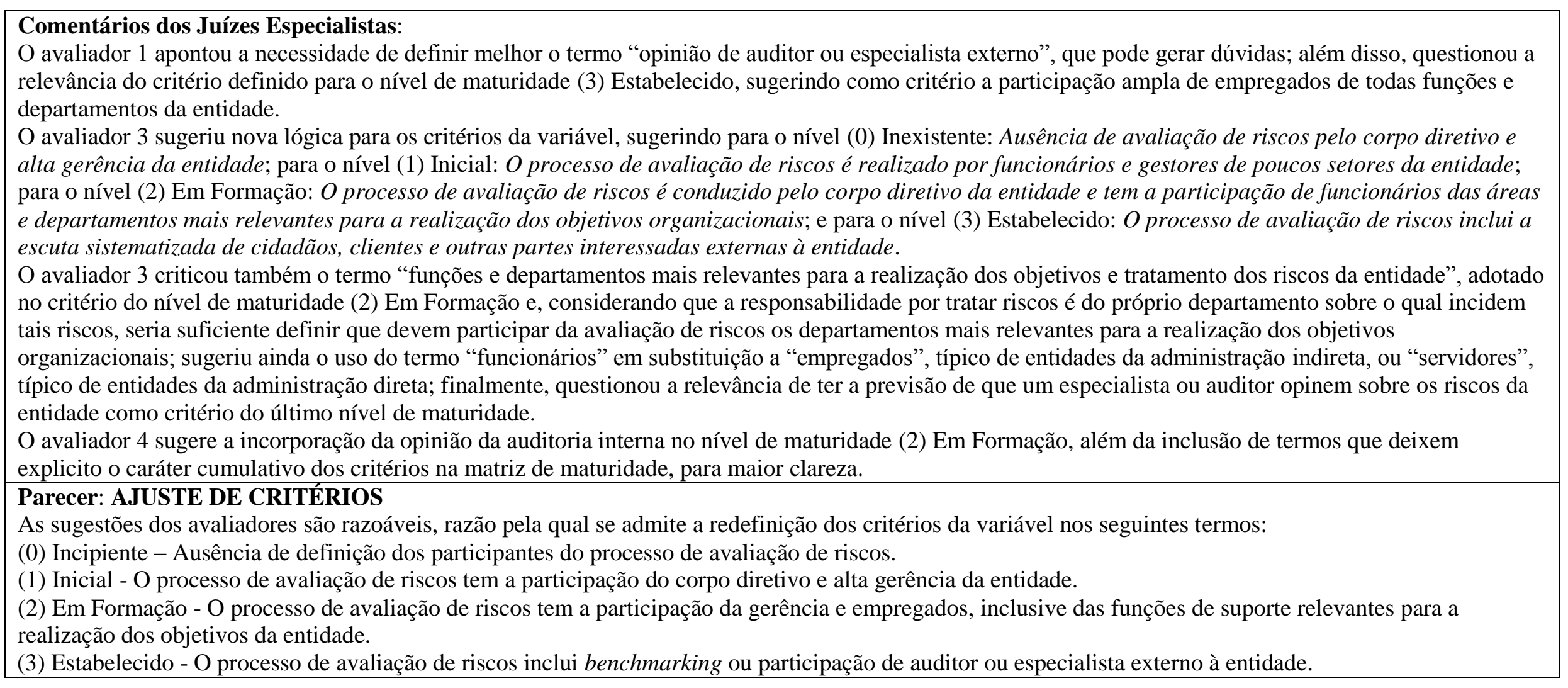

Variável 2.2.3 - Fatores Considerados na Avaliação de Riscos

\begin{tabular}{|l|l|l|l|}
\hline \multicolumn{1}{|c|}{ (0) Inexistente } & \multicolumn{1}{|c|}{$(\mathbf{1})$ Inicial } & \multicolumn{1}{|c|}{ (2) Em Formação } & \multicolumn{1}{|c|}{ Estabelecido } \\
\hline Ausência de avaliação de riscos. & $\begin{array}{l}\text { O processo de avaliação de riscos } \\
\text { considera fatores internos e externos } \\
\text { à entidade. }\end{array}$ & $\begin{array}{l}\text { O processo de avaliação de riscos da } \\
\text { entidade inclui o risco decorrente de } \\
\text { mudanças no ambiente externo, } \\
\text { modelo de negócios e liderança da } \\
\text { entidade. }\end{array}$ & $\begin{array}{l}\text { O processo de avaliação de riscos } \\
\text { inclui o risco de fraude, incluindo } \\
\text { incentivos e pressões, oportunidades, } \\
\text { atitudes e racionalizações, além de } \\
\text { abordagens para burlar controles. }\end{array}$ \\
\hline Avaliação dos Juízes Especialistas: Clareza $-3,5 ;$ Pertinência $-4,5$. & \multicolumn{2}{|l}{} \\
\hline
\end{tabular}




\begin{tabular}{|c|}
\hline $\begin{array}{l}\text { Comentários dos Juízes Especialistas: } \\
\text { O avaliador } 1 \text { questionou a relevância de ter a previsão consideração do risco de fraude como critério do último nível de maturidade, sugerindo como critério a } \\
\text { consideração de riscos de projetos e inovações. } \\
\text { O avaliador } 2 \text { questionou a adequação do texto do critério definido para o nível de maturidade (1) Inicial, indagando quanto à viabilidade de uma avaliação de } \\
\text { riscos que não inclua fatores externos à entidade. } \\
\text { O avaliador } 3 \text { questiona os critérios definidos para a variável e propõe uma nova lógica, sugerindo para o nível (1) Inicial: O processo de avaliação de riscos } \\
\text { considera, porém de forma não sistemática, alguns fatores internos e externos à entidade; para o nível (2) Em Formação: O processo de avaliação de riscos } \\
\text { da entidade aborda os principais fatores de risco internos e externos, inclusive mudanças no ambiente externo, no modelo de negócios e na liderança da } \\
\text { entidade; e para o nível (3) Estabelecido: O processo de avaliação de riscos aborda o risco de fraude, incluindo fatores tais como incentivos e pressões, } \\
\text { oportunidades, atitudes e racionalizaçôes, bem como meios para burlar controles. O avaliador } 3 \text { também questiona o significado do termo "racionalizações", } \\
\text { no critério do nível de maturidade (3) Estabelecido. } \\
\text { O avaliador } 4 \text { entende que os critérios dos níveis } 1 \text { e } 2 \text { podem se confundir, e questiona o significado do termo "modelo de negócio" no âmbito de entidades do } \\
\text { setor governamental. }\end{array}$ \\
\hline $\begin{array}{l}\text { Parecer: AJUSTE DE CRITÉRIOS } \\
\text { Entende-se que as observações dos avaliadores } 1 \text { a } 3 \text { são pertinentes, mas não justificam a realização de ajustes nos critérios da variável. } \\
\text { As sugestões do avaliador } 4 \text { são razoáveis, razão pela qual se admite a redefinição dos critérios da variável nos seguintes termos: } \\
\text { (0) Incipiente - Ausência de definição dos fatores que devem ser considerados na avaliação de riscos. } \\
\text { (1) Inicial - O processo de avaliação de riscos considera fatores internos e externos à entidade. } \\
\text { (2) Em Formação - O processo de avaliação de riscos da entidade inclui mecanismos para a antecipar a identificação, análise e resposta a riscos decorrentes de } \\
\text { mudanças (no ambiente externo, nas políticas públicas de responsabilidade da entidade e na liderança da entidade). } \\
\text { (3) Estabelecido - O processo de avaliação de riscos inclui o risco de fraude (incentivos e pressões, oportunidades, atitudes e racionalizações, abordagens para } \\
\text { burlar controles). }\end{array}$ \\
\hline
\end{tabular}

Variável 2.2.4 - Níveis Organizacionais da Avaliação de Riscos

\begin{tabular}{|l|l|l|l|}
\hline \multicolumn{1}{|c|}{ (0) Inexistente } & \multicolumn{1}{|c|}{$(\mathbf{1})$ Inicial } & \multicolumn{1}{c|}{ (2) Em Formação } & \multicolumn{1}{c|}{ (3) Estabelecido } \\
\hline Ausência de avaliação de riscos. & $\begin{array}{l}\text { Avaliação de riscos da organização } \\
\text { como um todo. }\end{array}$ & $\begin{array}{l}\text { Avaliação de riscos levando em } \\
\text { consideração os vários níveis da } \\
\text { estrutura organizacional. }\end{array}$ & $\begin{array}{l}\text { Avaliação de riscos em nível de } \\
\text { atividade, para os processos internos } \\
\text { mais relevantes para os objetivos e } \\
\text { riscos da entidade. }\end{array}$ \\
\hline Avaliação dos Juízes Especialistas: Clareza -4; Pertinência - 4,5. & & \\
\hline
\end{tabular}




Comentários dos Juízes Especialistas:
O avaliador 2 apresenta questionamento a respeito da situação de entidades que possuem avaliação de riscos realizada apenas em determinadas áreas ou
departamentos, e não em toda a organização; questiona também a respeito de entidades que lidam com categorias específicas de riscos, como o Banco Central
do Brasil, que além dos riscos operacionais realiza avaliação de riscos financeiros.
O avaliador 3 questiona o significado dos termos “avaliar os riscos da organização como um todo" e "avaliar considerando os vários níveis da estrutura
organizacional”, e partindo do pressuposto que o objetivo da variável é verificar se a avaliação de riscos é feita em nível de atividade e de entidade, propõe
uma nova lógica para os critérios da variável, sugerindo para o nível (1) Inicial: A avaliação de riscos é feita em nível de atividade para alguns processos da
entidade; para o nível (2) Em Formação: A avaliação de riscos é feita periodicamente em nível de atividade para os principais processos da entidade; e para o
nível (3) Estabelecido: A avaliação de riscos é feita em nível de entidade e os riscos-chave são revisados periodicamente pela alta administração.
O avaliador 4 sugere a supressão da referência aos riscos da entidade no critério do nível (3) Estabelecido.
Parecer: REFORMULAÇÃO DOS CRITÉRIOS (COM INVERSÃO DA LÓGICA EVOLUTVA)
Entende-se que as sugestões dos avaliadores são razoáveis e indicam que a variável pode ser aprimorada com a inversão da lógica evolutiva (ordem dos
critérios), nos seguintes termos:
(0) Incipiente - Ausência de definição de níveis organizacionais na avaliação de riscos.
(1) Inicial - Avaliação de riscos em nível de atividade, para os processos mais relevantes para a realização dos objetivos da entidade.
(2) Em Formação - Avaliação de riscos levando em consideração as unidades e subunidades organizacionais.
(3) Estabelecido - Avaliação de riscos em nível de entidade.

\section{Dimensão 3 - Atividades de Controle}

Subdimensão 3.1 - Projeto de Controles para Mitigação de Riscos

Variável 3.1.1 - Documentação das Atividades de Controle

\begin{tabular}{|l|l|l|}
\hline \multicolumn{1}{|c|}{$(\mathbf{0})$ Inexistente } & \multicolumn{1}{|c|}{ (1) Inicial } & \multicolumn{1}{c|}{ (2) Em Formação } \\
\hline $\begin{array}{l}\text { Ausência de documentação das } \\
\text { atividades de controle. }\end{array}$ & $\begin{array}{l}\text { Elaboração de Matriz de Riscos e } \\
\text { Controles. }\end{array}$ & $\begin{array}{l}\text { Documentação das atividades de } \\
\text { controle, incluindo a infraestrutura de } \\
\text { tecnologia que provê suporte ao } \\
\text { funcionamento dos controles, } \\
\text { seguindo modelos padronizados pela } \\
\text { entidade. }\end{array}$ \\
$\begin{array}{l}\text { Avaliação dos Juízes Especialistas: Clareza }-3,8 ; \text { Pertinência }-4,8 . \\
\text { da entidade, em nível de atividade. }\end{array}$ \\
\hline
\end{tabular}




Comentários dos Juízes Especialistas:
O avaliador 1 apontou a necessidade de observar a relação custo-benefício do controle, no sentido de que nem todos os controles devem estar formalizados.
Além disso, o avaliador 1 afirma que os saltos entre os níveis são grandes.
O avaliador 5 comentou o seguinte: não está claro o motivo pelo qual a descrição do critério "em formação 2 " inclui a infraestrutura de tecnologia que provê
suporte ao funcionamento dos controles.
Parecer: AJUSTE DE TERMOS
Apesar do entendimento dos avaliadores, não ficou configurada evidência suficiente de que os critérios da variável necessitam de ajustes além dos termos
adotados para a simplificação e uniformização dos critérios.

\section{Variável 3.1.2 - Níveis das Atividades de Controle}

\begin{tabular}{|c|c|c|c|}
\hline (0) Inexistente & (1) Inicial & (2) Em Formação & (3) Estabelecido \\
\hline $\begin{array}{l}\text { Ausência de documentação das } \\
\text { atividades de controle. }\end{array}$ & $\begin{array}{l}\text { Atividades de controle em nível de } \\
\text { transações para os processos internos } \\
\text { relevantes para os objetivos e riscos } \\
\text { da entidade. }\end{array}$ & $\begin{array}{l}\text { Atividades de controle em nível de } \\
\text { departamento. }\end{array}$ & $\begin{array}{l}\text { Atividades de controle em nível de } \\
\text { entidade e controles para os } \\
\text { prestadores de serviços terceirizados } \\
\text { que realizam funções relevantes para } \\
\text { os objetivos e riscos da entidade. }\end{array}$ \\
\hline \multicolumn{4}{|l|}{ Avaliação dos Juízes Especialis } \\
\hline \multicolumn{4}{|c|}{$\begin{array}{l}\text { Comentários dos Juízes Especialistas: } \\
\text { O avaliador } 1 \text { questionou os termos utilizados para definir o critério do nível de maturidade (0) Inexistente, indagando se o objetivo da variável é verificar a } \\
\text { existência de documentação das atividades de controle ou verificar a existência de atividades de controle; além disso, o avaliador } 1 \text { novamente afirma que os } \\
\text { saltos entre os níveis são grandes. } \\
\text { O avaliador } 2 \text { teceu as seguintes considerações: Os órgãos e entidades da administração pública, via de regra, possuem uma enorme quantidade de } \\
\text { atribuições fixadas em normativos (leis ou regulamentos) e uma estrutura muito hierarquizada, sem priorização clara de suas atividades mais importantes. } \\
\text { Nesse contexto, é predominante o entendimento de que todas essas atividades normatizadas são igualmente importantes, e o controle mais implementado é } \\
\text { aquele a nível departamental, ainda que coordenado por uma estrutura central de controle externo. Essa dinâmica, no meu modo de ver, dificulta uma } \\
\text { grande completude dos controles internos, pois pode gerar um efeito cíclico de mais procedimentos burocráticos e um negligenciamento das atividades-fim } \\
\text { do órgão/entidade. } \\
\text { O avaliador } 3 \text { indicou que a utilização do modelo de maturidade na prática dependerá do detalhamento de termos como “atividades de controle em nível de } \\
\text { departamento". } \\
\text { O avaliador } 5 \text { sugeriu que a descrição do nível de } 1 \text { contemple quaisquer processos internos, enquanto a descrição do nível } 2 \text { envolva necessariamente os } \\
\text { processos internos relevantes para a entidade. }\end{array}$} \\
\hline
\end{tabular}




\section{Parecer: REFORMULAÇÃO DA VARIÁVEL (NOVO NOME) E AJUSTE DE TERMOS}

Para maior clareza quanto ao objeto da variável, entende-se que o seu nome deve ser modificado para "Níveis Organizacionais das Atividades de Controle".

Considerando o teor das sugestões dos avaliadores, admite-se a redefinição dos critérios da variável nos seguintes termos:

(0) Incipiente - Ausência de diagnóstico dos níveis organizacionais das atividades de controle.

(1) Inicial - Atividades de controle em nível de transações, para os processos relevantes para a realização dos objetivos da entidade.

(2) Em Formação - Atividades de controle em nível de unidades e subunidades organizacionais.

(3) Estabelecido - Atividades de controle em nível de entidade e controles para terceiros que realizam funções relevantes para a realização dos objetivos da entidade.

\begin{tabular}{|c|c|c|c|}
\hline (0) Inexistente & (1) Inicial & (2) Em Formação & (3) Estabelecido \\
\hline $\begin{array}{l}\text { Ausência de processos para a } \\
\text { representação fidedigna da } \\
\text { informação contábil-financeira. }\end{array}$ & $\begin{array}{l}\text { Processos formalmente estabelecidos } \\
\text { para a realização dos Procedimentos } \\
\text { Contábeis Patrimoniais (MCASP } \\
\text { Parte II). }\end{array}$ & $\begin{array}{l}\text { Processo formalmente estabelecidos } \\
\text { para a conformidade contábil das } \\
\text { demonstrações financeiras. }\end{array}$ & $\begin{array}{l}\text { Processo formalmente estabelecidos } \\
\text { para a conciliação entre os dados } \\
\text { registrados no SIAFI e outros } \\
\text { sistemas da Administração Pública } \\
\text { Federal (SPIUNET, SIASG, RMB). }\end{array}$ \\
\hline \multicolumn{4}{|c|}{ Avaliação dos Juízes Especialistas: Clareza - 5; Pertinência - 5 . } \\
\hline \multicolumn{4}{|c|}{$\begin{array}{l}\text { Comentários dos Juízes Especialistas: } \\
\text { O avaliador } 4 \text { destacou a necessidade de estabelecer um processo de conformidade contábil que efetivamente verifique as possíveis falhas, uma vez que o } \\
\text { registro da conformidade pode ser feito no SIAFI apenas para cumprimento da exigência formal. }\end{array}$} \\
\hline
\end{tabular}

Variável 3.1.4 - Segregação de Funções

\begin{tabular}{|c|c|c|c|}
\hline (0) Inexistente & (1) Inicial & (2) Em Formação & (3) Estabelecido \\
\hline $\begin{array}{l}\text { Ausência de matriz de controle de } \\
\text { acesso e segregação de funções. }\end{array}$ & $\begin{array}{l}\text { A entidade elabora matriz de controle } \\
\text { de acesso e segregação de funções } \\
\text { (autorização, aprovação e } \\
\text { verificação) para os processos, } \\
\text { políticas e procedimentos relevantes } \\
\text { para os objetivos e riscos da entidade. }\end{array}$ & $\begin{array}{l}\text { Projeto de controles alternativos para } \\
\text { os processos, políticas e } \\
\text { procedimentos relevantes para os } \\
\text { objetivos e riscos da entidade que } \\
\text { não podem ter a segregação de } \\
\text { funções adequada. }\end{array}$ & $\begin{array}{l}\text { Política da entidade determina a } \\
\text { reavaliação periódica da matriz de } \\
\text { controle de acesso e segregação de } \\
\text { funções. }\end{array}$ \\
\hline
\end{tabular}




\begin{tabular}{l} 
Comentários dos Juízes Especialistas: \\
O avaliador 5 sugeriu para esta variável a mesma lógica sugerida para a variável 3.1 .2 (nível 1 abrangendo todos os processos da entidade, nível 2 com \\
identificação dos processos críticos). \\
\hline Parecer: AJUSTE DE TERMOS \\
Para maior clareza e uniformização, admite-se a redefinição dos critérios da variável nos seguintes termos: \\
(0) Incipiente - Ausência de diagnóstico da segregação de funções nos os processos, políticas e procedimentos relevantes para a realização dos objetivos da \\
entidade. \\
(1) Inicial - A entidade elabora matriz de controle de acesso e segregação de funções (autorização, aprovação e verificação) para os processos, políticas e \\
procedimentos relevantes para a realização dos objetivos da entidade. \\
(2) Em Formação - A entidade identifica os processos, políticas e procedimentos relevantes para a realização dos objetivos que não podem ter a segregação de \\
funções adequada e elabora atividades de controle alternativas. \\
(3) Estabelecido - Política da entidade determina a reavaliação periódica da matriz de controle de acesso e segregação de funções. \\
\hline
\end{tabular}

\section{Subdimensão 3.2: Implantação de Controles}

\section{Variável 3.2.1 - Políticas e Procedimentos de Controle}

\begin{tabular}{|c|c|c|c|}
\hline (0) Inexistente & (1) Inicial & (2) Em Formacão & (3) Estabelecido \\
\hline $\begin{array}{l}\text { Ausência de políticas e } \\
\text { procedimentos para definição de } \\
\text { responsabilidades e implantação dos } \\
\text { controles da entidade. }\end{array}$ & $\begin{array}{l}\text { Entidade elabora políticas e } \\
\text { procedimentos para a definição de } \\
\text { responsabilidades e implantação dos } \\
\text { controles de todos os processos } \\
\text { relevantes para os objetivos e riscos } \\
\text { da entidade e documenta seguindo } \\
\text { modelos padronizados pela entidade. }\end{array}$ & $\begin{array}{l}\text { Políticas e procedimentos } \\
\text { especificam a tempestividade } \\
\text { (frequência ou oportunidade) na } \\
\text { execução dos controles, as ações } \\
\text { corretivas caso sejam identificados } \\
\text { problemas e o nível de competência e } \\
\text { autoridade necessária para a } \\
\text { execução adequada. }\end{array}$ & $\begin{array}{l}\text { Política da entidade determina a } \\
\text { reavaliação periódica das políticas e } \\
\text { procedimentos de controles da } \\
\text { entidade, ou sempre que forem } \\
\text { identificadas mudanças nas } \\
\text { atividades de negócios ou sistemas e } \\
\text { processos relevantes para os } \\
\text { objetivos e riscos da entidade. }\end{array}$ \\
\hline \multicolumn{4}{|c|}{ Avaliação dos Juízes Especialistas: Clareza - 3,8; Pertinência-4,8. } \\
\hline \multicolumn{4}{|c|}{$\begin{array}{l}\text { Comentários dos Juízes Especialistas: } \\
\text { O avaliador } 1 \text { mais uma vez afirma que os saltos entre os níveis são muito grandes. } \\
\text { O avaliador } 5 \text { sugeriu considerar a situação em que, apesar de existir a política, as condutas operacionais evidenciem procedimentos diversos. }\end{array}$} \\
\hline
\end{tabular}




\section{Parecer: AJUSTE DE CRITÉRIOS}

Apesar do entendimento dos avaliadores, não ficou configurada evidência suficiente de que os critérios da variável necessitam de ajustes.

Para maior clareza e uniformização, admite-se a redefinição dos critérios da variável nos seguintes termos:

(0) Incipiente - Ausência de políticas e procedimentos para definir responsabilidades e orientar a implantação dos controles da entidade.

(1) Inicial - A entidade elabora políticas e procedimentos para definir as responsabilidades e orientar a implantação dos controles dos processos relevantes para a realização dos objetivos entidade.

(2) Em Formação - As políticas e procedimentos especificam a tempestividade (frequência ou oportunidade) na execução dos controles, as ações corretivas caso sejam identificados problemas e o nível de competência e autoridade necessária para a execução adequada.

(3) Estabelecido - Política da entidade determina a revisão periódica das políticas e procedimentos de controles da entidade, ou sempre que forem identificadas mudanças nas atividades, sistemas e processos relevantes para a realização dos objetivos da entidade.

\section{Subdimensão 3.3: Projeto de Controles sobre a Tecnologia}

\section{Variável 3.3.1 - Uso da Computação de Usuário Final}

\begin{tabular}{|c|c|c|c|}
\hline (0) Inexistente & (1) Inicial & (2) Em Formação & (3) Estabelecido \\
\hline $\begin{array}{l}\text { Ausência de documentação do uso de } \\
\text { computação do usuário final nos } \\
\text { processos, políticas e procedimentos } \\
\text { relevantes para os objetivos e riscos } \\
\text { da entidade e nas atividades de } \\
\text { controle associadas. }\end{array}$ & $\begin{array}{l}\text { O uso de computação do usuário } \\
\text { final nos processos, políticas e } \\
\text { procedimentos relevantes os } \\
\text { objetivos e riscos da entidade e nas } \\
\text { atividades de controle associadas é } \\
\text { mapeado e documentado. }\end{array}$ & $\begin{array}{l}\text { Gerência avalia os riscos decorrentes } \\
\text { do uso de computação do usuário } \\
\text { final nos processos, políticas e } \\
\text { procedimentos relevantes para os } \\
\text { objetivos e riscos da entidade e nas } \\
\text { atividades de controle associadas e } \\
\text { elabora controles adicionais } \\
\text { conforme necessário. }\end{array}$ & $\begin{array}{l}\text { As atividades de controle dos } \\
\text { processos, políticas e procedimentos } \\
\text { relevantes para os objetivos e riscos } \\
\text { da entidade não dependem de } \\
\text { computação do usuário final. }\end{array}$ \\
\hline
\end{tabular}




\begin{tabular}{|c|c|}
\hline & $\begin{array}{l}\text { Comentários dos Juízes Especialistas: } \\
\text { O avaliador } 2 \text { entende que existe paradoxo ao definir o critério do nível de maturidade (3) Estabelecido como as atividades de controle dos processos, políticas } \\
\text { e procedimentos relevantes para os objetivos e riscos da entidade não dependem de computação do usuário final. Da maneira como está definido, o critério } \\
\text { estaria aceitando a não correlação entre a variável e as práticas como sendo o melhor nível, enquanto o adequado seria que o critério refletisse práticas ainda } \\
\text { melhores que as estabelecidas no nível anterior. } \\
\text { O avaliador } 3 \text { afirma que o critério do nível de maturidade (3) Estabelecido não está claro e que, em sua opinião, descreve uma situação inatingível. } \\
\text { O avaliador } 4 \text { manifestou não ter compreendido o significado dos termos "computação de usuário final" e "riscos da entidade", e questionou também o padrão } \\
\text { evolutivo estabelecido, em seus termos o crescimento da maturidade desde ausência, mapeamento, documentação e gerência de riscos... chegando a } \\
\text { independência. } \\
\text { O avaliador } 5 \text { também manifestou não ter compreendido o significado do termo "computação de usuário final" e criticou o foco em documentação, para então } \\
\text { questionar padrão evolutivo estabelecido, que em seus termos começa tratando de documentação e termina sem dependência de computação... salto } \\
\text { loooongo. }\end{array}$ \\
\hline & $\begin{array}{l}\text { Parecer: AJUSTE DE CRITÉRIOS } \\
\text { A avaliação dos especialistas e os resultados obtidos nos estudos de caso indicaram que os critérios da variável podem ser aprimorados para maior clareza, nos } \\
\text { seguintes termos: } \\
\text { (0) Incipiente - Ausência de diagnóstico do uso de computação do usuário final nos processos, políticas e procedimentos relevantes para a realização dos } \\
\text { objetivos da entidade. } \\
\text { (1) Inicial - O uso de computação do usuário final nos processos, políticas e procedimentos relevantes para a realização dos objetivos da entidade e nas } \\
\text { atividades de controle associadas é identificado e documentado. } \\
\text { (2) Em Formação - Gerência avalia os riscos decorrentes do uso de computação do usuário final nos processos, políticas e procedimentos relevantes para a } \\
\text { realização dos objetivos da entidade e nas atividades de controle associadas e elabora controles adicionais conforme necessário. } \\
\text { (3) Estabelecido - As atividades de controle dos processos, políticas e procedimentos relevantes para a realização dos objetivos da entidade são automatizadas } \\
\text { com o apoio de aplicativos, sistemas de informações outros recursos de tecnologia. }\end{array}$ \\
\hline
\end{tabular}

\section{Variável 3.3.2 - Políticas de Segurança de TI}

\begin{tabular}{|c|c|c|c|}
\hline (0) Inexistente & (1) Inicial & (2) Em Formação & (3) Estabelecido \\
\hline $\begin{array}{l}\text { Ausência de políticas de segurança } \\
\text { de TI. }\end{array}$ & $\begin{array}{l}\text { A entidade possui política de } \\
\text { segurança de TI formalmente } \\
\text { estabelecida. }\end{array}$ & $\begin{array}{l}\text { A entidade possui política de controle } \\
\text { de acesso à informação e aos } \\
\text { recursos de TI formalmente } \\
\text { estabelecida, consistente com as } \\
\text { funções do trabalho e com a } \\
\text { segregação de funções. }\end{array}$ & $\begin{array}{l}\text { A infraestrutura de TI que suporta os } \\
\text { processos, políticas e procedimentos } \\
\text { relevantes para os objetivos e riscos } \\
\text { da entidade possui plano de } \\
\text { continuidade e recuperação de } \\
\text { desastres. }\end{array}$ \\
\hline
\end{tabular}




Comentários dos Juízes Especialistas:
O avaliador 2 indica que o critério do nível de maturidade (3) Estabelecido deve incluir em sua abrangência o critério do nível de maturidade (2) Em
Formação, para evitar a situação de uma entidade que seja avaliada num nível de maturidade superior sem ter cumprido os requisitos dos níveis inferiores.
O avaliador 3 entende que o critério definido para o nível de maturidade (3) Estabelecido deve incluir a auditoria periódica das políticas de segurança de TI.
O avaliador 4 sugere uma modificação nos critérios da variável, nos seguintes termos: a PSI possui diversas políticas de controle, por vezes, existente em
documentos esparsos. Talvez essa seja uma ideia para o nível 1. O nível 2 seria a junção do 2 com o 1 (formalmente).
O avaliador 5 sugere ajuste no critério no nível de maturidade (2) Em Formação, afirmando que uma política de controle de acesso é inútil sem uma política
de classificação de informações. Sugere também o mapeamento de processos críticos para o negócio, que é insumo para plano de recuperação de desastres e
plano de continuidade de negócios, mas também não costuma existir nas organizações.
Parecer: AJUSTE DE TERMOS
Entende-se que as observações dos avaliadores são pertinentes, mas não ficou configurada evidência suficiente de que os critérios da variável necessitam de
ajustes além dos necessários para maior clareza e uniformização dos termos.

Variável 3.3.3 - Processos de Aquisição, Desenvolvimento e Manutenção da TI

\begin{tabular}{|c|c|c|c|}
\hline (0) Inexistente & (1) Inicial & (2) Em Formação & (3) Estabelecido \\
\hline $\begin{array}{l}\text { Ausência de processos de } \\
\text { gerenciamento de configuração e } \\
\text { mudança para a infraestrutura de TI } \\
\text { da entidade. }\end{array}$ & $\begin{array}{l}\text { Processos formalmente estabelecidos } \\
\text { para o gerenciamento de } \\
\text { configuração e mudança da } \\
\text { infraestrutura de TI que suporta os } \\
\text { processos, políticas e procedimentos } \\
\text { relevantes para os objetivos e riscos } \\
\text { da entidade. }\end{array}$ & $\begin{array}{l}\text { Entidade adota um SDLC completo, } \\
\text { tanto para o software desenvolvido } \\
\text { internamente quanto para os pacotes } \\
\text { adquiridos. }\end{array}$ & $\begin{array}{l}\text { Fases e controles previstos no SDLC } \\
\text { da entidade são definidos em função } \\
\text { de uma classificação de riscos da } \\
\text { mudança, definida conforme o } \\
\text { tamanho, esforço, complexidade e } \\
\text { impactos em processos e controles } \\
\text { relevantes para os objetivos e riscos } \\
\text { da entidade. }\end{array}$ \\
\hline \multicolumn{4}{|c|}{ Avaliação dos Juízes Especialistas: Clareza - 3,4; Pertinência-4,2. } \\
\hline \multicolumn{4}{|c|}{$\begin{array}{l}\text { Comentários dos Juízes Especialistas: } \\
\text { O avaliador } 1 \text { indicou que o texto de alguns critérios está muito grande; sugeriu ainda o uso dos termos por extenso ao invés de siglas, mesmo quando o termo } \\
\text { é de conhecimento geral, para que o critério fique mais claro. } \\
\text { O avaliador } 3 \text { sugeriu a divisão da variável em duas, uma para software e outra para infraestrutura, para uma avaliação mais precisa. } \\
\text { O avaliador } 5 \text { questiona a clareza do termo "relevantes para os objetivos e riscos da entidade”, sugerindo a menção apenas aos objetivos da entidade ou o uso } \\
\text { do termo "alcance dos objetivos e gestão de riscos"; além disso, entende que os critérios da variável misturam conceitos potencialmente diferentes: enquanto a } \\
\text { gestão de configuração e mudança é mais ligada a infraestrutura de TI, o SDLC é mais focado em software. Assim, sugere a divisão em duas variáveis. }\end{array}$} \\
\hline
\end{tabular}




\section{Parecer: AJUSTE DE CRITÉRIOS}

As sugestões dos avaliadores são razoáveis, razão pela qual se admite a redefinição dos critérios da variável nos seguintes termos:

(0) Incipiente - Ausência de processos de gerenciamento de configuração e mudança para a infraestrutura de TI da entidade.

(1) Inicial - Processos formalmente estabelecidos para o gerenciamento de configuração e mudança da infraestrutura de TI que suporta os processos, políticas e procedimentos relevantes para a realização dos objetivos da entidade.

(2) Em Formação - Entidade adota um ciclo de vida de desenvolvimento de sistemas completo, tanto para o software desenvolvido internamente quanto para os pacotes adquiridos.

(3) Estabelecido - Fases e controles previstos no ciclo de vida de desenvolvimento de sistemas da entidade são definidos em função de uma classificação de riscos da mudança, definida conforme o tamanho, esforço, complexidade e impactos em processos e controles relevantes para a realização dos objetivos da entidade.

\section{Dimensão 4 - Informação e Comunicação}

\section{Subdimensão 4.1 - Sistema de Informação da Entidade}

Variável 4.1.1 - Relevância e Qualidade da Informação

\begin{tabular}{|c|c|c|c|}
\hline (0) Inexistente & (1) Inicial & (2) Em Formação & (3) Estabelecido \\
\hline $\begin{array}{l}\text { Ausência de processos para } \\
\text { identificar e documentar as } \\
\text { necessidades, produzir, coletar, tratar, } \\
\text { armazenar, processar e descartar } \\
\text { dados e informações necessárias para } \\
\text { apoiar o funcionamento o controle } \\
\text { interno da entidade. }\end{array}$ & $\begin{array}{l}\text { Processo formalmente estabelecido } \\
\text { para identificar e documentar as } \\
\text { informações necessárias para apoiar } \\
\text { o funcionamento do controle interno } \\
\text { da entidade. }\end{array}$ & $\begin{array}{l}\text { Processos formalmente estabelecidos } \\
\text { para produção, coleta, tratamento, } \\
\text { armazenamento, processamento e } \\
\text { descarte dos dados e informações que } \\
\text { apoiam o funcionamento do controle } \\
\text { interno da entidade. }\end{array}$ & $\begin{array}{l}\text { A entidade estabelece um programa } \\
\text { de governança para a manutenção da } \\
\text { qualidade dos dados e informações } \\
\text { que apoiam o funcionamento do } \\
\text { controle interno da entidade. }\end{array}$ \\
\hline \multicolumn{4}{|c|}{ Avaliação dos Juízes Especialistas: Clareza - 2,5; Pertinência - 3.} \\
\hline \multicolumn{4}{|c|}{$\begin{array}{l}\text { Comentários dos Juízes Especialistas: } \\
\text { O avaliador } 1 \text { entendeu que o texto dos critérios dos níveis de maturidade (1) Inicial e (2) Em Formação estabelece uma diferenciação muito tênue entre os } \\
\text { dois níveis. } \\
\text { O avaliador } 2 \text { teceu o seguinte comentário: Achei o formulário um tanto confuso, mas pelo que vi ambas as varáveis buscam avaliar a mesma coisa: } \\
\text { existência. Como a primeira variável tem a ver com relevância e qualidade da informaçâ, ela deveria refletir se as informações são importantes e úteis para } \\
\text { tomada de decisão, bem como se o conteúdo das informações é apropriado, se a informação é oportuna, atual, se é confiável, se é de fácil acesso etc. Por fim, } \\
\text { informação e comunicação não são restritas a apoiar o funcionamento o controle interno da entidade. Elas, primordialmente, são utilizadas para facilitar } \\
\text { que a entidade possa atingir os objetivos fixados. }\end{array}$} \\
\hline
\end{tabular}




\section{Parecer: AJUSTE NOS TERMOS}

Para maior clareza e distinção entre os níveis de maturidade, admite-se a redefinição dos critérios da variável nos seguintes termos:

(0) Incipiente - Ausência de diagnóstico dos processos para a disponibilização das informações necessárias para apoiar o funcionamento o controle interno da entidade.

(1) Inicial - Processo formalmente estabelecido para identificar e documentar as necessidades de informações para apoiar o funcionamento do controle interno da entidade.

(2) Em Formação - Processos formalmente estabelecidos para produzir ou coletar, tratar, armazenar, processar e descartar os dados e informações que apoiam o funcionamento do controle interno da entidade.

(3) Estabelecido - A entidade estabelece um programa de governança para a manutenção da qualidade dos dados e informações que apoiam o funcionamento da estrutura de controle interno.

Não ficou configurada evidência suficiente de que os critérios da variável necessitam de outros ajustes.

\begin{tabular}{|c|c|c|c|}
\hline (0) Inexistente & cial & (2) Em Formacão & 3) Fstahelecido \\
\hline $\begin{array}{l}\text { Ausência de processos de } \\
\text { comunicação interna e externa. }\end{array}$ & $\begin{array}{l}\text { Processos formalmente estabelecidos } \\
\text { para comunicar tempestivamente ao } \\
\text { público interno e externo as } \\
\text { informações necessárias e esperadas. }\end{array}$ & $\begin{array}{l}\text { Processos de comunicação interna e } \\
\text { externa incluem a seleção dos } \\
\text { métodos de comunicação, levando } \\
\text { em consideração a tempestividade, } \\
\text { audiência, natureza da comunicação e } \\
\text { requisitos, expectativas legais, } \\
\text { regulatórias e contratuais, e a relação } \\
\text { custo x benefício. }\end{array}$ & $\begin{array}{l}\text { A entidade define canais de } \\
\text { comunicação internos e externos } \\
\text { múltiplos e bidirecionais para evitar a } \\
\text { perda de informações relevantes, } \\
\text { incluindo canal de denúncias com } \\
\text { garantia de anonimato para a } \\
\text { comunicação de questões } \\
\text { significativas relacionadas ao } \\
\text { controle interno. }\end{array}$ \\
\hline \multicolumn{4}{|c|}{ Avaliação dos Juízes Especialistas: Clareza - 3; Pertinência - 3.} \\
\hline \multicolumn{4}{|c|}{$\begin{array}{l}\text { Comentários dos Juízes Especialistas: } \\
\text { O avaliador } 2 \text { teceu o seguinte comentário: os comentários anteriores valem para a variável 2. Da forma como os critérios estão redigidos, no meu } \\
\text { entendimento, não refletirão o que deles se espera. }\end{array}$} \\
\hline \multicolumn{4}{|c|}{$\begin{array}{l}\text { Apesar do entendimento do avaliador, não ficou configurada evidência suficiente de que os critérios da variável necessitam de ajustes. Para maior clareza e, } \\
\text { admite-se a redefinição do critério do nível de maturidade }(0) \text { Inexistente para "Ausência de diagnóstico dos processos de comunicação interna e externa". }\end{array}$} \\
\hline
\end{tabular}

\section{Dimensão 5 - Monitoramento}

\section{Subdimensão 5.1 - Monitoramento da Estrutura de Controle Interno}


Variável 5.1.1 - Monitoramento Contínuo

\begin{tabular}{|c|c|c|c|}
\hline (0) Inexistente & (1) Inicial & (2) Em Formação & (3) Estabelecido \\
\hline $\begin{array}{l}\text { Ausência de atividades de } \\
\text { monitoramento contínuo dos } \\
\text { processos, políticas e procedimentos } \\
\text { relevantes para os objetivos e riscos } \\
\text { da entidade. }\end{array}$ & $\begin{array}{l}\text { Os processos, políticas e } \\
\text { procedimentos relevantes para os } \\
\text { objetivos e riscos da entidade } \\
\text { possuem atividades de } \\
\text { monitoramento integradas. }\end{array}$ & $\begin{array}{l}\text { As atividades de monitoramento são } \\
\text { documentadas seguindo modelos } \\
\text { padronizados pela entidade. }\end{array}$ & $\begin{array}{l}\text { As atividades de monitoramento dos } \\
\text { processos, políticas e procedimentos } \\
\text { relevantes para os objetivos e riscos } \\
\text { da entidade são automatizadas, com o } \\
\text { uso de tecnologia. }\end{array}$ \\
\hline
\end{tabular}

\section{Avaliação dos Juízes Especialistas: Clareza - 3; Pertinência - 5.}

\section{Comentários dos Juízes Especialistas:}

O avaliador 1 afirma que o termo "atividades de monitoramento integradas" é dúbio, sendo necessário deixar mais claro o seu significado.

$\mathrm{O}$ avaliador 2 entende que os critérios da variável estabelecem enfoque nos pontos de controle (processos, políticas e procedimentos) embora o princípio 16 do

COSO defina que o monitoramento deve verificar a presença e funcionamento dos componentes do controle interno. Além disso, também questiona o

significado do termo "atividades de monitoramento integradas".

\section{Parecer: AJUSTE DE TERMOS}

O significado do termo "atividades de monitoramento integradas" pode ser objeto de nota de esclarecimento, não sendo necessária modificação nos critérios da variável.

Além disso, acatando sugestão realizada na avaliação de outras variáveis, substitui-se o termo "[...] relevantes para os objetivos e riscos da entidade" pelo termo “[...] relevantes para a realização dos objetivos da entidade”, para simplificação e uniformização.

Para maior clareza, entende-se que o critério do nível de maturidade (0) Incipiente deve ser definido nos seguintes termos: "Ausência de diagnóstico das atividades de monitoramento contínuo dos processos, políticas e procedimentos relevantes para os objetivos e riscos da entidade".

Apesar do entendimento dos avaliadores, não ficou configurada evidência suficiente de que os critérios da variável necessitam de outros ajustes.

\section{Variável 5.1.2 - Avaliações Avulsas}

\begin{tabular}{|c|c|c|c|}
\hline (0) Inexisten & & & \\
\hline $\begin{array}{l}\text { Ausência de avaliações avulsas da } \\
\text { estrutura de controle interno da } \\
\text { entidade. }\end{array}$ & $\begin{array}{l}\text { Avaliações avulsas da estrutura de } \\
\text { controle interno são realizadas pela } \\
\text { gerência da entidade. }\end{array}$ & $\begin{array}{l}\text { Avaliações avulsas da estrutura de } \\
\text { controle interno são realizadas pela } \\
\text { gerência da entidade e pela auditoria } \\
\text { interna. }\end{array}$ & $\begin{array}{l}\text { Avaliações avulsas da estrutura de } \\
\text { controle interno são realizadas pela } \\
\text { gerência da entidade, pela auditoria } \\
\text { interna e por auditoria independente } \\
\text { ou consultores externos. }\end{array}$ \\
\hline \multicolumn{4}{|c|}{ Avaliação dos Juízes Especialistas: Clareza - 5; Pertinência - 5.} \\
\hline \multicolumn{4}{|c|}{$\begin{array}{l}\text { Comentários dos Juízes Especialistas: } \\
\text { O avaliador } 1 \text { sugeriu que os critérios devem abranger não apenas a existência de avaliações da estrutura de controle interno, mas também a formalização } \\
\text { dessas avaliações. }\end{array}$} \\
\hline
\end{tabular}




\section{Parecer: AJUSTE DOS CRITÉRIOS}

Para maior clareza e simplificação, admite-se a redefinição dos critérios da variável nos seguintes termos:

(0) Incipiente - Ausência de avaliações avulsas da estrutura de controle interno da entidade.

(1) Inicial - Avaliações avulsas da estrutura de controle interno são realizadas periodicamente pela gerência da entidade.

(2) Em Formação - Avaliações avulsas da estrutura de controle interno são realizadas periodicamente pela auditoria interna.

(3) Estabelecido - Avaliações avulsas da estrutura de controle interno são realizadas periodicamente por auditoria independente ou consultores externos.

\section{Variável 5.1.3 - Comunicação das Deficiências de Controle Interno e Acompanhamento das Ações Corretivas}

\begin{tabular}{|c|c|c|c|}
\hline (0) Inexistente & (1) Inicial & (2) Em Formação & (3) Estabelecido \\
\hline $\begin{array}{l}\text { Ausência de políticas e processos } \\
\text { para a comunicação das deficiências } \\
\text { de controle interno e } \\
\text { acompanhamento das ações } \\
\text { corretivas. }\end{array}$ & $\begin{array}{l}\text { A entidade possui políticas } \\
\text { formalmente estabelecidas definindo } \\
\text { a classificação dos problemas } \\
\text { identificados nas atividades de } \\
\text { monitoramento, além do nível de } \\
\text { detalhe da documentação, as } \\
\text { responsabilidades pelas ações } \\
\text { corretivas e as partes que devem ser } \\
\text { comunicadas, conforme a } \\
\text { classificação. }\end{array}$ & $\begin{array}{l}\text { A entidade possui processos } \\
\text { formalmente estabelecidos para o } \\
\text { acompanhamento das ações } \\
\text { corretivas para as deficiências } \\
\text { identificadas nos controles internos. }\end{array}$ & $\begin{array}{l}\text { A entidade possui processos } \\
\text { formalmente estabelecidos para a } \\
\text { verificação da eficácia das ações } \\
\text { corretivas adotadas para deficiências } \\
\text { de controles internos significativas. }\end{array}$ \\
\hline \multicolumn{4}{|c|}{ Avaliação dos Juízes Especialistas: Clareza - 4; Pertinência -4,5. } \\
\hline \multicolumn{4}{|c|}{$\begin{array}{l}\text { Comentários dos Juízes Especialistas: } \\
\text { O avaliador } 1 \text { entendeu que os termos dos critérios não estabelecem claramente a diferenciação entre os níveis de maturidade (1) Inicial e (2) Em Formação; } \\
\text { que o critério do nível de maturidade (1) Inicial aparenta ser mais complexo que o critério do nível de maturidade (2) Em Formação; e que os critérios } \\
\text { estabelecem foco na formalização das políticas, não incluindo o que ocorre não prática. }\end{array}$} \\
\hline
\end{tabular}




\section{APÊNDICE H - MODELO DE SOLICITAÇÃO DE DOCUMENTOS ÀS ENTIDADES ESTUDADAS}

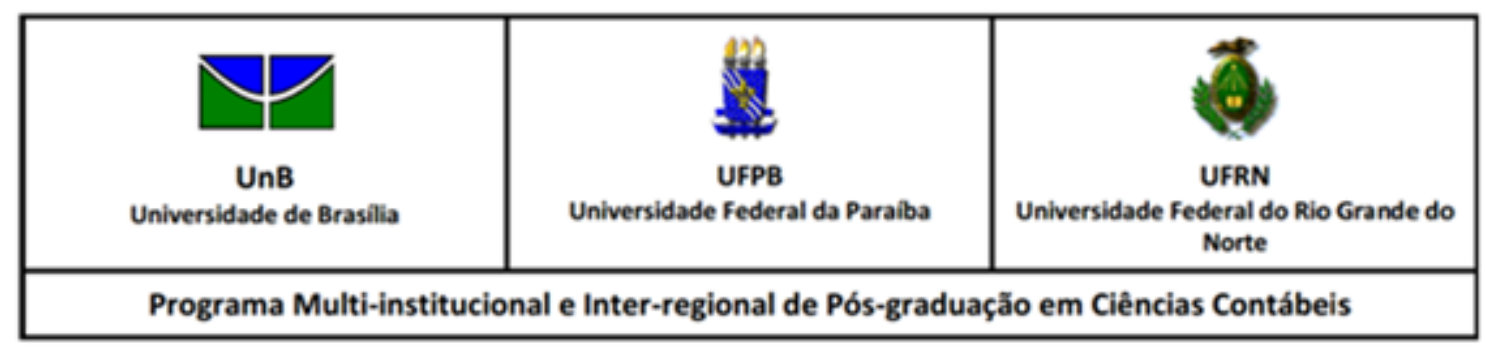

A Sua Senhoria o Senhor

Nome Completo

Cargo Ocupado

Endereço da Entidade

Prezado Senhor,

Com o objetivo de subsidiar os procedimentos do estudo de caso da Entidade no âmbito da pesquisa acadêmica "Proposta de Modelo de Maturidade para Sistemas de Controles Internos nos Órgãos e Entidades da Administração Pública Federal Brasileira”, realizada nos termos da carta de apresentação anexada, solicito a documentação conforme a lista a seguir:

1. Lei de Criação;

2. Estatuto;

3. Regimento Interno;

4. Organogramas;

5. Relatório de Gestão;

6. Plano Anual de Atividades da Auditoria Interna (PAINT);

7. Relatório Anual de Atividades da Auditoria Interna (RAINT);

8. Normas, regulamentos, padrões ou Código de Conduta;

9. Normas e regulamentos referentes a programas de capacitação ou programas de desenvolvimento de competências dos servidores;

10. Normas e regulamentos que contenham determinações a respeito da realização de treinamentos sobre os padrões de conduta;

11. Norma que institui a Comissão de Ética;

12. Relatórios com os resultados dos processos de avaliação da gestão da ética;

13. Planos de trabalho da Comissão de Ética;

14. Regimento ou regulamento da Comissão de Ética;

15. Relatórios de atividades da Comissão de Ética; 
16. Normas e regulamentos que contenham determinações a respeito de realização de auditorias de ética;

17. Normas e regulamentos referentes à realização de procedimentos de averiguação da independência e competência (due diligence) de indivíduos do corpo diretivo ${ }^{81}$;

18. Descrições de cargos do corpo diretivo;

19. Normas e regulamentos referentes a requisitos ou expectativas de competências dos indivíduos do corpo diretivo;

20. Descrições de cargos dos servidores;

21. Normas e regulamentos referentes a responsabilidades de controle interno para os servidores;

22. Normas e regulamentos referentes a requisitos ou expectativas de competências para os servidores;

23. Planos Estratégicos;

24. Planos Táticos;

25. Planos Operacionais;

26. Relatórios de avaliação de riscos corporativos;

27. Normas e regulamentos referentes à avaliação de desempenho dos servidores;

28. Normas e regulamentos referentes às principais rubricas remuneratórias dos servidores (parcelas fixas e variáveis);

29. Normas e regulamentos referentes à progressão funcional e promoção dos servidores;

30. Normas e regulamentos referentes à lotação, movimentação e remoção dos servidores;

31. Normas e regulamentos referentes aos processos de planejamento estratégico, tático e operacional;

32. Mapas dos principais processos ${ }^{82}$;

33. Descrição dos principais processos;

34. Descrição das atividades dos principais processos;

35. Manuais de procedimentos das atividades dos principais processos;

36. Relatórios com os resultados dos processos de acompanhamento ou avaliação do desempenho institucional;

37. Relatórios de avaliação de riscos corporativos;

38. Normas e regulamentos referentes aos processos de avaliação de riscos corporativos;

39. Relatórios de avaliação de riscos das atividades dos principais processos;

40. Matrizes de riscos e controles;

41. Inventários de atividades de controle;

42. Descrição das atividades de controle;

43. Descrição das atividades de controle dos principais processos;

44. Manuais de procedimentos das atividades de controle dos principais processos;

45. Normas e regulamentos referentes aos principais processos;

${ }^{81}$ O termo “corpo diretivo" se refere ao conselho de administração ou outra estrutura responsável por supervisionar a gestão da entidade.

${ }^{82}$ O termo "principais processos" se refere aos processos críticos para a realização dos objetivos do MAPA, incluindo processos primários (finalísticos), processos de suporte e processos de gestão. 
46. Norma que determina a reavaliação periódica das normas, regulamentos e controles dos principais processos;

47. Normas e regulamentos referentes aos processos para a realização dos procedimentos contábeis patrimoniais (MCASP Parte II);

48. Mapas dos processos para a realização dos procedimentos contábeis patrimoniais (MCASP Parte II);

49. Demonstrações contábeis;

50. Normas e regulamentos referentes aos processos para a conformidade das demonstrações contábeis (conformidade contábil);

51. Mapas dos processos para a conformidade das demonstrações contábeis (conformidade contábil);

52. Normas e regulamentos referentes aos processos para a conciliação das informações contábeis;

53. Mapas dos processos para a conciliação das informações contábeis;

54. Matrizes de responsabilidades ou segregação de funções e controle de acesso dos principais processos;

55. Norma que determina a reavaliação periódica das matrizes de responsabilidades ou segregação de funções e controle de acesso dos principais processos;

56. Relatórios de avaliação de riscos das atividades de controle dos principais processos;

57. Política de segurança de TI;

58. Política de controle de acesso à TI;

59. Plano de continuidade de serviços de TI;

60. Plano de recuperação de desastres para a infraestrutura de TI;

61. Normas e regulamentos referentes a processos de gerenciamento de configuração e mudança da infraestrutura de TI;

62. Mapas dos processos de gerenciamento de configuração e mudança da infraestrutura de TI;

63. Normas e regulamentos referentes a processos de desenvolvimento de sistemas (processo de software);

64. Mapas dos processos de desenvolvimento de sistemas (processo de software);

65. Normas e regulamentos referentes a processos para identificar e documentar as informações necessárias para apoiar o funcionamento do controle interno;

66. Mapas dos processos para identificar e documentar as informações necessárias para apoiar o funcionamento do controle interno;

67. Normas e regulamentos referentes a processos de produção, coleta, tratamento, armazenamento, processamento e descarte dos dados e informações que apoiam o funcionamento do controle interno;

68. Mapas dos processos para a produção, coleta, tratamento, armazenamento, processamento e descarte dos dados e informações que apoiam o funcionamento do controle interno;

69. Normas e regulamentos referentes a processos de governança de dados;

70. Normas e regulamentos referentes a processos de comunicação interna e externa;

71. Mapas dos processos para comunicação interna e externa;

72. Normas e regulamentos referentes a canais de comunicação internos e externos; 
73. Descrição das atividades de monitoramento dos principais processos;

74. Manuais de procedimentos das atividades de monitoramento dos principais processos;

75. Relatórios de avaliações de controles internos realizadas pelos gerentes;

76. Normas e regulamentos referentes à avaliação de controles internos;

77. Mapas dos processos para a avaliação de controles internos;

78. Relatórios de avaliações de controles internos realizadas pela auditoria interna;

79. Relatórios de avaliações de controles internos realizadas por auditor independente ou consultor externo;

80. Normas e regulamentos referentes à classificação dos problemas identificados nas atividades de monitoramento;

81. Mapas dos processos para a classificação dos problemas identificados nas atividades de monitoramento;

82. Normas e regulamentos referentes a processos de acompanhamento das ações corretivas para as deficiências identificadas nos controles internos;

83. Mapas dos processos para o acompanhamento das ações corretivas para as deficiências identificadas nos controles internos;

84. Normas e regulamentos referentes a processos de verificação da eficácia das ações corretivas adotadas para deficiências significativas de controles internos;

85. Mapas dos processos para a verificação da eficácia das ações corretivas adotadas para deficiências significativas de controles internos.

A documentação poderá ser entregue em formato e mídia eletrônica, ou encaminhada ao endereço de correio eletrônico internet do pesquisador (ricardo_capovilla@hotmail.com). Eventuais dúvidas a respeito da documentação solicitada serão esclarecidas pelo pesquisador, por mensagem ao endereço internet mencionado ou por telefone (61 8127-3594).

Sem mais para o momento, aproveito o ensejo para manifestar-lhes cordiais saudações.

Ricardo Augusto Capovilla

Discente

Programa Multi-institucional e Inter-regional de Pós Graduação em Ciências Contábeis da UnB/UFPB/UFRN 


\section{APÊNDICE I - PROPOSTA DE MODELO DE MATURIDADE DE SISTEMAS DE CONTROLE INTERNO EM ENTIDADES GOVERNAMENTAIS}

\section{DIMENSÃO 1 - AMBIENTE DE CONTROLE}

\begin{tabular}{|c|c|c|c|c|}
\hline \multicolumn{5}{|c|}{ SUBDIMENSÃO 1.1 - PADRÕES DE CONDUTA } \\
\hline VARIÁVEL & (0) INCIPIENTE & (1) INICIAL & (2) EM FORMAÇÃO & (3) ESTABELECIDO \\
\hline $\begin{array}{l}\text { Destinatários dos } \\
\text { Padrões de Conduta }\end{array}$ & $\begin{array}{l}\text { Ausência de padrões de conduta } \\
\text { próprios da entidade. }\end{array}$ & $\begin{array}{l}\text { A entidade possui padrões de } \\
\text { conduta próprios, com } \\
\text { disposições gerais, aplicáveis a } \\
\text { todos os empregados. }\end{array}$ & $\begin{array}{l}\text { Padrões de conduta da entidade } \\
\text { incluem disposições específicas } \\
\text { para gerentes, indivíduos do } \\
\text { corpo diretivo e empregados de } \\
\text { funções relevantes para a } \\
\text { realização dos objetivos da } \\
\text { entidade. }\end{array}$ & $\begin{array}{l}\text { Padrões de conduta da entidade } \\
\text { incluem disposições específicas } \\
\text { para terceiros (fornecedores de } \\
\text { produtos e serviços e empregados } \\
\text { terceirizados que atuam em nome } \\
\text { da entidade), exigidas } \\
\text { contratualmente ou por SLA. }\end{array}$ \\
\hline $\begin{array}{l}\text { Disseminação dos } \\
\text { Padrões de Conduta, } \\
\text { Ética e Valores }\end{array}$ & $\begin{array}{l}\text { Ausência de ações de } \\
\text { disseminação dos padrões de } \\
\text { conduta e temas ligados a ética e } \\
\text { valores na entidade. }\end{array}$ & $\begin{array}{l}\text { A entidade realiza ações de } \\
\text { disseminação dos padrões de } \\
\text { conduta e temas ligados a ética e } \\
\text { valores. }\end{array}$ & $\begin{array}{l}\text { As ações de disseminação dos } \\
\text { padrões de conduta da entidade e } \\
\text { temas ligados a ética e valores } \\
\text { são programadas e incluem } \\
\text { treinamento presencial e ações de } \\
\text { sensibilização à distância por } \\
\text { múltiplos canais de comunicação. }\end{array}$ & $\begin{array}{l}\text { As ações de disseminação dos } \\
\text { padrões de conduta e temas } \\
\text { ligados a ética e valores incluem } \\
\text { a sensibilização de terceirizados e } \\
\text { parceiros. }\end{array}$ \\
\hline $\begin{array}{l}\text { Estrutura } \\
\text { Organizacional para } \\
\text { Avaliação da } \\
\text { Aderência aos Padrões } \\
\text { de Conduta }\end{array}$ & $\begin{array}{l}\text { Ausência de estrutura } \\
\text { organizacional para avaliação da } \\
\text { aderência aos padrões de conduta } \\
\text { da entidade. }\end{array}$ & $\begin{array}{l}\text { A entidade instituiu Comissão de } \\
\text { Ética e avalia a gestão da ética } \\
\text { conforme processo coordenado } \\
\text { pela Comissão de Ética Pública - } \\
\text { CEP, nos termos do Decreto }{ }^{\circ} \\
6.029 / 2007 \text {. }\end{array}$ & $\begin{array}{l}\text { A Comissão de Ética da entidade } \\
\text { realiza a apuração dos desvios } \\
\text { conforme a Resolução CEP n }{ }^{\circ} \\
\text { 10/2008 e dispõe de canal de } \\
\text { comunicação para denúncias } \\
\text { anônimas. }\end{array}$ & $\begin{array}{l}\text { Política de entidade determina a } \\
\text { realização periódica de auditoria } \\
\text { de ética, conduzida pela auditoria } \\
\text { interna ou auditor independente. }\end{array}$ \\
\hline
\end{tabular}




\begin{tabular}{|c|c|c|c|c|}
\hline \multicolumn{5}{|c|}{ SUBDIMENSÃO 1.2 - INDEPENDÊNCIA E COMPETÊNCIA DO CORPO DIRETIVO } \\
\hline VARIÁVEL & (0) INCIPIENTE & (1) INICIAL & (2) EM FORMAÇÃO & (3) ESTABELECIDO \\
\hline $\begin{array}{l}\text { Políticas de Due } \\
\text { Diligence para o Corpo } \\
\text { Diretivo }\end{array}$ & $\begin{array}{l}\text { Ausência de políticas de } d u e \\
\text { diligence para os indivíduos do } \\
\text { corpo diretivo da entidade. }\end{array}$ & $\begin{array}{l}\text { Políticas da entidade estabelecem } \\
\text { a realização de procedimentos de } \\
\text { due diligence como parte do } \\
\text { processo de seleção dos } \\
\text { candidatos ao corpo diretivo. }\end{array}$ & $\begin{array}{l}\text { Políticas da entidade estabelecem } \\
\text { a realização periódica de } \\
\text { procedimentos de due diligence } \\
\text { para a confirmação da } \\
\text { competência e independência dos } \\
\text { membros do corpo diretivo. }\end{array}$ & $\begin{array}{l}\text { Políticas da entidade estabelecem } \\
\text { que os procedimentos de due } \\
\text { diligence sejam supervisionados } \\
\text { por um comitê de nominação } \\
\text { independente ou firma de } \\
\text { contratação e os resultados devem } \\
\text { ser divulgados. }\end{array}$ \\
\hline $\begin{array}{l}\text { Requisitos de } \\
\text { Competências do } \\
\text { Corpo Diretivo }\end{array}$ & $\begin{array}{l}\text { Ausência de definição de } \\
\text { requisitos de competências para } \\
\text { os integrantes do corpo diretivo } \\
\text { da entidade. }\end{array}$ & $\begin{array}{l}\text { Definição de requisitos gerais de } \\
\text { competências, exigidos de todos } \\
\text { os integrantes do corpo diretivo. }\end{array}$ & $\begin{array}{l}\text { Exigência de indivíduos com } \\
\text { conhecimentos especializados no } \\
\text { corpo diretivo da entidade, de } \\
\text { acordo com as necessidades de } \\
\text { supervisão. }\end{array}$ & $\begin{array}{l}\text { Exigência de que os integrantes } \\
\text { do corpo diretivo cumpram um } \\
\text { programa de capacitação para } \\
\text { manutenção dos conhecimentos } \\
\text { adequados para as } \\
\text { responsabilidades de supervisão. }\end{array}$ \\
\hline
\end{tabular}

\begin{tabular}{|c|c|c|c|c|}
\hline \multicolumn{5}{|c|}{ SUBDIMENSÃO 1.3 - RESPONSABILIDADES DE CONTROLE INTERNO E REQUISITOS DE COMPETÊNCIAS } \\
\hline VARIÁVEL & (0) INCIPIENTE & (1) INICIAL & (2) EM FORMAÇÃO & (3) ESTABELECIDO \\
\hline $\begin{array}{l}\text { Responsabilidades de } \\
\text { Controle Interno na } \\
\text { Organização }\end{array}$ & $\begin{array}{l}\text { Ausência de definição das } \\
\text { autoridades e responsabilidades } \\
\text { de controle interno na entidade. }\end{array}$ & $\begin{array}{l}\text { Definição das autoridades e } \\
\text { responsabilidades de controle } \\
\text { interno para a alta gerência e a } \\
\text { auditoria interna da entidade. }\end{array}$ & $\begin{array}{l}\text { Definição das autoridades e } \\
\text { responsabilidades de controle } \\
\text { interno para os gerentes das } \\
\text { divisões, unidades operacionais e } \\
\text { funções de suporte relevantes } \\
\text { para a realização dos objetivos da } \\
\text { entidade. }\end{array}$ & $\begin{array}{l}\text { Definição das autoridades e } \\
\text { responsabilidades de controle } \\
\text { interno para os empregados das } \\
\text { divisões, unidades operacionais e } \\
\text { funções de suporte, e prestadores } \\
\text { de serviços terceirizados } \\
\text { relevantes para a realização dos } \\
\text { objetivos da entidade. }\end{array}$ \\
\hline $\begin{array}{l}\text { Requisitos de } \\
\text { Competências na } \\
\text { Organização }\end{array}$ & $\begin{array}{l}\text { Ausência de definição dos } \\
\text { requisitos de competências na } \\
\text { entidade. }\end{array}$ & $\begin{array}{l}\text { Definição de requisitos gerais de } \\
\text { competências, exigíveis de todos } \\
\text { os empregados da entidade e } \\
\text { prestadores de serviços } \\
\text { terceirizados. }\end{array}$ & $\begin{array}{l}\text { Definição de requisitos de } \\
\text { competências específicos para } \\
\text { empregados e gerentes das } \\
\text { divisões, unidades operacionais e } \\
\text { funções de suporte relevantes } \\
\text { para a realização dos objetivos da } \\
\text { entidade, inclusive a auditoria } \\
\text { interna. }\end{array}$ & $\begin{array}{l}\text { Definição de requisitos de } \\
\text { competências específicos para a } \\
\text { alta gerência da entidade. }\end{array}$ \\
\hline
\end{tabular}




\begin{tabular}{|c|c|c|c|c|}
\hline \multicolumn{5}{|c|}{ SUBDIMENSÃO 1.4 - ATRAÇÃO, DESENVOLVIMENTO E RETENÇÃO DE INDIVÍDUOS } \\
\hline VARIÁVEL & (0) INCIPIENTE & (1) INICIAL & (2) EM FORMAÇÃO & (3) ESTABELECIDO \\
\hline $\begin{array}{l}\text { Programa de } \\
\text { Desenvolvimento de } \\
\text { Competências }\end{array}$ & $\begin{array}{l}\text { Ausência de programa de } \\
\text { desenvolvimento de } \\
\text { competências para os } \\
\text { empregados da entidade. }\end{array}$ & $\begin{array}{l}\text { A entidade possui um programa } \\
\text { de desenvolvimento de } \\
\text { competências. }\end{array}$ & $\begin{array}{l}\text { O programa de desenvolvimento } \\
\text { de competências abrange as } \\
\text { funções e atividades relevantes } \\
\text { para a realização dos objetivos da } \\
\text { entidade. }\end{array}$ & $\begin{array}{l}\text { O programa de desenvolvimento } \\
\text { de competências da entidade } \\
\text { inclui múltiplas técnicas de } \\
\text { entrega (ações instrucionais em } \\
\text { sala de aula, autoestudo e } \\
\text { treinamento no trabalho). }\end{array}$ \\
\hline
\end{tabular}

\begin{tabular}{|c|c|c|c|c|}
\hline \multicolumn{5}{|c|}{ SUBDIMENSÃO 1.5 - AVALIAÇÃO DE DESEMPENHO } \\
\hline VARIÁVEL & (0) INCIPIENTE & (1) INICIAL & (2) EM FORMAÇÃ̃ & (3) ESTABELECIDO \\
\hline $\begin{array}{l}\text { Fatores da Avaliação } \\
\text { de Desempenho }\end{array}$ & $\begin{array}{l}\text { Ausência de definição dos fatores } \\
\text { de avaliação de desempenho. }\end{array}$ & $\begin{array}{l}\text { Avaliação da produtividade dos } \\
\text { empregados da entidade. }\end{array}$ & $\begin{array}{l}\text { Avaliação da conduta ética dos } \\
\text { empregados da entidade. }\end{array}$ & $\begin{array}{l}\text { Avaliação das competências dos } \\
\text { empregados da entidade. }\end{array}$ \\
\hline $\begin{array}{l}\text { Níveis Organizacionais } \\
\text { da Avaliação de } \\
\text { Desempenho }\end{array}$ & $\begin{array}{l}\text { Ausência de definição de níveis } \\
\text { organizacionais na avaliação de } \\
\text { desempenho. }\end{array}$ & $\begin{array}{l}\text { Avaliação de desempenho dos } \\
\text { empregados e gerência da } \\
\text { entidade. }\end{array}$ & $\begin{array}{l}\text { Avaliação de desempenho da alta } \\
\text { gerência da entidade. }\end{array}$ & $\begin{array}{l}\text { Avaliação de desempenho da } \\
\text { direção executiva e corpo diretivo } \\
\text { da entidade. }\end{array}$ \\
\hline $\begin{array}{l}\text { Níveis Organizacionais } \\
\text { das Metas de } \\
\text { Desempenho }\end{array}$ & $\begin{array}{l}\text { Ausência de definição de níveis } \\
\text { organizacionais nas metas de } \\
\text { desempenho. }\end{array}$ & $\begin{array}{l}\text { Definição de metas de } \\
\text { desempenho em nível de } \\
\text { entidade. }\end{array}$ & $\begin{array}{l}\text { Definição de metas de } \\
\text { desempenho para as unidades e } \\
\text { subunidades organizacionais da } \\
\text { entidade. }\end{array}$ & $\begin{array}{l}\text { Definição de metas de } \\
\text { desempenho individuais, para } \\
\text { cada empregado da entidade. }\end{array}$ \\
\hline $\begin{array}{l}\text { Recompensas e } \\
\text { Sanções da Avaliação } \\
\text { de Desempenho }\end{array}$ & $\begin{array}{l}\text { Ausência de definição de } \\
\text { recompensas e sanções na } \\
\text { avaliação de desempenho. }\end{array}$ & $\begin{array}{l}\text { Recompensas e sanções de } \\
\text { caráter administrativo e } \\
\text { disciplinar. }\end{array}$ & $\begin{array}{l}\text { Parcela variável da remuneração } \\
\text { dos empregados é afetada. }\end{array}$ & $\begin{array}{l}\text { Promoção (evolução nos níveis } \\
\text { da carreira) e movimentação } \\
\text { (inclusive remoção) levam em } \\
\text { consideração as avaliações de } \\
\text { desempenho do empregado. }\end{array}$ \\
\hline $\begin{array}{l}\text { Frequência da } \\
\text { Avaliação de } \\
\text { Desempenho }\end{array}$ & $\begin{array}{l}\text { Ausência de definição da } \\
\text { frequência da avaliação de } \\
\text { desempenho. }\end{array}$ & $\begin{array}{l}\text { Avaliação de desempenho } \\
\text { realizada anualmente. }\end{array}$ & $\begin{array}{l}\text { Avaliação de desempenho } \\
\text { realizada semestralmente. }\end{array}$ & $\begin{array}{l}\text { Avaliação de desempenho } \\
\text { realizada quadrimestralmente (ou } \\
\text { frequência maior). }\end{array}$ \\
\hline
\end{tabular}




\section{DIMENSÃO 2: AVALIAÇÃO DE RISCOS}

\begin{tabular}{|c|c|c|c|c|}
\hline \multicolumn{5}{|c|}{ SUBDIMENSÃO 2.1 - DEFINIÇÃO DE OBJETIVOS } \\
\hline VARIÁVEL & (0) INCIPIENTE & (1) INICIAL & (2) EM FORMAÇÃO & (3) ESTABELECIDO \\
\hline $\begin{array}{l}\text { Processo de } \\
\text { Formulação de } \\
\text { Objetivos }\end{array}$ & $\begin{array}{l}\text { Ausência de processos para a } \\
\text { definição de objetivos. }\end{array}$ & $\begin{array}{l}\text { Entidade possui objetivos } \\
\text { definidos de forma casuística, } \\
\text { sem processo formalmente } \\
\text { estabelecido. }\end{array}$ & $\begin{array}{l}\text { Processo formalmente } \\
\text { estabelecido para definição dos } \\
\text { objetivos da entidade. }\end{array}$ & $\begin{array}{l}\text { Processo de definição de } \\
\text { objetivos é realizado } \\
\text { periodicamente (mínimo de uma } \\
\text { vez ao ano) para a reavaliação } \\
\text { dos objetivos da entidade. }\end{array}$ \\
\hline $\begin{array}{l}\text { Participantes do } \\
\text { Processo de } \\
\text { Formulação de } \\
\text { Objetivos }\end{array}$ & $\begin{array}{l}\text { Ausência de definição dos } \\
\text { participantes do processo de } \\
\text { formulação de objetivos. }\end{array}$ & $\begin{array}{l}\text { Processo para a formulação de } \\
\text { objetivos envolve apenas o corpo } \\
\text { diretivo e alta gerência da } \\
\text { entidade. }\end{array}$ & $\begin{array}{l}\text { Processo para a formulação de } \\
\text { objetivos envolve ampla } \\
\text { participação dos empregados da } \\
\text { entidade. }\end{array}$ & $\begin{array}{l}\text { Processo para a formulação de } \\
\text { objetivos envolve ampla } \\
\text { participação, inclusive de partes } \\
\text { interessadas externas. }\end{array}$ \\
\hline Tipos de Objetivos & $\begin{array}{l}\text { Ausência de definição de tipos de } \\
\text { objetivos. }\end{array}$ & $\begin{array}{l}\text { Os objetivos são definidos no } \\
\text { nível estratégico, mas não são } \\
\text { desdobrados no nível } \\
\text { operacional. }\end{array}$ & $\begin{array}{l}\text { Os objetivos são definidos até o } \\
\text { nível operacional, a partir do } \\
\text { desdobramento dos objetivos } \\
\text { estratégicos. }\end{array}$ & $\begin{array}{l}\text { Além dos objetivos operacionais, } \\
\text { também são definidos objetivos } \\
\text { de conformidade e objetivos de } \\
\text { comunicação (relatórios internos } \\
\text { e externos). }\end{array}$ \\
\hline $\begin{array}{l}\text { Níveis Organizacionais } \\
\text { dos Objetivos }\end{array}$ & $\begin{array}{l}\text { Ausência de definição de níveis } \\
\text { organizacionais nos objetivos. }\end{array}$ & $\begin{array}{l}\text { Definição apenas de objetivos } \\
\text { gerais, em nível de entidade. }\end{array}$ & $\begin{array}{l}\text { Definição de objetivos para as } \\
\text { unidades e subunidades } \\
\text { organizacionais, ou } \\
\text { desdobramento dos objetivos } \\
\text { gerais em objetivos específicos. }\end{array}$ & $\begin{array}{l}\text { Definição de objetivos para as } \\
\text { atividades dos processos } \\
\text { relevantes para a realização dos } \\
\text { objetivos da entidade. }\end{array}$ \\
\hline $\begin{array}{l}\text { Mensuração dos } \\
\text { Objetivos }\end{array}$ & $\begin{array}{l}\text { Ausência de mensuração dos } \\
\text { objetivos da entidade. }\end{array}$ & $\begin{array}{l}\text { Os objetivos da entidade são } \\
\text { mensurados. }\end{array}$ & $\begin{array}{l}\text { Os objetivos da entidade possuem } \\
\text { metas associadas. }\end{array}$ & $\begin{array}{l}\text { Os objetivos da entidade possuem } \\
\text { cronograma e orçamento } \\
\text { definidos para a sua realização. }\end{array}$ \\
\hline
\end{tabular}

\begin{tabular}{|l|l|l|l|l|}
\hline \multicolumn{1}{|c|}{ SUBDIMENSÃO 2.2 - IDENTIFICAÇÃO, ANÁLISE E RESPOSTA AOS RISCOS } \\
\hline \multicolumn{1}{|c|}{ VARIÁVEL } & \multicolumn{1}{|c|}{ (0) INCIPIENTE } & \multicolumn{1}{c|}{ (1) INICIAL EM FORMAÇÃO } & \multicolumn{1}{c|}{ (3) ESTABELECIDO } \\
\hline $\begin{array}{l}\text { Processo de Avaliação } \\
\text { de Riscos }\end{array}$ & $\begin{array}{l}\text { Ausência de processo para a } \\
\text { avaliação de riscos. }\end{array}$ & $\begin{array}{l}\text { Entidade possui avaliação de } \\
\text { riscos realizada de forma } \\
\text { casuística, sem processo } \\
\text { formalmente estabelecido. }\end{array}$ & $\begin{array}{l}\text { Entidade possui processo } \\
\text { formalmente estabelecido para a } \\
\text { avaliação de riscos. }\end{array}$ & $\begin{array}{l}\text { Processo de avaliação de riscos é } \\
\text { realizado periodicamente } \\
\text { (mínimo de uma vez ao ano), } \\
\text { para a reavaliação dos riscos. }\end{array}$ \\
\hline
\end{tabular}




\begin{tabular}{|c|c|c|c|c|}
\hline \multicolumn{5}{|c|}{ SUBDIMENSÃO 2.2 - IDENTIFICAÇÃO, ANÁLISE E RESPOSTA AOS RISCOS } \\
\hline VARIÁVEL & (0) INCIPIENTE & (1) INICIAL & (2) EM FORMAÇÃ̃ & (3) ESTABELECIDO \\
\hline $\begin{array}{l}\text { Participantes da } \\
\text { Avaliação de Riscos }\end{array}$ & $\begin{array}{l}\text { Ausência de definição dos } \\
\text { participantes do processo de } \\
\text { avaliação de riscos. }\end{array}$ & $\begin{array}{l}\text { O processo de avaliação de riscos } \\
\text { tem a participação do corpo } \\
\text { diretivo e alta gerência da } \\
\text { entidade. }\end{array}$ & $\begin{array}{l}\text { O processo de avaliação de riscos } \\
\text { tem a participação da gerência e } \\
\text { empregados, inclusive das } \\
\text { funções de suporte relevantes } \\
\text { para a realização dos objetivos da } \\
\text { entidade. }\end{array}$ & $\begin{array}{l}\text { O processo de avaliação de riscos } \\
\text { inclui benchmarking ou } \\
\text { participação de auditor ou } \\
\text { especialista externo à entidade. }\end{array}$ \\
\hline $\begin{array}{l}\text { Fatores Considerados } \\
\text { na Avaliação de Riscos }\end{array}$ & $\begin{array}{l}\text { Ausência de definição dos fatores } \\
\text { que devem ser considerados na } \\
\text { avaliação de riscos. }\end{array}$ & $\begin{array}{l}\text { O processo de avaliação de riscos } \\
\text { considera fatores internos e } \\
\text { externos à entidade. }\end{array}$ & $\begin{array}{l}\text { O processo de avaliação de riscos } \\
\text { da entidade inclui mecanismos } \\
\text { para a antecipar a identificação, } \\
\text { análise e resposta a riscos } \\
\text { decorrentes de mudanças (no } \\
\text { ambiente externo, nas políticas } \\
\text { públicas de responsabilidade da } \\
\text { entidade e na liderança da } \\
\text { entidade). }\end{array}$ & $\begin{array}{l}\text { O processo de avaliação de riscos } \\
\text { inclui o risco de fraude } \\
\text { (incentivos e pressões, } \\
\text { oportunidades, atitudes e } \\
\text { racionalizações, abordagens para } \\
\text { burlar controles). }\end{array}$ \\
\hline $\begin{array}{l}\text { Níveis Organizacionais } \\
\text { da Avaliação de Riscos }\end{array}$ & $\begin{array}{l}\text { Ausência de definição de níveis } \\
\text { organizacionais na avaliação de } \\
\text { riscos. }\end{array}$ & $\begin{array}{l}\text { Avaliação de riscos em nível de } \\
\text { atividade, para os processos mais } \\
\text { relevantes para a realização dos } \\
\text { objetivos da entidade. }\end{array}$ & $\begin{array}{l}\text { Avaliação de riscos levando em } \\
\text { consideração as unidades e } \\
\text { subunidades organizacionais. }\end{array}$ & $\begin{array}{l}\text { Avaliação de riscos em nível de } \\
\text { entidade. }\end{array}$ \\
\hline
\end{tabular}

\section{DIMENSÃO 3: ATIVIDADES DE CONTROLE}

\begin{tabular}{|c|c|c|c|c|}
\hline \multicolumn{5}{|c|}{ SUBDIMENSÃO 3.1 - PROJETO DE CONTROLES PARA MITIGAÇÃO DE RISCOS } \\
\hline VARIÁVEL & (0) INCIPIENTE & (1) INICIAL & (2) EM FORMAÇÃO & (3) ESTABELECIDO \\
\hline $\begin{array}{l}\text { Documentação das } \\
\text { Atividades de Controle }\end{array}$ & $\begin{array}{l}\text { Ausência de documentação das } \\
\text { atividades de controle. }\end{array}$ & $\begin{array}{l}\text { Elaboração de Matriz de Riscos e } \\
\text { Controles. }\end{array}$ & $\begin{array}{l}\text { Documentação das atividades de } \\
\text { controle, incluindo a } \\
\text { infraestrutura de tecnologia que } \\
\text { provê suporte ao funcionamento } \\
\text { dos controles, seguindo modelos } \\
\text { padronizados pela entidade. }\end{array}$ & $\begin{array}{l}\text { Mapeamento dos processos } \\
\text { relevantes para a realização dos } \\
\text { objetivos da entidade, em nível de } \\
\text { atividade. }\end{array}$ \\
\hline $\begin{array}{l}\text { Níveis Organizacionais } \\
\text { das Atividades de } \\
\text { Controle }\end{array}$ & $\begin{array}{l}\text { Ausência de diagnóstico dos } \\
\text { níveis organizacionais das } \\
\text { atividades de controle. }\end{array}$ & $\begin{array}{l}\text { Atividades de controle em nível } \\
\text { de transações, para os processos } \\
\text { relevantes para a realização dos } \\
\text { objetivos da entidade. }\end{array}$ & $\begin{array}{l}\text { Atividades de controle em nível } \\
\text { de unidades e subunidades } \\
\text { organizacionais. }\end{array}$ & $\begin{array}{l}\text { Atividades de controle em nível } \\
\text { de entidade e controles para } \\
\text { terceiros que realizam funções } \\
\text { relevantes para a realização dos } \\
\text { objetivos da entidade. }\end{array}$ \\
\hline
\end{tabular}




\begin{tabular}{|l|l|l|l|}
\hline \multicolumn{4}{|c|}{ SUBDIMENSÃO 3.1 - PROJETO DE CONTROLES PARA MITIGAÇÃO DE RISCOS } \\
\hline \multicolumn{1}{|c|}{ VARIÁVEL } & \multicolumn{1}{|c|}{ (0) INCIPIENTE } & \multicolumn{1}{c|}{ (1) INICIAL } & \multicolumn{1}{c|}{ (3) ESTABELECIDO FORMAÇÃO } \\
\hline $\begin{array}{l}\text { Representação } \\
\text { Fidedigna da } \\
\text { Informação Contábil- } \\
\text { Financeira }\end{array}$ & $\begin{array}{l}\text { Ausência de processos para a } \\
\text { representação fidedigna da } \\
\text { informação contábil-financeira. }\end{array}$ & $\begin{array}{l}\text { Processos formalmente } \\
\text { estabelecidos para a realização } \\
\text { dos Procedimentos Contábeis } \\
\text { Patrimoniais (MCASP Parte II). }\end{array}$ & $\begin{array}{l}\text { Processo formalmente } \\
\text { estabelecidos para a } \\
\text { conformidade contábil das } \\
\text { demonstrações financeiras. }\end{array}$ \\
\hline & $\begin{array}{l}\text { Ausência de diagnóstico da } \\
\text { segregação de funções nos } \\
\text { processos, políticas e } \\
\text { procedimentos relevantes para a } \\
\text { realização dos objetivos da } \\
\text { entidade. }\end{array}$ & $\begin{array}{l}\text { A entidade elabora matriz de } \\
\text { controle de acesso e segregação } \\
\text { de funções (autorização, } \\
\text { aprovação e verificação) para os } \\
\text { processos, políticas e } \\
\text { procedimentos relevantes para a } \\
\text { realização dos objetivos da } \\
\text { SIAFI e outros sistemas da } \\
\text { Administração Pública Federal } \\
\text { (SPIUNET, SIASG, RMB). }\end{array}$ & $\begin{array}{l}\text { A entidade identifica os } \\
\text { processos, políticas e } \\
\text { procedimentos relevantes para a } \\
\text { realização dos objetivos que não } \\
\text { podem ter a segregação de } \\
\text { funções adequada e elabora } \\
\text { atividades de controle } \\
\text { alternativas. }\end{array}$ \\
\hline
\end{tabular}

\section{SUBDIMENSÃO 3.2 - IMPLANTACÃO DE CONTROLES}

\begin{tabular}{|c|c|c|c|c|}
\hline \multicolumn{5}{|c|}{ SUBDIMENSÃO 3.2 - IMPLANTAÇÃO DE CONTROLES } \\
\hline VARIÁVEL & (0) INCIPIENTE & (1) INICIAL & (2) EM FORMAÇÃ̃O & (3) ESTABELECIDO \\
\hline $\begin{array}{l}\text { Políticas e } \\
\text { Procedimentos de } \\
\text { Controle }\end{array}$ & $\begin{array}{l}\text { Ausência de políticas e } \\
\text { procedimentos para definir } \\
\text { responsabilidades e orientar a } \\
\text { implantação dos controles da } \\
\text { entidade. }\end{array}$ & $\begin{array}{l}\text { A entidade elabora políticas e } \\
\text { procedimentos para definir as } \\
\text { responsabilidades e orientar a } \\
\text { implantação dos controles dos } \\
\text { processos relevantes para a } \\
\text { realização dos objetivos entidade }\end{array}$ & $\begin{array}{l}\text { As políticas e procedimentos } \\
\text { especificam a tempestividade } \\
\text { (frequência ou oportunidade) na } \\
\text { execução dos controles, as ações } \\
\text { corretivas caso sejam } \\
\text { identificados problemas e o nível } \\
\text { de competência e autoridade } \\
\text { necessária para a execução } \\
\text { adeguada }\end{array}$ & $\begin{array}{l}\text { Política da entidade determina a } \\
\text { revisão periódica das políticas e } \\
\text { procedimentos de controles da } \\
\text { entidade, ou sempre que forem } \\
\text { identificadas mudanças nas } \\
\text { atividades, sistemas e processos } \\
\text { relevantes para a realização dos } \\
\text { objetivos da entidade. }\end{array}$ \\
\hline
\end{tabular}




\begin{tabular}{|c|c|c|c|c|}
\hline \multicolumn{5}{|c|}{ SUBDIMENSÃO 3.3 - PROJETO DE CONTROLES SOBRE A TECNOLOGIA } \\
\hline VARIÁVEL & (0) INCIPIENTE & (1) INICIAL & (2) EM FORMAÇÃ̃O & (3) ESTABELECIDO \\
\hline $\begin{array}{l}\text { Uso da Computação de } \\
\text { Usuário Final }\end{array}$ & $\begin{array}{l}\text { Ausência de diagnóstico do uso } \\
\text { de computação do usuário final } \\
\text { nos processos, políticas e } \\
\text { procedimentos relevantes para a } \\
\text { realização dos objetivos da } \\
\text { entidade. }\end{array}$ & $\begin{array}{l}\text { O uso de computação do usuário } \\
\text { final nos processos, políticas e } \\
\text { procedimentos relevantes para a } \\
\text { realização dos objetivos da } \\
\text { entidade e nas atividades de } \\
\text { controle associadas é identificado } \\
\text { e documentado. }\end{array}$ & $\begin{array}{l}\text { Gerência avalia os riscos } \\
\text { decorrentes do uso de } \\
\text { computação do usuário final nos } \\
\text { processos, políticas e } \\
\text { procedimentos relevantes para a } \\
\text { realização dos objetivos da } \\
\text { entidade e nas atividades de } \\
\text { controle associadas e elabora } \\
\text { controles adicionais conforme } \\
\text { necessário. }\end{array}$ & $\begin{array}{l}\text { As atividades de controle dos } \\
\text { processos, políticas e } \\
\text { procedimentos relevantes para a } \\
\text { realização dos objetivos da } \\
\text { entidade são automatizadas com o } \\
\text { apoio de aplicativos, sistemas de } \\
\text { informações outros recursos de } \\
\text { tecnologia. }\end{array}$ \\
\hline $\begin{array}{l}\text { Políticas de Segurança } \\
\text { de TI }\end{array}$ & $\begin{array}{l}\text { Ausência de políticas de } \\
\text { segurança de TI. }\end{array}$ & $\begin{array}{l}\text { A entidade possui políticas de } \\
\text { segurança de TI formalmente } \\
\text { estabelecidas. }\end{array}$ & $\begin{array}{l}\text { A entidade possui política de } \\
\text { controle de acesso à informação e } \\
\text { aos recursos de TI formalmente } \\
\text { estabelecida, consistente com as } \\
\text { funções do trabalho e com a } \\
\text { segregação de funções. }\end{array}$ & $\begin{array}{l}\text { A infraestrutura de TI que suporta } \\
\text { os processos, políticas e } \\
\text { procedimentos relevantes para a } \\
\text { realização dos objetivos da } \\
\text { entidade possui plano de } \\
\text { continuidade de serviços e plano } \\
\text { de recuperação de desastres. }\end{array}$ \\
\hline $\begin{array}{l}\text { Processos de } \\
\text { Aquisição, } \\
\text { Desenvolvimento e } \\
\text { Manutenção da TI }\end{array}$ & $\begin{array}{l}\text { Ausência de processos de } \\
\text { gerenciamento de configuração e } \\
\text { mudança para a infraestrutura de } \\
\text { TI da entidade. }\end{array}$ & $\begin{array}{l}\text { Processos formalmente } \\
\text { estabelecidos para o } \\
\text { gerenciamento de configuração e } \\
\text { mudança da infraestrutura de TI } \\
\text { que suporta os processos, } \\
\text { políticas e procedimentos } \\
\text { relevantes para a realização dos } \\
\text { objetivos da entidade. }\end{array}$ & $\begin{array}{l}\text { Entidade adota um ciclo de vida } \\
\text { de desenvolvimento de sistemas } \\
\text { completo, tanto para o software } \\
\text { desenvolvido internamente } \\
\text { quanto para os pacotes } \\
\text { adquiridos. }\end{array}$ & $\begin{array}{l}\text { Fases e controles previstos no } \\
\text { ciclo de vida de desenvolvimento } \\
\text { de sistemas da entidade são } \\
\text { definidos em função de uma } \\
\text { classificação de riscos da } \\
\text { mudança, definida conforme o } \\
\text { tamanho, esforço, complexidade } \\
\text { e impactos em processos e } \\
\text { controles relevantes para a } \\
\text { realização dos objetivos da } \\
\text { entidade. }\end{array}$ \\
\hline
\end{tabular}




\section{DIMENSÃO 4: INFORMAÇÃO E COMUNICAÇÃO}

\begin{tabular}{|c|c|c|c|c|}
\hline \multicolumn{5}{|c|}{ SUBDIMENSÃO 4.1 - SISTEMA DE INFORMAÇÃO DA ENTIDADE } \\
\hline VARIÁVEL & (0) INCIPIENTE & (1) INICIAL & (2) EM FORMAÇÃO & (3) ESTABELECIDO \\
\hline $\begin{array}{l}\text { Relevância e } \\
\text { Qualidade da } \\
\text { Informação }\end{array}$ & $\begin{array}{l}\text { Ausência de diagnóstico dos } \\
\text { processos para a disponibilização } \\
\text { das informações necessárias para } \\
\text { apoiar o funcionamento o } \\
\text { controle interno da entidade. }\end{array}$ & $\begin{array}{l}\text { Processo formalmente } \\
\text { estabelecido para identificar e } \\
\text { documentar as necessidades de } \\
\text { informações para apoiar o } \\
\text { funcionamento do controle } \\
\text { interno da entidade. }\end{array}$ & $\begin{array}{l}\text { Processos formalmente } \\
\text { estabelecidos para produzir ou } \\
\text { coletar, tratar, armazenar, } \\
\text { processar e descartar os dados e } \\
\text { informações que apoiam o } \\
\text { funcionamento do controle } \\
\text { interno da entidade. }\end{array}$ & $\begin{array}{l}\text { A entidade estabelece um } \\
\text { programa de governança para a } \\
\text { manutenção da qualidade dos } \\
\text { dados e informações que apoiam } \\
\text { o funcionamento da estrutura de } \\
\text { controle interno. }\end{array}$ \\
\hline $\begin{array}{l}\text { Comunicação Interna } \\
\text { e Externa }\end{array}$ & $\begin{array}{l}\text { Ausência de diagnóstico dos } \\
\text { processos de comunicação interna } \\
\text { e externa. }\end{array}$ & $\begin{array}{l}\text { Processos formalmente } \\
\text { estabelecidos para comunicar } \\
\text { tempestivamente ao público } \\
\text { interno e externo as informações } \\
\text { necessárias e esperadas. }\end{array}$ & $\begin{array}{l}\text { Processos de comunicação } \\
\text { interna e externa incluem a } \\
\text { seleção dos métodos de } \\
\text { comunicação, levando em } \\
\text { consideração a tempestividade, } \\
\text { audiência, natureza da } \\
\text { comunicação e requisitos, } \\
\text { expectativas legais, regulatórias e } \\
\text { contratuais, e a relação custo x } \\
\text { benefício. }\end{array}$ & $\begin{array}{l}\text { A entidade define canais de } \\
\text { comunicação internos e externos } \\
\text { múltiplos e bidirecionais para } \\
\text { evitar a perda de informações } \\
\text { relevantes, incluindo canal de } \\
\text { denúncias com garantia de } \\
\text { anonimato para a comunicação de } \\
\text { questões significativas } \\
\text { relacionadas ao controle interno. }\end{array}$ \\
\hline
\end{tabular}

\section{DIMENSÃO 5: MONITORAMENTO}

\begin{tabular}{|c|c|c|c|c|}
\hline \multicolumn{5}{|c|}{ SUBDIMENSÃO 5.1 - MONITORAMENTO DA ESTRUTURA DE CONTROLE INTERNO } \\
\hline VARIÁVEL & (0) INCIPIENTE & (1) INICIAL & (2) EM FORMAÇÃO & (3) ESTABELECIDO \\
\hline $\begin{array}{l}\text { Monitoramento } \\
\text { Contínuo }\end{array}$ & $\begin{array}{l}\text { Ausência de diagnóstico das } \\
\text { atividades de monitoramento } \\
\text { contínuo dos processos, políticas } \\
\text { e procedimentos relevantes para a } \\
\text { realização dos objetivos da } \\
\text { entidade. }\end{array}$ & $\begin{array}{l}\text { Os processos, políticas e } \\
\text { procedimentos relevantes para a } \\
\text { realização dos objetivos da } \\
\text { entidade possuem atividades de } \\
\text { monitoramento integradas. }\end{array}$ & $\begin{array}{l}\text { As atividades de monitoramento } \\
\text { são documentadas seguindo } \\
\text { modelos padronizados pela } \\
\text { entidade. }\end{array}$ & $\begin{array}{l}\text { As atividades de monitoramento } \\
\text { dos processos, políticas e } \\
\text { procedimentos relevantes para a } \\
\text { realização dos objetivos da } \\
\text { entidade são automatizadas, com } \\
\text { o uso de tecnologia. }\end{array}$ \\
\hline Avaliações Avulsas & $\begin{array}{l}\text { Ausência de avaliações avulsas } \\
\text { da estrutura de controle interno } \\
\text { da entidade. }\end{array}$ & $\begin{array}{l}\text { Avaliações avulsas da estrutura } \\
\text { de controle interno são realizadas } \\
\text { periodicamente pela gerência da } \\
\text { entidade. }\end{array}$ & $\begin{array}{l}\text { Avaliações avulsas da estrutura } \\
\text { de controle interno são realizadas } \\
\text { periodicamente pela auditoria } \\
\text { interna. }\end{array}$ & $\begin{array}{l}\text { Avaliações avulsas da estrutura } \\
\text { de controle interno são realizadas } \\
\text { periodicamente por auditoria } \\
\text { independente ou consultores } \\
\text { externos. }\end{array}$ \\
\hline
\end{tabular}




\begin{tabular}{|c|c|c|c|c|}
\hline \multicolumn{5}{|c|}{ SUBDIMENSÃO 5.1 - MONITORAMENTO DA ESTRUTURA DE CONTROLE INTERNO } \\
\hline VARIÁVEL & (0) INCIPIENTE & (1) INICIAL & (2) EM FORMAÇÃ̃O & (3) ESTABELECIDO \\
\hline $\begin{array}{l}\text { Comunicação das } \\
\text { Deficiências de } \\
\text { Controle Interno e } \\
\text { Acompanhamento das } \\
\text { Ações Corretivas }\end{array}$ & $\begin{array}{l}\text { Ausência de políticas e processos } \\
\text { para a comunicação das } \\
\text { deficiências de controle interno e } \\
\text { acompanhamento das ações } \\
\text { corretivas. }\end{array}$ & $\begin{array}{l}\text { A entidade possui políticas } \\
\text { formalmente estabelecidas } \\
\text { definindo a classificação dos } \\
\text { problemas identificados nas } \\
\text { atividades de monitoramento, } \\
\text { além do nível de detalhe da } \\
\text { documentação, as } \\
\text { responsabilidades pelas ações } \\
\text { corretivas e as partes que devem } \\
\text { ser comunicadas, conforme a } \\
\text { classificação. }\end{array}$ & $\begin{array}{l}\text { A entidade possui processos } \\
\text { formalmente estabelecidos para o } \\
\text { acompanhamento das ações } \\
\text { corretivas para as deficiências } \\
\text { identificadas nos controles } \\
\text { internos. }\end{array}$ & $\begin{array}{l}\text { A entidade possui processos } \\
\text { formalmente estabelecidos para a } \\
\text { verificação da eficácia das ações } \\
\text { corretivas adotadas para } \\
\text { deficiências de controles internos } \\
\text { significativas. }\end{array}$ \\
\hline
\end{tabular}


APÊNDICE J - AVALIAÇÃO DO NÍVEL DE MATURIDADE DAS ENTIDADES ESTUDADAS NAS DIMENSÕES

DIMENSÃO 1 - Ambiente de Controle

\begin{tabular}{|c|c|c|c|c|c|c|c|c|c|c|c|c|}
\hline \multirow{2}{*}{ Variável } & \multicolumn{4}{|c|}{ МАРА } & \multicolumn{4}{|c|}{ Incra } & \multicolumn{4}{|c|}{ Conab } \\
\hline & (0) & (1) & (2) & (3) & (0) & (1) & (2) & (3) & (0) & (1) & (2) & (3) \\
\hline 1.1 .1 & $100 \%$ & $0 \%$ & $0 \%$ & $0 \%$ & $100 \%$ & $0 \%$ & $0 \%$ & $0 \%$ & $0 \%$ & $100 \%$ & $50 \%$ & $0 \%$ \\
\hline 1.1 .2 & $0 \%$ & $100 \%$ & $100 \%$ & $0 \%$ & $100 \%$ & $0 \%$ & $0 \%$ & $0 \%$ & $100 \%$ & $0 \%$ & $0 \%$ & $0 \%$ \\
\hline 1.1 .3 & $0 \%$ & $50 \%$ & $100 \%$ & $0 \%$ & $0 \%$ & $50 \%$ & $100 \%$ & $0 \%$ & $0 \%$ & $100 \%$ & $0 \%$ & $0 \%$ \\
\hline 1.2.1 & $100 \%$ & $0 \%$ & $0 \%$ & $0 \%$ & $100 \%$ & $0 \%$ & $0 \%$ & $0 \%$ & $100 \%$ & $0 \%$ & $0 \%$ & $0 \%$ \\
\hline 1.2.2 & $100 \%$ & $0 \%$ & $0 \%$ & $0 \%$ & $100 \%$ & $0 \%$ & $0 \%$ & $0 \%$ & $100 \%$ & $0 \%$ & $0 \%$ & $0 \%$ \\
\hline 1.3.1 & $0 \%$ & $100 \%$ & $100 \%$ & $0 \%$ & $0 \%$ & $100 \%$ & $100 \%$ & $0 \%$ & $0 \%$ & $100 \%$ & $100 \%$ & $100 \%$ \\
\hline 1.3.2 & $100 \%$ & $0 \%$ & $0 \%$ & $0 \%$ & $100 \%$ & $0 \%$ & $0 \%$ & $0 \%$ & $0 \%$ & $100 \%$ & $100 \%$ & $100 \%$ \\
\hline 1.4 .1 & $0 \%$ & $100 \%$ & $100 \%$ & $100 \%$ & $0 \%$ & $100 \%$ & $100 \%$ & $100 \%$ & $0 \%$ & $100 \%$ & $100 \%$ & $100 \%$ \\
\hline 1.5 .1 & $0 \%$ & $100 \%$ & $100 \%$ & $100 \%$ & $0 \%$ & $100 \%$ & $100 \%$ & $100 \%$ & $0 \%$ & $100 \%$ & $0 \%$ & $100 \%$ \\
\hline 1.5 .2 & $0 \%$ & $100 \%$ & $50 \%$ & $0 \%$ & $0 \%$ & $100 \%$ & $50 \%$ & $0 \%$ & $0 \%$ & $100 \%$ & $0 \%$ & $0 \%$ \\
\hline 1.5 .3 & $0 \%$ & $100 \%$ & $100 \%$ & $100 \%$ & $0 \%$ & $100 \%$ & $100 \%$ & $100 \%$ & $100 \%$ & $0 \%$ & $0 \%$ & $0 \%$ \\
\hline 1.5 .4 & $0 \%$ & $100 \%$ & $100 \%$ & $50 \%$ & $0 \%$ & 0\% & $100 \%$ & $50 \%$ & $0 \%$ & $100 \%$ & $0 \%$ & $50 \%$ \\
\hline 1.5 .5 & $0 \%$ & $100 \%$ & $0 \%$ & $0 \%$ & $0 \%$ & $100 \%$ & $\mathbf{0 \%}$ & $0 \%$ & $0 \%$ & $100 \%$ & $0 \%$ & $0 \%$ \\
\hline \multirow{2}{*}{ Avaliação } & $30,8 \%$ & $65,4 \%$ & $57,7 \%$ & $26,9 \%$ & $38,5 \%$ & $50,0 \%$ & $50,0 \%$ & $26,9 \%$ & $30,8 \%$ & $69,2 \%$ & $26,9 \%$ & $34,6 \%$ \\
\hline & \multicolumn{4}{|c|}{ (2) Em Formação } & \multicolumn{4}{|c|}{ (2) Em Formação } & \multicolumn{4}{|c|}{ (1) Inicial } \\
\hline
\end{tabular}


DIMENSÃO 2 - Avaliação de Riscos

\begin{tabular}{|c|c|c|c|c|c|c|c|c|c|c|c|c|}
\hline \multirow{2}{*}{ Variável } & \multicolumn{4}{|c|}{ MAPA } & \multicolumn{4}{|c|}{ Incra } & \multicolumn{4}{|c|}{ Conab } \\
\hline & (0) & (1) & $(2)$ & (3) & (0) & (1) & (2) & (3) & (0) & (1) & $(2)$ & (3) \\
\hline 2.1.1 & $0 \%$ & $100 \%$ & $50 \%$ & $50 \%$ & $0 \%$ & $100 \%$ & $0 \%$ & $0 \%$ & $0 \%$ & $100 \%$ & $50 \%$ & $0 \%$ \\
\hline 2.1 .2 & $0 \%$ & $100 \%$ & $50 \%$ & $50 \%$ & $0 \%$ & $100 \%$ & $50 \%$ & $50 \%$ & $0 \%$ & $100 \%$ & $0 \%$ & $0 \%$ \\
\hline 2.1 .3 & $0 \%$ & $100 \%$ & $0 \%$ & $0 \%$ & $0 \%$ & $100 \%$ & $0 \%$ & $0 \%$ & $0 \%$ & $100 \%$ & $0 \%$ & $0 \%$ \\
\hline 2.1 .4 & $0 \%$ & $100 \%$ & $0 \%$ & $0 \%$ & $0 \%$ & $100 \%$ & $0 \%$ & $0 \%$ & $0 \%$ & $100 \%$ & $0 \%$ & $0 \%$ \\
\hline 2.1 .5 & $0 \%$ & $50 \%$ & $50 \%$ & $0 \%$ & $0 \%$ & $100 \%$ & $100 \%$ & $0 \%$ & $0 \%$ & $50 \%$ & $50 \%$ & $0 \%$ \\
\hline 2.2.1 & $100 \%$ & $0 \%$ & $0 \%$ & $0 \%$ & $100 \%$ & $0 \%$ & $0 \%$ & $0 \%$ & $0 \%$ & $100 \%$ & $0 \%$ & $0 \%$ \\
\hline 2.2 .2 & $100 \%$ & $0 \%$ & $0 \%$ & $0 \%$ & $100 \%$ & $0 \%$ & $0 \%$ & $0 \%$ & $0 \%$ & $0 \%$ & $100 \%$ & $0 \%$ \\
\hline 2.2 .3 & $100 \%$ & $0 \%$ & $0 \%$ & $0 \%$ & $100 \%$ & $0 \%$ & $0 \%$ & $0 \%$ & $0 \%$ & $100 \%$ & $0 \%$ & $0 \%$ \\
\hline 2.2 .4 & $100 \%$ & $0 \%$ & $0 \%$ & $0 \%$ & $100 \%$ & $0 \%$ & $0 \%$ & $0 \%$ & $0 \%$ & $50 \%$ & $0 \%$ & $0 \%$ \\
\hline \multirow{2}{*}{ Avaliação } & $44,4 \%$ & $50,0 \%$ & $16,7 \%$ & $11,1 \%$ & $44,4 \%$ & $55,6 \%$ & $16,7 \%$ & $5,6 \%$ & $0,0 \%$ & $77,8 \%$ & $22,2 \%$ & $0,0 \%$ \\
\hline & \multicolumn{4}{|c|}{ (1) Inicial } & \multicolumn{4}{|c|}{ (1) Inicial } & \multicolumn{4}{|c|}{ (1) Inicial } \\
\hline
\end{tabular}

DIMENSÃO 3 - Atividades de Controle

\begin{tabular}{|c|c|c|c|c|c|c|c|c|c|c|c|c|}
\hline \multirow{2}{*}{ Variável } & \multicolumn{4}{|c|}{ МАРА } & \multicolumn{4}{|c|}{ Incra } & \multicolumn{4}{|c|}{ Conab } \\
\hline & (0) & (1) & (2) & (3) & (0) & (1) & (2) & (3) & (0) & (1) & (2) & (3) \\
\hline 3.1 .1 & $100 \%$ & $0 \%$ & $0 \%$ & $0 \%$ & $100 \%$ & $0 \%$ & $0 \%$ & $0 \%$ & $100 \%$ & $0 \%$ & $0 \%$ & $0 \%$ \\
\hline 3.1 .2 & $100 \%$ & $0 \%$ & $0 \%$ & $0 \%$ & $100 \%$ & $0 \%$ & $0 \%$ & $0 \%$ & $100 \%$ & $0 \%$ & $0 \%$ & $0 \%$ \\
\hline 3.1 .3 & $0 \%$ & $50 \%$ & $50 \%$ & $0 \%$ & $0 \%$ & $50 \%$ & $50 \%$ & $0 \%$ & $0 \%$ & $50 \%$ & $50 \%$ & $0 \%$ \\
\hline 3.1 .4 & $100 \%$ & $0 \%$ & $0 \%$ & $0 \%$ & $100 \%$ & $0 \%$ & $0 \%$ & $0 \%$ & $100 \%$ & $0 \%$ & $0 \%$ & $0 \%$ \\
\hline 3.2 .1 & $0 \%$ & $100 \%$ & $0 \%$ & $0 \%$ & $0 \%$ & $100 \%$ & $0 \%$ & $0 \%$ & $0 \%$ & $100 \%$ & $100 \%$ & $100 \%$ \\
\hline 3.3.1 & $100 \%$ & $0 \%$ & $0 \%$ & $0 \%$ & $100 \%$ & $0 \%$ & $0 \%$ & $0 \%$ & $100 \%$ & $0 \%$ & $0 \%$ & $0 \%$ \\
\hline 3.3 .2 & $0 \%$ & $100 \%$ & $0 \%$ & $0 \%$ & $0 \%$ & $100 \%$ & $0 \%$ & $0 \%$ & $0 \%$ & $100 \%$ & $50 \%$ & $0 \%$ \\
\hline 3.3 .3 & $0 \%$ & $0 \%$ & $50 \%$ & $0 \%$ & $100 \%$ & $0 \%$ & $0 \%$ & $0 \%$ & $100 \%$ & $0 \%$ & $0 \%$ & $0 \%$ \\
\hline \multirow{2}{*}{ Avaliação } & $50,0 \%$ & $31,3 \%$ & $12,5 \%$ & $0,0 \%$ & $62,5 \%$ & $31,3 \%$ & $6,3 \%$ & $0,0 \%$ & $62,5 \%$ & $31,3 \%$ & $25,0 \%$ & $12,5 \%$ \\
\hline & \multicolumn{4}{|c|}{ (0) Incipiente } & \multicolumn{4}{|c|}{ (0) Incipiente } & \multicolumn{4}{|c|}{ (0) Incipiente } \\
\hline
\end{tabular}


DIMENSÃO 4 - Informação e Comunicação

\begin{tabular}{|c|c|c|c|c|c|c|c|c|c|c|c|c|}
\hline \multirow{2}{*}{ Variável } & \multicolumn{4}{|c|}{ MAPA } & \multicolumn{4}{|c|}{ Incra } & \multicolumn{4}{|c|}{ Conab } \\
\hline & (0) & (1) & $(2)$ & (3) & (0) & (1) & $(2)$ & (3) & (0) & (1) & $(2)$ & (3) \\
\hline 4.1.1 & $100 \%$ & $0 \%$ & $0 \%$ & $0 \%$ & $100 \%$ & $0 \%$ & $0 \%$ & $0 \%$ & $100 \%$ & $0 \%$ & $0 \%$ & $0 \%$ \\
\hline 4.1.2 & $100 \%$ & $0 \%$ & $0 \%$ & $0 \%$ & $100 \%$ & $0 \%$ & $0 \%$ & $0 \%$ & $0 \%$ & $50 \%$ & $0 \%$ & $0 \%$ \\
\hline \multirow{2}{*}{ Avaliação } & $100,0 \%$ & $0,0 \%$ & $0,0 \%$ & $0,0 \%$ & $100,0 \%$ & $0,0 \%$ & $0,0 \%$ & $0,0 \%$ & $50,0 \%$ & $25,0 \%$ & $0,0 \%$ & $0,0 \%$ \\
\hline & \multicolumn{4}{|c|}{ (0) Incipiente } & \multicolumn{4}{|c|}{ (0) Incipiente } & \multicolumn{4}{|c|}{ (0) Incipiente } \\
\hline
\end{tabular}

DIMENSÃO 5 - Monitoramento

\begin{tabular}{|c|c|c|c|c|c|c|c|c|c|c|c|c|}
\hline \multirow{2}{*}{ Variável } & \multicolumn{4}{|c|}{ MAPA } & \multicolumn{4}{|c|}{ Incra } & \multicolumn{4}{|c|}{ Conab } \\
\hline & (0) & (1) & (2) & (3) & (0) & (1) & (2) & (3) & (0) & (1) & $(2)$ & (3) \\
\hline 5.1.1 & $100 \%$ & $0 \%$ & $0 \%$ & $0 \%$ & $100 \%$ & $0 \%$ & $0 \%$ & $0 \%$ & $100 \%$ & $0 \%$ & $0 \%$ & $0 \%$ \\
\hline 5.1 .2 & $0 \%$ & $0 \%$ & $0 \%$ & $50 \%$ & $0 \%$ & $0 \%$ & $50 \%$ & $50 \%$ & $0 \%$ & $0 \%$ & $100 \%$ & $50 \%$ \\
\hline 5.1 .3 & $100 \%$ & $0 \%$ & $0 \%$ & $0 \%$ & $0 \%$ & $0 \%$ & $50 \%$ & $50 \%$ & $0 \%$ & $50 \%$ & $100 \%$ & $0 \%$ \\
\hline \multirow{2}{*}{ Avaliação } & $66,7 \%$ & $0,0 \%$ & $0,0 \%$ & $16,7 \%$ & $33,3 \%$ & $0,0 \%$ & $33,3 \%$ & $33,3 \%$ & $33,3 \%$ & $16,7 \%$ & $66,7 \%$ & $16,7 \%$ \\
\hline & \multicolumn{4}{|c|}{ (0) Incipiente } & \multicolumn{4}{|c|}{ (0) Incipiente } & \multicolumn{4}{|c|}{ (0) Incipiente } \\
\hline
\end{tabular}


ESTRUTURA DE CONTROLE INTERNO

\begin{tabular}{|c|c|c|c|c|c|c|c|c|c|c|c|c|}
\hline \multirow{2}{*}{ Variável } & \multicolumn{4}{|c|}{ MAPA } & \multicolumn{4}{|c|}{ Incra } & \multicolumn{4}{|c|}{ Conab } \\
\hline & $(\mathbf{0})$ & (1) & (2) & (3) & $(\mathbf{0})$ & (1) & (2) & (3) & $(\mathbf{0})$ & (1) & (2) & (3) \\
\hline 1.1.1 & $100 \%$ & $0 \%$ & $0 \%$ & $0 \%$ & $100 \%$ & $0 \%$ & $0 \%$ & $0 \%$ & $0 \%$ & $100 \%$ & $50 \%$ & $0 \%$ \\
\hline 1.1 .2 & $0 \%$ & $100 \%$ & $100 \%$ & $0 \%$ & $100 \%$ & $0 \%$ & $0 \%$ & $0 \%$ & $100 \%$ & $0 \%$ & $0 \%$ & $0 \%$ \\
\hline 1.1.3 & $0 \%$ & $50 \%$ & $100 \%$ & $0 \%$ & $0 \%$ & $50 \%$ & $100 \%$ & $0 \%$ & $0 \%$ & $100 \%$ & $0 \%$ & $0 \%$ \\
\hline 1.2.1 & $100 \%$ & $0 \%$ & $0 \%$ & $0 \%$ & $100 \%$ & $0 \%$ & $0 \%$ & $0 \%$ & $100 \%$ & $0 \%$ & $0 \%$ & $0 \%$ \\
\hline 1.2 .2 & $100 \%$ & $0 \%$ & $0 \%$ & $0 \%$ & $100 \%$ & $0 \%$ & $0 \%$ & $0 \%$ & $100 \%$ & $0 \%$ & $0 \%$ & $0 \%$ \\
\hline 1.3 .1 & $0 \%$ & $100 \%$ & $100 \%$ & $0 \%$ & $0 \%$ & $100 \%$ & $100 \%$ & $0 \%$ & $0 \%$ & $100 \%$ & $100 \%$ & $100 \%$ \\
\hline 1.3 .2 & $100 \%$ & $0 \%$ & $0 \%$ & $0 \%$ & $100 \%$ & $0 \%$ & $0 \%$ & $0 \%$ & $0 \%$ & $100 \%$ & $100 \%$ & $100 \%$ \\
\hline 1.4.1 & $0 \%$ & $100 \%$ & $100 \%$ & $100 \%$ & $0 \%$ & $100 \%$ & $100 \%$ & $100 \%$ & $0 \%$ & $100 \%$ & $100 \%$ & $100 \%$ \\
\hline 1.5.1 & $0 \%$ & $100 \%$ & $100 \%$ & $100 \%$ & $0 \%$ & $100 \%$ & $100 \%$ & $100 \%$ & $0 \%$ & $100 \%$ & $0 \%$ & $100 \%$ \\
\hline 1.5.2 & $0 \%$ & $100 \%$ & $50 \%$ & $0 \%$ & $0 \%$ & $100 \%$ & $50 \%$ & $0 \%$ & $0 \%$ & $100 \%$ & $0 \%$ & $0 \%$ \\
\hline 1.5 .3 & $0 \%$ & $100 \%$ & $100 \%$ & $100 \%$ & $0 \%$ & $100 \%$ & $100 \%$ & $100 \%$ & $100 \%$ & $0 \%$ & $0 \%$ & $0 \%$ \\
\hline 1.5 .4 & $0 \%$ & $100 \%$ & $100 \%$ & $50 \%$ & $0 \%$ & $0 \%$ & $100 \%$ & $50 \%$ & $0 \%$ & $100 \%$ & $0 \%$ & $50 \%$ \\
\hline 1.5.5 & $0 \%$ & $100 \%$ & $0 \%$ & $0 \%$ & $0 \%$ & $100 \%$ & $0 \%$ & $0 \%$ & $0 \%$ & $100 \%$ & $0 \%$ & $0 \%$ \\
\hline 2.1.1 & $0 \%$ & $100 \%$ & $50 \%$ & $50 \%$ & $0 \%$ & $100 \%$ & $0 \%$ & $0 \%$ & $0 \%$ & $100 \%$ & $50 \%$ & $0 \%$ \\
\hline 2.1 .2 & $0 \%$ & $100 \%$ & $50 \%$ & $50 \%$ & $0 \%$ & $100 \%$ & $50 \%$ & $50 \%$ & $0 \%$ & $100 \%$ & $0 \%$ & $0 \%$ \\
\hline 2.1 .3 & $0 \%$ & $100 \%$ & $0 \%$ & $0 \%$ & $0 \%$ & $100 \%$ & $0 \%$ & $0 \%$ & $0 \%$ & $100 \%$ & $0 \%$ & $0 \%$ \\
\hline 2.1.4 & $0 \%$ & $100 \%$ & $0 \%$ & $0 \%$ & $0 \%$ & $100 \%$ & $0 \%$ & $0 \%$ & $0 \%$ & $100 \%$ & $0 \%$ & $0 \%$ \\
\hline 2.1 .5 & $0 \%$ & $50 \%$ & $50 \%$ & $0 \%$ & $0 \%$ & $100 \%$ & $100 \%$ & $0 \%$ & $0 \%$ & $50 \%$ & $50 \%$ & $0 \%$ \\
\hline 2.2 .1 & $100 \%$ & $0 \%$ & $0 \%$ & $0 \%$ & $100 \%$ & $0 \%$ & $0 \%$ & $0 \%$ & $0 \%$ & $100 \%$ & $0 \%$ & $0 \%$ \\
\hline 2.2 .2 & $100 \%$ & $0 \%$ & $0 \%$ & $0 \%$ & $100 \%$ & $0 \%$ & $0 \%$ & $0 \%$ & $0 \%$ & $0 \%$ & $100 \%$ & $0 \%$ \\
\hline 2.2 .3 & $100 \%$ & $0 \%$ & $0 \%$ & $0 \%$ & $100 \%$ & $0 \%$ & $0 \%$ & $0 \%$ & $0 \%$ & $100 \%$ & $0 \%$ & $0 \%$ \\
\hline 2.2 .4 & $100 \%$ & $0 \%$ & $0 \%$ & $0 \%$ & $100 \%$ & $0 \%$ & $0 \%$ & $0 \%$ & $0 \%$ & $50 \%$ & $0 \%$ & $0 \%$ \\
\hline 3.1.1 & $100 \%$ & $0 \%$ & $0 \%$ & $0 \%$ & $100 \%$ & $0 \%$ & $0 \%$ & $0 \%$ & $100 \%$ & $0 \%$ & $0 \%$ & $0 \%$ \\
\hline 3.1.2 & $100 \%$ & $0 \%$ & $0 \%$ & $0 \%$ & $100 \%$ & $0 \%$ & $0 \%$ & $0 \%$ & $100 \%$ & $0 \%$ & $0 \%$ & $0 \%$ \\
\hline 3.1.3 & $0 \%$ & $50 \%$ & $50 \%$ & $0 \%$ & $0 \%$ & $50 \%$ & $50 \%$ & $0 \%$ & $0 \%$ & $50 \%$ & $50 \%$ & $0 \%$ \\
\hline 3.1.4 & $100 \%$ & $0 \%$ & $0 \%$ & $0 \%$ & $100 \%$ & $0 \%$ & $0 \%$ & $0 \%$ & $100 \%$ & $0 \%$ & $0 \%$ & $0 \%$ \\
\hline 3.2.1 & $0 \%$ & $100 \%$ & $0 \%$ & $0 \%$ & $0 \%$ & $100 \%$ & $0 \%$ & $0 \%$ & $0 \%$ & $100 \%$ & $100 \%$ & $100 \%$ \\
\hline 3.3.1 & $100 \%$ & $0 \%$ & $0 \%$ & $0 \%$ & $100 \%$ & $0 \%$ & $0 \%$ & $0 \%$ & $100 \%$ & $0 \%$ & $0 \%$ & $0 \%$ \\
\hline 3.3.2 & $0 \%$ & $100 \%$ & $0 \%$ & $0 \%$ & $0 \%$ & $100 \%$ & $0 \%$ & $0 \%$ & $0 \%$ & $100 \%$ & $50 \%$ & $0 \%$ \\
\hline 3.3.3 & $0 \%$ & $0 \%$ & $50 \%$ & $0 \%$ & $100 \%$ & $0 \%$ & $0 \%$ & $0 \%$ & $100 \%$ & $0 \%$ & $0 \%$ & $0 \%$ \\
\hline 4.1.1 & $100 \%$ & $0 \%$ & $0 \%$ & $0 \%$ & $100 \%$ & $0 \%$ & $0 \%$ & $0 \%$ & $100 \%$ & $0 \%$ & $0 \%$ & $0 \%$ \\
\hline 4.1.2 & $100 \%$ & $0 \%$ & $0 \%$ & $0 \%$ & $100 \%$ & $0 \%$ & $0 \%$ & $0 \%$ & $0 \%$ & $50 \%$ & $0 \%$ & $0 \%$ \\
\hline 5.1.1 & $100 \%$ & $0 \%$ & $0 \%$ & $0 \%$ & $100 \%$ & $0 \%$ & $0 \%$ & $0 \%$ & $100 \%$ & $0 \%$ & $0 \%$ & $0 \%$ \\
\hline 5.1 .2 & $0 \%$ & $0 \%$ & $0 \%$ & $50 \%$ & $0 \%$ & $0 \%$ & $50 \%$ & $50 \%$ & $0 \%$ & $0 \%$ & $100 \%$ & $50 \%$ \\
\hline 5.1 .3 & $100 \%$ & $0 \%$ & $0 \%$ & $0 \%$ & $0 \%$ & $0 \%$ & $50 \%$ & $50 \%$ & $0 \%$ & $50 \%$ & $100 \%$ & $0 \%$ \\
\hline \multirow{2}{*}{ Avaliação } & $45,7 \%$ & $44,3 \%$ & $28,6 \%$ & $14,3 \%$ & $48,6 \%$ & $40,0 \%$ & $27,1 \%$ & $14,3 \%$ & $31,4 \%$ & $55,7 \%$ & $27,1 \%$ & $17,1 \%$ \\
\hline & \multicolumn{4}{|c|}{ (0) INCIPIENTE } & \multicolumn{4}{|c|}{ (0) INCIPIENTE } & \multicolumn{4}{|c|}{ (1) INICIAL } \\
\hline
\end{tabular}


ANEXO A - TIPOS DE ATIVIDADES DE CONTROLE SEGUNDO O GAO

\begin{tabular}{|c|c|}
\hline Tipo & Descrição \\
\hline $\begin{array}{l}\text { Revisão de desempenho } \\
\text { real em alto nível }\end{array}$ & $\begin{array}{l}\text { Gerência acompanha as grandes realizações e compara com os planos, } \\
\text { metas e objetivos definidos pela entidade. A alta gerência deve revisar } \\
\text { regularmente o desempenho em comparação com orçamentos, } \\
\text { previsões e resultados de períodos anteriores; desenvolver planos } \\
\text { estratégicos e comparar os resultados com os planos e metas definidos; } \\
\text { e realizar ações de acompanhamento das iniciativas mais significativas } \\
\text { da entidade. }\end{array}$ \\
\hline $\begin{array}{l}\text { Revisão da gerência em } \\
\text { nível de função ou } \\
\text { atividade }\end{array}$ & $\begin{array}{l}\text { Gerência acompanha o desempenho real em comparação com os } \\
\text { resultados planejados ou esperados e analisa as diferenças } \\
\text { significativas. Os gerentes em todos os níveis da organização devem } \\
\text { revisar relatórios de desempenho, analisar tendências e analisar a } \\
\text { realização das metas; comparar os resultados com resultados } \\
\text { financeiros, orçamentários e operacionais, planejados ou esperados; e } \\
\text { implantar controles para verificar e circularizar os resultados } \\
\text { apresentados em relatórios sintetizados. }\end{array}$ \\
\hline $\begin{array}{l}\text { Gerenciamento do capital } \\
\text { humano }\end{array}$ & $\begin{array}{l}\text { Avaliação contínua das necessidades de conhecimentos e habilidades } \\
\text { para atingir os objetivos da entidade. Inclui o planejamento estratégico } \\
\text { da entidade e uma estratégia geral de capital humano, especificação de } \\
\text { tipos de liderança desejados, políticas de recrutamento, treinamento, } \\
\text { supervisão, sistema de avaliação de desempenho e feedback, sistema de } \\
\text { recompensas, política de retenção de empregados e planejamento de } \\
\text { sucessão. }\end{array}$ \\
\hline $\begin{array}{l}\text { Controles sobre o } \\
\text { processamento da } \\
\text { informação }\end{array}$ & $\begin{array}{l}\text { Controles como validação das entradas de dados; atribuição de } \\
\text { numeração sequencial às transações; comparação de totais de arquivos } \\
\text { com contas de controle; exame e correção de exceções e violações } \\
\text { apontadas por outras atividades de controle; e controle de acesso a } \\
\text { dados, arquivos e programas. }\end{array}$ \\
\hline $\begin{array}{l}\text { Controle físico sobre } \\
\text { ativos vulneráveis }\end{array}$ & $\begin{array}{l}\text { Segurança e acesso limitado a dinheiro, valores, inventários e } \\
\text { equipamentos vulneráveis a risco de perda ou uso não autorizado. A } \\
\text { gerência deve frequentemente realizar a contagem e comparação com } \\
\text { registros de controle. A entidade deve identificar e proteger seus ativos } \\
\text { mais críticos; elaborar, testar e divulgar um plano de recuperação de } \\
\text { desastres; e utilizar mecanismos diversos de segurança física e lógica } \\
\text { para controlar e proteger ativos vulneráveis. }\end{array}$ \\
\hline $\begin{array}{l}\text { Estabelecimento e } \\
\text { revisão de indicadores e } \\
\text { medidas de desempenho }\end{array}$ & $\begin{array}{l}\text { Atividades de controle para monitorar medidas e indicadores de } \\
\text { desempenho da entidade e dos indivíduos. Indicadores de desempenho } \\
\text { devem ser estabelecidos em todos os níveis hierárquicos da } \\
\text { organização; que a integridade dos indicadores deve ser periodicamente } \\
\text { revisada; que indicadores devem ser estabelecidos para relatórios } \\
\text { operacionais e financeiros. }\end{array}$ \\
\hline
\end{tabular}




\begin{tabular}{|c|c|}
\hline Tipo & Descrição \\
\hline Segregação das funções & $\begin{array}{l}\text { Separação das responsabilidades pela autorização, registro, aprovação e } \\
\text { revisão das principais transações e eventos para evitar erro, mau uso ou } \\
\text { fraude. Nenhum indivíduo deve ser capaz de controlar todos os } \\
\text { principais aspectos de uma transação ou evento; Quando possível, } \\
\text { nenhum indivíduo deve trabalhar sozinho com dinheiro, títulos } \\
\text { negociáveis ou outros bens valiosos; A abertura de correio deve ser } \\
\text { feita por pessoal que não tenha responsabilidades ou acesso às contas a } \\
\text { receber ou ao caixa; Contas bancárias devem ser reconciliadas por } \\
\text { empregados que não tenham responsabilidade por recebimentos, } \\
\text { desembolsos ou custódia de dinheiro; e a gerência deve trabalhar para } \\
\text { reduzir as possibilidades de conluio. }\end{array}$ \\
\hline $\begin{array}{l}\text { Adequada execução das } \\
\text { transações }\end{array}$ & $\begin{array}{l}\text { Autorização e execução das atividades por pessoas agindo estritamente } \\
\text { no escopo de sua autoridade. Os controles devem garantir que somente } \\
\text { transações e eventos válidos são iniciados e registrados; os controles } \\
\text { devem garantir que todas as transações e eventos sejam autorizados e } \\
\text { executados somente por pessoas que tenham autoridade; as autorizações } \\
\text { são comunicadas claramente aos gerentes e empregados e incluem as } \\
\text { condições específicas sob as quais a autorização é feita; e os termos da } \\
\text { autorização devem respeitar as políticas e procedimentos da entidade, } \\
\text { bem como as leis e regulamentos aplicáveis. }\end{array}$ \\
\hline $\begin{array}{l}\text { Registro preciso e } \\
\text { tempestivo das } \\
\text { transações }\end{array}$ & $\begin{array}{l}\text { Incluindo o ciclo de vida completo da transação ou evento, desde sua } \\
\text { iniciação ou autorização até sua classificação nos registros sintéticos. }\end{array}$ \\
\hline $\begin{array}{l}\text { Restrições de acesso e } \\
\text { accountability por } \\
\text { recursos e registros }\end{array}$ & $\begin{array}{l}\text { Restrição de acesso a recursos e registros somente a indivíduos } \\
\text { autorizados, que recebem a mantém o accountability pela sua custódia e } \\
\text { uso. A gerência deve frequentemente realizar a comparação dos } \\
\text { recursos com o accountability registrado para reduzir o risco de erro, } \\
\text { mau uso, fraude ou alteração não autorizada. }\end{array}$ \\
\hline $\begin{array}{l}\text { Documentação adequada } \\
\text { das transações e do } \\
\text { controle interno }\end{array}$ & $\begin{array}{l}\text { Documentação do controle interno e todas as transações e eventos } \\
\text { significativos, de modo que a documentação esteja pronta para exame. } \\
\text { Inclui as diretrizes da gerência, políticas administrativas, manuais } \\
\text { operacionais, etc. }\end{array}$ \\
\hline
\end{tabular}

Fonte: GAO (2001, 2014). 


\section{ANEXO B - DESCRIÇÃO DOS NÍVEIS DO MODELO DE MATURIDADE DO COBIT (VERSÃO 4.1)}

\begin{tabular}{|c|c|}
\hline Nível & Situação do Ambiente de Controle Interno \\
\hline $\begin{array}{c}(0) \\
\text { Inexistente }\end{array}$ & $\begin{array}{l}\text { Não há reconhecimento da necessidade de um controle interno. O controle não } \\
\text { faz parte da cultura ou missão da organização. Alto risco de deficiências de } \\
\text { controle e incidentes. }\end{array}$ \\
\hline $\begin{array}{l}\text { (1) } \\
\text { Inicial / por } \\
\text { demanda }\end{array}$ & $\begin{array}{l}\text { Há algum reconhecimento da necessidade de controle interno. A abordagem aos } \\
\text { requisitos de controle e risco é desorganizada e por demanda, sem comunicação } \\
\text { ou monitoramento. As deficiências não são identificadas. Os funcionários não } \\
\text { estão cientes de suas responsabilidades. }\end{array}$ \\
\hline $\begin{array}{l}\text { (2) } \\
\text { Repetível, mas } \\
\text { intuitivo }\end{array}$ & $\begin{array}{l}\text { Os controles estão instalados, mas não são documentados. Sua operação é } \\
\text { dependente do conhecimento e motivação dos indivíduos. A eficácia não é } \\
\text { adequadamente avaliada. Existem muitas deficiências de controle, e não são } \\
\text { tratadas de forma adequada; o impacto pode ser grave. As ações de gestão para } \\
\text { resolver os problemas de controle não são priorizadas ou consistentes. Os } \\
\text { funcionários podem não ser conscientes de suas responsabilidades. }\end{array}$ \\
\hline $\begin{array}{c}\text { (3) } \\
\text { Processo definido }\end{array}$ & $\begin{array}{l}\text { Controles estão instalados e estão devidamente documentados. A eficácia } \\
\text { operacional é avaliada periodicamente e há um número médio de problemas. No } \\
\text { entanto, o processo de avaliação não é documentado. Embora a gestão seja capaz } \\
\text { de lidar de maneira previsível com a maioria dos problemas de controle, algumas } \\
\text { deficiências de controle persistem e os impactos poderiam ainda ser graves. Os } \\
\text { funcionários estão cientes das suas responsabilidades para o controle. }\end{array}$ \\
\hline $\begin{array}{l}\text { (4) } \\
\text { Administrado e } \\
\text { mensurável }\end{array}$ & $\begin{array}{l}\text { Há um ambiente efetivo de controle interno e gestão de risco. Uma avaliação } \\
\text { formal, documentada de controles ocorre com frequência. Muitos controles são } \\
\text { automatizados e revisados regularmente. A gestão é suscetível de detectar a } \\
\text { maioria dos problemas de controle, mas nem todos os problemas são } \\
\text { rotineiramente identificados. Há acompanhamento consistente para resolver a } \\
\text { deficiências de controle identificadas. A utilização limitada, tática de tecnologia } \\
\text { é aplicada para automatizar controles. }\end{array}$ \\
\hline $\begin{array}{l}(5) \\
\text { Otimizado }\end{array}$ & $\begin{array}{l}\text { Um programa de riscos e controle em toda a empresa fornece resolução contínua } \\
\text { e eficaz dos problemas de controle e risco. O controle interno e a gestão de riscos } \\
\text { são integrados com as operações da entidade, apoiados com monitoramento } \\
\text { automatizado em tempo real com responsabilidade plena pelo monitoramento do } \\
\text { controle, gestão de risco e fiscalização de conformidade. A avaliação de controle } \\
\text { é contínua, com base na auto-avaliação e análises de gap e causa-raiz. Os } \\
\text { funcionários estão envolvidos de forma proativa em melhorias de controle. }\end{array}$ \\
\hline
\end{tabular}

Fonte: Isaca (2007, p. 179). 